\title{
ENGLISH ATTRITION IN KOREAN-ENGLISH BILINGUAL CHILDREN
}

\begin{abstract}
A DISSERTATION SUBMITTED TO THE GRADUATE DIVISION OF THE UNIVERSITY OF HAWAI'I AT MĀNOA IN PARTIAL FULFILLMENT OF THE REQUIREMENTS FOR THE DEGREE OF
\end{abstract}

DOCTOR OF PHILOSOPHY

IN

LINGUISTICS

AUGUST 2011

By

Sang-Gu Kang

Dissertation Committee:

William O'Grady, Chairperson

Kamil Ud Deen

Luca Onnis

Bonnie D. Schwartz

Kimi Kondo-Brown 
(C) 2011, Sang-Gu Kang 


\section{ACKNOWLEDGEMENTS}

It would have been impossible to complete this dissertation without the help of a great many people and organizations.

I owe so much to my chair, William O'Grady, who trained me to become a linguist and encouraged me to always aim high. His generous support and expertise help fueled everything from experiment designs to data analysis and writing. I will always remember his challenging, but warm-hearted guidance.

I would like to extend my deepest and sincere appreciation to my committee members. This work owes a lot to their support and valuable comments. I was able to expand my background knowledge of language acquisition and experiment procedures when I was taking Kamil Ud Deen's classes in the first couple of years in the program. Also, his kind support was always encouraging. I also thank Luca Onnis for his expertise in bilingualism. It was when I was taking his class that I was able to encounter a lot of literature and start thinking about how I should introduce my work. Then, the enthusiasm of Bonnie D. Schwartz inside and outside the classroom always inspired me. Her relentless work ethic and analytic skills were admirable. I also appreciate Kimi Kondo-Brown's for being the outside member of the committee despite her heavy duties as associate dean. Especially, her comments on the second part of my dissertation were so important and helpful.

I would also like to express gratitude to the faculty of the Linguistics program who provided guidance for my work. I am especially indebted to Michael Forman, Robert Blust, Amy Schafer, Katie Drager, and Yuko Otsuka. Also, I must thank the best department secretaries, Jennifer Kanda and Nora Lum for their excellence.

I am also grateful to several organizations for supporting my graduate study. The East-West Center provided me with a perfect residence environment and the opportunity to interact with friends from all over the world working in various fields. Then, a part of my fieldwork was funded by the University of Hawai' $i$ Graduate Student Organization. Also, special thanks to YB Min of YBM Sisa for his generous support of my research.

My deep appreciation goes to my advisors in Korea, Kyung-Ja Park and Hikyoung Lee, who showed incredible amount of support throughout the years starting from my undergraduate years. 
The two people who devoted an even bigger love and support are my parents, Whoa Seug Kang and Mi Ryoung Song, who this work is dedicated to. My sincere thanks also goes to Min Sun and my sister, Jane, for having faith in me.

Last but not the least, I thank all my participants and their parents for inviting me to be a part of their lives. 


\begin{abstract}
The main goal of this dissertation is to investigate English attrition in three KoreanEnglish bilingual children who had returned to Korea after a two-year stay in the U.S. Although the children had lived in the U.S. for two years, individual English proficiency varied, perhaps due to factors such as age and environment, resulting in different paths and rates of attrition. Repeated experiments on the children's production and comprehension of English articles, irregular past tense verbs, passives, and relative clauses were conducted. Results on these four phenomena as well as observation of code switching and of the use of null subjects are reported. The findings suggest that the attrition is first detected in the speakers' general processing skills in production. Thus, the experiments that are targeted to examine a few aspects of English grammar are likely to produce meaningful results only after attrition is detected in production errors.
\end{abstract}

The contribution of this study is greater in the area of methodology rather than in the results themselves. Collecting data at different points in time repeatedly using the same material appeared to offer an effective measure of attrition. In addition, it seems clear that Korean-English bilinguals' English attrition is not likely to occur within a short period because of the highly valued status of English in Korea. 
The scope of attrition research is much wider than mere descriptions of the phenomenon. From the researcher's stance, issues such as theory and methodology can be interesting. However, from the attriters' and their parents' viewpoint, pedagogies customized for returnees could well be the most meaningful contribution of attrition research. The first step for researchers is to describe the attrition phenomenon and establish related theories. Then, based on these foundations, pedagogies that will benefit those trying to evade attrition can be developed. I hope that by drawing on the results described in this dissertation, this research helps to reveal the perils and prospects of attrition research and opens the door to future progress in this area. 


\section{TABLE OF CONTENTS}

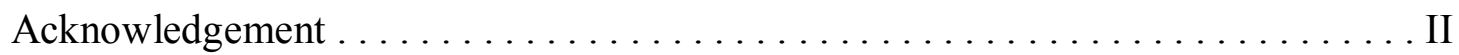

Abstract . . . . . . . . . . . . . . . . . . . . . . . IV

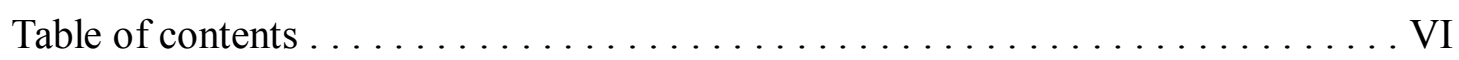

List of tables . . . . . . . . . . . . . . . . . . . .

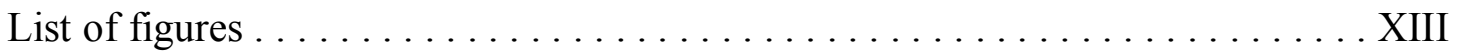

Chapter 1. Introduction: The study of language attrition .............

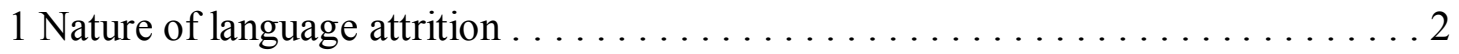

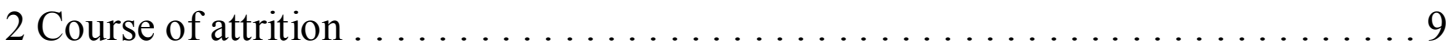

2.1 Regression hypothesis . . . . . . . . . . . . . . 9

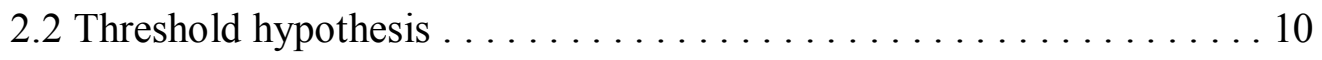

2.3 Interference hypothesis $\ldots \ldots \ldots \ldots \ldots \ldots \ldots \ldots \ldots \ldots \ldots \ldots$

3 Research questions . . . . . . . . . . . . . . . . . . 13

Part I. Case studies: Loss of English morphology and syntax

Chapter 2. Methodology $\ldots \ldots \ldots \ldots \ldots \ldots \ldots \ldots \ldots \ldots \ldots \ldots \ldots$

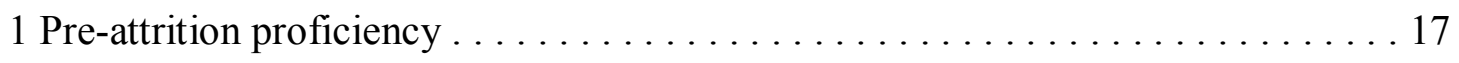

2 Case study methods . . . . . . . . . . . . . . . . . . . . . . . . . . . 19

2.1 Participants .............................. 20

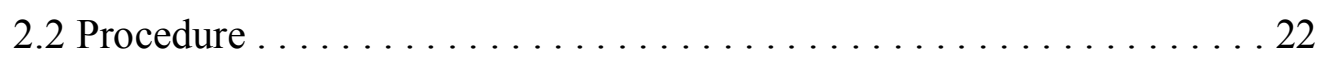

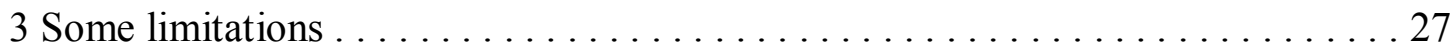

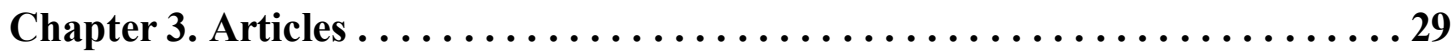

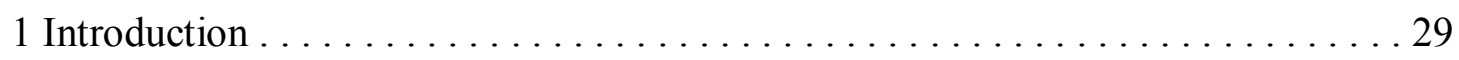

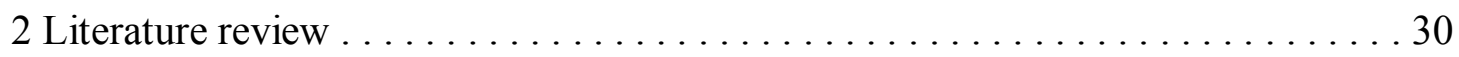

3 Materials . . . . . . . . . . . . . . . . . . . . . . . . 32

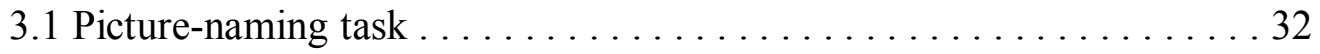

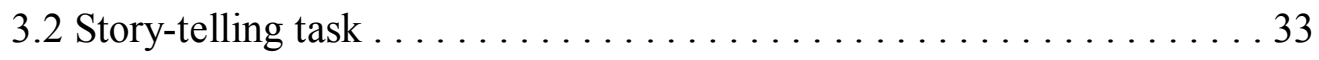

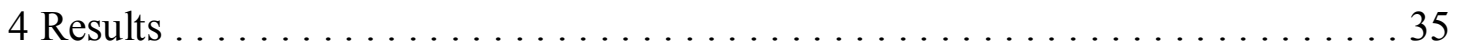

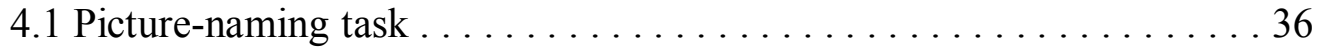

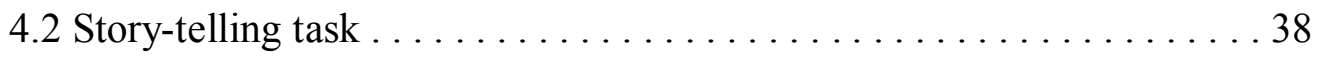

5 Discussion . . . . . . . . . . . . . . . . . . . . 40

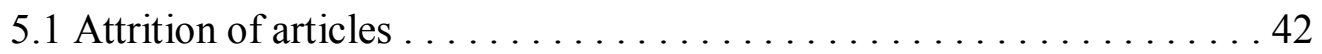


Chapter 4. Irregular past tense verbs . . . . . . . . . . . . . . . 45

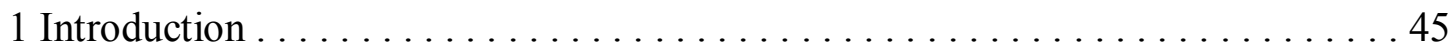

2 Literature review . . . . . . . . . . . . . . . . . . . 47

3 Materials . . . . . . . . . . . . . . . . . . . . . . 49

3.1 Judgment task . . . . . . . . . . . . . . . . . 50

3.2 Elicitation task . . . . . . . . . . . . . . . . 52

3.3 Naturalistic data . . . . . . . . . . . . . . . . . . 52

4 Results . . . . . . . . . . . . . . . . . . . . . . . . . 53

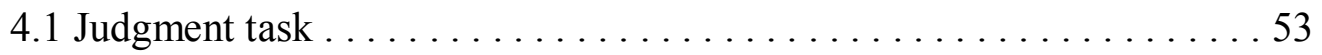

4.2 Elicitation task . . . . . . . . . . . . . . . . . 57

4.3 Naturalistic data . . . . . . . . . . . . . . 61

4.4 Error analysis . . . . . . . . . . . . . . . . 64

5 Discussion . . . . . . . . . . . . . . . . . . . . . . . . . . . . . 65

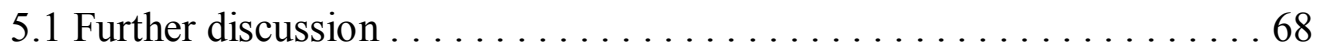

Chapter 5. Passives. ............................ 74

1 Introduction . . . . . . . . . . . . . . . . . . . . . . . . . . . 74

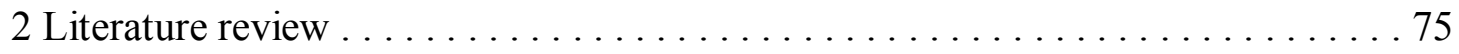

3 Materials . . . . . . . . . . . . . . . . . . . . . 77

3.1 Comprehension task . . . . . . . . . . . . . . 78

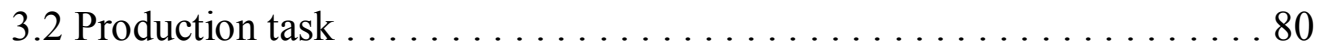

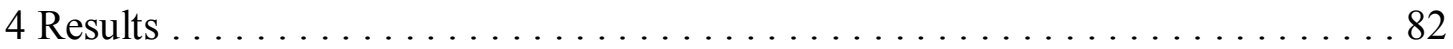

4.1 Comprehension task . . . . . . . . . . . . . . . . 82

4.2 Production task . . . . . . . . . . . . . . . . . . . . . 87

5 Discussion . . . . . . . . . . . . . . . . . . . . . . . . . . 89

Chapter 6. Relative clauses . . . . . . . . . . . . . . . . . 92

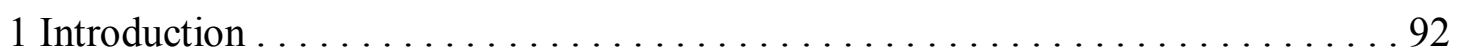

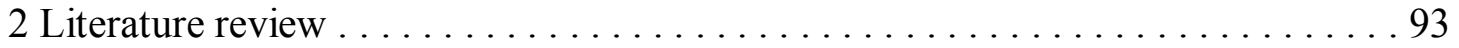

3 Materials . . . . . . . . . . . . . . . . . . . . . . . . 95

3.1 Comprehension task . . . . . . . . . . . . . . . . . . 95

3.1.1 Subject RCs . . . . . . . . . . . . . . . . . . . . . . . . . 99

3.1.2 Direct object RCs . . . . . . . . . . . . . . . . . . . . 99

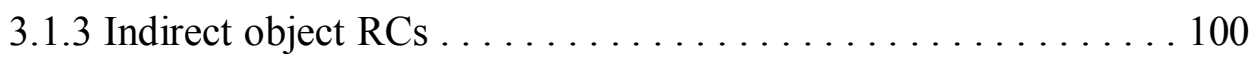

3.1 .4 Oblique $\mathrm{RCs} \ldots \ldots \ldots \ldots \ldots \ldots \ldots$. . . . . . . . . . . . . . 101

3.1.5 Object of comparison RCs . . . . . . . . . . . . . . . . 102

3.2 Production task . . . . . . . . . . . . . . . . . . . . . . . 103 
4 Results ............................................... 104

4.1 Comprehension task ............................. 104

4.1.1 Error analysis ................................. 109

4.1.1.1 Error analysis of subject RC $\ldots \ldots \ldots \ldots \ldots \ldots \ldots$

4.1.1.2 Error analysis of DO, IO, oblique and OCOMP RCs .... 111

4.2 Production task ............................... 115

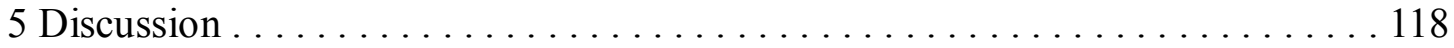

Chapter 7. Non-experimental data: Null subject, code switching ....... 120

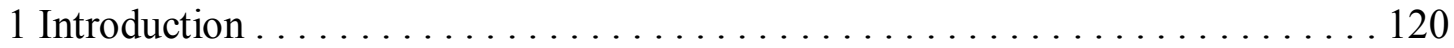

2 English null subjects .............................. 121

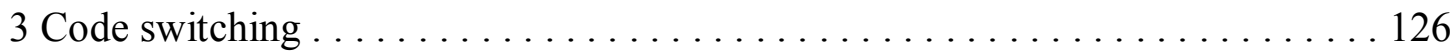

Chapter 8. Part I summary . . . . . . . . . . . . . . . . . . . . . . 135

1 Participants' English proficiency. . . . . . . . . . . . . . . . . . . . 135

2 Individual attrition: Sammy, Hera, and Rita . . . . . . . . . . . . . . . . . 139

2.1 Sammy. . . . . . . . . . . . . . . . . . . . . . . . . . . . . . . . 139

2.2 Hera and Rita. .................................. 139

3 Course of attrition ................................... 141

3.1 Regression hypothesis . . . . . . . . . . . . . . . . . . . . . 142

3.2 Threshold hypothesis . . . . . . . . . . . . . . . . . . . . 142

3.3 Interference hypothesis . . . . . . . . . . . . . . . . . . . . . 143

\section{Part II. Picture-naming latency}

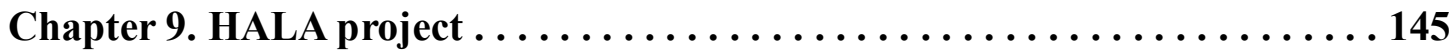

1 Introduction .......................................... 145

2 The HALA project . . . . . . . . . . . . . . . . . . . . . . . . . 147

3 Methods ......................................... 150

3.1 Participants .................................. 150

3.2 Materials ................................... 151

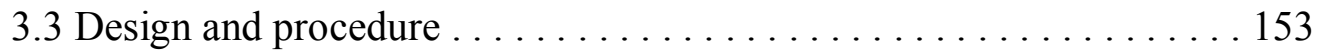

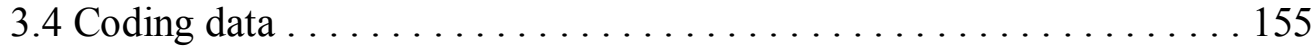

4 Results ...................................... 156

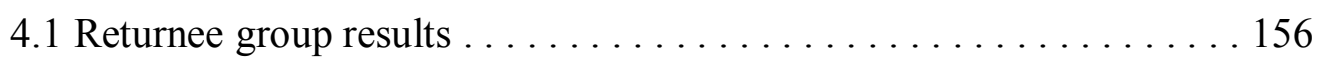

4.1 .1 Returnee group accuracy . . . . . . . . . . . . . . . . 158

4.1.2 Returnee group response time ..................... 159 


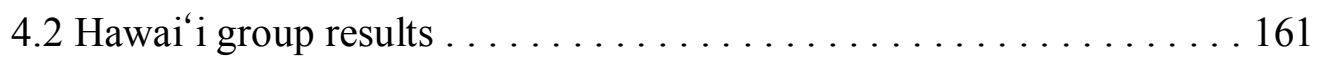

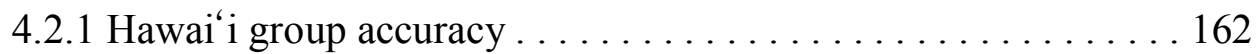

4.2 .2 Hawai' $i$ group response time $\ldots \ldots \ldots \ldots \ldots \ldots \ldots \ldots \ldots \ldots \ldots$

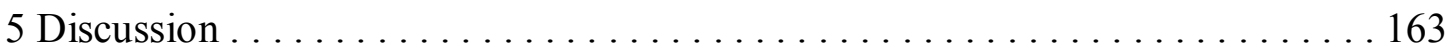

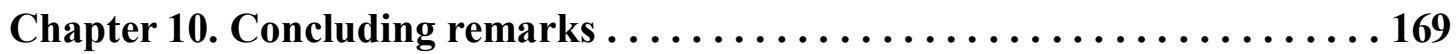

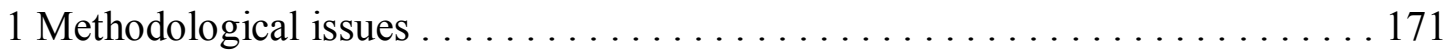

1.1 Part I case studies: loss of English morphology and syntax . . . . . . 171

1.2 Part II picture-naming latency . . . . . . . . . . . . . . . . 174

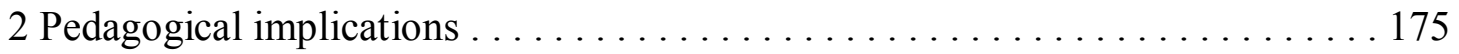

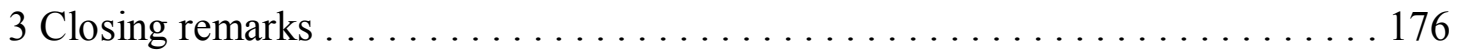

Appendix A. List of irregular past tense verbs . . . . . . . . . . . . . . 178

Appendix B. Part I experiment materials . . . . . . . . . . . . . . . . . . . . . . . . 179

Appendix C. HALA questionnaire . . . . . . . . . . . . . . . . . . . . . 223

References. . . . . . . . . . . . . . . . . . . . . . . . . . . . 224 


\section{LIST OF TABLES}

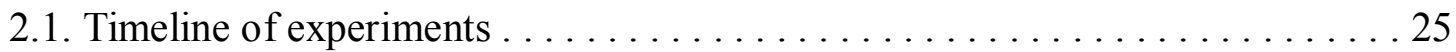

3.1. Sammy's use of articles in picture-naming task $\ldots \ldots \ldots \ldots \ldots \ldots$

3.2. Hera's use of articles in picture-naming task . . . . . . . . . . . 37

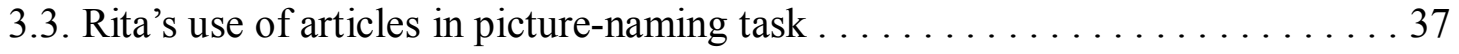

3.4. Sammy's use of articles in story-telling task . . . . . . . . . . . . . . 39

3.5. Hera's use of articles in story-telling task . . . . . . . . . . . . 39

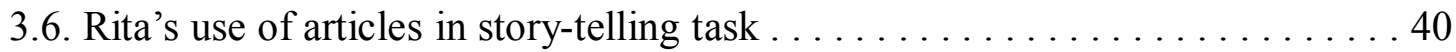

4.1. Sammy's performance on judgment tasks that used the same stories . . . . . . 53

4.2. Hera's performance on judgment tasks that used the same stories . . . . . . . 54

4.3. Sammy's performance on fillers in judgment tasks that used the same stories . .56

4.4. Hera's performance on fillers in judgment tasks that used the same stories . . . 57

4.5. Sammy's performance on elicitation tasks that used the same stories . . . . . 58

4.6. Hera's performance on elicitation tasks that used the same stories . . . . . . . 59

4.7. Rita's performance on elicitation tasks that used the same stories . . . . . . 60

4.8. Three children's error rates in the elicitation task . . . . . . . . . . . 64

4.9. Three children's error rates in the naturalistic data $\ldots \ldots \ldots \ldots \ldots \ldots 6$

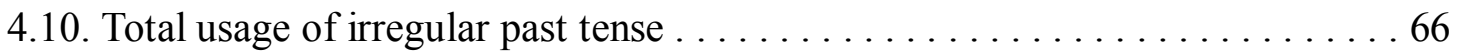

4.11. Sammy's error rate for high- and low-frequency verbs in the experiments . . 69 
4.12. Hera's error rate for high- and low-frequency verbs in experiments . . . . . 70

4.13. Rita's error rate of high- and low-frequency verbs in spontaneous speech . . . 70

4.14. Proportion of overregularization errors in some irregular verb classes . . . . . 71

4.15. Rita's proportion of overregularization errors in irregular verb classes in natural speech

5.1. Sammy's accuracy in the passive comprehension task

5.2. Hera's accuracy in the passive comprehension task

5.3. Rita's accuracy in the passive comprehension task 85

5.4. Proportion of reversal errors in the passive comprehension task 86

5.5. Overall performance in the passive production task 88

5.6. Response rates in actives and passives on semantically reversible and nonreversible items

5.7. Rita's errors in the final three sessions .

6.1. Summary of error types related to figure 6.1

6.2. Number of Rita's subject RC errors in each period

6.3. Number of children's errors on non-subject RCs in each period

6.4. Three children's RC production

7.1. Analysis of Sammy's null/overt subjects in relation to finiteness of verbs

7.2. Sammy's CS analyses of each session 
7.3. Hera's CS analyses of each session .

7.4. Rita's CS analyses of each session .

7.5. Hera and Rita's CS analyses in four periods

9.1. Test item by stratum

9.2. Returnee group participants' baseline information at session 1

9.3. Hawai 'i group participants' baseline information at session 1 161

9.4. Returnee group's self-assessment of language proficiency

10.1. Hera's speech rate and use of fillers in the story-telling task . 173 


\section{LIST OF FIGURES}

1.1. Initial and final states of $\mathrm{L} 1$ acquisition and $\mathrm{L} 1$ attrition $\ldots \ldots \ldots \ldots$

1.2. Degree of attrition and reactivation points $\ldots \ldots \ldots \ldots \ldots \ldots \ldots \ldots$

3.1. Test item for picture-naming task $\ldots \ldots \ldots \ldots \ldots \ldots \ldots \ldots \ldots \ldots \ldots \ldots \ldots \ldots \ldots \ldots$

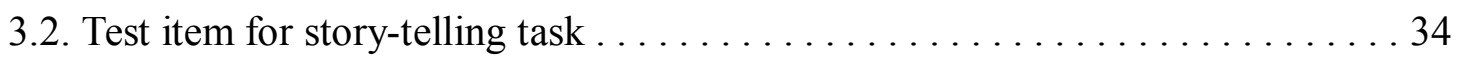

4.1. Sammy's performance in the judgment task . . . . . . . . . . . . 53

4.2. Hera's performance in the judgment task . . . . . . . . . . . . 54

4.3. Proportion of Rita's filler corrections in the judgment task . . . . . . . . . 55

4.4. Proportion of Sammy's filler corrections in the judgment task . . . . . . . 56

4.5. Proportion of Hera's filler corrections in the judgment task . . . . . . . . 57

4.6. Sammy's performance in the elicitation task $\ldots \ldots \ldots \ldots \ldots \ldots \ldots$

4.7. Hera's performance in the elicitation task $\ldots \ldots \ldots \ldots \ldots \ldots \ldots$

4.8. Rita's performance in the elicitation task $\ldots \ldots \ldots \ldots \ldots \ldots \ldots \ldots \ldots \ldots \ldots$

4.9. Sammy's TLU from naturalistic data $\ldots \ldots \ldots \ldots \ldots \ldots \ldots \ldots \ldots \ldots \ldots \ldots \ldots \ldots$

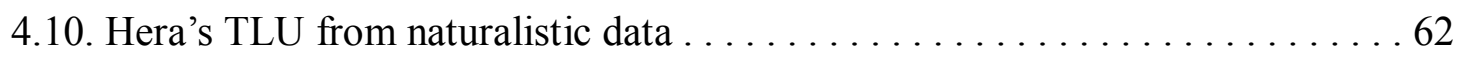

4.11. Rita's TLU from naturalistic data $\ldots \ldots \ldots \ldots \ldots \ldots \ldots \ldots \ldots \ldots \ldots \ldots \ldots$

5.1. Test item for a passive comprehension task $\ldots \ldots \ldots \ldots \ldots \ldots \ldots$

5.2. Test item for a passive production task (non-priming condition) $\ldots \ldots \ldots . .81$

5.3. Test item for a passive production task (priming condition) $\ldots \ldots \ldots \ldots 2$ 
5.4. Sammy's RTs in the passive comprehension task $\ldots \ldots \ldots \ldots \ldots \ldots$

5.5. Hera's RTs in the passive comprehension task . . . . . . . . . . . . . 84

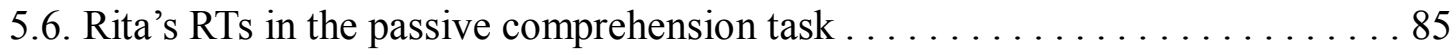

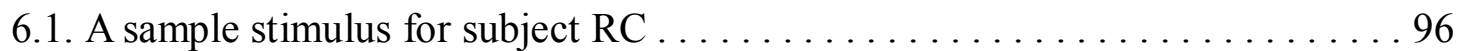

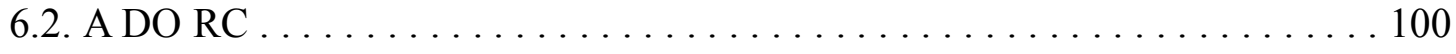

6.3. An IO RC . . . . . . . . . . . . . . . . . . . . . . . . . . 100

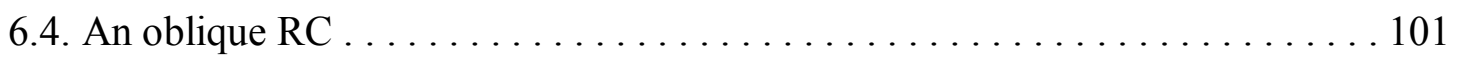

6.5. An OCOMP RC . . . . . . . . . . . . . . . . . . . . . . 102

6.6. Sample pictures used for $\mathrm{RC}$ production task . . . . . . . . . . 103

6.7. Sammy's accuracy on RC comprehension task . . . . . . . . . . . . . . . . . 104

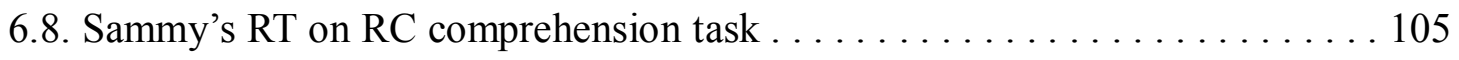

6.9. Hera's accuracy on RC comprehension task . . . . . . . . . . . . . . 106

6.10. Hera's RT on RC comprehension task . . . . . . . . . . . . 107

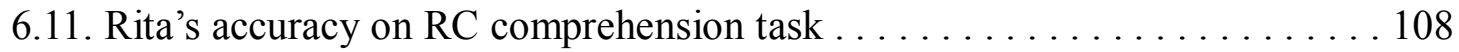

6.12. Rita's RT of RC comprehension task . . . . . . . . . . . . . . . . . . 109

6.13. Proportion of children's errors on non-subject RCs in each period . . . . . . . 114

6.14. An RC production task item targeted to elicit a $\mathrm{DO} \mathrm{RC} \ldots \ldots \ldots \ldots 117$

7.1. Sammy's use of null subjects in the passive elicitation task . . . . . . . 123

7.2. Sammy's use of null subject in irregular past tense elicitation task . . . . . 123 
7.3. Sammy's aggregate use of null subject in two tasks .

9.1. Test item for body-part, "leg".

9.2. Participants' self-assessment sheet

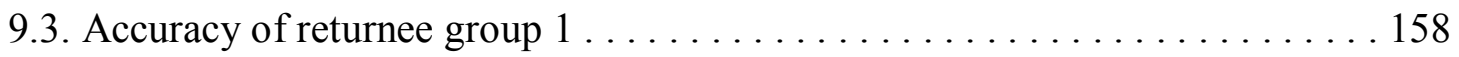

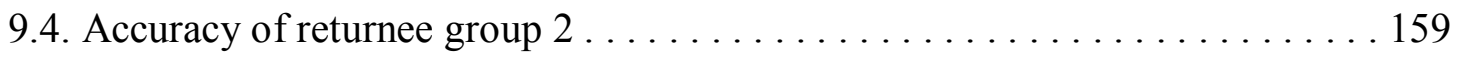

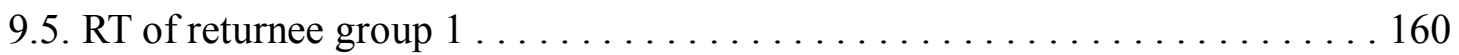

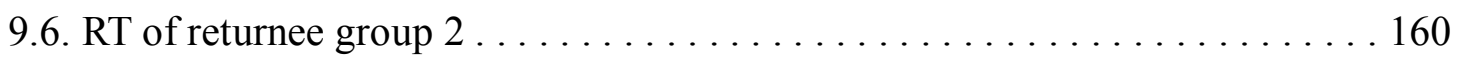

9.7. Accuracy of Hawai' i group . . . . . . . . . . . . . . . . . . 162

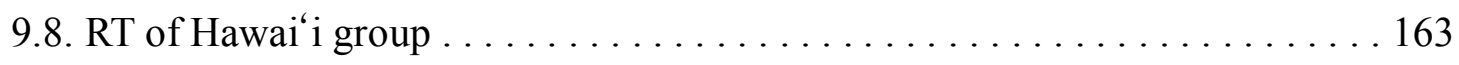

9.9. Projected RTs of Hawai'i group stratum $2 \ldots \ldots \ldots \ldots \ldots \ldots$ 


\section{CHAPTER 1 \\ INTRODUCTION: THE STUDY OF LANGUAGE ATTRITION}

The last several decades have seen remarkable interest in the field of language acquisition, and for good reason; we watch how children almost effortlessly acquire their native language (L1) while second language (L2) learners often struggle, in part because their mother tongue interferes with L2 acquisition. Although research has revealed much about the process of language acquisition, both L1 and L2, numerous questions remain unanswered. Among the many facets of acquisition still to be explored, one has remained largely unnoticed: language attrition, or language loss, has so far received very little scholarly attention, especially at the individual level. Language attrition can be broadly defined as any loss or reduction in the ability to produce and/or understand language, due to deficits in linguistic knowledge and/or in access to that knowledge.

Despite the short history of work on language attrition and the scarcity of related research, there is a growing interest in the phenomenon of non-pathological language loss. Studies in Second Language Acquisition was the first scholarly journal to devote an entire issue (11[2]) to the theme of language attrition in 1989. More recently, in 2004, the International Journal of Bilingualism published a special issue (8[3]) on L1 attrition, and in 2010, Bilingualism: Language and Cognition devoted an issue (13[1]) to the same topic.

Language attrition has perhaps not been able to attract much scholarly interest simply because losing a language does not seem as interesting as acquiring it. But just as the course of language acquisition and the influence of the speaker's native language on L2 acquisition are frequently researched topics, the course of language 
attrition and the effect of the newly acquired language on the attriting language is also worthy of attention, and research into this topic is likely to contribute valuable insights into human cognition, language acquisition, and linguistic theory.

Language attrition can have various causes. Probably the most prevalent cause of language loss is contact with another language. On a community level, contact with a dominant or prestigious language can lead to death of the native language in some extreme cases. On an individual level, attrition results from a change of linguistic environment that accompanies contact with another language. For instance, when a child is relocated to a foreign country because one of her parents is studying abroad or is appointed to a position in a foreign branch of a company, she will quickly start acquiring the foreign language and her native tongue will often begin to slip away. Language loss can also happen for unfortunate pathological reasons, but neither language endangerment and death on the community level nor pathological language loss will be discussed here. Rather, my focus will be attrition caused by a change of linguistic environment.

In this introductory chapter, I will briefly discuss several important linguistic issues and the major claims that have been made in the literature of language attrition research. The primary research questions pertaining to the dissertation will follow this discussion.

\section{Nature of language attrition}

Can an individual completely lose or forget a language due to contact with another language? Or does language attrition simply mean that the language becomes difficult to access in the mind? If attrition leads to total language loss, then relearning the lost language after prolonged non-use would be similar to learning a foreign language. On 
the other hand, if extended discontinued use simply pushes the attrited language to a dormant state so that it cannot be easily accessed, someone who was relearning an attrited language would have advantages over a novice second language learner of the same language, assuming that increased input would reactivate the dormant attrited language.

Several studies focusing on phonology have shown an advantage of early linguistic exposure to the attrited language, suggesting that prolonged lack of exposure may not result in total loss of phonological knowledge that is acquired early. Tees and Werker (1984) studied English-speaking adults who had been exposed to Hindi during the first year or two of life and found that they had an advantage over first-time L2 learners of Hindi in discriminating a retroflex-dental contrast. Au et al. (2002) also showed that the pronunciation of adult participants who had been regularly exposed to Spanish in childhood before the age of six was more Spanishlike compared to that of first-time L2 Spanish learners when both groups were evaluated in Spanish classes at university. The same group of researchers (Oh et al. 2003) demonstrated that adults learning Korean who were either childhood Korean overhearers or childhood Korean speakers performed better than novice adult Korean L2 learners and as well as native Korean speakers in a phoneme perception task involving Korean minimal triplets (plain, tense, and aspirated) of stop consonants. In a phoneme production task, on the other hand, only the childhood Korean speakers performed like native speakers: their performance was significantly better than that of both the childhood Korean overhearers and the learners of Korean as a foreign language. These studies seem to demonstrate the existence of phonological remnants in the attriter's ${ }^{1}$ mind despite discontinued use.

\footnotetext{
1 The person experiencing language attrition will be referred to as attriter rather than attritor since the latter seems to be reserved for "a high-energy stirred-ball mill used for mechanically alloying metal
} 
However, Ventureyra et al. (2004) point out that the participants in the above studies came from immigrant communities or grew up in communities where the attrited language may have been consistently used. For this reason, they recruited a population of Korean adoptees living in French-speaking families who had not had contact with Korean since childhood. The study showed that in a phoneme discrimination task similar to that used in Oh et al. (2003), the adoptees were not able to perform significantly better than French native speakers who had never been exposed to Korean. In a publication preceding Ventureyra et al., Pallier et al. (2003) found that a different group of Korean adoptees living in France did not perform better than native French speakers in language-identification and word-recognition tasks, confirming their claim that the attriters had completely lost their native language. Moreover, fMRI data revealed no difference in the adoptees' brains between listening to Korean and listening to other unknown languages such as Polish and Japanese; in contrast their brain activation while listening to French was similar to that of French native speakers. Pallier et al. cautiously concluded that an early experience with Korean did not leave implicit unconscious traces, which would be detectible through the fMRI methods. Taken together, results seem to indicate that continued non-use can lead to total loss of a language.

Other studies did not corroborate these findings; rather, they suggest that early but time-limited exposure to a language has a long-lasting impact on a person's ability to relearn that language, even after complete separation from that language has caused attrition. Bowers et al. (2009) administered a Hindi or Zulu phonemediscrimination task involving 112 items approximately once a day for 30 days to native speakers of English who had been exposed to Hindi $(n=4)$ or Zulu $(n=3)$ in their childhood but had no apparent remaining knowledge of their childhood language. 
Participants received feedback (correct or incorrect) after each item. The results indicated that all participants under the age of $40(n=3)$ showed significant learning in the later sessions, while participants over the age of $40(n=4)$ and the control group, native monolingual English speakers in their twenties, did not show any significant sign of learning. Although the attriters did not show preserved knowledge of their childhood language on initial testing, those under the age of 40 regained sensitivity to the phoneme contrast after practice.

Hyltenstam et al. (2009) compared Korean adoptees (the "attrition group") in Sweden with native Swedes acquiring Korean. The length of time studying Korean had been greater for the native Swedes than for the experimental attrition group, and the Swedes were more motivated to learn Korean than the attrition group because they were Korean language professionals and/or had a Korean spouse. Both groups had spent time in Korea as adults, but the native Swedes had spent more time there than the adoptees. In a sentence acceptability judgment test, native Swedes scored significantly better than the adoptee group, which may not be surprising considering their more favorable learning circumstances. However, in the phoneme perception task, there was no significant difference between the two groups. Notably, though, some of the adoptees scored better in the phoneme perception task than the highest scorer in the native Swede group, which did not happen in the acceptability judgment task. Despite the fact that the native Swedish participants seem to have been more committed and more successful learners of Korean than the attrition group, as revealed by their attitude and acceptability judgments, this did not necessarily mean that their perception of phonetic details was better.

The results from the Bowers et al. (2009) and Hyltenstam et al. (2009) studies refute the position of Pallier et al. (2003) and Ventureyra et al. (2004) and support the 
position that attrition results in a language becoming difficult to access rather than being completely lost. Indeed, in the discussion of their results, Pallier et al.

(2003:159) speculated that "more extensive retraining experiments might reveal faster learning of Korean in subjects who had early exposure to Korean relative to control subjects," which was revealed to be at least partially correct in Hyltenstam et al. (2009).

However, the two hypotheses, total loss versus access difficulty, do not have to be categorical: they should be able to co-exist along a continuum. Figure 1.1 illustrates the initial and final states of L1 acquisition and attrition.

\section{$\underline{\text { L1 Acquisition }}$}

initial state

final state (native-like proficiency)

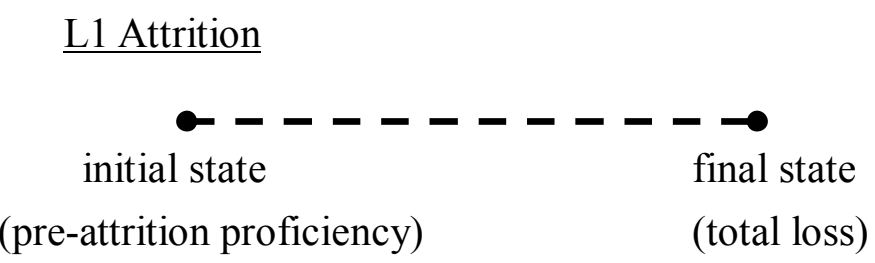

FIGURE 1.1. INITIAL AND FINAL STATES OF L1 ACQUISITION AND L1 ATTRITION

L1 acquisition starts with an initial state without any parameters or values set, and the final state of L1 acquisition is usually the attainment of native-like proficiency, which children easily reach within their first few years of life. In most cases of L1 attrition, the final state of L1 acquisition is the initial state of attrition. However, since it is possible for an attriter to be relocated to a new linguistic environment before reaching native-like proficiency in L1, the initial state of attrition does not have to be nativelike proficiency. I will therefore call the initial state of L1 attrition "pre-attrition proficiency." If the attrition proceeds to the extreme where no trace is left, it results in 
total loss, which would be the absolute final state of attrition. Imagine a child adopted into another linguistic environment when he has barely started to utter his first words. If he does not come into contact with his childhood language again until his dying day as an old man, his final state of attrition would presumably be very close to total loss. It would be extremely difficult to access his childhood knowledge. This extreme difficulty of access to his mother tongue would be the equivalent of total loss.

Although the final state of L1 acquisition is the initial state of L1 attrition, the final state of L1 attrition cannot be the same as the initial state of L1 acquisition. This is because the final state of L1 attrition implies the existence of another (contact) language, which probably caused the attrition process in the first place, while the initial state of L1 acquisition does not. Also, the path of loss in L1 attrition may not be the reverse of the path of development in L1 acquisition, which is why different types of lines are used in figure 1.1 .

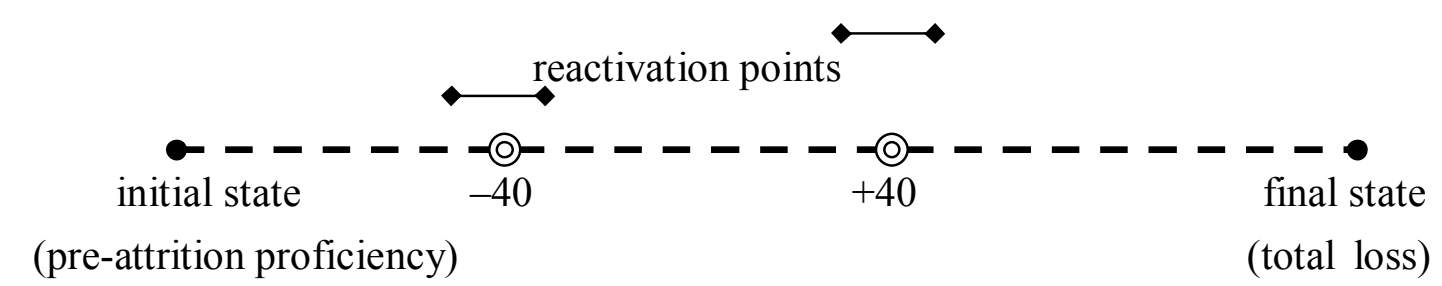

FIGURE 1.2. DEGREE OF ATTRITION AND REACTIVATION POINTS

The results of the Bowers et al. (2009) study, which tested native English speakers who had been exposed to Hindi or Zulu only in their childhood, can be used to elaborate this idea more clearly. In their study, attriters under the age of 40 performed significantly better on the phoneme discrimination task after the first 15 tests, whereas attriters over the age of 40 and native English speakers in their twenties who had had no exposure to either language failed to show improvement over the entire testing 
period. If we accept this as an indicator that participants under 40 attrited less than participants over 40, there are hypothetical spots for the two groups on the line in figure 1.2: the under-40 group is closer to the initial state than the over-40 group, reflecting less attrition, probably due to shorter non-exposure to the childhood language. Over each spot is a potential reactivation point which the attriter has to "jump over" in order to "awaken" at least some parts of the dormant attrited knowledge. As the spot gets closer to the final state, the reactivation point is set at a higher threshold level. At the final state, the threshold point is set so high that relearning the attrited language is probably no different from learning a second language. Returning to the participants in Bowers et al. (2009), 15 days of practice was enough to help the under-40 group leap over the reactivation point and start distinguishing phonemes in their childhood language. Although the over-40 group may need more days of practice, we would expect them to need less practice than the control group of native monolingual English speakers.

Thus, it seems that language attrition may be a matter of language-accessing difficulty which can lead to total loss in extreme cases. However, we must note that none of the participants in the previous studies who did not show signs recovering their childhood language had ever reached a native proficiency in the childhood language. This might suggest that an individual who did reach a native-like proficiency as a child is unlikely to experience total loss of that language in every linguistic aspect (such as phonology, vocabulary, and syntax) solely due to prolonged discontinued use. 


\section{Course of attrition}

Another important linguistic issue raised by attrition research is the course of attrition. Just as L1 acquisition research has revealed a path of development, the course of attrition should be probed as well. Bardovi-Harlig and Stringer (2010) provide the most recent overview of the general hypotheses aiming to account for the course of attrition. I will provide a selected summary of hypotheses, specifically those that have implications for this dissertation.

\subsection{Regression hypothesis}

The regression hypothesis, also referred to as first in, last out, suggests that the path of attrition is the mirror image of the path of acquisition: that is, the language is lost in the reverse order of the acquisition of the same language. Several studies have tested this hypothesis, with mixed findings (e.g., Cohen 1975; Jordens, De Bot, and Trapman 1989; Kuhberg 1992; Olshtain 1989). For instance, Cohen (1975) presented supporting data for the hypothesis as well as some counter-evidence against it.

Cohen examined L2 attrition in three first grade L1-English children who were L2 learners of Spanish over one summer. The children had been attending Spanish-immersion schools but spent the summer vacation without any Spanish contact. Data collected from the children before and after the summer break were compared to the children's longitudinal (approximately 20 months) Spanish acquisition data, which had been collected earlier and made available to Cohen. Two children provided examples to support the regression hypothesis in several aspects of their post-summer Spanish use. For instance, one child substituted the third person present tense inflection for the first person inflection (e.g., *yo puede instead of yo puedo). Cohen reports that the child appeared to have acquired this distinction late, in 
the seventeenth month of language contact, which suggests that this was a case of last learned-first forgotten. While two of the three children at least provided a few cases of unlearning in reverse order from the original acquisition process, one child did not go through such a process in her attrition.

Finding mixed results should not be surprising, as the attrited language is potentially influenced by the L2 being acquired whereas the L1 is acquired as the sole language and is not subject to the influence of another language (Yukawa 1997). But even when one compares L2 acquisition and L2 loss in cases where the same language is involved in both procedures, as in Cohen (1975), the order of attrition is not always exactly the reverse of acquisition.

\subsection{Threshold hypothesis}

The threshold hypothesis, discussed by De Bot and Clyne (1989), suggests that if a certain threshold of use is achieved for certain linguistic constructions/phenomena, learners may be less vulnerable to attrition or even immune from loss. A higher threshold is activated by frequency of language use, in which case the acquired representation becomes resistant to attrition. In an earlier study, Clyne (1981) conducted research on elderly German and Dutch immigrants to Australia in the 1970s using measures such as code switching. As immigrants grow older, their dependence on and preference for their ethnic language becomes stronger than in middle age. Data from his elderly informants demonstrated evidence for L2 (English) attrition and L1 (German or Dutch) reversion. When De Bot and Clyne (1989) interviewed some of these participants after more than 15 years, they found surprisingly little loss of proficiency in either Dutch or German. 
Other studies suggesting a correlation between pre-attrition proficiency and retention rate (Bahrick 1984; Weltens, Van Els, and Schils 1989) also seem to be in line with the threshold hypothesis. For example, Bahrick (1984) conducted a crosssectional study of L2 Spanish attrition. He recruited diverse age groups of participants who were taking or had taken Spanish courses as a foreign language at a high school or college level. The participants were tested on various aspects of Spanish such as word order, reading comprehension, and idiom recall. Results showed that after some loss in the first five to six years after acquisition stopped, not much more had been forgotten a quarter of a century later.

This research suggests that there are points beyond which some aspects of language become resistant to attrition. The location of these points may be affected by factors such as age and frequency of use. However, it would be difficult to test this hypothesis without first establishing a way to examine whether particular aspects of language had reached the threshold or not.

\subsection{Interference hypothesis}

The interference hypothesis emphasizes the cross-linguistic influence of the competing language in the new environment to account for loss in the attriting language. While transfer in L2 acquisition deals with development of L2 competence in which the language with the higher proficiency (the learner's L1) influences the acquisition of the language with the lower proficiency (the L2), transfer in attrition deals with the loss of competence. The initially lower-proficiency language, the language being acquired in the new environment, influences the initially higherproficiency language, the attriting language, in which the speaker has presumably already reached a certain level of proficiency. 
Olshtain (1989) observed Hebrew-speaking children losing English when they returned to Israel from an English-dominant environment where they had spent at least two years and had acquired native-like proficiency in English before returning. In a dative construction with a direct object, indirect object, and adverb, English allows only the word orders in (5) and (6) or a double object construction like (7). In Hebrew, word orders (1) to (6) are all acceptable, depending on the focus. Olshtain reports that upon returning to Israel where Hebrew is the dominant language, the children soon abandoned the strict grammatical word order required in English and allowed various orderings in English, including (8).

(1) Give to mommy the knife immediately.

(2) Give to mommy immediately the knife.

(3) Give immediately the knife to mommy.

(4) Give immediately to mommy the knife.

(5) Give the knife immediately to mommy.

(6) Give the knife to mommy immediately.

(7) Give mommy the knife immediately.

(8) I never saw in my life a dinosaur.

In a more recent study, McCormack (2004) examined the loss of constraints on English reflexive binding (Binding Principle A) among Japanese college students. More specifically, the foci of the study were whether knowledge of the governing category (GC) of English is prone to loss, and if so, how it affects a speaker's reflexive pronoun system. As is widely known, English reflexives must be bound to a local antecedent, while Japanese does not restrict the reflexive in this way; instead, Japanese allows binding to either a local or long-distance antecedent. The examples 
below illustrate the point. In both languages, either a finite clause, as in (9), or a nonfinite clause, as in (10), can serve as a GC.

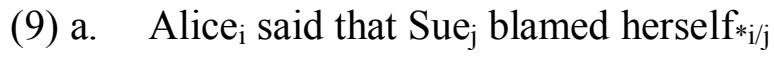

b. Alice ${ }_{i}-$ wa Sue $_{j}-$ ga zibun $_{\mathrm{i} / \mathrm{j}}-\mathrm{O}$ semeto-to itta

Alice-Top Sue-Nom self-Acc blame-Pst-Comp say-Pst

(10) a. Alice told $_{\text {Sue }}$ to blame herself $*_{i} / \mathrm{j}$

b. Alice $_{i}-$ wa $\quad$ Sue $_{j}-$ ga zibun $_{\mathrm{i} / \mathrm{j}}-\mathrm{O} \quad$ semeto-to itta Alice-Top Sue-Nom self-Acc blame-Comp say-Pst

Truth-value judgment and grammaticality judgment tasks were conducted with six Japanese females over various periods of time, ranging from nine months to 16 months, after the participants returned to Japan from having lived in the U.S. The entire data collection was divided into three sub-periods (initial, secondary, and final) with approximately four months of test data included in each sub-period. Data from the initial period showed a high understanding of English reflexive binding. However, over the course of nine to 16 months, the scores of at least four participants declined. McCormack suggests that the L1 influence from Japanese is one of the factors responsible for their increasing acceptance of non-locally bound anaphors in English, since Japanese allows them.

\section{Research questions}

Most of the attrition studies reviewed above deal with a single aspect of language use within the population being investigated. In fact, most attrition research, including the longitudinal case studies that will be discussed throughout this dissertation, focuses on at most a couple of aspects of the language attrition. Thus, the literature includes a 
shortage of longitudinal research that comprehensively examines the course of attrition beginning at the onset of contact with another language. Moreover research on English attrition in Korean native speakers who returned to Korea after living in English-dominant countries is nonexistent.

This dissertation aims to probe diverse aspects of English attrition based on data from several Korean children who returned to Korea from English-dominant countries. My research consists of two separately designed studies. The first is a case study of three children who returned to Korea after living in the U.S. for two years. In particular, I explore their use of English morphology and syntax. The second part of the research assesses the relative strength in Korean and English of two other groups of bilinguals at the vocabulary level. The first group comprises 11 children who returned to Korea after living in the U.S. The second group consists of three children, who moved to an English-dominant environment in Hawai' $\mathrm{i}$ from Korea.

Three major research questions are relevant to this research. The first two, which I explore in the first part of this dissertation, are related to the loss of English morphology and syntax, and the last one, which I discuss in the second part of the dissertation, concerns a shift in the relative speed of English and Korean word naming.

1) How quickly will evidence of morphological and syntactic attrition appear in the experimental data (if it appears at all)? The children's English performance can be expected to decline over time, as increased exposure to Korean leads to a decline in their English proficiency. However, considering that the children's dominant language is English at the point of their return to Korea, that their parents are strongly invested in their children maintaining English, and that English is highly valued in Korean society, the rate of attrition may be slowed or even halted by factors such as special schools and/or extra-curricular activities. 
2) Will the (morpho)syntactic attrition occur selectively? Not all aspects of the language are expected to undergo attrition simultaneously or at the same rate. For example, signs of relative clause attrition might not be found at the same time as a decline in usage of the passive voice. And even within relative clauses, subject relative clauses might be processed with ease for a longer period than, say, genitive relative clauses.

3) Will changes in accuracy and response time (RT) measures for word naming reveal a change in the relative strengths of the two languages? Based on what is known from earlier work on other languages (e.g., Mägiste's 1979 study of German and Swedish), for the returnees to Korea, Korean RTs can be expected to slowly decrease as Korean becomes dominant, while the RTs for the attriting English can be expected to increase, until there is a crossover between the RTs. 


\section{PART I}

CASE STUDIES:

LOSS OF ENGLISH MORPHOLOGY AND SYNTAX 


\section{CHAPTER 2 METHODOLOGY}

Part I comprises seven chapters that report results from the case studies of three children who returned to Korea after two years in the U.S. This chapter addresses the time sensitivity of attrition research and the methodology used for the case studies reported here. The next four chapters (chapters 3 to 6 ) report the results of experiments designed to diagnose possible signs of attrition in the children's use of English articles, irregular past tense verbs, passives, and relative clauses. Chapter 7 deals with the children's use of null subjects and code switching, all in their naturalistic data. Finally, chapter 8 concludes the first part of this dissertation with a summary.

\section{Pre-attrition proficiency}

From a purely linguistic perspective, perhaps the most significant and natural question to ask is, 'What is lost in the attrition process?' Yukawa (1997: ch. 3) provides a summary of research findings in terms of what is lost at different linguistic levels such as phonology, morphology, lexicon, syntax, and supra-sentential communicative skills. Since that summary, more than a decade of research has suggested additional answers to the question of what is lost. However, this matter is not of direct interest here since what is lost beyond some common basic level will inevitably vary depending on the attriters and the languages involved in the attrition process. Rather, my interest lies in examining the methodology used in some of the L1 attrition research summarized in Yukawa (1997). Some research (e.g., Olshtain and Barzilay 1991) gauges the amount and type of attrition by comparing the study group with a control group consisting of 
native speakers of the attriting language. Other studies (e.g., Altenberg 1991) use prescriptive grammar as a baseline to measure the attriter's language loss. However, these methodologies do not adequately and clearly describe attrition since they lack the attention to pre-attrition proficiency (PAP).

The most important and basic premise of any attrition research should be the evaluation of the attriter's PAP. Without PAP data, a researcher cannot be sure whether a non-target form observed in the data is a product of attrition or a form that was never fully acquired. If prescriptive grammar or the native speaker's judgment is what the attrition data is being compared to, the deviant form will be attributed to attrition. However, if the person under investigation never fully acquired the grammatical form, which is a possibility, especially when the research participants are young children, the deviant form produced by the attriter should not be counted as a case of attrition. This judgment cannot be made without knowledge about PAP. In the same vein, the lack of a particular linguistic representation cannot be confidently attributed to attrition if PAP was not measured because there is always a possibility that it was never acquired before the attrition process.

The importance of PAP data forces attrition research to be time-sensitive. Any empirical research on language attrition needs to measure PAP shortly before or after the individual is relocated to a new linguistic environment. Some researchers (Berman and Olshtain 1983; Kuhberg 1992; Olshtain 1989) started collecting data shortly after their participants' relocation, which lends credibility to their observations on certain aspects of language loss.

After establishing the PAP, a researcher must collect data regularly and longitudinally. One of the difficulties of L1 attrition research is that attriters do not constitute a homogeneous population, whereas L1 acquirers can be considered 
homogeneous. That is, all children acquiring their native language are known to go through a similar path of development, which makes both cross-sectional and longitudinal studies effective in L1 acquisition research. However, this is not the case for attrition. Different contact languages for different attriters make a group of attriters heterogeneous. Even extra-linguistic variables such as age, motivation, and length of exposure can contribute to inconsistent outcomes among individuals even if the contact language is identical. Therefore, generally, attrition research favors investigating individuals or small groups with similar backgrounds, whereas L1 acquisition research can often be more group-oriented. This leads attrition researchers to lean toward longitudinal methods that require regular data collection, ideally until no further signs of attrition are observed, whether due to complete loss or reaching a certain point where the remnant seems immune to attrition. ${ }^{2}$

Finding answers to the research question 'what is lost?' can be as difficult as, if not harder than, figuring out what is acquired, because attrition studies will encounter myriad instances where the adage 'Absence of evidence is not evidence of absence' can apply. Natural and experimental data are likely to demonstrate more clearly what is maintained than what is attrited. In order to truly find out what is lost, establishing a study participant's PAP is essential because a deviant form or apparent absence of linguistic representation in the data cannot be attributed to attrition before comparing the data to PAP.

\section{Case study methods}

This section provides some details regarding the methodology used for the longitudinal study of three Korean returnee children, focusing on the participants and

2 However, attrition research could also adopt the cross-sectional methodology of L2 research if a group of attriters shares the same contact languages involved in the attrition process. In fact, some of the discussions in the second part of this dissertation rely on cross-sectional analysis. 
data-collecting procedure relevant to the six chapters in part I. I will describe the experiment materials in the respective chapters that follow.

\subsection{Participants}

Two girls and a boy, referred to with pseudonyms, agreed to participate in this longitudinal project starting in the summer of 2008 . Hera and Rita are sisters, and were aged 6;9 and 4;11 when they began participating. They had been living in Honolulu, Hawai' $i$, for two years with their mother, who was in a post-doctorate program in the Department of Linguistics at the University of Hawai' $i$ at Mānoa before returning to Korea in late June 2008. The third child, Sammy, was age 11;10 when he was first tested in mid-July 2008, a day after he returned to Korea from East Lansing, Michigan, after a two-year stay. Hera and Rita participated for two years and Sammy participated for only a year before he went back to Michigan in 2009.

Both Hera and Rita spoke only Korean when they first arrived in Hawai 'i, but their linguistic dominance switched drastically during their two-year stay: by the time they returned to Korea they were fluent English speakers with limited proficiency in Korean. They seemed to understand Korean to some degree, as their mother used both

English and Korean at home, but their Korean production was limited to greetings and a few vocabulary items. During their time with me a few days before their departure from Hawai' i, they responded only in English to both English and Korean spoken by their mother and me. Also, their mother reported that they rarely spoke Korean even to their father or grandparents in Korea over the phone, and when they did, they did not sound native-like. Hera and Rita were attending public school and kindergarten, respectively, when they left Hawai'i. 
Even after their return to Korea, Hera and Rita continued to use English at home, where, after a few hours at school and kindergarten every day, they spent most of their time under the supervision of a monolingual Korean babysitter until their parents came home from work. Although the parents did not plan to use English with their daughters, they spoke to the girls mostly in English since both girls were more fluent in that language, especially soon after they returned to Korea. Near the end of the two-year project, both girls were speaking Korean to their mother, but Hera reported that her interaction with her little sister was still more English dominant than Korean because she thought Rita was not fully proficient in Korean. They had English classes at their schools, but both reported that they were too easy for them since the focus of the classes was on the alphabet and a few words or expressions. For this reason, two or three times a week after school, they were sent to a private institution where they were enrolled in a class with other returnee children from Englishdominant countries. When they stopped going to the private institution after a few months, their mother had a native English-speaking tutor come to the home approximately twice a week for two-hour visits to talk and play with them.

The other participant, Sammy, had been attending public school in Michigan for two years and reported at our first meeting that he was more comfortable with English than Korean. Still, he was able to understand and express himself in fluent Korean. Considering that he had been raised in Korea for almost 10 years before he went to Michigan, it was not surprising to witness a different pattern of language dominance compared to that of Hera and Rita. After a year back in Korea, Sammy self-reported that he felt as though his English and Korean were at a somewhat equal level. Like most of his peers in Seoul, Sammy attended an English class at his middle school every day. Some of those classes were instructed by a native English speaker. 
In addition, he was sent to private institutions that taught English reading and grammar for about five hours a week, and his mother tried to speak English with him at home as much as possible, although Korean was the more dominant language of the family. ${ }^{3}$ He once reported, about eight months after his return to Korea, that he felt as though his English was slipping away. However, when his friend from Michigan came and stayed at his house for a couple of weeks, he was surprised to find himself a fluent English speaker.

\subsection{Procedure}

I conducted and audio-recorded nine experiments in order to examine five aspects of English grammar: relative clauses (RC), passive voice, irregular past tense, articles, and subject-verb agreement. Four of these - all except subject-verb agreement - were tested in two separate experiments. The $\mathrm{RC}$ and passive voice experiments included a production task and a comprehension task. Participants were asked to produce irregular past tense verbs in one experiment and make a judgment in another. Two different experiments elicited articles. However, only one experiment tested subjectverb agreement, which I will not report in detail due to the problems with the experiment design.

I conducted these nine experiments in two or three different sessions. Usually, there was a three- to seven-day interval in between. It took about two weeks to complete all nine tests. Sammy participated 15 times over a one-year period (July 18, 2008 to August 16, 2009) before he returned to the U.S. Because he was older than the other two participants and was busier with more schoolwork and extra-curricular activities, I was not able to collect as much data from him as from the other two

${ }^{3}$ Sammy used only Korean with his father. Sammy also had an older brother who was attending college in the U.S. but their interaction was not always English dominant when his older brother was at home during vacations. 
children. He usually concentrated solely on the tasks and needed only about 20 minutes every session and completed all nine experiments in two sessions. Testing took place at his home at his convenience, usually during the weekend. For instance, session 1 would take place on a Sunday afternoon and session 2 on the next Sunday. Then, session 1 of the next round of experiments would be conducted a week later. The following shows the experiments conducted in each session.

Sammy: Session 1) RC comprehension, Irregular verb judgment, Agreement, Article I, Passive production

Session 2) RC production, Irregular verb elicitation, Article II, Passive comprehension

Hera and Rita completed 27 rounds of experiments over a two-year period (June 23, 2008 to August 12, 2010). The girls were tested individually and each session, on average, usually took more than 30 minutes. Unlike Sammy, Hera and Rita tended to be very talkative and it was difficult to maintain focus solely on the tasks for any length of time, especially in the case of the younger Rita, which is why I divided the nine experiments into three sessions. The following shows the experiments conducted in each session. However, over time the children's ability to concentrate seemed to improve; so starting from the $23^{\text {rd }}$ round, the schedule for each of the final five rounds followed Sammy's and they finished each round in two sessions. A brief timeline for the data collection is as follows: 
$\begin{array}{ll}\text { Hera } & \text { Session 1) RC production, Irregular verb judgment, Agreement } \\ \text { \& Rita: } & \text { Session 2) Passive production, RC comprehension, Article I } \\ & \text { Session 3) Passive comprehension, Article II, Irregular verb elicitation }\end{array}$

Round 1: June 23 26, 2008 in Hawai' $i$ (returned to Korea in June 28, 2008)

Rounds 2 22: July 23, 2008 to Aug. 17, 2009 in Korea

Rounds 23 24: Dec. 23, 2009 to Jan. 05, 2010 in Korea

Rounds 25 27: May 25, 2010 to Aug. 12, 2010 in Korea

Hera and Rita began participating in the project in Hawai' $i$ during the week of their departure to Korea. I was able to resume experimental work with them about a month later in Korea. For most of the sessions, I visited their home at their convenience on weekdays. However, on a few occasions shortly after their return to Korea, I visited their daycare center because the family was not yet settled in their new home. Typically, Hera and Rita completed one full round of experiments every two weeks: session 1 on Monday, session 2 on Thursday, and session 3 on the next Monday. Then, after a weeklong break, we resumed with a new set of experiments.

Table 2.1 shows the timeline of the experiments. When the three participants returned to Korea in the summer of 2008, I also returned to Korea from Hawai' $i$ and stayed for a year while Sammy completed 15 rounds, and Hera and Rita completed 22 rounds. Then, I went back to Hawai' i for the Fall 2009 semester and returned to Korea in December 2009 to conduct experiment rounds 23 and 24 for Hera and Rita. Again, I spent the Spring 2010 semester in Hawai' $i$ and visited Korea in the summer of 2010 to complete the final three rounds (rounds 25 to 27) with Hera and Rita. Therefore, a 
total of more than four months elapsed without experiments between rounds 22 and 23 , and rounds 24 and 25 .

TABLE 2.1. TIMELINE OF EXPERIMENTS (WEEKS AFTER RETURN)

\begin{tabular}{|c|c|c|}
\hline Round & Sammy & Hera \& Rita \\
\hline $\mathbf{1}$ & 0 & -1 \\
\hline $\mathbf{2}$ & 2 & 4 \\
\hline $\mathbf{3}$ & 5 & 6 \\
\hline $\mathbf{4}$ & 7 & 9 \\
\hline $\mathbf{5}$ & 10 & 13 \\
\hline $\mathbf{6}$ & 12 & 15 \\
\hline $\mathbf{7}$ & 16 & 17 \\
\hline $\mathbf{8}$ & 20 & 19 \\
\hline $\mathbf{9}$ & 24 & 22 \\
\hline $\mathbf{1 0}$ & 26 & 27 \\
\hline $\mathbf{1 1}$ & 29 & 29 \\
\hline $\mathbf{1 2}$ & 32 & 32 \\
\hline $\mathbf{1 3}$ & 44 & 35 \\
\hline $\mathbf{1 4}$ & 51 & 37 \\
\hline $\mathbf{1 5}$ & 55 & 39 \\
\hline $\mathbf{1 6}$ & & 43 \\
\hline $\mathbf{1 7}$ & & 45 \\
\hline $\mathbf{1 8}$ & & 47 \\
\hline $\mathbf{1 9}$ & & 49 \\
\hline $\mathbf{2 0}$ & & 51 \\
\hline $\mathbf{2 1}$ & & 54 \\
\hline $\mathbf{2 2}$ & & 58 \\
\hline $\mathbf{2 3}$ & & 76 \\
\hline $\mathbf{2 4}$ & & \\
\hline \hline $\mathbf{2 5}$ & & 05 \\
\hline $\mathbf{2 6}$ & & \\
\hline $\mathbf{2 7}$ & & 59 \\
\hline & & \\
\hline
\end{tabular}


Two experiments testing the same grammatical phenomenon were never included in the same session so as to avoid any possibility of the first experiment priming the second. For example, if RC production and RC comprehension tasks were conducted in the same session, regardless of order, the second task could had been influenced by the performance on the first task. Also, the RC comprehension and passive comprehension tasks were not conducted during the same session because they were the only two experiments that involved the children using a laptop keyboard.

All but the two experiments pertaining to the irregular past tense verbs had five different versions. After experimental round 5, the same materials were recycled in the same order. Therefore, for example, the materials used for agreement, articles, passive production, and $\mathrm{RC}$ production in sessions $1,6,11,16,21$, and 26 were identical. In the case of passive comprehension and $\mathrm{RC}$ comprehension, which were picture-selection tasks involving a laptop computer, each of the five versions had two sub-forms. Every test item in the two laptop-oriented experiments included two reversible animate arguments. After the fifth experiment, the same sets of pictures were used while the two arguments were reversed in each test item. For example, the two arguments in one of the items in passive comprehension test set 1, The man is pushed by the woman, were reversed as The woman is pushed by the man to constitute a test item in test set 6 . Therefore, the passive comprehension and $\mathrm{RC}$ comprehension materials used in sessions 1,11 , and 21 were identical, while materials used in sessions 6,16 and 26 were sub-sets of the material used in sessions 1, 11, and 21: sessions 6,16 , and 26 recycled the exact same pictures as sessions 1,11 , and 21 , but the test items reversed the two animate arguments. The two experiments pertaining to the irregular past tense verbs had nine different versions. Therefore, for example, sets 
2,11 , and 20 shared the same materials. More detail on the design of the experiments will be provided in the relevant chapters.

The distribution of test materials across experiments created sets comprising experiments with varying versions. For example, these are experiments included in session 17:

-Agreement ver2

-Article I ver.2

-Article II ver.2

-Passive production ver.2 •Passive comprehension ver.7

•RC comprehension ver.7 • RC production ver.2

- Irregular past verb production ver. 8

- Irregular past verb judgment ver. 8

Therefore, by the end of the project, some versions of the experiments had been used more than rest.

\section{Some limitations}

We must keep in mind the fact that participants were constantly provided with English input even after returning to Korea. Sammy's mother was eager to invest in her son's English, particularly in a way that would help him receive good grades at school. ${ }^{4}$ This meant that he was sent to private English institutions and he was spoken to in English at home. Although Hera and Rita did not receive explicit English lessons, they used English when they attended the private institution that accepted only returnee children like them. Also, most importantly, Hera and Rita talked to each other in English at home, where they spent most of their time together.

The fact that these children were exposed to English in Korea, whether in formal English lessons or everyday use, exposes a potential limitation of this project.

\footnotetext{
${ }^{4}$ Although Sammy was a fluent English speaker, that does not guarantee high English grades in Korean middle school as other aspects of language such as grammar and reading are also tested.
} 
In a way, continued English input obscures the true process of English attrition in these children's data, pointing to the need for a "baseline" group of children who would receive no English input once they return to Korea from an English-dominant environment. This kind of group, if there is one, could allow us to estimate the rate and timing of attrition. However, without such a group, it is difficult to make a definite statement regarding the influence of continuous English use on the three children participating in this research. Although it is important to acknowledge that the absence of a baseline group is a potential problem, the problem is not easily overcome. It is quite safe to say that most of the parents of Korean returnee children are highly educated middle- to upper-class citizen, who typically invest considerable time and resources to retain their children's English. Still, as the need for such a group for future research is evident, I hope to find Korean returnees whose parents are not planning to devote extra effort to maintain their children's English. 


\title{
CHAPTER 3
}

\begin{abstract}
ARTICLES

\section{Introduction}

The English definite article the is typically associated with an established discourse referent that is familiar to both speaker and hearer. On the other hand, the indefinite article $a(n)$ is used to introduce a new referent. It is widely known that articles cause problems for both young L1 children and L2 learners of English, which makes articles an interesting and relevant topic for attrition research. ${ }^{5}$ In fact, Cohen $(1974,1975)$ studied children's use of articles with respect to attrition research in Spanish. Cohen's participants were young native English speakers enrolled in a Spanish immersion program who were tested before and after a summer recess of three months.

In Cohen (1974), most of the errors involved incorrect selection of gender.
\end{abstract} While the error rates in the pre- and post-tests did not differ significantly (26.8 vs. $30 \%$ ), error patterns for definite and indefinite articles did vary. In the pre-test, 61 percent of the definite article errors resulted from use of the masculine article $e l$ with a feminine noun, and 39 percent of errors involved the use of the feminine article $l a$ with a masculine noun. The trend changed dramatically in the post-test: 70 percent of the errors resulted from using la with a masculine noun. Unlike definite articles, error patterns of indefinite articles did not change after three months of recess. ${ }^{6}$ Cohen

\footnotetext{
5 English articles are known to be notoriously difficult for L2 learners (Parrish 1987; Thomas 1989; Robertson 2000, among many others). In particular, L2 learners of English who lack articles in their L1 (like Korean) demonstrate overuse and underuse of both the indefinite and definite articles. See Ionin et al. $(2003,2008)$ for discussion of the use of articles by Korean L2 learners of English.

${ }^{6}$ Cohen (1974:65) suggests that the asymmetry between the error patterns of Spanish definite and indefinite articles might be due to a clearer marking for gender in indefinite articles than definite articles. Not only is the $o$ of uno changed to $a$ before feminine nouns (e.g., una pelota), but the $o$ even drops off before a masculine noun (e.g., un niño), further differentiating the masculine from the feminine article with respect to syllable length.
} 
(1975) reported a similar finding: two of the three participants started overusing the feminine singular definite article la after summer recess.

In this chapter, I will report on the returnee children's article production skills in English as tested with a picture-naming task and a story-telling task. Both tasks had a tripartite design: 1) elicitation of indefinite articles, 2) introduction of new nominals, and 3) elicitation of definite articles to refer to the new nominals after their introduction.

\section{Literature review}

English articles cause problems up to age five for children acquiring English. It is widely known that they tend to overuse the definite article when referring to a new discourse entity. Some of the recent research on this issue is summarized below.

Schaeffer and Matthewson (2005) examined article production in children acquiring English as their L1; the research focused on children's awareness of the common ground of speaker and hearer. In one condition, exemplified in (1) below, the child, given no verbal introduction, looked at a picture that included the intended referent and was asked a question that required a response using the indefinite article since the referent was only known to the child, not the experimenter. In another condition, shown in (2), the referent was not known to either the speaker (Elmo) or the hearer (the child), and the target article was also $a$. Schaeffer and Matthewson found overuse of the in about 25 percent of the responses in condition (1), but they found no overuse in condition (2). They conclude that young children lack a pragmatic principle that states that speaker and hearer assumptions are always independent. If children cannot make a proper distinction between speaker and hearer 
knowledge, incorrect use of articles is expected because they compute the common ground incorrectly.

(1) Experimenter shows picture of Mickey Mouse, who just finished drawing a house.

Exp: What did Mickey Mouse just do?

Target: He drew $a$ house

(2) Big Bird: Oh, I'm so bored. I don't know what to do. Oh, you know what, I'm going to the forest, and I'm gonna draw something there.

Elmo: What do you think Big Bird is gonna do in the forest?

Target: Draw $a$ tree.

There is, however, an alternative explanation for the children's responses. In their extensive review of previous studies on young children's article use, Van Hout et al. (2010) point out that overuse of the in $a$-eliciting situations occurs when there is a visual referent or when a set of entities is mentioned in the previous discourse, even without a unique referent singled out. However, children correctly use $a$ when they introduce an entirely new referent into the discourse. Thus, even when researchers use a purely verbal context with no pictures or props to elicit indefinite articles, as in Schafer and de Villiers (2000), test items like (3) elicited overuse of the but items like (4) did not.

(3) Three ducks and two dogs were walking over a bridge. One of the animals fell off and said, 'Quack!' What was it? Target: a duck

(4) I bet you have something hanging on your wall at home. What is it? Target: a picture 
Note that the mean ages of the participants in the studies discussed above were less than $4 ; 6$ while the ages of the participants in this attrition study were $4 ; 11,6 ; 9$, and 11;10. Although these three children were exposed to an English-dominant environment for only two years, their cognitive maturity should be considered in the analysis of their errors.

\section{Materials}

I used two experiments to examine the children's ability to use the indefinite article to introduce a new referent and the definite article to refer to an already-introduced referent. The first experiment involved a picture-naming technique and the second, a story-telling task. Five different versions of experiments were recycled in the same order after every fifth experiment.

\subsection{Picture-naming task}

For this task, five envelopes were used, each containing two small pictures of a countable object. The pictures were put into envelopes to let the children know that I was not aware of the content in the pictures. When the child picked an envelope, I took out the pictures without looking at them. Participants looked at the first picture while I said, 'What is this? This is 'The participant was expected to finish the sentence with a target answer such as 'a cake.' I then asked the same question as the participant looked at another picture. After the second response, I asked two more questions, each one leading the participants to name one of the items from the pictures. Figure 3.1 is a sample test item. The questions were expected to be answered with a noun preceded by a definite or indefinite article. There were five picture pairs in each 
test set. Thus, in each test set, participants were given 10 opportunities to use each of the indefinite and definite articles.

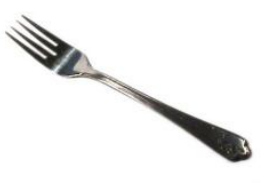

Q: 1) What is this? This is Expected answer: $\underline{\boldsymbol{a}}$ cake

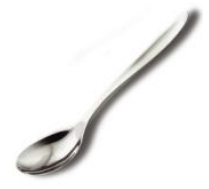

2) What is this? This is an orange
Q: 3) Which one do you use for a slice of apple? Expected answer: the cake
4) Which one do you use for soup? the orange

FIGURE 3.1. TEST ITEM FOR PICTURE-NAMING TASK

\subsection{Story-telling task}

The story-telling task replicated one of the experiments from Warden (1976). Each story comprised three sequential events, each drawn on a separate piece of paper. Usually, the first picture contained three animate characters and at least one inanimate object, all of which I expected the children to refer to with the indefinite article since they were being introduced for the first time. Each referent from the first picture reappeared at least once in the next two pictures. Upon their reappearance, each referent should be preceded by the definite article. Also, usually in each of the last two pictures, a new character, which should be preceded by the indefinite article, was introduced in order to develop the story. When a new character from the second picture showed up again in the last picture, the use of the definite article would be appropriate. In most cases, there were more than six instances that required the indefinite article depending on how the child built the story. As for the definite article, the participant had more than a dozen opportunities to use it since some referents 
appeared twice more after their introduction. Figure 3.2 shows an example of pictures from the story-telling task and the target answer.
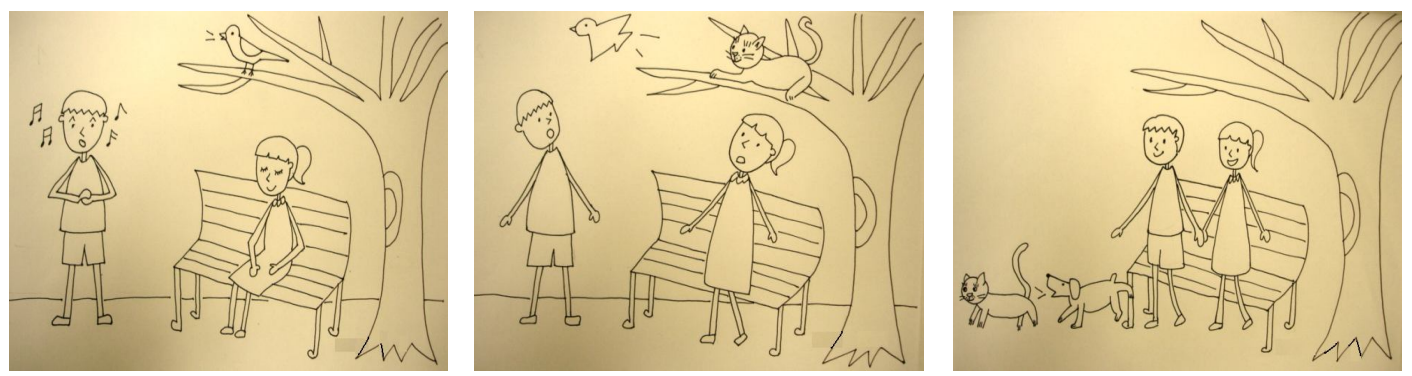

Picture 1: $\underline{A}$ girl sitting on a bench is listening to $\underline{a}$ boy sing. $\underline{A}$ bird is also singing on $\underline{\text { a }}$ tree.

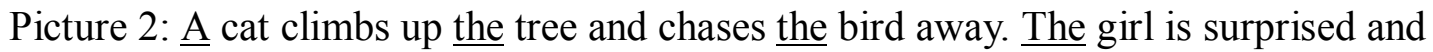
stands up from the bench. The boy is also surprised.

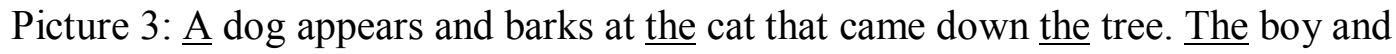
the girl are holding hands in front of the bench.

\section{FIGURE 3.2. TEST ITEM FOR STORY-TELLING TASK}

Each test set consisted of three stories, and each set of pictures was put inside a separate envelope. As in the picture-naming task, this was to prevent participants from assuming that I had prior knowledge about the context. After they chose an envelope, I took out the pictures one at a time (they were in the correct order in the envelope) and held them in front of my face so that I was looking at the back of the paper and was not able to see the drawing. In Warden's (1976) original experiment, children were tested in pairs: they took turns composing a story based on the drawings and narrating it to the partner, who could not see the pictures. ${ }^{7}$ Thomas (1989) points out

\footnotetext{
${ }^{7}$ In Warden (1976), all groups (3-, 5-, 7-, and 9-year-olds, and adults) used the definite article correctly over $90 \%$ of the time. However, 3-, 5-, and 7-year-olds did not perform well when the situation called for an indefinite article. All three of these age groups used more definite than indefinite articles in these situations, although only the 3-year-olds showed a statistically significant difference. Among them, only 9 -year-olds significantly used more indefinite articles and the adults' performance was perfect.
} 
that the requirement that the speaker narrate the story to the other child rather than to the experimenter is an important feature of this methodology because if the children were to address the experimenter, they might assume that the experimenter is already familiar with the content of the drawings, legitimizing the use of definite articles even with nouns not previously mentioned in the discourse. However, since such a method was impractical for this project I had to pretend that I had no prior knowledge about the story by taking the pictures out of the envelope without looking at them and showing them only to the participants.

\section{Results}

In reporting the results of the picture-naming and the story-telling tasks, I will focus on the three returnee children's use of indefinite and definite articles, including omissions. (In a few cases, children used deictic expressions such as this (once for Sammy) and that (once each for Hera and Rita) in the determiner position or the plural form of a nominal, neither of which will be included nor discussed in the tables below.)

Results from each group of five sessions will be clustered together for reporting purposes because the tasks were based on recycling five different test sets; each round of five tests usually took place over a three to four month period. Since Sammy was tested 15 times, his data are divided into three periods: sessions 1 to 5, 6 to 10 , and 11 to 15 . However, Hera and Rita were tested 27 times: 22 times in the first year, twice after a four-month break, and three more times after another four-month break. Data from their first 20 sessions are divided into four periods: sessions 1 to 5, 6 to 10,11 to 15 , and 16 to 20 . The last seven sessions are grouped according to data collection breaks. The two four-month breaks served as boundaries between periods 
(see ch.2), which results in three additional periods: sessions 21 and 22, sessions 23 and 24, and sessions 25 to 27. Data from Hera and Rita is therefore divided into seven different periods.

\subsection{Picture-naming task}

Sammy never used the definite article to introduce a new object in the picture-naming task; in approximately 80 percent of his responses, he used the correct indefinite article (table 3.1). When he did not use $a$, Sammy simply named the object in its bare form leaving the determiner position unoccupied (e.g., 'Ø saxophone').

TABLE 3.1. SAMMY'S USE OF ARTICLES IN PICTURE-NAMING TASK (NO. OF USE/TOTAL)

\begin{tabular}{|c||c|c|c||c|c|c|}
\hline \multirow{2}{*}{\multicolumn{1}{|c||}{ Session }} & \multicolumn{3}{c||}{$1^{\text {st }}$ mention } & \multicolumn{3}{c|}{$2^{\text {nd }}$ mention } \\
\cline { 2 - 7 } & $\mathbf{a}$ & the & $\varnothing$ & $\mathbf{a}$ & the & $\boldsymbol{\emptyset}$ \\
\hline $1 \sim 5$ & $80 \%(40 / 50)$ & $0 \%(0 / 50)$ & $20 \%(10 / 50)$ & $78 \%(39 / 50)$ & $2 \%(1 / 50)$ & $18 \%(9 / 50)$ \\
\hline $6 \sim 10$ & $74 \%(37 / 50)$ & $0 \%(0 / 50)$ & $26 \%(13 / 50)$ & $70 \%(35 / 50)$ & $2 \%(1 / 50)$ & $28 \%(14 / 50)$ \\
\hline $11 \sim 15$ & $84 \%(42 / 50)$ & $0 \%(0 / 50)$ & $16 \%(8 / 50)$ & $82 \%(41 / 50)$ & $4 \%(2 / 50)$ & $14 \%(7 / 50)$ \\
\hline
\end{tabular}

*target response

In the later questions, designed to elicit the, Sammy still rarely used the definite article. Most of his responses involved the incorrect use of $a$. In other words, in general, Sammy's responses to questions eliciting $a$ showed the same pattern as those eliciting the.

Hera also never used the in responses to questions eliciting $a$ (table 3.2). Her use of $a$ fluctuated between 72 and 95 percent in each period. When she did not use $a$, most of her responses involved using the bare noun. Note that the last two periods have the highest correct use of the indefinite article. 
In the later questions, designed to elicit definite articles, Hera correctly responded more than half of the time with the. Her correct use of the definite article ranged from 54 to 80 percent. Her incorrect use of $a$ instead of the was rather consistent (except in the second and fourth periods), at approximately 20 percent, and most of her responses that included neither $a$ nor the were bare nouns. Note that just as with the early questions eliciting the use of $a$, the last two periods have the highest correct usage of the, and in these two periods, Hera's use of no article decreased dramatically.

TABLE 3.2. HERA'S USE OF ARTICLES IN PICTURE-NAMING TASK (NO. OF USE/TOTAL)

\begin{tabular}{|c||c|c|c||c|c|c|}
\hline \multirow{2}{*}{\multicolumn{1}{|c||}{ Session }} & \multicolumn{3}{|c||}{$1^{\text {st }}$ mention } & \multicolumn{3}{c|}{$2^{\text {nd }}$ mention } \\
\cline { 2 - 7 } & $\mathbf{a}$ & the & $\varnothing$ & a & the & $\varnothing$ \\
\hline $1 \sim 5$ & $78 \%(39 / 50)$ & $0 \%(0 / 50)$ & $20 \%(10 / 50)$ & $20 \%(10 / 50)$ & $60 \%(30 / 50)$ & $18 \%(9 / 50)$ \\
\hline $6 \sim 10$ & $76 \%(38 / 50)$ & $0 \%(0 / 50)$ & $24 \%(12 / 50)$ & $10 \%(5 / 50)$ & $70 \%(35 / 50)$ & $18 \%(9 / 50)$ \\
\hline $11 \sim 15$ & $82 \%(41 / 50)$ & $0 \%(0 / 50)$ & $14 \%(7 / 50)$ & $18 \%(9 / 50)$ & $54 \%(27 / 50)$ & $22 \%(11 / 50)$ \\
\hline $16 \sim 20$ & $72 \%(36 / 50)$ & $0 \%(0 / 50)$ & $26 \%(13 / 50)$ & $6 \%(3 / 50)$ & $56 \%(28 / 50)$ & $34 \%(17 / 50)$ \\
\hline $21 \sim 22$ & $75 \%(15 / 20)$ & $0 \%(0 / 20)$ & $25 \%(5 / 20)$ & $20 \%(4 / 20)$ & $55 \%(11 / 20)$ & $10 \%(2 / 20)$ \\
\hline $23 \sim 24$ & $95 \%(18 / 20)$ & $0 \%(0 / 20)$ & $5 \%(1 / 20)$ & $15 \%(3 / 20)$ & $75 \%(15 / 20)$ & $5 \%(1 / 20)$ \\
\hline $25 \sim 27$ & $83 \%(25 / 30)$ & $0 \%(0 / 30)$ & $17 \%(5 / 30)$ & $17 \%(5 / 30)$ & $80 \%(24 / 30)$ & $3 \%(1 / 30)$ \\
\hline
\end{tabular}

*target response

TABLE 3.3. RITA'S USE OF ARTICLES IN PICTURE-NAMING TASK (NO. OF USE/TOTAL)

\begin{tabular}{|c||c|c|c||c|c|c|}
\hline \multirow{2}{*}{\multicolumn{1}{|c||}{ Session }} & \multicolumn{3}{c||}{$1^{\text {st }}$ mention } & \multicolumn{3}{c|}{$2^{\text {nd }}$ mention } \\
\cline { 2 - 7 } & $\mathbf{a}$ & the & $\varnothing$ & a & the & $\varnothing$ \\
\hline $1 \sim 5$ & $38 \%(19 / 50)$ & $0 \%(0 / 50)$ & $62 \%(31 / 50)$ & $20 \%(10 / 50)$ & $10 \%(5 / 50)$ & $68 \%(34 / 50)$ \\
\hline $6 \sim 10$ & $48 \%(24 / 50)$ & $0 \%(0 / 50)$ & $52 \%(26 / 50)$ & $56 \%(28 / 50)$ & $0 \%(0 / 50)$ & $44 \%(22 / 50)$ \\
\hline $11 \sim 15$ & $52 \%(26 / 50)$ & $0 \%(0 / 50)$ & $48 \%(24 / 50)$ & $42 \%(21 / 50)$ & $4 \%(2 / 50)$ & $50 \%(25 / 50)$ \\
\hline $16 \sim 20$ & $82 \%(41 / 50)$ & $0 \%(0 / 50)$ & $18 \%(9 / 50)$ & $66 \%(33 / 50)$ & $2 \%(1 / 50)$ & $30 \%(15 / 50)$ \\
\hline $21 \sim 22$ & $75 \%(15 / 20)$ & $0 \%(0 / 20)$ & $25 \%(5 / 20)$ & $85 \%(17 / 20)$ & $0 \%(0 / 20)$ & $15 \%(3 / 20)$ \\
\hline $23 \sim 24$ & $75 \%(15 / 20)$ & $5 \%(1 / 20)$ & $20 \%(4 / 20)$ & $40 \%(8 / 20)$ & $0 \%(0 / 20)$ & $60 \%(12 / 20)$ \\
\hline $25 \sim 27$ & $20 \%(6 / 30)$ & $0 \%(0 / 30)$ & $80 \%(24 / 30)$ & $17 \%(5 / 30)$ & $7 \%(2 / 30)$ & $77 \%(23 / 30)$ \\
\hline
\end{tabular}


Rita behaved like the other two children by not using the in her response to questions eliciting indefinite articles (except once in session 24). When she did not use $a$ in these situations, she used the bare noun (table 3.3). Her correct use of $a$ increased after session 15 from approximately 50 to 75 percent. However, in the last three sessions, correct use of $a$ dropped to 20 percent.

Like Sammy, Rita's use of the definite article remained incorrect throughout the sessions. When the context called for the, Rita, for the most part, used either $a$ or no determiner at all. Notably, Rita's use of no articles hit the highest point in the final period (the last three sessions) in responding to the questions eliciting both $a$ and the.

I later noticed that among the 50 picture stimuli used for this task there were five for which the noun could be considered either countable and uncountable. (For instance, cake works this way: I ate cake or I ate a cake.) There was one noun of this type in each of the first three test sets and two in set 4 . Children tended to avoid using the indefinite article in their first mention of these objects compared to the nouns such as fork that can be only countable: $66.6 \%$ vs. $80.7 \%$ for Sammy, $25.9 \%$ vs. $84.4 \%$ for Hera, and $18.5 \%$ vs. $58 \%$ for Rita. Although this is a flaw in my experimental design, it does not change the trend reported earlier, as the number of relevant items constitutes only $10 \%$ of the stimuli and the children's response to them are rather consistent throughout the testing period.

\subsection{Story-telling task}

Sammy's pattern of article usage in the story-telling task is probably the most puzzling result to be reported in this chapter. In the first five sessions, he correctly used $a$ most of the time (86\%), while he correctly responded with a definite article less than half of the time (table 3.4). In the next five sessions, Sammy's correct $a$ - 
response decreased by 10 percent while he showed more correct use of the $(60 \%)$. In the final five sessions, his correct use of $a$ dropped even further to 54 percent and his correct use of the increased to 67 percent. Thus, it seems that while his ability to associate the indefinite article with a newly introduced nominal decreased, he became more able to associate the definite article with an established discourse referent.

Note also that incorrect use of the in response to questions targeting $a$ consistently increased. At the same time, incorrect use of $a$ declined when the was called for. Meanwhile, the use of bare nouns without any determiner remained rare. This demonstrates a trend of increasing definite article overuse.

TABLE 3.4. SAMMY'S USE OF ARTICLES IN STORY-TELLING TASK (NO. OF USE/TOTAL)

\begin{tabular}{|c||c|c|c||c|c|c|}
\hline \multirow{2}{*}{\multicolumn{1}{|c||}{ Session }} & \multicolumn{3}{c||}{$1^{\text {st }}$ mention } & \multicolumn{3}{c|}{$2^{\text {nd }}$ mention } \\
\cline { 2 - 7 } & $\mathbf{a}$ & the & $\varnothing$ & $\mathbf{a}$ & the & $\emptyset$ \\
\hline $1 \sim 5$ & $86 \%(81 / 94)$ & $10 \%(9 / 94)$ & $1 \%(1 / 94)$ & $43 \%(71 / 164)$ & $44 \%(72 / 164)$ & $9 \%(15 / 164)$ \\
\hline $6 \sim 10$ & $76 \%(71 / 93)$ & $22 \%(20 / 93)$ & $2 \%(2 / 93)$ & $33 \%(47 / 141)$ & $60 \%(85 / 141)$ & $6 \%(9 / 141)$ \\
\hline $11 \sim 15$ & $54 \%(51 / 95)$ & $41 \%(39 / 95)$ & $4 \%(4 / 95)$ & $28 \%(35 / 126)$ & $67 \%(85 / 126)$ & $4 \%(5 / 126)$ \\
\hline
\end{tabular}

*target response

TABLE 3.5. HERA'S USE OF ARTICLES IN STORY-TELLING TASK (NO. OF USE/TOTAL)

\begin{tabular}{|c||c|c|c||c|c|c|}
\hline \multirow{2}{*}{ Session } & \multicolumn{3}{|c||}{$1^{\text {st }}$ mention } & \multicolumn{3}{c|}{$2^{\text {nd }}$ mention } \\
\cline { 2 - 7 } & $\mathbf{a}$ & the & $\varnothing$ & $\mathbf{a}$ & the & $\varnothing$ \\
\hline $1 \sim 5$ & $81 \%(79 / 98)$ & $14 \%(14 / 98)$ & $2 \%(2 / 98)$ & $10 \%(19 / 192)$ & $88 \%(168 / 192)$ & $2 \%(3 / 192)$ \\
\hline $6 \sim 10$ & $71 \%(65 / 92)$ & $27 \%(25 / 92)$ & $0 \%(0 / 92)$ & $5 \%(7 / 144)$ & $92 \%(132 / 144)$ & $3 \%(4 / 144)$ \\
\hline $11 \sim 15$ & $81 \%(76 / 94)$ & $10 \%(9 / 94)$ & $7 \%(7 / 94)$ & $4 \%(6 / 144)$ & $90 \%(129 / 144)$ & $4 \%(6 / 144)$ \\
\hline $16 \sim 20$ & $83 \%(76 / 92)$ & $13 \%(12 / 92)$ & $3 \%(3 / 92)$ & $3 \%(6 / 172)$ & $95 \%(164 / 172)$ & $1 \%(2 / 172)$ \\
\hline $21 \sim 22$ & $75 \%(27 / 36)$ & $19 \%(7 / 36)$ & $0 \%(0 / 36)$ & $2 \%(1 / 55)$ & $98 \%(54 / 55)$ & $0 \%(0 / 55)$ \\
\hline $23 \sim 24$ & $68 \%(27 / 40)$ & $28 \%(11 / 40)$ & $5 \%(2 / 40)$ & $2 \%(1 / 63)$ & $97 \%(61 / 63)$ & $2 \%(1 / 63)$ \\
\hline $25 \sim 27$ & $82 \%(46 / 56)$ & $16 \%(9 / 56)$ & $2 \%(1 / 56)$ & $7 \%(6 / 89)$ & $91 \%(81 / 89)$ & $1 \%(1 / 89)$ \\
\hline
\end{tabular}


Hera's use of articles in the story-telling event was quite stable. Table 3.5 shows that she performed well, showing command of both articles in appropriate contexts.

However, she was always more accurate with the use of definite articles.

Table 3.6 shows that Rita was relatively accurate in her use of definite articles.

Except in the first five sessions, she associated the with established discourse referents more than 80 percent of the time. However, her correct usage of indefinite articles remained low at approximately 30 percent. In all periods except the first, the proportion of incorrect the usage when a new entity was introduced was higher than the correct use of $a$, demonstrating Rita's general overuse of definite articles.

TABLE 3.6. RITA'S USE OF ARTICLES IN STORY-TELLING TASK (NO. OF USE/TOTAL)

\begin{tabular}{|c||c|c|c||c|c|c|}
\hline \multirow{2}{*}{ Session } & \multicolumn{3}{|c||}{$1^{\text {st }}$ mention } & \multicolumn{3}{c|}{$2^{\text {nd }}$ mention } \\
\cline { 2 - 7 } & $\mathbf{a}$ & the & $\varnothing$ & $\mathbf{a}$ & the & $\varnothing$ \\
\hline $1 \sim 5$ & $44 \%(42 / 95)$ & $44 \%(42 / 95)$ & $9 \%(9 / 95)$ & $20 \%(28 / 142)$ & $67 \%(95 / 142)$ & $12 \%(17 / 142)$ \\
\hline $6 \sim 10$ & $26 \%(26 / 99)$ & $62 \%(61 / 99)$ & $11 \%(11 / 99)$ & $12 \%(16 / 139)$ & $83 \%(116 / 139)$ & $4 \%(6 / 139)$ \\
\hline $11 \sim 15$ & $35 \%(34 / 98)$ & $57 \%(56 / 98)$ & $7 \%(7 / 98)$ & $12 \%(18 / 157)$ & $82 \%(129 / 157)$ & $6 \%(9 / 157)$ \\
\hline $16 \sim 20$ & $39 \%(36 / 92)$ & $55 \%(51 / 92)$ & $5 \%(5 / 92)$ & $8 \%(11 / 138)$ & $86 \%(119 / 138)$ & $6 \%(8 / 138)$ \\
\hline $21 \sim 22$ & $33 \%(13 / 39)$ & $64 \%(25 / 39)$ & $3 \%(1 / 39)$ & $5 \%(3 / 63)$ & $95 \%(60 / 63)$ & $0 \%(0 / 63)$ \\
\hline $23 \sim 24$ & $18 \%(7 / 39)$ & $74 \%(29 / 39)$ & $8 \%(3 / 39)$ & $6 \%(4 / 65)$ & $92 \%(60 / 65)$ & $2 \%(1 / 65)$ \\
\hline $25 \sim 27$ & $30 \%(17 / 56)$ & $59 \%(33 / 56)$ & $9 \%(5 / 56)$ & $10 \%(8 / 79)$ & $82 \%(65 / 79)$ & $8 \%(6 / 79)$ \\
\hline
\end{tabular}

\section{Discussion}

The two tasks discussed in this chapter each provide different insights on the three returnees' article use. ${ }^{8}$ In the picture-naming task (tables 3.1-3.3), Sammy and Hera never overused the and Rita overused the definite article only once during the twoyear testing period. Sometimes, they responded with bare nouns without any

${ }^{8}$ Data from young native speakers should be collected in order to ensure the validity of these tests and make appropriate adjustments. For example, we need to be sure that the $a$-eliciting context in the picture-naming task provides a sufficient condition for the use of indefinite articles. 
determiner (about $20 \%$ of the time for Sammy and Hera, and about $50 \%$ for Rita), but for the most part, they used $a$ to introduce a new referent. In conditions that elicited the, only Hera responded correctly over 60 percent of the time. Sammy mostly used $a$ and Rita either answered by using $a$ or no determiner while rarely producing the correct the. It is possible that Sammy and Rita are not aware of the contexts in which the use of definite article is called for to begin with. In contrast, in the story-telling task (compared to the picture-naming task), all three children show more incorrect use of the in places where $a$ was expected (tables 3.4-3.6). And in conditions eliciting the, all three children demonstrate a much higher accuracy than in the picture-naming task.

In their literature review, Van Hout et al. (2010) point out that visual referents tend to elicit the from children when referring to a new discourse entity. Although both tasks in this attrition study used picture stimuli, overuse of the was observed only in the story-telling task. Such a discrepancy between the results of the two tasks is probably due to the ways the experiments were set up.

In the picture-naming task, the context eliciting $a$ involved answering my explicit question asking what was in the picture. Presumably then, it was clear to the children that I had no knowledge about the picture, which led them to respond with the indefinite article. Contrary to the conclusion previously discussed in section 2 by Schaeffer and Matthewson (2005), who worked with younger children, the three participants in this study seemed to know the pragmatic principle that speaker and hearer assumptions are always independent, although they were only able to apply it in the picture-naming task. In the picture-naming task, when I asked them what the picture (that I showed them) was, they could assume that I was asking the question because I did not know the object in the picture. Thus, my explicit question seemed to facilitate their application of the pragmatic principle (that I am not aware of the object 
that they are looking at), which led them to override the existence of picture stimuli and avoid the use of definite articles in $a$-eliciting contexts. In contrast, no such questions were asked in the story-telling task, in which the children simply had to narrate a story while looking at the pictures. In this case, children may not have always assumed that I did not know the content of the pictures. Thus, the pragmatic principle did not operate, resulting in the pictures inducing overuse of the. ${ }^{9}$ However, this does not clearly explain Sammy and Rita's avoidance of the definite article (except in a few instances) in the the-eliciting context of the picture-naming task: there is no apparent reason for the two children to keep avoiding the use of the when they were mentioning the test items again after the first introduction.

On the other hand, the story-telling task did exhibit the children's ability to associate the definite article with already established referents. In this task, even though all three children overused the in the $a$-eliciting condition, the proportion of the use in correct contexts was always larger than in incorrect contexts.

\subsection{Attrition of articles}

Of the three children, Hera showed the best command of articles in both tasks. She was usually able to use the indefinite article in correct contexts above 75 percent of her responses in both tasks. She also used the definite article in correct contexts in more than half of her responses in the picture-naming task and in at least 88 percent of responses in the story-telling task. In general, she did not show any decline in her ability to use English articles, which is especially notable in her best performance of

\footnotetext{
9 There is no way to know whether the children thought I was aware of the pictures used for the storytelling task. However, Hera frequently expressed familiarity with the pictures in the story-telling task (but not in the picture-naming task) when they were recycled. Therefore, there is a high chance that the other two children also recognized at least some of the recycled picture sequences used for story-telling. It would therefore have been easier for them to assume that I was already aware of the pictures even though they took the pictures out from envelopes. A better experimental design could involve making participants talk to a puppet or a different experimenter so they could assume that they are talking to someone who is not aware of the stories.
} 
the picture-naming task in the last two periods (sessions 23-24 and 25-27; see table $3.2)$.

On the other hand, Hera's little sister, Rita, showed some signs of attrition, with her correct use of $a$ declining sharply from about 75 percent (sessions 16-24) to 20 percent, in the last period (sessions 25-27) of the picture-naming task; this was her lowest score in the picture-naming task. When her use of $a$ declined, the proportion of bare nouns without any determiner increased from 20 to 80 percent. However, her score for the correct use of indefinite articles in the last period of the story-telling task was not her lowest score for this task. Meanwhile, her correct use of the was either consistently low $(0-10 \%)$ in the picture-naming task or consistently accurate (over $80 \%$ after the first five sessions) in the story-telling task.

Sammy's pattern of article use is more noteworthy. In the story-telling task, his article use in the final five sessions was different from that of the first five sessions. In the picture-naming task, Sammy's correct use of the indefinite article stayed consistently around 80 percent, whereas in the story-telling task, correct use of $a$ steadily declined from 86 to 76 percent, and finally, to 54 percent: the use of incorrect the in $a$-eliciting contexts filled in the deficit. At the same time, the correct use of the definite article gradually rose from 44 to 60 percent, and finally, to 67 percent (table 3.4). It seems that the pattern of change in Sammy's article use involves increasing use of the in contexts eliciting both indefinite and definite articles. The fact that the overuse of the gradually increased only in the story-telling task might suggest that this change shows up first in a task where Sammy mistakenly assumed that the speaker (himself) and the hearer (me) were standing on common ground. When Sammy was able to figure out that his and my assumptions were independent (in the picturenaming task), he did not overuse the. 
In conclusion, while Hera was the most accurate and consistent of the participants with her use of articles, Rita and Sammy showed patterns of article use in the final sessions that were different from the earlier sessions. Rita's correct use of $a$ decreased significantly in the final three sessions of the picture-naming task. Instead of using $a$, she used no determiner at all for the nominals. Meanwhile, Sammy's correct use of $a$ gradually decreased and was replaced by the incorrect use of the in $a$ eliciting situations. At the same time, his correct use of the consistently increased while the incorrect use of $a$ dropped in the-eliciting situations. Thus, attrition in the ability to associate the indefinite article $a$ with a new referent is observed in Rita and Sammy. However, Sammy's data could be interpreted in another way. Sammy's use of articles in the story-telling task (table 3.4) also demonstrates a general overuse of the, both in $a$-eliciting and the-eliciting contexts. Thus, one could argue that the overuse of the definite article is a sign of attrition with respect to English articles. 


\section{CHAPTER 4}

\section{IRREGULAR PAST TENSE VERBS}

\section{Introduction}

Regular English verbs are inflected for past tense with the -ed suffix. Some irregular verbs do not conform to this rule, though, and this leads children acquiring their first language and some adult L2 learners to make two types of errors: overregularization and mis-irregularization. Overregularization involves applying the regular past tense suffix -ed to the bare form of irregular verbs, as in breaked and comed instead of broke and came. Marcus et al. (1992) report that overregularization errors occur in about 4.2 percent of all instances of young children's irregular verb use. This type of error indicates that the regular rule is internalized in the children's mind: just as an adult native speaker would apply the regular suffix to a novel English verb, so the child tends to apply it to all verbs, resulting in overapplication in the case of irregular verbs.

In contrast, mis-irregularization of the past tense is the selection of the wrong irregular past tense form, resulting in deviant forms such as brang instead of brought for the past tense of bring (probably due to analogy with ring-rang), or the deviant wope as the past tense of wipe. However, these types of errors are exceedingly rare, representing only 0.2 percent of all instances of children's irregular verb use (Xu and Pinker 1995).

(1) The blocking principle:

A rule cannot apply to a word to create a form whose function is identical to an already existing form. With irregular past tense verbs, knowledge of 
the irregular form blocks application of the regular past tense form. (Maratsos 2000; Pinker 1999)

In an attempt to explain why the errors occur, Pinker (1999) claims that children lack the blocking principle. Adult native speakers usually do not make such errors because the irregular form brought inhibits the application of the -ed rule to the root bring. Thus, brought, listed in the mental lexicon as the past tense of bring, blocks the general past tense rule, pre-empting bringed. However, in order for blocking to operate smoothly, children have to hear the irregular form frequently enough to make it easily accessible when they need to express the past tense of bring. If they fail to retrieve the irregular form, or at least not quickly enough to include it in their utterance, the general rule might apply resulting in bringed. Or if the analogy with ring-rang is evoked before the general rule applies, the deviant form brang will win out. While children are more susceptible than adults to such errors due to having had less access to input, they become more accurate as they gain more experience.

This chapter focuses not on the mechanism underlying the production and/or comprehension of irregular past tense but on the behavior of Sammy, Hera, and Rita concerning English irregular past tense forms. After a literature review and a description of the experimental tasks involved, I will report on the children's performance in an irregular past tense elicitation task and a judgment task as well as their use of irregular verbs in spontaneous speech. More specifically, I will search for signs of attrition in their use of irregular verbs after their return to Korea. An error analysis examining the distribution of errors such as overregularization and misirregularization will also be provided. Finally, I will report on two incidental 
observations, one about how the children's responses resemble native Englishspeaking children's behavior and one about how they differ.

\section{Literature review}

Three studies in a Japanese context provide an indicator of what can be expected from returnees' use of irregular past tense forms. Reetz-Kurashige (1999) tested 18 Japanese returnee children on two types of story-telling tasks. ${ }^{10}$ However, only 16 children took both types of tests: the other two children participated in only one of the tests. The study assessed the children individually at two or three different times over a period of 12 to 19 months. Based on the collected data, Reetz-Kurashige analyzed the returnees' usage of verb tense and aspect in terms of target-like usage (TLU). ${ }^{11}$ The observed changes in TLU from one test session to the next indicate that seven participants from each story-telling task retained their proficiency or performed better on English irregular past tense forms on the final test than on the first test. Six children in the first task and five children in the second task showed less than a 20 percent decline in TLU after 12 to 19 months. The other four and five children from each task either showed more than a 20 percent decline in TLU or began with less than 60 percent TLU in the first test.

Yoshitomi (1999) also used TLU to measure the performance of four girls (two 9-year-olds and two 11-year-olds) who had lived in the U.S. for 3;3 to 5;5 years. One from each age group had returned within the month previous to the initial data collection, while the other two had returned 13 and 15 months before the initial data

\footnotetext{
10 Participants' ages ranged from 6;5 to 13;7 (average 9;8) and their length of stay in the U.S. ranged from $1 ; 0$ to $5 ; 4$ (average $2 ; 4$ ). Although most of the participants started participating in the study within three months of their return, six children began the study eight to 19 months after their return. 11 Reetz-Kurashige applied the TLU formula set forth in Pica's (1983) methods of morpheme quantification:

No. Correctly Supplied Morphemes/Forms in Obligatory Context

No. Obligatory Contexts + No. Supplied in Nonobligatory Context
} 
collection. The children were tested four times over the year-long study. Yoshitomi designed five different tasks, but English irregular past tense data came only from 'story description' and 'free interaction' tasks. All participants maintained nearly 100 percent TLU in every 'story description' task. Two of the girls also maintained 100 percent TLU across all the 'free interaction' tasks. Of the remaining two, one girl showed improvement over the course of the study, ending up at 100 percent in the last session, after starting at 59 percent TLU. The other showed a slight decline from 100 percent in sessions one and two to 97 percent in session three and 86 percent in session four. Thus, no one showed a significant decline in irregular past tense TLU. Tomiyama (1999) observed an eight-year-old boy named Ken who had lived in California for nearly seven years. Data collection began two months after Ken returned to Japan and continued to 19 months after his return. Ken's irregular past tense verb data are based on elicitations from the Bilingual Syntax Measure (BSM), spontaneous data, and story-telling tasks. His accuracy for the BSM was perfect at the second, ninth, and eleventh months, although he produced only three or four tokens in each session. However, his spontaneous and story-telling data showed signs of decline in correct usage. Spontaneous data show that Ken used the irregular past tense perfectly at the second month, but that his accuracy fell to 89 percent at the thirteenth month and to 86 percent at the seventeenth month. Moreover, his storytelling data indicate a sharp decline to 69 percent at the nineteenth month after perfect accuracy at both the ninth and thirteenth months.

These three studies all followed returnee children for at least a year and tested the children two or three times. (Although Tomiyama [1999] tested her subject 13 times, she reported results from only three sessions.) Data from these studies show that many Japanese children retain their English irregular past tense forms even in 
their second or third year after returning to Japan from the U.S., suggesting that research examining the attrition of English irregular past tense verbs may need more than two or three years of data collection in order to witness some signs of attrition.

\section{Materials}

In order to measure the children's ability to produce and make judgments on irregular past tense verbs, I conducted both an elicitation task and a judgment task. I chose 54 irregular verbs for the two tasks (appendix A) based on frequency: they are the 54 most frequently used irregular verbs in the English language, according to Kučera and Francis (1967). ${ }^{12}$ In each of nine different experiment sets, approximately 42 irregular verbs were tested in the judgment task, while the other 12 were reserved for the elicitation task. Across the nine sets, each verb was included seven times in the judgment task and twice in the elicitation task. Thus, the total number of irregular verbs used in each of the two tasks was not consistent throughout the experiment sets. The actual number of irregular verbs used for the elicitation task ranged from 10 to 15 in each experiment set, while between 39 and 44 were used in each judgment task.

After the nine sets of items had all been used, which took place over a period of about five and half months, the same set of tests was used again in the exact same order. $^{13}$ Therefore, experiment sessions 1,10 , and 19 were conducted with the same set, experiment sessions 2, 11, and 20 used the same set, and so on.

\footnotetext{
${ }^{12}$ Irregular past tense forms of grammatical auxiliaries be, have, do, and get were not included in the 54 verbs used for the experiments. In addition, see was not included, since the overregularized form, seed, can be mistaken for another English word, and say was not included because the overregularized form, sayed, sounds very similar to the correct form, said.

${ }^{13}$ Hera showed familiarity with some stories only in the judgment task when she heard them for the second and third time. However, she did not realize that the same stories were recycled for the elicitation task. The other participants, Rita and Sammy, showed no signs of familiarity with either task when they heard the prompt again.
} 


\subsection{Judgment task}

Children are often able to detect overregularization errors. The well-known examples of conversations between linguists Dan Slobin and Tom Bever with their children demonstrate children's judgment capacities (Lachter and Bever 1988).

Tom: Where's Mommy?

Child: Mommy goed to the store.

Tom: Mommy goed to the store?

Child: No! (annoyed) Daddy, I say it that way, not you.

Tom: Mommy wented to the store?

Child: No!

Tom: Mommy went to the store.

Child: That's right, Mommy wennn... Mommy goed to the store.

Child: You readed some of it too ... she readed all the rest.

Dan: She read the whole thing to you, huh?

Child: Nu-uh, you read some.

Dan: Oh, that's right, yeah. I readed the beginning of it.

Child: Readed? (annoyed surprise) Read! (pronounced rĕd)

Dan: Oh, yeah, read.

Child: Will you stop that, Papa?

Another illustration of children's proficiency at detecting irregular verb errors is given in Pinker's (1999:197) report on Stromswold's (1994) study of a four-year-old mute child, who was an avid listener and understood complex English sentences. The boy was asked to teach a dog puppet to talk by giving it a bone when it spoke correctly and a rock when it made an error. He awarded the puppet for heated, baked, showed, and sewed, while punishing it for eated, taked, and knowed. His only error was awarding a bone to the puppet for goed. This shows that the child, at around four 
years of age, was able to make correct judgments on both the regular and irregular past tense of verbs most of the time.

Following these studies, I administered a judgment task in order to test the children's ability to correct the overregularized errors. Before participants listened to a story that I had created, they were told that it had been written by a beginning-level English learner who was practicing English composition. From the beginning, then, the children were aware that the story might contain errors and I asked them to stop me at any time while listening to the story to correct anything that they thought was strange or wrong. By doing so, I told them, they were helping me revise the writing.

On average, one sentence in every three contained an erroneous overregularization of an irregular past tense verb. The other two sentences were filler sentences that either had an error of another kind or no error at all. The following is an example of a three-sentence paragraph that contains a sentence with a target irregular verb error, another sentence with a number error, and a grammatical sentence.

\section{(2) Example:}

Last night, Mickey sleeped late at night.

It was because he watched a very interesting movies.

The movie he watched was Kung Fu Panda.

The first sentence contains the overregularized form of the past tense of sleep, sleeped, instead of the correct form, slept. The second sentence contains a filler error, a mismatch of number between the article $a$ and the following plural noun, movies. And the last sentence, also a filler, is grammatical. Children seemed to enjoy this task, perhaps because it was a chance for them to show off their linguistic proficiency and 
background knowledge about the familiar characters appearing in the stories. Since each judgment task contained approximately 42 target (i.e., irregular verb) errors, each story contained approximately 126 sentences $(\approx 42 \times 3)$.

\subsection{Elicitation task}

In the elicitation task, participants listened to a short story that I had created following the model used by Ullman et al. (2005). Usually, the story contained three or four short sentences. In the story, the target irregular verb was presented in its uninflected form. At the end of each story, I asked a short comprehension question aimed at eliciting an irregular past tense form of that verb. The following is an example of a test item.

\section{(3) Sample test item:}

Yesterday, John went to the beach to swim.

But before swimming, he decided to build a sand castle.

After the sand castle was done, he enjoyed swimming.

Q: What did John do at the beach yesterday before swimming?

Target answer: John $\underline{\text { built }}$ a sand castle.

\subsection{Naturalistic data}

The naturalistic data consisted of spontaneous speech data collected from the subjects while they were talking casually to me or participating in other experiments not directly related to the irregular past tense. These other experiments were conducted concurrently as part of the dissertation related to English articles, passives, and relative clauses, and are discussed in other chapters. 


\section{Results}

\subsection{Judgment task}

Figure 4.1 illustrates Sammy's performance in the judgment task. Even though sessions 10 to 15 were repeats of earlier experiments, they show a slight decline in his ability to correct overregularization errors. For instance, while Sammy was able to correct 36 out of 44 total overregularization errors in session 1, he only corrected 24 in session 10, which used the same story. Similarly, he corrected 30 errors in session 2, but only 26 when presented with the same story in session 11. Comparing sessions 3 and 12, 4 and 13, 5 and 14, and 6 and 15 (each pair using the same stories) reveals that each cycle shows a slight decline in their correct judgment (table 4.1). ${ }^{14}$

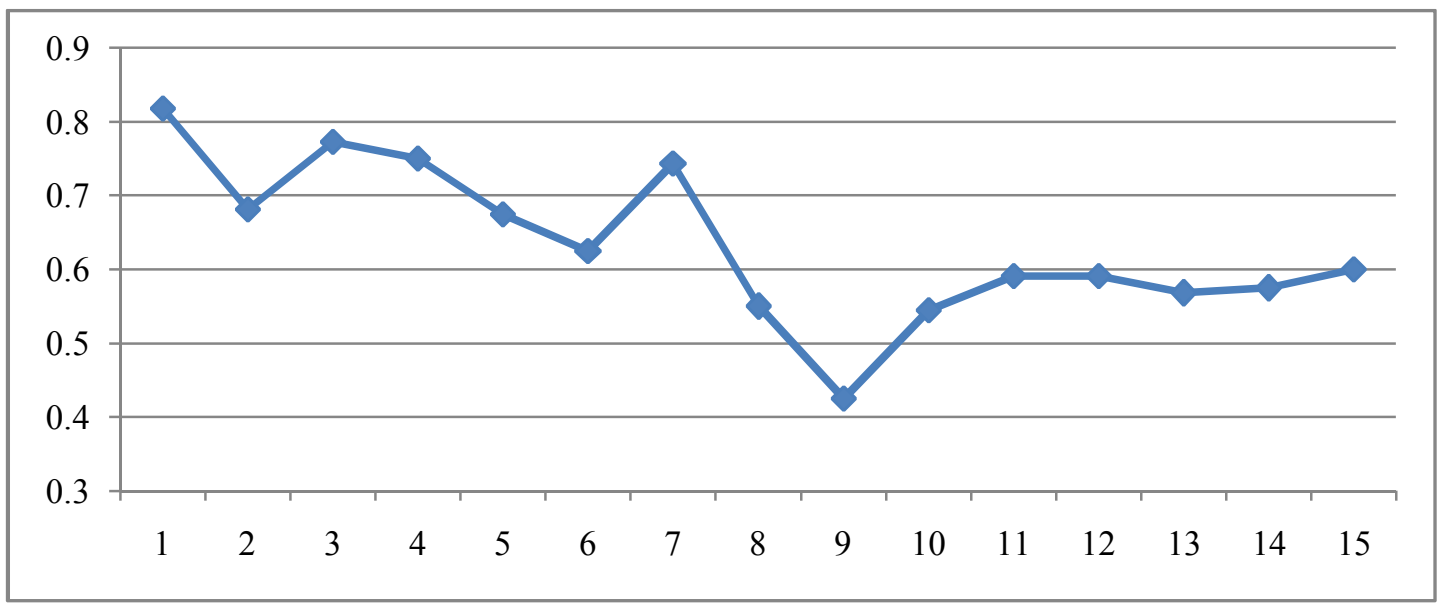

FIGURE 4.1. SAMMY’S PERFORMANCE IN THE JUDGMENT TASK

TABLE 4.1. SAMMY'S PERFORMANCE ON JUDGMENT TASKS THAT USED THE SAME STORIES

\begin{tabular}{|l|l|l|l|l|l|l|l|l|l|l|l|}
\hline Sess.1 & $36 / 44$ & Sess.2 & $30 / 44$ & Sess.3 & $34 / 44$ & Sess.4 & $33 / 44$ & Sess.5 & $27 / 40$ & Sess.6 & $25 / 40$ \\
\hline Sess.10 & $24 / 44$ & Sess.11 & $26 / 44$ & Sess.12 & $26 / 44$ & Sess.13 & $25 / 44$ & Sess.14 & $23 / 40$ & Sess.15 & $24 / 40$ \\
\hline
\end{tabular}

*The sessions in each column made use of the same stories.

\footnotetext{
${ }^{14}$ Unfortunately, inferential statistics cannot be provided to show (in)significance of the numerical data concerning the decline.
} 
In contrast, Hera's judgments do not indicate any loss of ability to correct overregularization errors in the experiments. In fact, figure 4.2 shows that her highest percentage of correct judgment was achieved in session 24 . Table 4.2 shows that in sessions 3,12 , and 21, sessions 4, 13, and 22, and sessions 6, 15, and 24 (each group of three using the same story), Hera performed better with each cycle, while in other groups of three sessions using the same story, her judgment fluctuated. For instance, Hera was only able to correct 19 overregularized verbs in session 6 but she corrected seven more errors in session 15 , and again, seven more in session 24 , thus improving her correct judgment to 33 out of a total 40 errors.

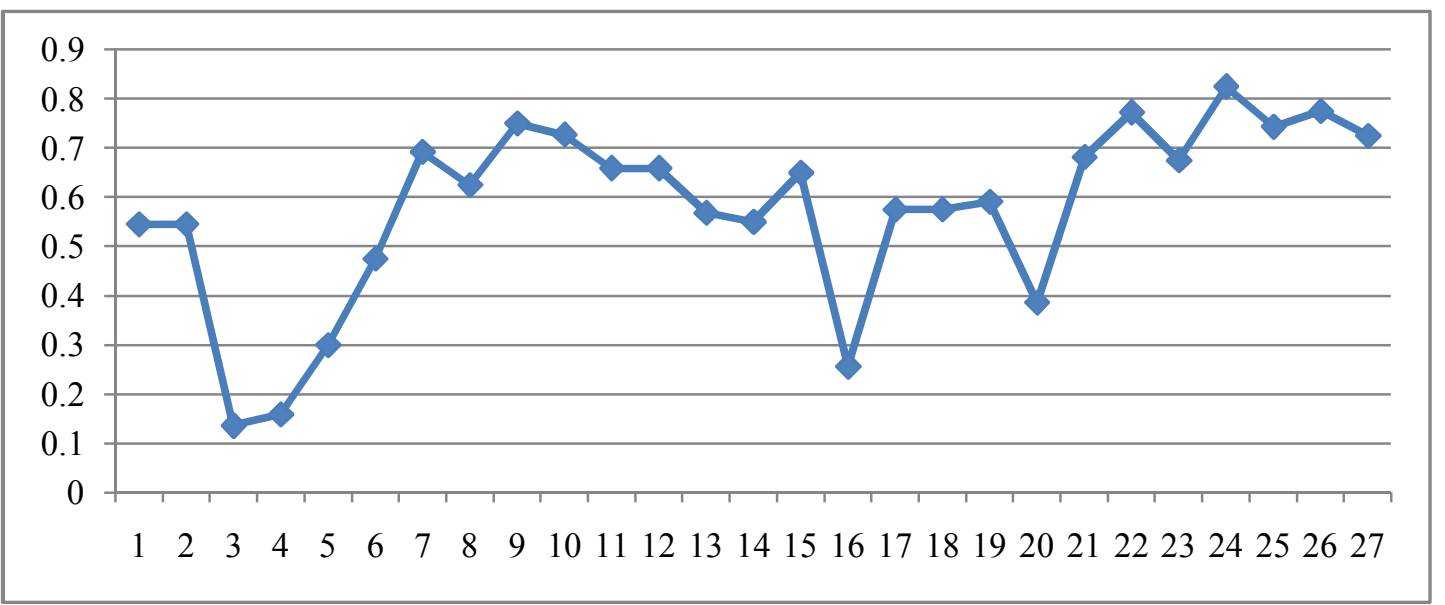

FIGURE 4.2. HERA'S PERFORMANCE IN THE JUDGMENT TASK

TABLE 4.2. HERA'S PERFORMANCE ON JUDGMENT TASKS THAT USED THE SAME STORIES

\begin{tabular}{|c|c|c|c|c|c|c|c|c|c|}
\hline \multirow{2}{*}{ Sessions } & $\begin{array}{c}1,10, \\
19\end{array}$ & $\begin{array}{c}2,11, \\
20\end{array}$ & $\begin{array}{c}3,12, \\
21\end{array}$ & $\begin{array}{c}4,13, \\
22\end{array}$ & $\begin{array}{c}5,14, \\
23\end{array}$ & $\begin{array}{c}6,15, \\
24\end{array}$ & $\begin{array}{c}7,16, \\
25\end{array}$ & $\begin{array}{c}8,17, \\
26\end{array}$ & $\begin{array}{c}9,18, \\
27\end{array}$ \\
\hline \multirow{2}{*}{$\begin{array}{c}\text { TLU } \\
\text { in each }\end{array}$} & $24 / 44$ & $24 / 44$ & $6 / 44$ & $7 / 44$ & $12 / 40$ & $19 / 40$ & $27 / 39$ & $25 / 40$ & $30 / 40$ \\
\cline { 2 - 10 } session & $32 / 44$ & $29 / 44$ & $29 / 44$ & $25 / 44$ & $22 / 40$ & $26 / 40$ & $10 / 39$ & $23 / 40$ & $23 / 40$ \\
\cline { 2 - 10 } & $26 / 44$ & $17 / 44$ & $30 / 44$ & $34 / 44$ & $27 / 40$ & $33 / 40$ & $29 / 39$ & $31 / 40$ & $29 / 40$ \\
\hline
\end{tabular}

*The sessions in each column made use of the same stories. 
Rita also completed all experiments, but her ability to correct overregularization errors was very limited. In fact, she was able to correct only seven errors throughout the project. Although the judgment task was her favorite task because she liked listening to stories featuring characters she knew from watching American animation movies, she performed very poorly.

However, Rita performed better on the filler errors, of which there were 32 to 57 in each session. Figure 4.3 shows that although she did not correct the filler errors in earlier sessions, her performance improved dramatically between sessions 10 and 22, after which it declined. (Note that the first 22 sessions were conducted within 13 months of her return to Korea, but that session 23 was conducted approximately four months after session 22.) This pattern is in sharp contrast to her performance on irregular verbs, suggesting that her low performance on irregular verb correction was not due to external factors such as distraction or loss of concentration.

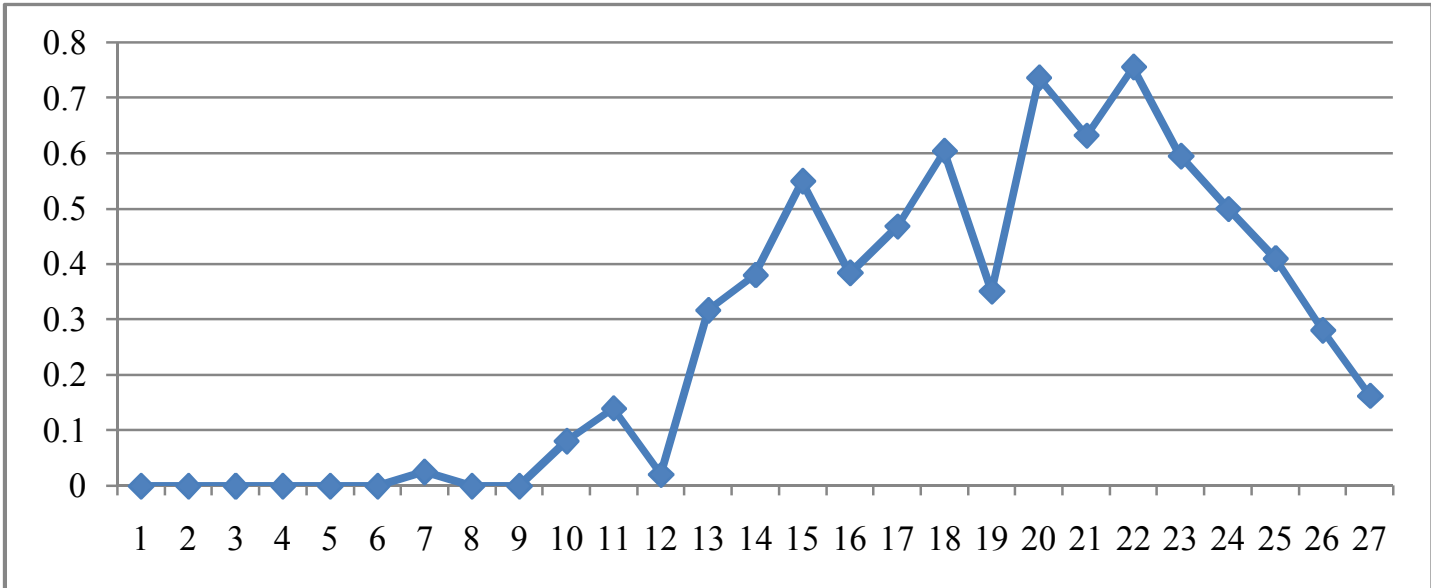

FIGURE 4.3. PROPORTION OF RITA'S FILLER CORRECTIONS IN THE JUDGMENT TASK

As for Sammy and Hera, they corrected the grammatical errors in the filler items in proportions similar to those for the overregularized past tense errors. Sammy's correction rate for irregular verbs ranged from 42.5 to 81.8 percent, while his filler 
item correction rate ranged from 43 to 80.5 percent (figure 4.4). Sammy's ability to correct fillers tended to increase in the second round of sessions (table 4.3), which contrasts with his proficiency in irregular verb correction (see table 4.1): it tended to decline in later sessions.

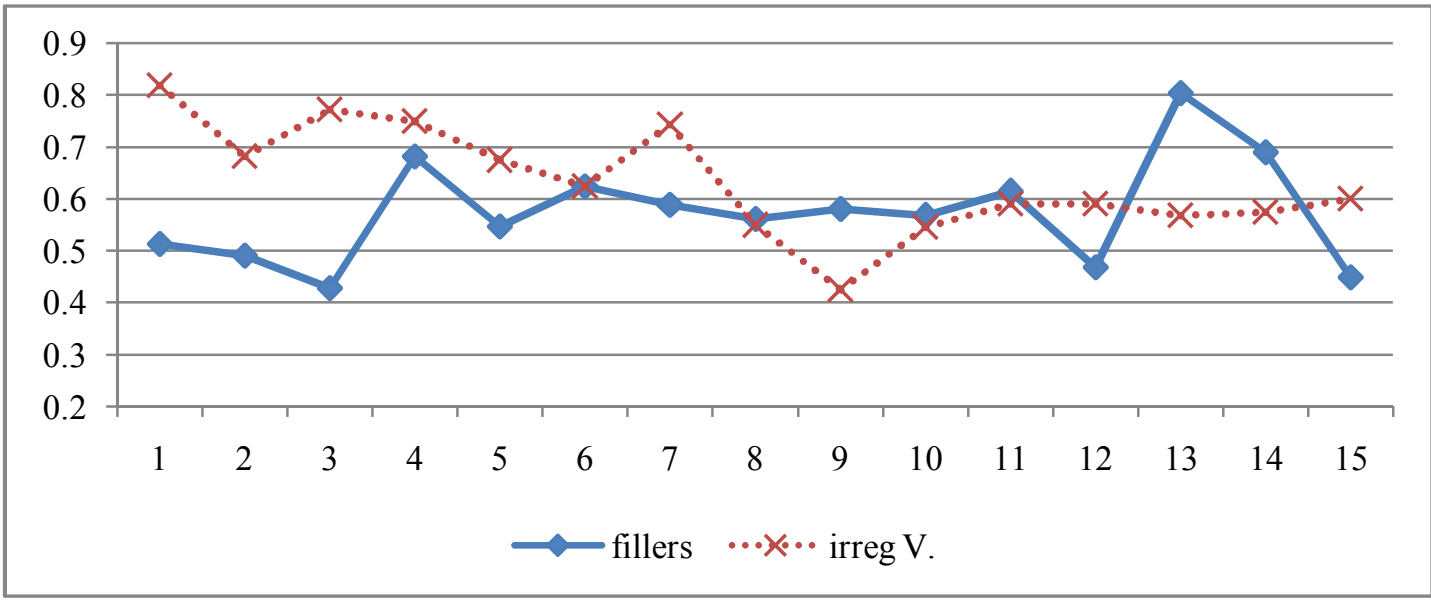

FIGURE 4.4. PROPORTION OF SAMMY'S FILLER CORRECTIONS IN THE JUDGMENT TASK

TABLE 4.3. SAMMY'S PERFORMANCE ON FILLERS IN JUDGMENT TASKS THAT USED THE SAME STORIES

\begin{tabular}{|l|l|l|l|l|l|l|l|l|l|l|l|}
\hline Sess.1 & $19 / 37$ & Sess.2 & $28 / 57$ & Sess.3 & $21 / 49$ & Sess.4 & $28 / 41$ & Sess.5 & $23 / 42$ & Sess.6 & $25 / 40$ \\
\hline Sess.10 & $21 / 37$ & Sess.11 & $35 / 57$ & Sess.12 & $23 / 49$ & Sess.13 & $33 / 41$ & Sess.14 & $29 / 42$ & Sess.15 & $18 / 40$ \\
\hline
\end{tabular}

*The sessions in each column made use of the same stories.

Meanwhile, Hera's filler item correction rate ranged from 29.3 to 90.5 percent and her irregular verb correction rate was between 13.6 and 82.5 percent (figure 4.5). Hera's tendency to correct more filler items on each successive cycle using the same story (table 4.4) closely resembles her performance on the irregular verb corrections (table 4.2). 
TABLE 4.4. HERA'S PERFORMANCE ON FILLERS IN JUDGMENT TASKS THAT USED THE SAME STORIES

\begin{tabular}{|c|c|c|c|c|c|c|c|c|c|}
\hline \multirow{2}{*}{ Sessions } & 1,10, & 2,11, & 3,12, & 4,13, & 5,14, & 6,15, & 7,16, & 8,17, & 9,18, \\
& 19 & 20 & 21 & 22 & 23 & 24 & 25 & 26 & 27 \\
\hline \multirow{2}{*}{$\begin{array}{c}\text { TLU } \\
\text { in each } \\
\text { session }\end{array}$} & $27 / 37$ & $30 / 57$ & $18 / 49$ & $12 / 41$ & $22 / 42$ & $20 / 40$ & $23 / 39$ & $18 / 32$ & $23 / 43$ \\
\cline { 2 - 10 } & $31 / 37$ & $33 / 57$ & $30 / 49$ & $24 / 41$ & $27 / 42$ & $25 / 40$ & $15 / 39$ & $19 / 32$ & $16 / 43$ \\
\cline { 2 - 10 } & $24 / 57$ & $32 / 49$ & $23 / 41$ & $38 / 42$ & $33 / 40$ & $30 / 39$ & $24 / 32$ & $25 / 43$ \\
\hline
\end{tabular}

*The sessions in each column made use of the same stories.

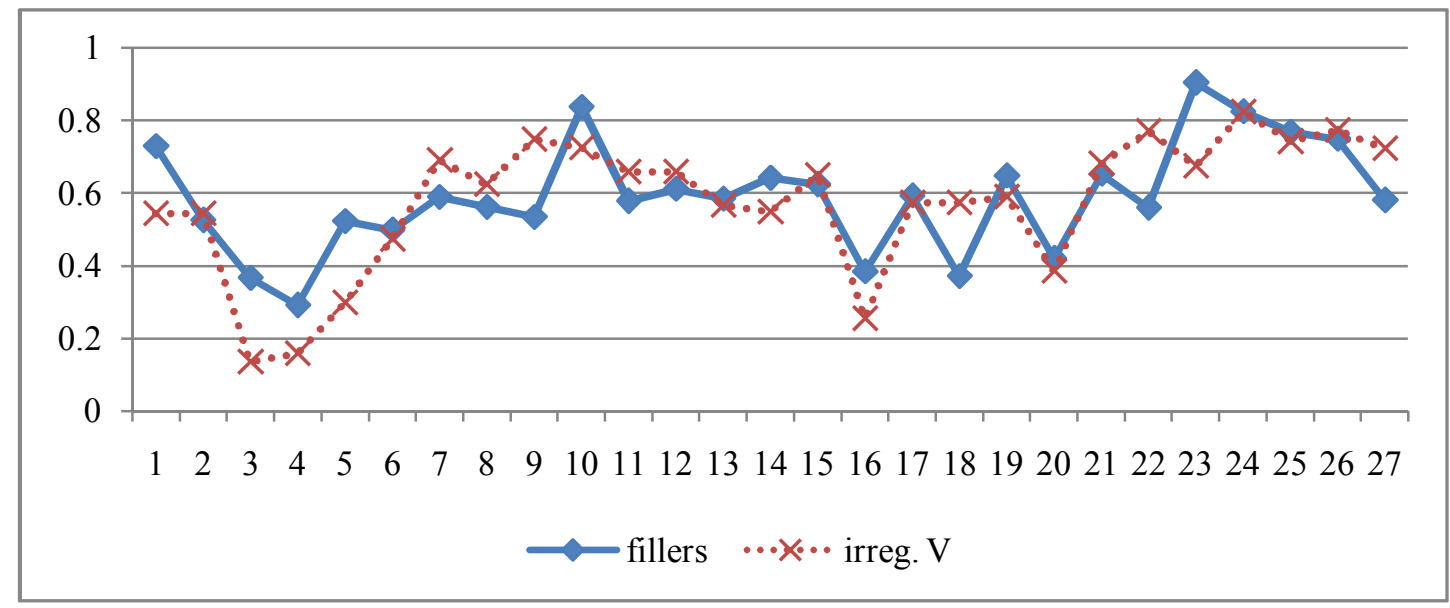

Figure 4.5. PROPORTION OF HERA'S FILLER CORRECTIONS IN THE JUDGMENT TASK

\subsection{Elicitation task}

Overall, the results from the elicitation task, shown in figures 4.6, 4.7, and 4.8 below, indicate that there was almost no decline in the participants' ability to produce English irregular past tense forms. As with the judgment task, after the ninth session, the same tasks were reused in their original order.

Figure 4.6 shows that during the second cycle (sessions 9 to 15), Sammy was able at least to match his performance on the same tasks from the first cycle (sessions 1 to 6 ), except for session 10. It is possible that an extraneous factor disturbed his performance on that task, leading to an exceptionally low score. However, in sessions 11,12 , and 14, Sammy scored the same as in sessions 2, 3, and 5, which used the 
same test sets, and his scores in sessions 13 and 15 show a slight improvement over those in sessions 4 and 6 (table 4.5).

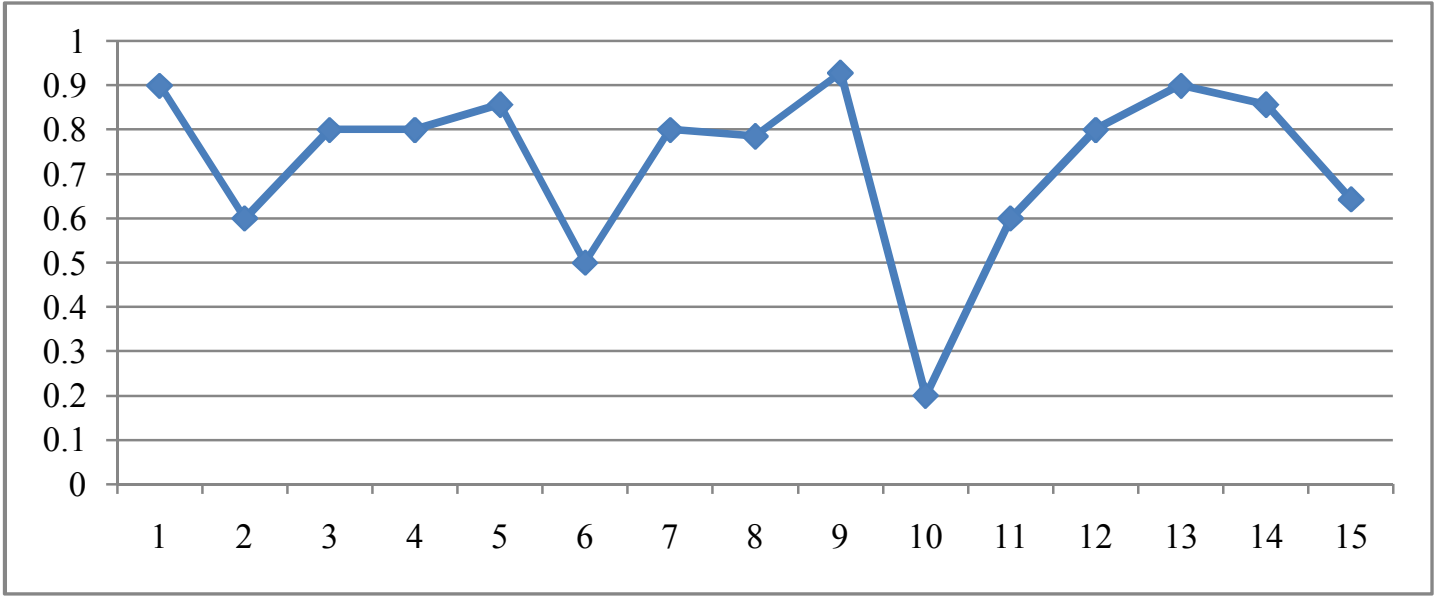

FIGURE 4.6. SAMMY'S PERFORMANCE IN THE ELICITATION TASK

TABLE 4.5. SAMMY'S PERFORMANCE ON ELICITATION TASKS THAT USED THE SAME STORIES

\begin{tabular}{|l|l|l|l|l|l|l|l|l|l|l|l|}
\hline Sess.1 & $9 / 10$ & Sess.2 & $6 / 10$ & Sess.3 & $8 / 10$ & Sess.4 & $8 / 10$ & Sess.5 & $12 / 14$ & Sess.6 & $7 / 14$ \\
\hline Sess.10 & $2 / 10$ & Sess.11 & $6 / 10$ & Sess.12 & $8 / 10$ & Sess.13 & $9 / 10$ & Sess.14 & $12 / 14$ & Sess.15 & $9 / 14$ \\
\hline
\end{tabular}

*The sessions in each column made use of the same stories.

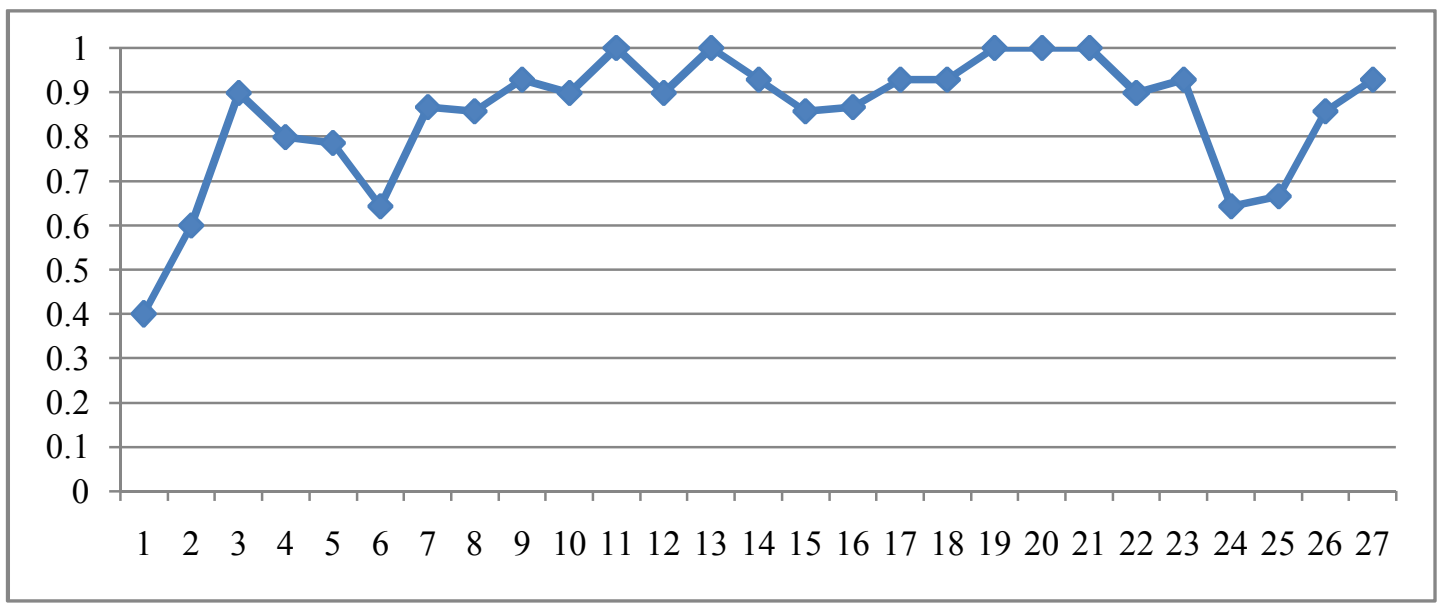

FIGURE 4.7. HERA'S PERFORMANCE IN THE ELICITATION TASK 
Figure 4.7 shows that Hera's performance for the elicitation task did not decline over time; rather, it improved or remained the same over the two-year span. With regard to the recycled stories, table 4.6 shows that her scores in the second round (sessions 10 to 18) were always higher than or the same as those in the sessions that used the same story in the first round (sessions 1 to 9). In the third round, Hera's accuracy dropped in four out of nine sessions $(22,24,25$, and 26$)$ from the scores in the corresponding sessions in the second round $(13,15,16$, and 17). This suggests a slight drop in her performance in the third round, especially considering that the final five sessions took place 19 months after the children's return to Korea while the first 22 sessions were conducted within 13 months of their return.

TABLE 4.6. HERA'S PERFORMANCE ON ELICITATION TASKS THAT USED THE SAME STORIES

\begin{tabular}{|c|c|c|c|c|c|c|c|c|c|}
\hline \multirow{2}{*}{ Sessions } & $\begin{array}{c}1,10, \\
\end{array}$ & $\begin{array}{c}2,11, \\
20\end{array}$ & $\begin{array}{c}3,12, \\
21\end{array}$ & $\begin{array}{c}4,13, \\
22\end{array}$ & $\begin{array}{c}5,14, \\
23\end{array}$ & $\begin{array}{c}6,15, \\
24\end{array}$ & $\begin{array}{c}7,16, \\
25\end{array}$ & $\begin{array}{c}8,17, \\
26\end{array}$ & $\begin{array}{c}9,18, \\
27\end{array}$ \\
\hline \multirow{2}{*}{$\begin{array}{c}\text { Score } \\
\text { in each }\end{array}$} & $4 / 10$ & $6 / 10$ & $9 / 10$ & $8 / 10$ & $11 / 14$ & $9 / 14$ & $13 / 15$ & $12 / 12$ & $13 / 14$ \\
\cline { 2 - 10 } session & $9 / 10$ & $10 / 10$ & $9 / 10$ & $10 / 10$ & $13 / 14$ & $12 / 14$ & $13 / 15$ & $13 / 14$ & $13 / 14$ \\
\cline { 2 - 10 } & $10 / 10$ & $10 / 10$ & $10 / 10$ & $9 / 10$ & $13 / 14$ & $9 / 14$ & $10 / 15$ & $12 / 14$ & $13 / 14$ \\
\hline
\end{tabular}

*The sessions in each column made use of the same stories.

Rita's performance for the elicitation task, as in the judgment task, was generally lower than the scores of the other two subjects (figure 4.8). She scored better in the second round than the first, but her scores in the third round decreased from the round before (table 4.7). Note, though, that Rita's performance was generally low: she never answered more than half of the items correctly. 


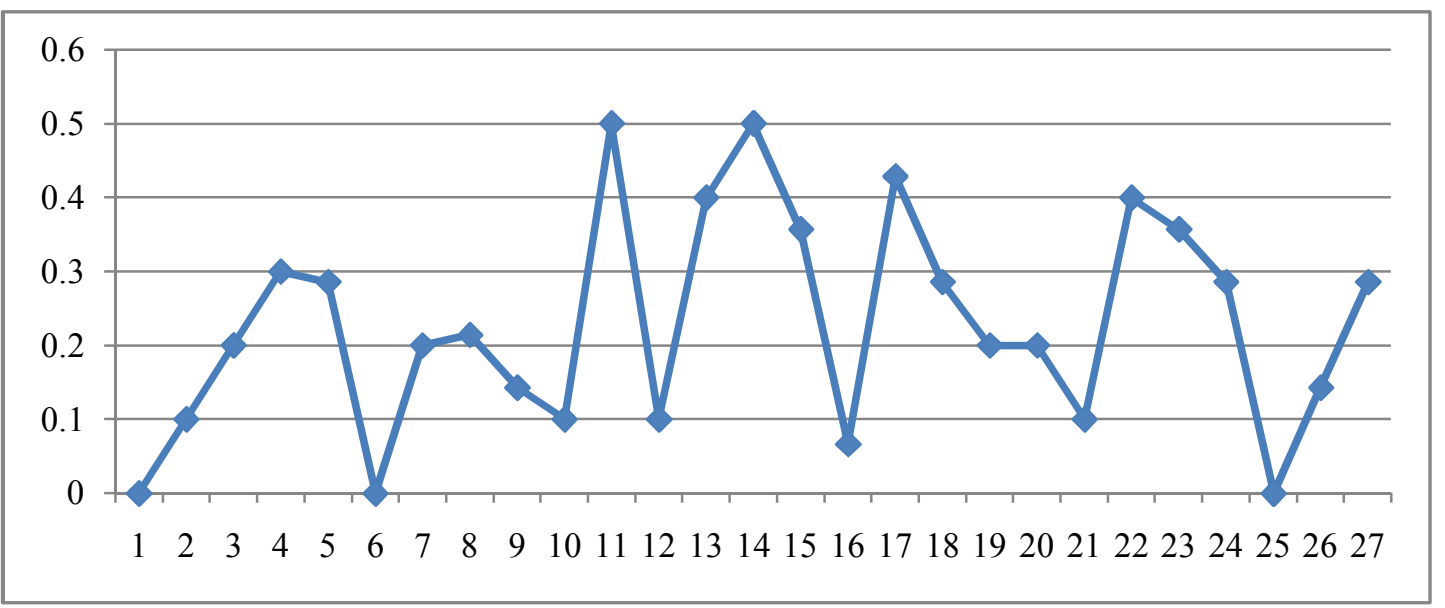

FIGURE 4.8. RITA'S PERFORMANCE IN THE ELICITATION TASK

TABLE 4.7. RITA'S PERFORMANCE ON ELICITATION TASKS THAT USED THE SAME STORIES

\begin{tabular}{|c|c|c|c|c|c|c|c|c|c|}
\hline \multirow{2}{*}{ Sessions } & 1,10, & 2,11, & 3,12, & 4,13, & 5,14, & 6,15, & 7,16, & 8,17, & 9,18, \\
& 19 & 20 & 21 & 22 & 23 & 24 & 25 & 26 & 27 \\
\hline \multirow{2}{*}{$\begin{array}{c}\text { Score } \\
\text { in each }\end{array}$} & $0 / 10$ & $1 / 10$ & $2 / 10$ & $3 / 10$ & $4 / 14$ & $0 / 14$ & $3 / 15$ & $3 / 12$ & $2 / 14$ \\
\cline { 2 - 10 } session & $1 / 10$ & $5 / 10$ & $1 / 10$ & $4 / 10$ & $7 / 14$ & $5 / 14$ & $1 / 15$ & $6 / 14$ & $4 / 14$ \\
\cline { 2 - 10 } & $2 / 10$ & $2 / 10$ & $1 / 10$ & $4 / 10$ & $5 / 14$ & $4 / 14$ & $0 / 15$ & $2 / 14$ & $4 / 14$ \\
\hline
\end{tabular}

*The sessions in each column made use of the same stories.

Note that there are huge fluctuations in Rita's performance. She scored 20 percent or less in 14 sessions and scored higher than 20 percent but no more than 50 percent in 13 sessions. All 13 scores higher than 20 percent are highlighted in grey in table 4.7, showing that Rita generally performed better in sessions that used test set versions 4, $5,6,8$, and 9 . This discrepancy can perhaps be attributed to the fact that those five test versions elicited more high-frequency verbs than versions 1, 2, 3, and 7. While 62 percent of Rita's correct response from versions 4, 5, 6, 8, and 9 were high-frequency verbs, only 31 percent of her correct usage from versions $1,2,3$, and 7 were highfrequency verbs. ${ }^{15}$

\footnotetext{
${ }^{15}$ Criteria for high-frequency verbs and related discussion are provided in section 5.1.
} 
Inevitably, every short story in the elicitation task contained past tense of verbs in order to describe an event in the past. Thus, it was possible for the past tense forms in the story to prime the target verb form in the children's response. In order to investigate the priming effect, I divided all the test items used in this task into four categories: 1) stories containing only past tense auxiliary verb(s) such as had, was, were, etc. (since these are included in almost every story, the other three types of stories may also include auxiliaries), 2) stories with regular past tense verb(s) but not irregulars, 3) stories including irregular verb(s) in the same irregular subclass as targeted, and 4) stories that have irregular verb(s) in a different irregular subclass than targeted. The irregular subclass in story types 3) and 4) followed the classification of Yang (2002) based on the phonological changes that occur when the roots are inflected into past tense. Also, types 3) and 4) may include regular past tense verb(s).

No priming effect was found. If there were priming effect, for example, children should have shown the highest accuracy in items from type 3) because the existence of a same subclass irregular verb in the story can facilitate the correct form of the target verb. However, none of the children scored the highest in these items. In fact, Hera and Rita scored the worst in these items and Sammy scored second best, which was still 20 percent lower than in 1).

\subsection{Naturalistic data}

In general, the experimental data did not reveal a decrease in the three children's abilities to use English irregular past tense forms. Analysis of their naturalistic data supports these findings. 


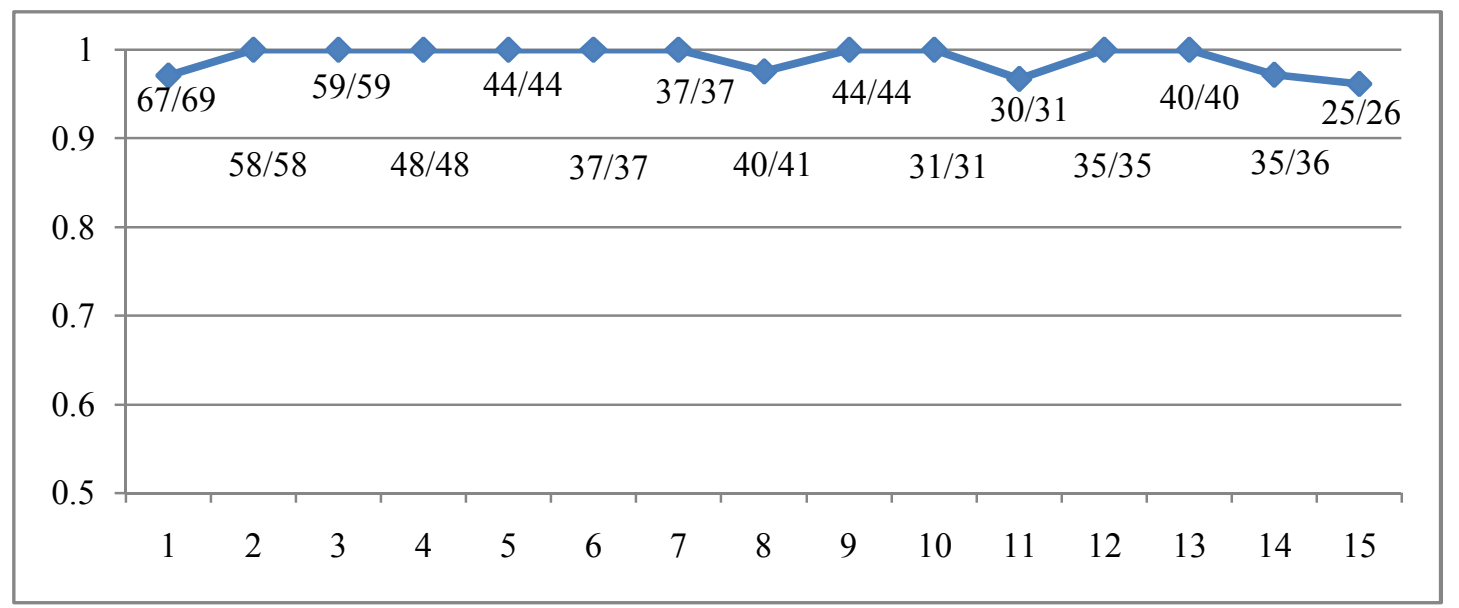

FIGURE 4.9. SAMMY's TLU FROM NATURALISTIC DATA (CORRECT / TOTAL USE)

Figure 4.9 illustrates Sammy's target-like usage (TLU) in his spontaneous speech. He showed near-perfect use of irregular past tense forms throughout the year, with his lowest TLU, 96.8 percent, recorded during session 11. Moreover, he did not misuse the irregular past tense more than once in any session with the exception of session 1 , in which he produced two errors.

Hera's TLU from naturalistic data (figure 4.10) shows that, like Sammy, she rarely produced irregular past tense errors. She consistently used the past tense of irregular verbs correctly, with her lowest score being 93.9 percent in session 12 .

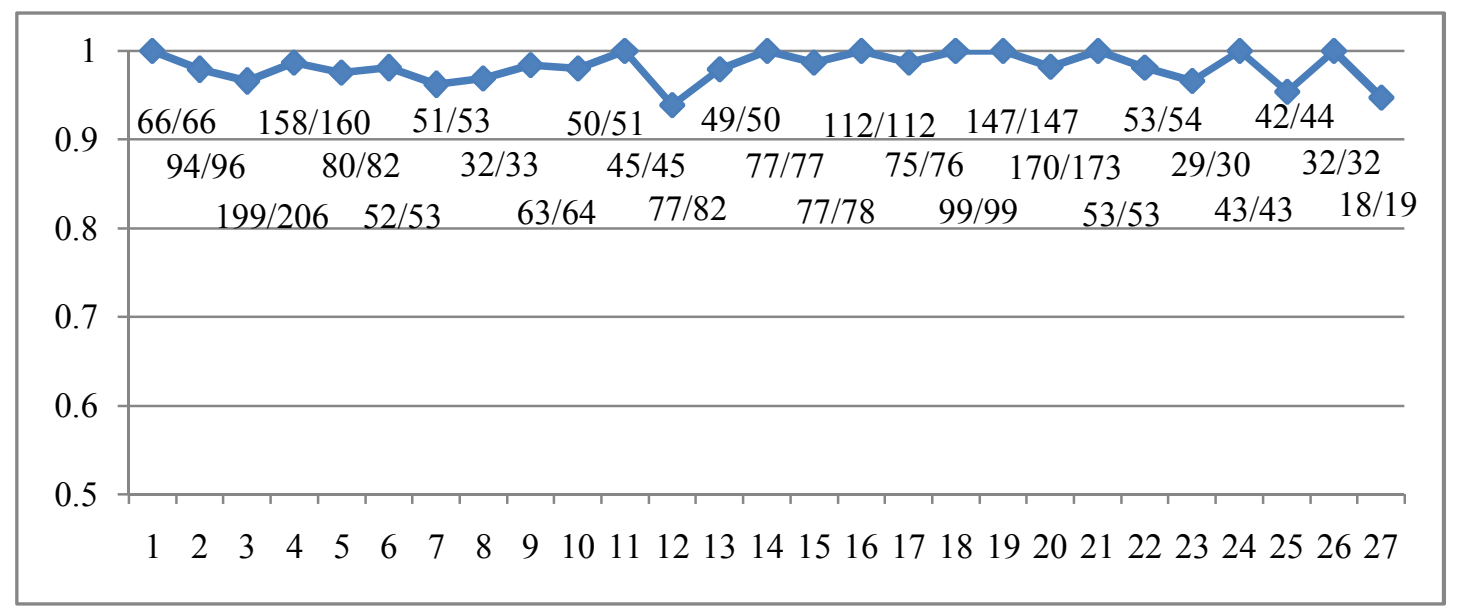

FIGURE 4.10. HERA'S TLU FROM NATURALISTIC DATA (CORRECT / TOTAL USE) 


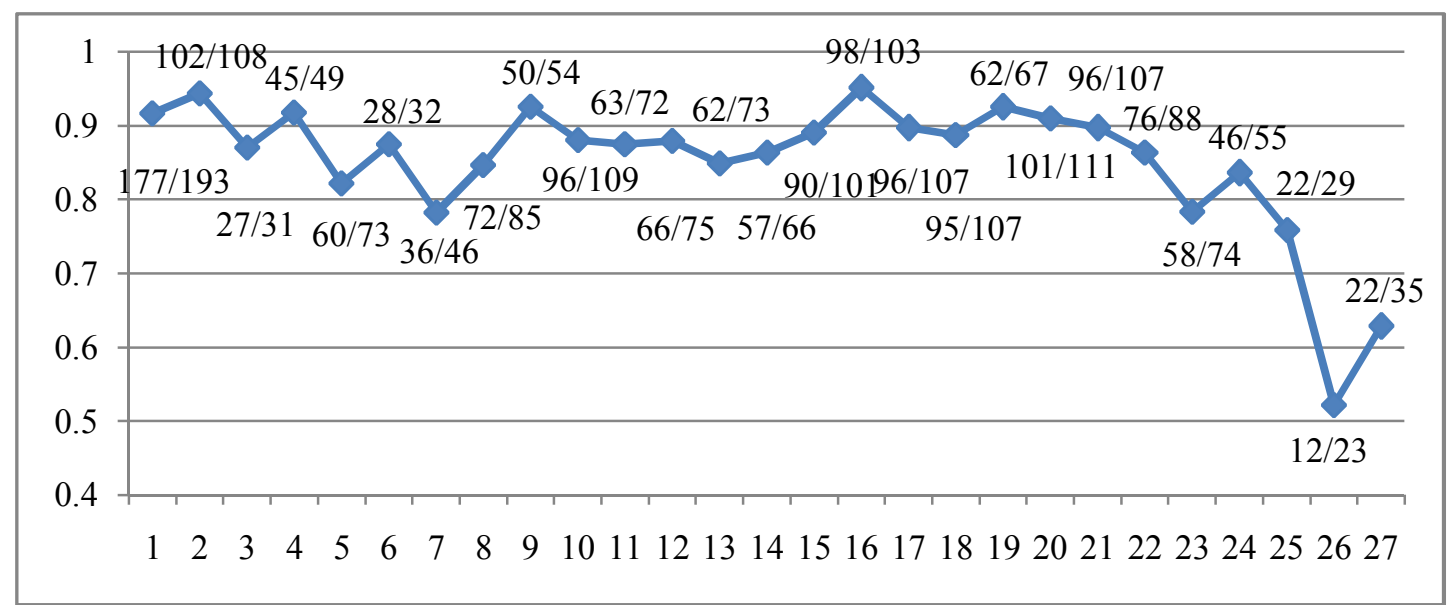

FIGURE 4.11. RITA's TLU FROM NATURALISTIC DATA (CORRECT / TOTAL USE)

Although Rita's command of irregular verb usage was not as developed as that of the other two children, she maintained a high TLU in her spontaneous speech throughout the first 24 sessions (figure 4.11). Until that point, she correctly used irregular past tense at least 78 percent of the time, and she scored lower than 80 percent only in sessions 7 and 23. However, in the final three sessions, which were conducted approximately two years after her return to Korea, her accuracy showed signs of decline. She scored 75.9 percent in session 25 and below 65 percent in the final two sessions.

Most of the past tense forms of irregular verbs that the three children produced (correctly and/or incorrectly) were the same items used in the experiments. Out of 45 different irregular verbs that Sammy produced in natural speech, 31 were included in the experimental verb list. For Hera, 44 irregular verbs among the total 71 that she produced were in the list, as were 41 of Rita's total 64 irregular verbs. All three children produced was, were, had, did, got, said, and saw, which were intentionally not included in the experiments (see note 3 ). The irregular verbs produced by the children that were not included in the experiment list are provided in appendix A. 


\subsection{Error analysis ${ }^{16}$}

The children's errors are categorized into three classes: overregularization, misirregularization, and bare stems. When the default -ed is suffixed to an irregular verb stem, an overregularization error occurs. Mis-irregularization errors include double tensing such as broked (broke $+-e d$ ), and other misanalyses, as described earlier. If the verb was not tensed at all when the context required past tense, the error was coded as bare stem.

TABLE 4.8. THREE CHILDREN'S ERROR RATES IN THE ELICITATION TASK

\begin{tabular}{|c|c|c|c|}
\hline & Sammy & Hera & Rita \\
\hline overregularization & $7.3 \%$ & $6.9 \%$ & $37.8 \%$ \\
\hline mis-irregularization & $1.7 \%$ & $2.4 \%$ & $0.9 \%$ \\
\hline bare stem & $7.9 \%$ & $0.9 \%$ & $25.2 \%$ \\
\hline
\end{tabular}

In the elicitation task, for both Sammy and Hera, overregularization and misirregularization errors made up approximately 7 percent and 2 percent of total usage, respectively. In contrast, overregularization errors accounted for 38 percent of Rita's irregular verb usage (table 4.8). The remaining erroneous productions comprised bare stems and a very small number of situations in which the subjects did not produce the target verb at all.

However, error analysis of naturalistic data shows much lower error rates (table 4.9). Sammy overregularized only 0.8 percent of his total irregular past tense verbs in spontaneous speech and never produced a mis-irregularization error. Hera overregularized only 0.3 percent and mis-irregularized 1 percent of her past tense forms, while Rita overregularized 10 percent and mis-irregularized 0.4 percent of her irregular past tenses. The total error rates of all three children are 4.5 percent for

16 There will be no error analysis for the judgment task, since the task involves correcting the already overregularized errors in the story. 
overregularization and 0.6 percent for mis-irregularization. This approximates the overregularization rate (4.2 percent) reported by Marcus et al. (1992) and the misirregularization rate (0.2 percent) in Xu and Pinker (1995) for native English-speaking children of similar ages.

TABLE 4.9. THREE CHILDREN'S ERROR RATES IN THE NATURALISTIC DATA

\begin{tabular}{|c|c|c|c|}
\hline & Sammy & Hera & Rita \\
\hline overregularization & $0.79 \%$ & $0.34 \%$ & $9.8 \%$ \\
\hline mis-irregularization & $0 \%$ & $1.06 \%$ & $0.43 \%$ \\
\hline bare stem & $0.15 \%$ & $0.29 \%$ & $2.1 \%$ \\
\hline
\end{tabular}

As a group, the three children's naturalistic data and the analysis of their errors indicated that they deviated very little from the performance of native Englishspeaking children. This is not surprising, considering that at the beginning of data collection, Hera and Rita could speak only English and Sammy felt more comfortable with English than Korean.

\section{Discussion}

As can be seen in table 4.10, naturalistic data seem to be a better measure of the children's actual competence in irregular past tense verb usage than experimental data, which Xu and Pinker also acknowledge (1995:544). For all participants, correct usage was highest in the naturalistic data, followed by the elicitation data and the judgment data, in that order. The judgment task seemed to be the most difficult, perhaps because it involves a two-step process: children must first notice the incorrect form and then provide the correct past tense form. Rita's performance indicated a problem in the first step since she accepted the incorrect overregularized past tense of irregular verbs in the story. Even the two older children accepted such forms approximately 40 percent 
of the time even though they rarely produced such incorrect forms in spontaneous speech. But although experimental data might reflect children's competence less accurately than the naturalistic data, the experiments provided an opportunity to test children with the same items at different times.

TABLE 4.10. TOTAL USAGE OF IRREGULAR PAST TENSE (CORRECT/ERROR/CORRECT \%)

\begin{tabular}{|c|c|c|c|}
\hline \multirow{2}{*}{ Participants } & \multicolumn{2}{|c|}{ Experimental data } & \multirow{2}{*}{ Naturalistic data } \\
\cline { 2 - 3 } & Judgment & Elicitation & \\
\hline Sammy & $401 / 230 / 63.5 \%$ & $132 / 47 / 73.7 \%$ & $630 / 6 / 99 \%$ \\
\hline Hera & $649 / 476 / 57.7 \%$ & $283 / 50 / 85 \%$ & $2043 / 35 / 98.3 \%$ \\
\hline Rita & $7 / 1118 / 0.6 \%$ & $76 / 257 / 22.8 \%$ & $1815 / 258 / 87.6 \%$ \\
\hline
\end{tabular}

The experimental data from my three participants resemble the results for young native English speakers reported by Kuczaj (1978). In one of Kuczaj's experiments, children aged $3 ; 4$ to $8 ; 6$ were divided into three age groups and were given an elicited production task and a judgment task targeting irregular past tense verbs. All three age groups performed better on the elicitation task than on the judgment task, and the youngest age group performed particularly poorly on the judgment task. My participants also performed better on the elicitation task than the judgment task. Moreover, Rita, the youngest child, who would fit in the youngest group of Kuczaj when she began participating, scored exceptionally low on the judgment task (table $4.10) .{ }^{17}$

The discrepancy between the results of naturalistic data and experimental (judgment and elicitation) data thus suggests that the children's problem with irregular past tense is more associated with the metalinguistic skills involved in the experimental settings rather than everyday usage. This also seems to be true among

17 Still, the overall accuracies of native children from Kuczaj's research were generally higher than my participants'. 
young native speakers in Kuczaj (1978): only the oldest group of average age 7;10 was able to score high ( $99 \%$ in elicitation and $81 \%$ in judgment); the other two younger groups scored lower, especially in the judgment task.

It therefore seems safe to say that the true picture of the children's mastery of the irregular past tense appears more clearly in the naturalistic data rather than in experimental results. Although there are some fluctuations in the experimental data (Sammy's judgment task and Rita's elicitation task), spontaneous speech data show more promise for the assessment of attrition. In this vein, Sammy and Hera hardly show any sign of attrition as they consistently produced the correct past tense of irregular verbs (figures 4.9 and 4.10) in their naturalistic data throughout their data collection periods. However, Rita's ability to produce irregular past tense verbs in spontaneous speech declined in the final three sessions (sessions 25 to 27), which took place four months after the previous session (session 24) and two years after her return to Korea (figure 4.11). While Rita generally used irregular past tense correctly over 85 percent (and at least 78 percent) of the time in the first 24 sessions, she scored 76,52 , and 63 percent in sessions 25,26 , and 27, respectively. This suggests that Rita started to lose proficiency in the production of irregular past tense approximately two years after her return to Korea.

It is important to note that low accuracy in the later sessions does not necessarily indicate attrition. If an incorrect form was used from the beginning, it simply suggests that the irregular past form was never fully acquired.

Moreover, it was sometimes difficult to observe a consistent trend in individual irregular verb use. For example, in the judgment task, Hera corrected keeped, the overregularized past tense form of keep, as kept three times out of seven tries in sessions 1 to 9 . Then, it seemed that her ability deteriorated, as she corrected it 
only once out of seven tries in the next nine sessions. However, her correction of keeped rose again to three out of seven in the final nine sessions. In spontaneous speech data, direct comparison of correct usage over time can be difficult because some low frequency verbs like bent only occurs once during the two years in Rita's speech. Even with the frequently used verbs, children's use of both the correct and incorrect forms within the same session made it difficult to measure past tense usage of individual verbs. For instance, Rita mostly produced bringed for the past tense of bring in her spontaneous speech: 80 times in 104 occasions. The fact that she used both brought and bringed in the final session (session 27) despite her overall decline of correct usage in the final sessions (figure 4.11), seems to indicate that she still had knowledge of the correct from.

\subsection{Further discussion}

I now turn to discussion of serendipitous observations from the three children's data that were not considered in the experimental design and do not seem directly related to English attrition. The observations concern the frequency of and subgroups within the irregular past tense verbs.

First, the children's accuracy varied depending on the frequency of verb use in English. Studies like Marchman (1997) show that native English speaking children tend to make fewer errors with high-frequency irregular verbs than with lowfrequency ones. Results from the three children in this project resemble the behavior of native English-speaking children in this respect. To assess this resemblance, I used only the experimental data from Sammy and Hera since both children's naturalistic data contained very few errors. In contrast, I examined only the naturalistic data set from Rita since her error rates were too high in the two experimental tasks. 
The performance of all three children was always more accurate with more frequently used verbs. I used the irregular-verb frequency tables in Rumelhart and McClelland (1986) and Marchman (1997) in order to determine the relative frequency of verbs used in this project. All high-frequency verbs in the tables from these two studies were classified as high-frequency verbs in this study. All medium- and lowfrequency verbs in Rumelhart and McClelland (1986) and all low-frequency verbs in Marchman (1997) were then classified as low-frequency verbs. This resulted in 18 high-frequency verbs and 31 low-frequency verbs out of the 54 total irregular verbs used for the two experiments. The other five verbs, which were not included in the tables from either of the two references, were excluded from the analysis since I had no measure of frequency for them. I therefore analyzed the performances of Sammy and Hera on 49 verbs in the experiments. However, turning to Rita's spontaneous speech, I found that she had used four additional high-frequency verbs and 11 additional low-frequency verbs from the frequency tables in Rumelhart and McClelland (1986) and Marchman (1997); as a result, I analyzed Rita's use of 22 high-frequency and 43 low-frequency verbs.

TABLE 4.11. SAMMY'S ERROR RATE FOR HIGH- AND LOW-FREQUENCY VERBS IN THE EXPERIMENTS (ERROR/TOTAL)

\begin{tabular}{|c|c|c|c|c|}
\hline Task & \multicolumn{2}{|c|}{ Judgment } & \multicolumn{2}{c|}{ Elicitation } \\
\hline Round & 1 & 2 & 1 & 2 \\
\hline High frequency & $20.6 \%(26 / 126)$ & $24.2 \%(22 / 91)$ & $8.3 \%(3 / 36)$ & $23.5 \%(4 / 17)$ \\
\hline Low frequency & $36.4 \%(79 / 217)$ & $41.4 \%(60 / 145)$ & $27.4 \%(17 / 62)$ & $31.7 \%(13 / 41)$ \\
\hline
\end{tabular}


TABLE 4.12. HERA'S ERROR RATE FOR HIGH- AND LOW-FREQUENCY VERBS IN EXPERIMENTS (ERROR/TOTAL)

\begin{tabular}{|c|c|c|c|c|c|c|}
\hline Task & \multicolumn{3}{|c|}{ Judgment } & \multicolumn{3}{c|}{ Elicitation } \\
\hline Round & 1 & 2 & 3 & 1 & 2 & 3 \\
\hline High & $42.9 \%$ & $30.2 \%$ & $27.8 \%$ & $8.3 \%$ & $2.8 \%$ & $5.6 \%$ \\
frequency & $(54 / 126)$ & $(38 / 126)$ & $(35 / 126)$ & $(3 / 36)$ & $(1 / 36)$ & $(2 / 36)$ \\
\hline Low & $58.1 \%$ & $41.9 \%$ & $30 \%$ & $29 \%$ & $8.1 \%$ & $17.7 \%$ \\
frequency & $(126 / 217)$ & $(91 / 217)$ & $(65 / 217)$ & $(18 / 62)$ & $(5 / 82)$ & $(11 / 62)$ \\
\hline
\end{tabular}

TABLE 4.13. RITA'S ERROR RATE OF HIGH- AND LOW-FREQUENCY VERBS IN SPONTANEOUS SPEECH (ERROR/TOTAL)

\begin{tabular}{|c|c|c|c|}
\hline Round & 1 & 2 & 3 \\
\hline High frequency & $27.6 \%(40 / 145)$ & $22.2 \%(28 / 126)$ & $28.7 \%(41 / 143)$ \\
\hline Low frequency & $39.7 \%(31 / 78)$ & $35.7 \%(60 / 168)$ & $45.8 \%(49 / 107)$ \\
\hline
\end{tabular}

Tables 4.11 to 4.13 show the error rates of the three children. Error rates of highfrequency verbs were always lower than those of low-frequency verbs across rounds, regardless of the tasks and participants. ${ }^{18}$ This is hardly a surprising result as this would be expected from native speakers of English as well.

However, I observed a noteworthy behavior in these children that is different from native English speakers. Slobin (1971) and Bybee and Slobin (1982) found that native English-speaking children's overregularization rates in two classes of irregular verbs differ. According to their classification, the root of an irregular verb either ends in a $d / t$ sound (e.g., put, lead) or does not (e.g., feel, come). It seems that all irregular verbs ending in a $d / t$ sound retain the sound at the end even in the past tense. In contrast, verbs that do not contain the final $d / t$ sound can be broadly divided into two groups, which are the two irregular verb classes of interest here. The first class (final

${ }^{18}$ Each round includes nine experiments. Since Hera was tested 27 times, all three rounds included nine experiments (round 1: experiments 1 9; round 2: experiments 10 18; round 3: experiments 19 27). Round 1 ended five and a half months after their first testing. Round 2 and round 3 were concluded about 11 and 25 months after their return to Korea. However, because Sammy was tested only 15 times, his second round consisted of only six experiments (round 1: experiments 1 9; round 2: experiments 10 15). Sammy's round 1 was completed five months after his first participation. 
$d / t$ addition class) acquires the final $d / t$ sound in the past tense (e.g., feel-felt, makemade) and the second class (non-addition class) does not (e.g., take-took, come-came). Various internal changes may occur for these verbs but they are irrelevant to this discussion.

Slobin (1971) investigated the spontaneous data of Eve, one of Brown's (1973) participants, and of 24 one-and-a-half to four-year-old children, while Bybee and Slobin (1982) conducted an elicitation task (similar to the one in this study) with 3- to 4-year-old children and collected spontaneous speech records from other children between the ages of one-and-a-half and five. Both studies found that children were more reluctant to produce overregularization errors with verbs in the final $d / t$ addition class compared to those in the non-addition class. The suggested explanation is that the final $d / t$ sound, which resembles the general past tense suffix, can block overregularization. In contrast, the lack of a final $d / t$ sound can tempt children to add the $-e d$ morpheme to non-addition class verbs, thus prompting rather than blocking overregularization.

TABLE 4.14. PROPORTION OF OVERREGULARIZATION ERRORS IN SOME IRREGULAR VERB CLASSES (ERRORS/TOTAL)

\begin{tabular}{|c|c|c|c|c|c|c|c|c|c|}
\hline & \multicolumn{4}{|c|}{ Final $-d /-t$ addition class } & \multicolumn{4}{|c|}{ Non-addition class } \\
\hline & & Round 1 & Round 2 & Round 3 & Total & Round 1 & Round 2 & Round 3 & Total \\
\hline \multirow{4}{*}{$\begin{array}{l}\text { Sam- } \\
\text { my }\end{array}$} & Judg- & $31.3 \%$ & $36.7 \%$ & & $33.5 \%$ & $19.3 \%$ & $22.9 \%$ & & $20.8 \%$ \\
\hline & ment & $(35 / 112)$ & $(29 / 79)$ & & $(64 / 191)$ & $(23 / 119)$ & $(19 / 83)$ & & $(42 / 202)$ \\
\hline & Elicita- & $9.4 \%$ & $17.6 \%$ & & $12.2 \%$ & $0 \%$ & $0 \%$ & & $0 \%$ \\
\hline & tion & $(3 / 32)$ & $(3 / 17)$ & & $(6 / 49)$ & $(0 / 34)$ & $(0 / 19)$ & & $(\mathbf{0} / \mathbf{5 3})$ \\
\hline \multirow{4}{*}{ Hera } & Judg- & $51.8 \%$ & $41.1 \%$ & $31.3 \%$ & $41.4 \%$ & $50.4 \%$ & $29.4 \%$ & $26.9 \%$ & $35.6 \%$ \\
\hline & ment & $(58 / 112)$ & $(46 / 112)$ & $(35 / 112)$ & $(139 / 336)$ & $(60 / 119)$ & $(35 / 119)$ & $(32 / 119)$ & $(127 / 357)$ \\
\hline & Elicita- & $9.4 \%$ & $6.3 \%$ & $12.5 \%$ & $9.4 \%$ & $2.9 \%$ & $0 \%$ & $5.9 \%$ & $2.9 \%$ \\
\hline & tion & $(3 / 32)$ & $(2 / 32)$ & $(4 / 32)$ & $(9 / 96)$ & $(1 / 34)$ & $(0 / 34)$ & $(2 / 34)$ & $(3 / 102)$ \\
\hline
\end{tabular}


Table 4.14 shows the proportion of overregularization errors from Hera and Sammy by class. In the elicitation task, Hera made a total of three errors with the non-addition class verbs and Sammy produced no overregularization errors with those verbs. However, both children produced more such errors with the final $d / t$ addition class verbs. This is exactly the reverse of the behavior reported in the studies with native English-speaking children discussed above. Even when the error rates are broken down by rounds, the performance of Hera and Sammy is different from that of the native children. Moreover, Hera and Sammy exhibited the same behavior in the judgment $\operatorname{task}^{19}$ : they accurately corrected more non-addition class irregular verbs in the story, and left more incorrect final $d / t$ addition class verbs unmodified.

Rita's performance, on the other hand, is strikingly similar to that of the native English-speaking children in Bybee and Slobin (1982). In that study, preschoolers regularized the final $d / t$ addition class verbs more than 10 percent of the time and the non-addition class more than 30 percent of the time, which is almost identical to Rita's results shown in table 4.15.

TABLE 4.15. RITA'S PROPORTION OF OVERREGULARIZATION ERRORS IN IRREGULAR VERB CLASSES IN NATURAL SPEECH (ERRORS/TOTAL)

\begin{tabular}{|c|c|c|c||c|c|c|c|}
\hline \multicolumn{3}{|c||}{ Final $-d /-t$ addition class } & \multicolumn{4}{c|}{ Non-addition class } \\
\hline Round 1 & Round 2 & Round 3 & Total & Round 1 & Round 2 & Round 3 & Total \\
\hline $10.1 \%$ & $12.6 \%$ & $14 \%$ & $12.5 \%$ & $35.5 \%$ & $28.9 \%$ & $39.7 \%$ & $34.5 \%$ \\
$(21 / 208)$ & $(54 / 428)$ & $(40 / 285)$ & $(115 / 921)$ & $(22 / 62)$ & $(22 / 76)$ & $(27 / 68)$ & $(71 / 206)$ \\
\hline
\end{tabular}

Since I did not plan for or foresee the observations discussed here, I can only speculate on the discrepancy between the performances of Rita and the other two children. The difference might simply be related to the fact that Sammy and Hera are

19 Slobin (1971) and Bybee and Slobin (1982) do not have data from a judgment task comparable to the data in table 4.11. However, since every irregular verb in the judgment task is presented in the root + -ed form, children are accepting the overregularized past tense when they are not revising it. 
older than Rita and were more proficient native speakers of Korean when they were first exposed to the English-speaking community. Rita may therefore have learned English more like a native speaker does than Sammy and Hera did. 


\section{CHAPTER 5 \\ PASSIVES}

\section{Introduction}

Passivization reorganizes the relationship between thematic roles and grammatical relations in an active sentence, where usually the agent and the theme serve as the subject and the direct object of a sentence, respectively. Passivization demotes the agent of the active sentence from a subject to an optional oblique marked by the preposition $b y$, while promoting the theme from a direct object to the subject. Also, as the example below illustrates, a passive VP adds an auxiliary (such as be or get) and the past participle form of the transitive verb.

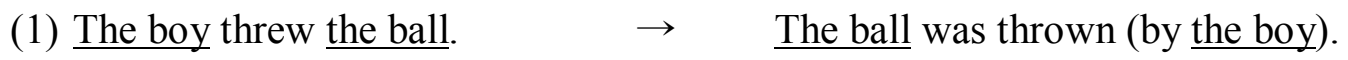
agent/subject theme/direct object theme/subject agent/oblique

Research on children's acquisition of the passive voice has resulted in disagreement about several issues, such as the age of acquisition. Perhaps the only consensus finding in these studies is the fact that passives are more difficult and less used than active sentences. The difficulty for children stems not only from the low frequency of the passives in the input but also from the reversal of the prototypical subject-agent and object-theme pattern, which is evidenced by the large proportion of children's reversal errors (e.g., Turner and Rommetveit 1967) that treat the theme subject as if it were the agent and the agent in the by-phrase as if it were the theme as in (2).

(2) The dog was bitten by the cat.

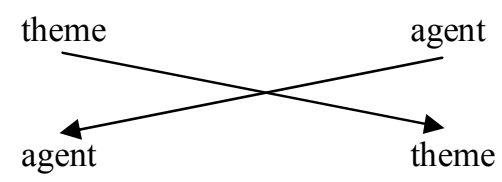

adult interpretation

children's reversed interpretation 
To make things worse, the VP of a passive requires an auxiliary such as be or get (and usually a morphological change to the transitive verb). For these reasons, the passive construction will break down unless the speaker creates an atypical mapping between thematic roles and grammatical relations, adds an auxiliary verb, uses the appropriate morphological form of the lexical verb, and selects the preposition by for the agent in the case of long passives. Thus, we might expect the complexity of the passive construction and its rarity in the input to contribute to its vulnerability to attrition.

\section{Literature review}

Previous research has debated several issues in the acquisition of the English passive voice. Early research (e.g., Baldie 1976) showed that passives cannot be understood or produced until around the age of six, but recent findings (e.g., O'Brien, Grolla, and Lillo-Martin 2006) suggest that children younger than six understand passives. Baldie (1976) and numerous other studies also report children's better understanding of nonreversible passives such as The house was painted by the man than reversible passives like The man was helped by the boy.

In other research (e.g., Maratsos et al. 1985), actional verb passives like The dog was bitten by the snake seemed to be acquired earlier than non-actional verb passives like The snake was sensed by the dog. Explanations such as A-chain deficit (Borer and Wexler 1987) or lack of theta-transmission (Fox and Grodzinsky 1998) were put forward to account for the discrepancy. Borer and Wexler argued that children lack the ability to form an A-chain when the direct object moves to subject position in passives, undermining comprehension of this structure. However, children appear to understand actional passives because these patterns are similar to simple adjectival patterns. Thus, children misanalyze and understand a passive participle in 
(4) as an adjectival pattern as in (3). On the other hand, non-actional verbs are incompatible with an adjectival meaning. Example (5) below would have to carry the meaning that the door was in the state of being seen if it were analyzed as an adjectival pattern. Since (5) does not carry such a meaning, young children cannot apply the strategy of analyzing the non-actional passive as if it were an adjectival pattern, which leaves them unable to resolve the meaning of a non-actional passive.

(3) The door was open. (i.e., the door was in the state of being open) adjectival pattern

(4) The door was opened. (i.e., the door was opened by someone) actional passive (5) The door was seen. (i.e., the door was seen by someone) non-actional passive

Fox and Grodzinsky (1998) suggest a different explanation for young children's failure with passives. Verbs (both actional and non-actional) ordinarily assign thetaroles to their arguments. In a passive, however, the theta-role is transmitted from the external argument position to the nominal in the by-phrase. Also, by can be an independent theta-assigner, which children seem to know. The problem arises because by can only assign limited theta-roles (e.g., agent and instrument but not experiencer) to nominals. In (6b), which is an equivalent of the actional passive (6a), by can properly assign an instrument theta-role to the nominal that follows by. On the other hand, in (7b), which is an equivalent of the non-actional passive (7a), by cannot assign the appropriate experiencer theta-role to the following nominal. When by fails to function as the theta-assigner, theta-transmission saves the construction by assigning a theta-role to the demoted subject, which happens in non-actional passives. Fox and Grodzinsky argue that children's deficiency in theta transmission accounts for their difficulty in dealing with non-actional $b e$-passives with the $b y$-phrase, while performing well on get-passives, actional passives, and non-actional be-passives 
without the by-phrase. However, more recently, Thatcher et al. (2008) did not find any difference between the two verb classes in their passive production task with three- to four-year-old participants.

(6) a. The city was destroyed by lightning.

actional passive

b. the destruction of the city by lightning

(7) a. Harry was feared by John.

non-actional passive

b. the fear of Harry (*by John)

Some research has also probed the effect of passive priming. Syntactic priming refers to the tendency of speakers to employ the syntactic structure used in previous discourse. Syntactic priming, specifically in the passive voice, has been observed in spontaneous speech (Weiner and Labov 1983) and experimental settings (Bock 1986). Even children as young as three or four years old were more likely to produce passives following passive primes than active primes (Thatcher et al. 2008).

Some of the issues that have been addressed in research on the acquisition of passives will serve as dependent measures in the comprehension and production tasks that I conducted to gauge potential attrition of actional and non-actional passives in the children I studied. The production task was designed to elicit from the children reversible and non-reversible passives in both priming and non-priming situations.

\section{Materials}

I used both a comprehension task and a production task to assess the participants' understanding of passives. There were five different test sets for each task. After the fifth session, I recycled the test sets in the same order. Since Sammy was tested 15 
times, each test set was used three times. Hera and Rita were tested 27 times, so the first two sets were used six times and the other three sets five times.

\subsection{Comprehension task}

A picture-selection task was used to measure the children's comprehension of passives. While looking at four different pictures on a computer screen, they heard a simple long passive sentence that included a by-phrase. The recording of each test item was manipulated to end exactly four seconds after the pictures appeared. Therefore, if the passive sentence lasted only 2.8 seconds, there was a 1.2 second silence between the first appearance of the picture and the onset of the recording.

Each picture contained three characters. Two of them appeared in the test sentence and another character was added to satisfy the "felicity condition" (Crain and Fodor 1993; O’Brien, Grolla, and Lillo-Martin 2006): the presence of an additional potential agent encourages the child to use a long passive (with a $b y$-phrase). Each picture contained the same set of characters and one of the four pictures depicted the activity described in the passive sentence. After hearing the passive sentence, the participants' task was to press a key on the computer keyboard (A, B, C or D) indicating the picture that they thought best illustrates the sentence. ${ }^{20}$ Only one of the pictures (A below) correctly represented the passive sentence. Another picture illustrated a situation described by the reversed interpretation of the test sentence (D below). The remaining two pictures were distracters (B and $\mathrm{C}$ below). A practice session with two active sentences preceded the test session. The participants' responses and RTs were measured by a stimulus presentation software, SuperLab 4.0.

\footnotetext{
20 Alphabet stickers were attached to the keyboard. Sticker 'A' was placed on ' $R$ ' on the keyboard and sticker 'B' on 'I'. Stickers ' $C$ ' and 'D' were put on the keys ' $C$ ' and ' $M$ ', respectively. The arrangement reflected the actual positions of the pictures on the computer screen as can be seen in figure 5.1.
} 
A
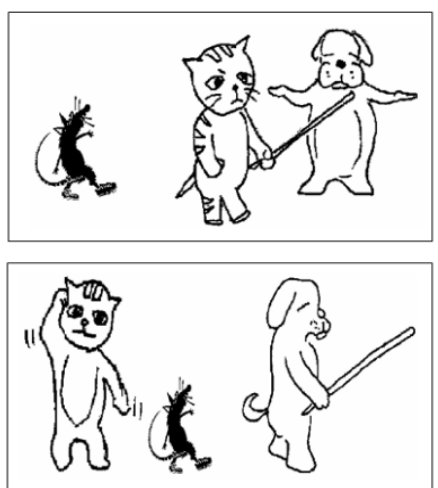

C
B
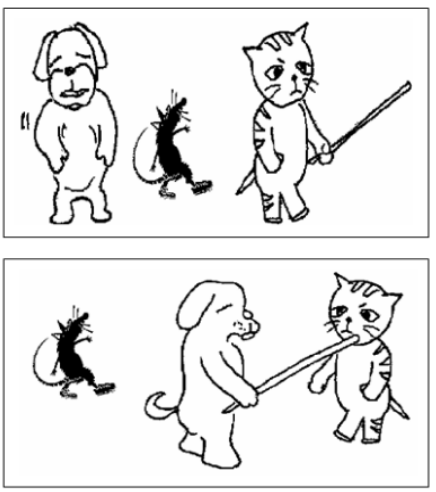

D

FIGURE 5.1. TEST ITEM FOR A PASSIVE COMPREHENSION TASK:

"THE DOG IS BLOCKED BY THE CAT"

There were six passive sentences each for actional and non-actional passives. Actional passives contained transitive verbs denoting actions such as brush, pinch, and push, while non-actional passives were built around experiential transitive verbs denoting cognitive, emotional, and perceptual events such as love, observe, and surprise. Thus, the experiment consisted of 12 test items and 18 filler active sentences; each passive test item was followed by one or two fillers. ${ }^{21}$ Since children tend to experience more difficulty with non-actional passives, I expected the first sign of attrition to appear in the analysis of non-actional passives rather than actional passives.

Each of the five different test sets had two versions: the theme or experiencer subject and the agent in the by-phrase of the original version were switched to create the second version. For example, the two arguments in The man is pushed by the woman were reversed as The woman is pushed by the man to constitute a test item in another version. Thus, after the fifth testing session, the reversed versions were used in the same order as the non-reversed versions in sessions 1 to 5 . Then, the 10 test sets were recycled after the tenth session. Therefore, testing sessions 1, 11, and 21 were

21 A typical filler sentence described a situation in one of the pictures. While passive test sentences usually consisted of seven words as in figure 5.1, most of the filler sentences were longer than seven words as in The dog is playing the guitar for the mouse. 
conducted using the same set of test items while sessions 6,16 , and 26 used the reversed version: the roles of the characters in the test sentence were switched while the picture choices remained the same. The filler items were left unchanged.

\subsection{Production task}

The long passive elicitation stimuli from Crain and Fodor (1993) were slightly modified for this passive production task. Crain and Fodor had children ask a puppet a question that contained a passive whereas in the current experiment, the participant was asked to answer two comprehension questions following a short story that accompanied two pictures. The first question was likely to be answered in an active voice and served as a filler. The second question was the critical question targeted to elicit a long passive with a $b y$-phrase.

Each picture was drawn or printed on a white sheet of paper and cut into an approximately 3 -inch x 4-inch $(7.5 \mathrm{~cm} \times 10 \mathrm{~cm})$ rectangle. There were three characters in each picture. In the first picture, the character in the middle was always a human performing an action affecting the other two characters. The other two characters were sets of animates (Pooh and Tiger) or inanimates (fork and knife). ${ }^{22}$ The experimenter provided a short description such as Look! The tall girl brings a tiger and a mouse while the child looked at the first picture.

In the second picture, which also contained three characters, the character in the middle was a different human who contrasted with the human in the first picture with respect to a feature such as size (tall vs. short) or sex (male vs. female). The other two characters from the first picture remained. In the second picture, one of the

\footnotetext{
22 A passive sentence involving an animate character is reversible: the subject of the passive sentence and the "affector" (O'Brien et al. 2006) in the by-phrase can be interchanged while maintaining a syntactically and semantically acceptable construction (e.g., The girl was kissed by Pooh / Pooh was kissed by the girl). However, a passive with an inanimate is usually non-reversible (e.g., The girl is poked by the fork / ? The fork is poked by the girl). The results section includes more discussion.
} 
remaining characters performed an action on the new human character. Again, I provided a short description such as Look over here! The tiger brushes the short girl. Then, I added another sentence like So the tiger, but not the mouse, brushes one of the girls, to make sure the participants understood that there were two potential agents in the second picture. This sentence was added to satisfy the felicity condition (Crain and Fodor 1993; O’Brien et al. 2006) explained above.

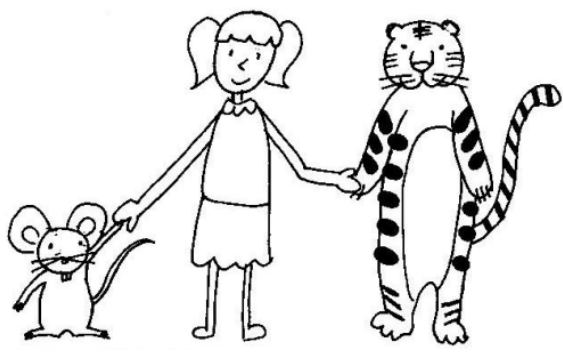

1) Look! The tall girl brings a tiger and a mouse.
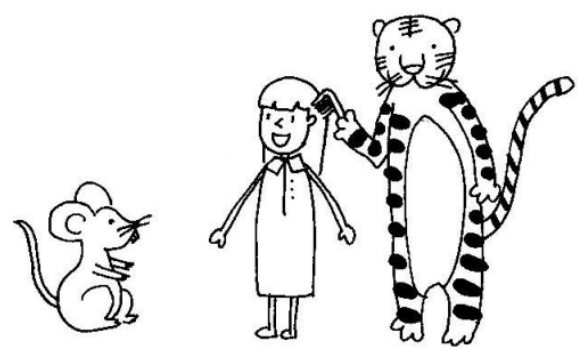

2) Look over here! The tiger brushes the short girl. So the tiger, but not the mouse, brushes one of the girls.

Q1) What did the tall girl do?

Q2) What happened to the short girl?

FIGURE 5.2. TEST ITEM FOR A PASSIVE PRODUCTION TASK (NON-PRIMING CONDITION)

I then showed the first picture again and asked a comprehension question such as 'What did the tall girl do?' After the participant answered, most likely in an active voice sentence, I showed the second picture to the child again and asked a second comprehension question, such as 'What happened to the short girl?' The second question was intended to elicit an answer that contained a passive sentence like 'She was brushed by the tiger.'

The task involved two conditions, non-priming and priming, with four test items in each condition. In the first half of the test, a passive voice sentence was absent from the context preceding the elicitation (non-priming condition), as in figure 5.2. However, the other four items contained a passive sentence in the description of 
the second picture (priming condition). Figure 5.3 illustrates a sample test item with a priming condition. Note that the underlined sentence in the second picture is in the passive voice. Items in the priming condition were tested only after all items in the non-priming condition were completed in order to avoid any residue of passive voice if a priming condition item preceded the non-priming condition.

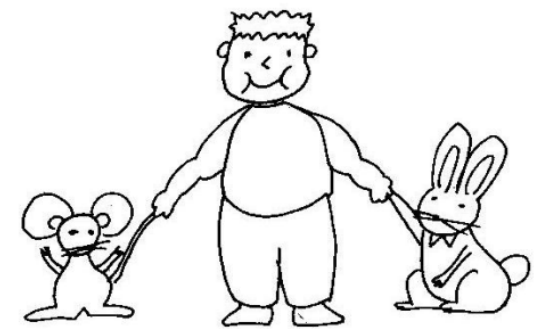

1) Look!

The fat boy comes with a rabbit and a mouse.

Q1) What did the fat boy do? ? $^{23}$
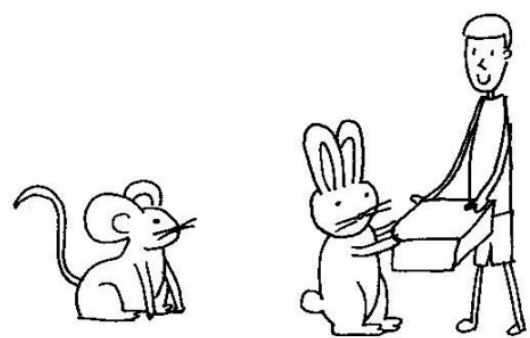

2) Look over here!

The slim boy is helped by the rabbit.

So the rabbit, but not the mouse, helps one of the boys.

Q2) What happened to the slim boy?

FIGURE 5.3. TEST ITEM FOR A PASSIVE PRODUCTION TASK (PRIMING CONDITION)

\section{Results}

\subsection{Comprehension task}

I expected attrition to occur as time went by, with a gradual decrease in accuracy and an increase in RT (response time, measured in milliseconds). However, in general, the passive comprehension task failed to show any signs of attrition with any of the three participants.

\footnotetext{
23 In most cases, the contrastive features of the human characters in the questions were expressed in the adjective that preceded the noun as in here (e.g., the fat boy). However, there were some instances where the contrastive feature followed the noun usually in a prepositional phrase (e.g., the man with glasses). There was no apparent difference between the answers elicited by the two types of questions. Hera produced only 6 percent more passives on the second type of questions while Sammy produced 5 percent more passives on the first type. Rita produced an equal proportion of passives with both types.
} 
The RTs of correct answers were averaged, and RTs longer than 2.5 standard deviations from the mean, which were virtually non-existent, were excluded. Table 5.1 shows the number of correct items in Sammy's performance. Out of six items in each of the two conditions, actional and non-actional, he always answered at least four items correctly. There is no sign of decline in any condition, and there seems to be no difference between his performances on the actional and non-actional passives. Sammy consistently performed better with fillers: he correctly responded to all active sentence items except in experiment 7. Even his RTs, represented in figure 5.4, do not seem to have slowed, although there are some fluctuations. With respect to actional and non-actional passives, there is no consistent advantage of one over the other, as shown in their mean RTs over the entire project ( 8270 vs. 8491.5 , respectively). The RTs were always faster for the filler items than for the passive items.

TABLE 5.1. SAMMY'S ACCURACY IN THE PASSIVE COMPREHENSION TASK

\begin{tabular}{|c|c|c|c|c|c|c|c|c|c|c|c|c|c|c|c|c|}
\hline Sessions & $\mathbf{1}$ & $\mathbf{2}$ & $\mathbf{3}$ & $\mathbf{4}$ & $\mathbf{5}$ & $\mathbf{6}$ & $\mathbf{7}$ & $\mathbf{8}$ & $\mathbf{9}$ & $\mathbf{1 0}$ & $\mathbf{1 1}$ & $\mathbf{1 2}$ & $\mathbf{1 3}$ & $\mathbf{1 4}$ & $\mathbf{1 5}$ & Total \\
\hline Actional & 5 & 6 & 6 & 6 & 6 & 5 & 4 & 6 & 5 & 5 & 6 & 5 & 6 & 5 & 6 & 82 \\
\hline Non-actional & 4 & 5 & 6 & 5 & 6 & 5 & 6 & 4 & 6 & 5 & 6 & 6 & 6 & 5 & 4 & 79 \\
\hline Fillers & 18 & 18 & 18 & 18 & 18 & 18 & 17 & 18 & 18 & 18 & 18 & 18 & 18 & 18 & 18 & 269 \\
\hline
\end{tabular}

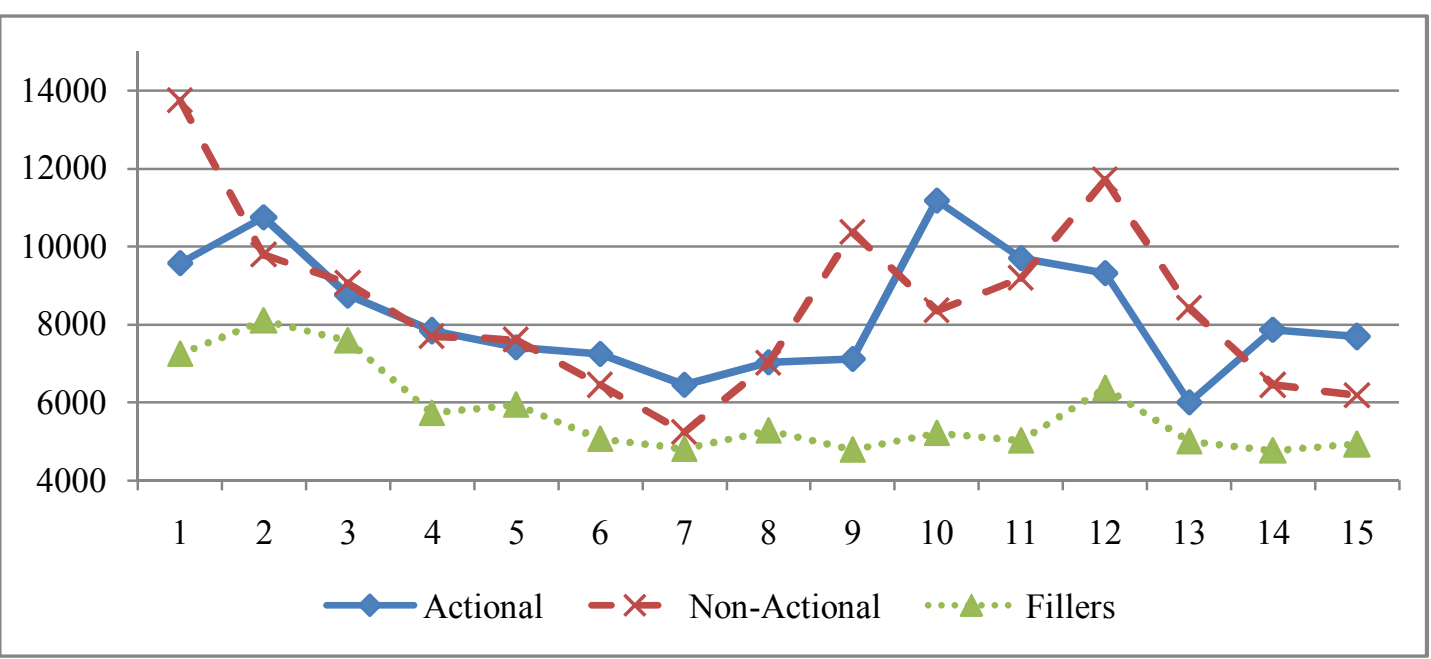

FIGURE 5.4. SAMMY'S RTS IN THE PASSIVE COMPREHENSION TASK 
Table 5.2 shows Hera's accuracy in the comprehension task. However, her data must be interpreted with caution because her data from sessions 11 to 20 are unreliable.

During these sessions, Hera started covering one hand with the other when she was pressing the computer keyboard as if she did not want to be observed. In an attempt to avoid distracting her, I kept some distance from her although I stayed in the same room. Initially, I thought that Hera's behavior reflected her lack of confidence, but I later realized that she was not taking the task seriously and was pressing random keys. She did so with some of the items in sessions 11 to 15 and with most of the items in sessions 16 to 20, which is why there are no scores for the latter sessions. After inspection of the answer sheets revealed her behavior, I stayed closer to her and Hera's performance became reliable again beginning with session 21 .

TABLE 5.2. HERA'S ACCURACY IN THE PASSIVE COMPREHENSION TASK

\begin{tabular}{|c|c|c|c|c|c|c|c|c|c|c|c|c|c|c|c|c|c|c|c|c|c|c|c|c|}
\hline S & $\mathbf{1}$ & $\mathbf{2}$ & $\mathbf{3}$ & $\mathbf{4}$ & $\mathbf{5}$ & $\mathbf{6}$ & $\mathbf{7}$ & $\mathbf{8}$ & $\mathbf{9}$ & $\mathbf{1 0}$ & $\mathbf{1 1}$ & $\mathbf{1 2}$ & $\mathbf{1 3}$ & $\mathbf{1 4}$ & $\mathbf{1 5}$ & $\mathbf{1 6 - 2 0}$ & $\mathbf{2 1}$ & $\mathbf{2 2}$ & $\mathbf{2 3}$ & $\mathbf{2 4}$ & $\mathbf{2 5}$ & $\mathbf{2 6}$ & $\mathbf{2 7}$ & Total \\
\hline $\mathrm{A}$ & 5 & 3 & 5 & 5 & 5 & 5 & 4 & 6 & 6 & 6 & 2 & 3 & 4 & 3 & 3 & & 5 & 5 & 6 & 5 & 6 & 6 & 5 & 103 \\
\hline $\mathrm{N}-\mathrm{A}$ & 3 & 3 & 2 & 5 & 6 & 4 & 6 & 3 & 5 & 5 & 5 & 4 & 4 & 2 & 4 & & 6 & 6 & 3 & 5 & 5 & 6 & 6 & 98 \\
\hline $\mathrm{F}$ & 17 & 18 & 18 & 18 & 17 & 17 & 17 & 17 & 18 & 16 & 12 & 13 & 9 & 7 & 13 & & 18 & 18 & 17 & 18 & 18 & 17 & 18 & 351 \\
\hline
\end{tabular}

*S: Sessions, A: Actional passive, N-A: Non-actional passive, F: Fillers

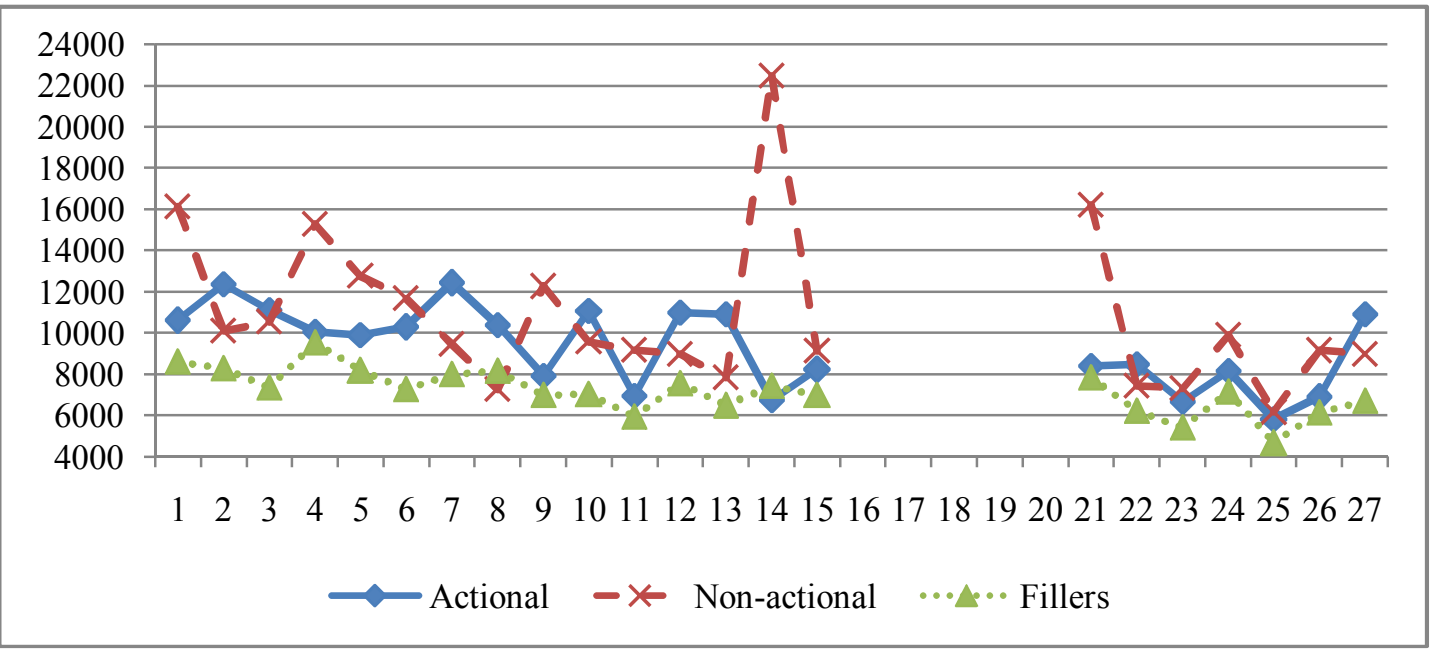

FIGURE 5.5. HERA'S RTS IN THE PASSIVE COMPREHENSION TASK 
As was the case with Sammy, Hera's accuracy data show that she performed in the later sessions as well as, if not better than, in the beginning sessions for both types of passives. Her accuracy seems not to be significantly different between actional and non-actional passives, and she correctly answered most of the filler items in the first 10 and final seven sessions. Likewise, her RTs in figure 5.5 do not show signs of attrition. Between actional and non-actional passives, there is no consistent advantage of one over the other, but her overall mean RT indicates that she responded slightly faster on actional than non-actional passives (9284.2 vs. 10575.8).

TABLE 5.3. RITA'S ACCURACY IN THE PASSIVE COMPREHENSION TASK

\begin{tabular}{|c|c|c|c|c|c|c|c|c|c|c|c|c|c|c|c|c|c|c|c|c|c|c|c|c|c|c|c|c|}
\hline S & $\mathbf{1}$ & $\mathbf{2}$ & $\mathbf{3}$ & $\mathbf{4}$ & $\mathbf{5}$ & $\mathbf{6}$ & $\mathbf{7}$ & $\mathbf{8}$ & $\mathbf{9}$ & $\mathbf{1 0}$ & $\mathbf{1 1}$ & $\mathbf{1 2}$ & $\mathbf{1 3}$ & $\mathbf{1 4}$ & $\mathbf{1 5}$ & $\mathbf{1 6}$ & $\mathbf{1 7}$ & $\mathbf{1 8}$ & $\mathbf{1 9}$ & $\mathbf{2 0}$ & $\mathbf{2 1}$ & $\mathbf{2 2}$ & $\mathbf{2 3}$ & $\mathbf{2 4}$ & $\mathbf{2 5}$ & $\mathbf{2 6}$ & $\mathbf{2 7}$ & Total \\
\hline $\mathrm{A}$ & 3 & 4 & 4 & 2 & 3 & 3 & 2 & 5 & 4 & 3 & 4 & 4 & 6 & 4 & 4 & 4 & 4 & 6 & 6 & 6 & 5 & 5 & 6 & 5 & 6 & 6 & 4 & 118 \\
\hline $\mathrm{N}-\mathrm{A}$ & 2 & 2 & 1 & 1 & 3 & 2 & 2 & 2 & 3 & 1 & 4 & 3 & 1 & 3 & 4 & 3 & 5 & 4 & 5 & 3 & 5 & 6 & 2 & 4 & 5 & 4 & 4 & 84 \\
\hline F & 13 & 15 & 12 & 15 & 14 & 18 & 15 & 17 & 16 & 14 & 15 & 17 & 17 & 17 & 18 & 16 & 17 & 17 & 18 & 17 & 18 & 18 & 18 & 18 & 18 & 16 & 18 & 442 \\
\hline
\end{tabular}

*S: Sessions, A: Actional passive, N-A: Non-actional passive, F: Fillers

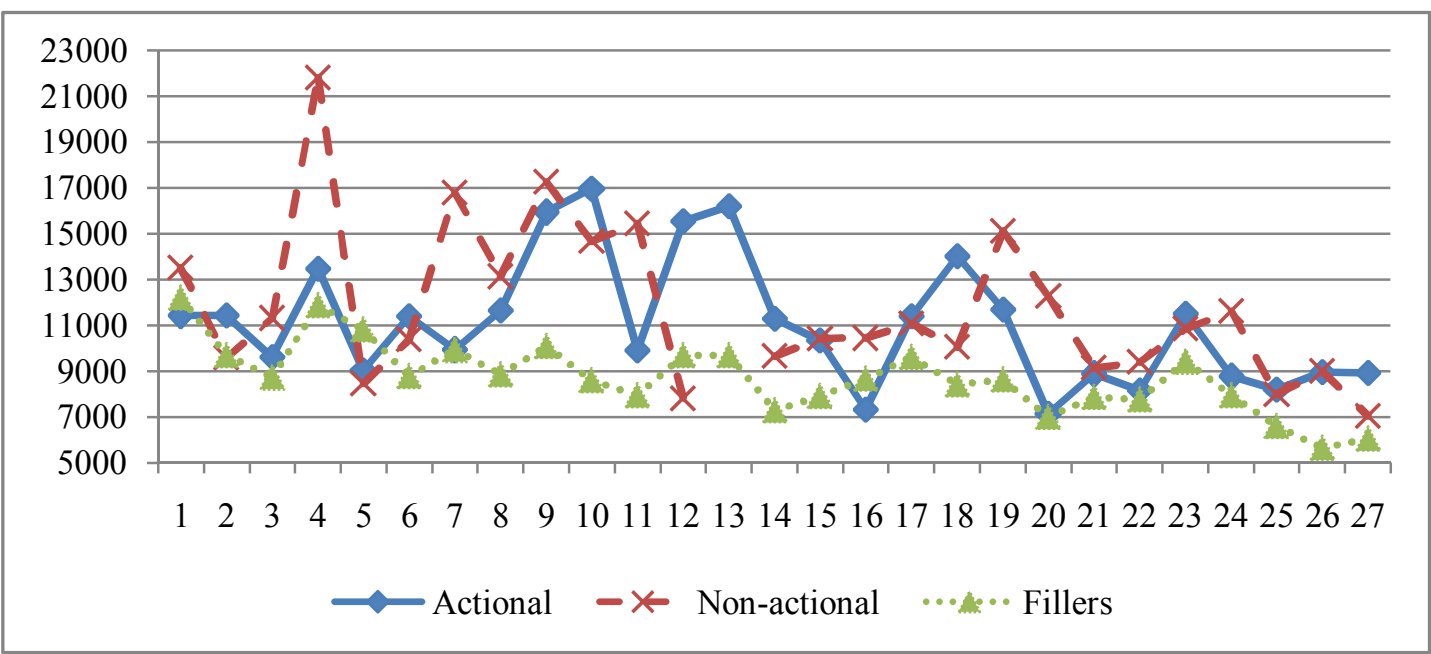

FIGURE 5.6. RITA’S RTS IN THE PASSIVE COMPREHENSION TASK

Rita shows a similar trend. Her accuracy did not decline over time, although she was more accurate on actional than non-actional passives (table 5.3). Moreover, there is 
also no sign of attrition in her RTs, which do not increase over time. Although her accuracy points toward an advantage for actional over non-actional passives, the overall RTs were similar (10981.3 vs. 10978.2, respectively).

TABLE 5.4. PROPORTION OF REVERSAL ERRORS IN THE PASSIVE COMPREHENSION TASK (NO. OF REVERSAL/TOTAL ERRORS)

\begin{tabular}{|c|c|c|c|c|c|c|}
\hline \multirow{2}{*}{ Sessions } & \multicolumn{2}{|c|}{ Sammy } & \multicolumn{2}{c|}{ Hera } & \multicolumn{2}{c|}{ Rita } \\
\cline { 2 - 7 } & Actional & Non-Actional & Actional & Non-Actional & Actional & Non-Actional \\
\hline $1 \sim 5$ & $0 / 1$ & $3 / 4$ & $5 / 7$ & $10 / 11$ & $6 / 14$ & $12 / 21$ \\
\hline $6 \sim 10$ & $4 / 5$ & $3 / 4$ & $2 / 3$ & $5 / 7$ & $7 / 13$ & $13 / 20$ \\
\hline $11 \sim 15$ & $2 / 2$ & $2 / 3$ & $4 / 15$ & $0 / 11$ & $3 / 8$ & $11 / 15$ \\
\hline $16 \sim 20$ & & & NA & NA & $3 / 5$ & $10 / 10$ \\
\hline $21 \sim 22$ & & & $1 / 2$ & $0 / 0$ & $1 / 1$ & $1 / 1$ \\
\hline $23 \sim 24$ & & & $1 / 1$ & $3 / 4$ & $0 / 1$ & $3 / 6$ \\
\hline $25 \sim 27$ & & & $1 / 1$ & $1 / 1$ & $0 / 2$ & $3 / 5$ \\
\hline Total & $6 / 8(75 \%)$ & $8 / 11(72.8 \%)$ & $14 / 29(48.3 \%)$ & $19 / 34(55.9 \%)$ & $20 / 44(45.5 \%)$ & $53 / 78(68 \%)$ \\
\hline
\end{tabular}

We now turn our attention to the error analysis. Previous research on the acquisition of passives (e.g., Turner and Rommetveit 1967) reports that most of children's errors are reversal errors that involve treating the theme subject of a passive as the agent. Table 5.4 shows the proportion of reversal errors in five sessions of testing. ${ }^{24}$ While more than 70 percent of Sammy's errors are reversals, the percentages of reversal errors for Hera and Rita are not as high. However, we must note that most of Hera's non-reversal errors are from sessions 11 to 20 (when she seemed to be pushing random buttons): the exclusion of errors from those sessions raises Hera's reversal error rates to 71.5 and 82.6 percent in actional and non-actional passives, respectively. Thus, while the older participants, Sammy and Hera, were producing many reversal

\footnotetext{
${ }^{24}$ Errors in five sessions are collapsed here because all testing materials used in the entire project were recycles or slight modifications based on five different test sets. However, sessions 21 to 27 were divided into three groups because a total of more than four months of no testing elapsed between sessions 22 and 23 , and sessions 24 and 27.
} 
errors, as young native English speakers would do, the youngest participant, Rita, tended to make fewer reversal errors than Sammy and Hera. Still, her reversal error rates (45.5 and 68 percent in actional and non-actional passives) are higher than expected by chance (33.3 percent because there were three incorrect pictures).

\subsection{Production task}

In general, the production task was successful in eliciting long passives from all three children. Sammy and Hera consistently produced long passives throughout the project while Rita, the youngest child, started producing errors in the final three sessions. The passive sentences that the children produced were predominantly get-passives accompanied by a by-phrase. The occurrence of long be-passives and short passives without a $b y$-phrase was quite rare. ${ }^{25}$ All passive forms were coded as correct. Occasionally, the children produced passives with an incorrect past participle form of the verb, usually by adding -ed to irregular past tense verbs (e.g., she got hurted by the cup). These were also considered correct. However, when children used a preposition other than by with the affector theta role in long passives, it was counted as an error even if it was an acceptable sentence (e.g., he got hit from the bat). ${ }^{26}$ Children could also elect to answer with active sentences. Table 5.5 shows the number of passive and active voice responses, as well as errors committed while attempting a passive sentence.

\footnotetext{
25 At least $83 \%$ of correct passives produced by every child were long passives in both priming and non-priming conditions.

${ }^{26}$ Several studies such as Horgan (1978) and Clark and Carpenter (1989) note children's use of prepositions like from and with in place of by. In Horgan (1978), long passives with the agent following prepositions other than by were considered correct. However, in this chapter, they will be treated as incorrect because the occurrence of the other preposition might be a sign of attrition.
} 
TABLE 5.5. OVERALL PERFORMANCE IN THE PASSIVE PRODUCTION TASK

(CORRECT / TOTAL)

\begin{tabular}{|c|c|c|c|c|c|c|}
\hline \multirow{2}{*}{} & \multicolumn{3}{|c|}{ Non-priming condition } & \multicolumn{3}{c|}{ Priming condition } \\
\cline { 2 - 7 } & Passive & Active & Error & Passive & Active & Error \\
\hline Sammy & $56 / 60$ & $1 / 60$ & $3 / 60$ & $57 / 60$ & $1 / 60$ & $2 / 60$ \\
\hline Hera & $87 / 108$ & $19 / 108$ & $2 / 108$ & $98 / 108$ & $7 / 108$ & $3 / 108$ \\
\hline Rita & $61 / 108$ & $32 / 108$ & $15 / 108$ & $79 / 108$ & $12 / 108$ & $17 / 108$ \\
\hline
\end{tabular}

Sammy consistently performed very well in both the non-priming and priming conditions across sessions. He made very few errors and he never made more than one error (non-priming and priming conditions combined) in a session. Among the 60 items in each condition (4 items x 15 sessions), he produced 56 passives in the nonpriming condition and 57 passives in the priming condition. He responded with an active sentence once in each condition. Thus, he produced five errors, one in each of sessions 4, 5, 8, 12, and 13. He omitted the get-verb twice (e.g., He Ø rescued by a bear) and used another preposition instead of by twice (e.g., [null subject] Got called from a tiger). Once, he started the sentence as a passive (with null subject) but switched and did not finish in a passive (Got supported by, got a support from a lion).

Hera also produced few errors but she responded more with passives in the priming condition. Among the 108 items in each condition (4 items x 27 sessions), she produced 87 passives in the non-priming condition and 98 in the priming condition. All of her five errors involved using a preposition other than by with the agent theta role.

Rita produced the most errors and a large proportion of her errors were concentrated in the final three sessions. Like Hera, she responded more with passives in the priming condition than the non-priming condition (79 vs. 61). However, the 
number of errors in each condition is similar since she produced more active sentence answers in the non-priming condition.

As mentioned before, target answers included reversible and non-reversible passives. $^{27}$ However, at times, the children could choose to answer in active sentences instead of passives. Rita produced more active sentences when the test item was meant to elicit a reversible passive, while Sammy and Hera showed little difference between test items targeting reversible and non-reversible passives. When they produced a passive response, their error rates differed depending on the types of passives. The sisters, Hera and Rita, tended to make more errors with non-reversible passives while Sammy showed the opposite tendency. However, we must note that the number of errors for Sammy and Hera is quite small to begin with.

TABLE 5.6. RESPONSE RATES IN ACTIVES AND PASSIVES ON SEMANTICALLY REVERSIBLE AND NON-REVERSIBLE ITEMS

\begin{tabular}{|c|c|c||c|c|}
\hline \multirow{2}{*}{} & \multicolumn{2}{|c||}{ Active sentence response rate } & \multicolumn{2}{c|}{ Passive error rate } \\
\cline { 2 - 5 } & Non-reversible & Reversible & Non-reversible & Reversible \\
\hline Sammy & $3 \%(1 / 33)$ & $1.2 \%(1 / 87)$ & $0 \%(0 / 33)$ & $6.3 \%(5 / 80)$ \\
\hline Hera & $13.6 \%(9 / 66)$ & $11.3 \%(17 / 150)$ & $7.5 \%(4 / 53)$ & $0.8 \%(1 / 133)$ \\
\hline Rita & $12.1 \%(8 / 66)$ & $24 \%(36 / 150)$ & $24.1 \%(14 / 58)$ & $15.8 \%(18 / 114)$ \\
\hline
\end{tabular}

\section{Discussion}

While the comprehension task showed no sign of attrition for the participants, Rita had difficulty producing passives in the later sessions of the elicitation task. The fact that the production task was partially successful in detecting attrition whereas the comprehension task failed is not surprising considering that the ability to comprehend a passive emerges before the ability to produce it (e.g., Turner and Rommetveit 1967).

\footnotetext{
${ }^{27}$ I acknowledge that this resulted from a flaw in the design since it would have been much better if reversible and non-reversible passives had not been mixed in the test items.
} 
In the comprehension task, all three children tended to score better and respond faster on the filler (active) sentence items. Sammy and Hera did not behave differently for actional and non-actional passives while Rita was more accurate with actional passives. Furthermore, Rita was the only one whose errors were mostly not reversals.

In the production task, all three children produced more passive sentences in the priming condition, although Sammy produced an almost equal number of passives in both conditions. This effect of priming was expected, based on previous research with young native speakers (Thatcher et al. 2008). Although the number of errors in each condition across participants is similar, they used more active sentences in the non-priming condition.

With respect to attrition, Rita is most noteworthy because she is the only one showing signs of attrition in the passive elicitation task. Out of the 44 active sentences she produced, 33 were elicited in the first 10 sessions, which means that she was a very prolific passive producer for the next 14 sessions (sessions 11 to 24 ) until her ability declined in the final three sessions. Even in session 24, she responded with passives for all eight items in both conditions. However, from session 25, her attempt to produce passives started failing in several phases. We must note, though, that there was a four-and-a-half-month span of no testing between sessions 24 and $25 .^{28}$

Out of Rita's total 34 errors, 16 are concentrated in sessions 25 to 27 and 15 occurred in the first ten sessions. There were only three errors from sessions 11 to 24 . Of the 18 errors made in the first 24 sessions, 16 were the result of Rita replacing by with another preposition. She omitted the get verb once and refused to answer once

\footnotetext{
28 There was also a four-month interruption between sessions 22 and 23. However, Rita was not affected by this hiatus and performed very well in sessions 23 and 24, producing only one error.
} 
because she did not like a particular picture on that day. In the final three sessions, then, not only did the proportion of errors increase but the types of errors diversified.

TABLE 5.7. RITA'S ERRORS IN THE FINAL THREE SESSIONS

\begin{tabular}{|c|l|l|}
\hline Session & \multicolumn{1}{|c|}{ Non-priming condition } & \multicolumn{1}{c|}{ Priming condition } \\
\hline 25 & $\mathrm{He} \_$kissed by a boy & She _ pinched by a monkey \\
\hline 26 & $\mathrm{He} \_$catched... for the bear & \\
\hline & $\mathrm{He}$ got ouched um.. _ ball & $\mathrm{He} \_$trip _ the radio \\
\hline & $\mathrm{He} \_$slapped _ the book & She _ bited uh, _ the blue fish \\
\hline 27 & $\mathrm{He} \_$scrap for the cat & He got hurt at a glass cup \\
\hline & He was um, cover with the blanket & He um, _ cutted by the knife \\
\hline & She got licked uh, _ the cow & The small girl get um, bited by, at the dog \\
\hline
\end{tabular}

Rita's omission of $b y$, as in the third error in the non-priming condition of session 27 (see table 5.7) never occurred before session 25, and this omission error is not found in the data of Sammy and Hera. Moreover, the combination of get-verb and by-drop, as in most of Rita's errors in the priming condition for session 26, indicates a total collapse of structure building, which was also unprecedented until this session. In the final three sessions, Rita produced one correct passive sentence in the non-priming condition and three in the priming condition. 


\section{CHAPTER 6 \\ RELATIVE CLAUSES}

\section{Introduction}

The syntax of English relative clauses (RCs) is quite complex. Not only does a clause embedded inside a noun phrase (NP) modify the head noun of that NP, but RCs also involve movement and co-indexation between the head noun outside the $\mathrm{RC}$ and usually a gap (or trace) inside the RC.

A restrictive $\mathrm{RC}$ helps narrow down the reference of the head noun that it modifies, whereas a non-restrictive RC only provides additional information about the head noun. For example, the restrictive RC that her sister likes in (1) identifies a particular dress from a set of dresses: that is, the head noun the dress is limited by the $\mathrm{RC}$ to a specific dress. On the other hand, the non-restrictive $\mathrm{RC}$ which has a blue ribbon in (2) simply presents more information about the head noun the dress, information that is not essential in specifying a particular referent from a set of possible referents. Only restrictive RCs will be included in the scope of the present study.

(1) the dress that her sister likes

(2) the dress, which has a blue ribbon

This chapter focuses on the three returnee children's understanding of English restrictive RCs based on the results of a comprehension task and a production task. The effects of attrition on English RCs will be the main concern of this chapter. 


\section{Literature review}

One of the most robust findings in research on relative clauses is that English subject RCs such as (3) are easier to understand than are direct object RCs such as (4) (e.g., Brown 1971; Cook 1975; Diessel and Tomasello 2005; Doughty 1991; Gass 1979).

(3) the man that [ likes the woman]

(4) the man that [ the woman likes

Some research even notes that the difficulty of various RC types (e.g., subject, direct object, indirect object, oblique, etc.) observed in young native speakers (e.g., Diessel and Tomasello 2005) and L2 learners (e.g., Gass 1979) seems to parallel (to a certain degree) the implicational relationships in Keenan and Comrie's (1977) relativization hierarchy (subject $>$ direct object $>$ indirect object $>$ oblique $>$ genitive $>$ object of comparison), which focuses on a hierarchy of grammatical relations concerning RCs in terms of language typology.

Studies that used elicited production tasks with young English-speaking children also consistently report that the children produced subject RCs more accurately than other types of RCs (e.g., Bar-Shalom et al. 1993; McDaniel et al. 1998). In these studies, some children opted to use a passive subject relative clause (e.g., the one who's being kissed) when the item was designed to elicit an object relative clause (e.g., the one who the boy is kissing). This strategy also appears in my data.

In order to account for the effect of the hierarchy on processing difficulty, several hypotheses have been suggested. However, most of them, such as the conjoined-clause, parallel function, and perceptual difficulty hypotheses, attempt to explain the difficulty of RCs embedded in a matrix clause such as 'the cow [that hit 
the pig] kissed the sheep,' which is not within the scope of the current research. ${ }^{29}$ One hypothesis that attempts to account for relative difficulty of RCs independent of their place in a matrix clause is the filler-gap hypothesis.

The filler-gap hypothesis suggests that the structural distance between the head noun and the gap determines the processing load of RCs: the shorter the structural distance between the head noun and the gap, the easier the processing of the RC. ${ }^{30}$ According to this hypothesis, the subject RC in (5) is easier than the direct object RC in (6) because there are only two maximal projections intervening between the filler and gap in (5) while there are three in (6).

(5) subject RC: the man $\left[_{\mathrm{CP}}\right.$ that ${ }_{\mathrm{IP}}$ likes the woman]] Number of nodes between head noun and gap: 2 (CP, IP)

(6) direct object RC: the man [CP that [IP the woman [vp likes ]]] Number of nodes between head noun and gap: 3 (CP, IP, VP)

However, this chapter does not intend to probe the relative difficulty of English RCs, per se. Although certain types of RCs are known to be more easily processed than others, our main focus is the performance over time of the three returnee children on each of five types of English RCs (subject, direct object, indirect object, oblique, and object of comparison) in terms of both comprehension and production. ${ }^{31}$ The analysis

\footnotetext{
${ }^{29}$ See Diessel and Tomasello (2005) for a brief review and history of the conjoined-clause hypothesis. For the parallel function and perceptual difficulty hypotheses, see Doughty (1991). See also Diessel (2004, ch.6) for an overview of the hypotheses.

${ }^{30}$ O'Grady et al. (2003) demonstrate that the distance should refer to structural distance, viz the depth of embedding of the gap, rather than linear distance, which simply counts the number of intervening words of any type.

${ }^{31}$ Hawkins (1999) removes the object of comparison position from discussion since the coding of this position is highly variable across languages. Also, the indirect object and oblique positions are collapsed. However, this chapter will include object of comparison RCs and distinguish indirect object RCs from oblique RCs mainly because some of my participants seem to show distinct performance on these RCs.
} 
of the errors and response times is expected to provide insight into the participants' English RC competence and to identify any signs of attrition with respect to RCs.

\section{Materials}

I used a comprehension task and a production task, each comprising five different test sets, to measure the children's competence in RCs. In the production task, the sets of test items were recycled in the same order after the fifth experiment. Since Sammy was tested 15 times, each test set was used three times. Hera and Rita were tested 27 times, so the first two sets were used six times and the other three sets were used five times. However, in the comprehension task, there were two versions, in which the two animate NPs were reversed, for each of the five different test (more detail will be provided in section 3.1). Thus, after the fifth experiment, the reversed version was used in the same order. The 10 test sets were then recycled after the tenth session. Therefore, in the comprehension test, sessions 1, 11, and 21 were conducted using the same test set while sessions 6,16 , and 26 used the reversed version with the choice of pictures remaining the same.

\subsection{Comprehension task}

For the comprehension task, I used a picture-selection task adopted and modified from O'Grady et al., (2001, 2003). A laptop computer installed with the stimulus presentation software SuperLab 4.0 was presented to the participants. At the same time as participants were looking at the screen containing two pictures like those in figure 6.1, they heard a recorded NP containing an RC such as the sheep that is poking the bird. The stimulus NPs were recorded and edited using Audacity 1.2.6. 
A

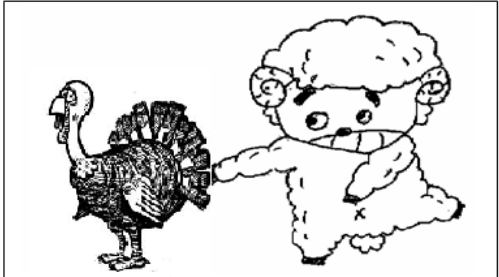

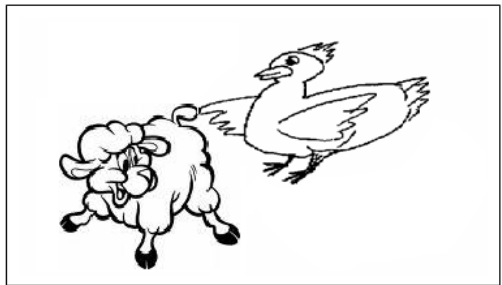

FIGURE 6.1. A SAMPLE STIMULUS FOR SUBJECT RC:

“THE SHEEP [THAT _ _ IS POKING THE BIRD]”

After hearing the stimulus while looking at the pictures, participants were instructed to press one of the keys, A, B, C or D. Alphabet stickers of the capital letters A, B, C and D were attached to the laptop keys, A, D, J and L to reflect the actual horizontal distance between the letters A, B, C and D in the pictures.

Each animate referent was represented in two different pictures in the boxes. That is, the two pictures did not share the exact same characters; for example, the sheep in the left box is different from the one in the right. This design was meant to satisfy the felicity condition suggested by Hamburger and Crain (1982), who argue that an appropriate situational context should be given to the participants to facilitate their understanding of RCs. Since the function of a restrictive RC is to specify one member of a set, it is natural that there be a set of two or more possible referents to choose from. Having two different characters for each referent ensured that the RCs occurred in a pragmatically appropriate context.

All sound files were manipulated to end exactly 4 seconds after the picture's appearance on the screen because SuperLab 4.0 also collected participants' response times (RTs). However, since the length of each stimulus differed, ranging from approximately 2.2 to 3.6 seconds, there was a silence ( 1.8 seconds at most and at least 0.4 seconds) at the beginning of the sound files. Therefore, even though the picture and the recording were presented at the same time, participants had a chance to look 
at the picture for between 0.4 and 1.8 seconds before they started hearing the recorded test item.

Before the actual test, participants were given three practice items. The first practice item was an NP containing a PP, the cat with a ball. The other two were NPs containing an RC. The second practice item was the boy that fell, containing a very simple $\mathrm{RC}$ consisting of an animate subject and an intransitive verb. The last practice item was the man that was pushed by the woman, which resembled an actual subject $\mathrm{RC}$ test item except that the verb was in the passive voice. The practice items familiarized the participants with the experiment software and ensured their understanding of the task before moving on to the actual test.

The task involved 36 test items, which were divided into six batteries, each of which contained one RC of each type: subject, direct object, indirect object, oblique, genitive, and object of comparison. However, results of the genitive RCs will not be reported due to problems with the test items. The order of the RCs was randomized within each battery, and the same type of RC never appeared consecutively. It took approximately five minutes to finish the task.

The test items were kept as short and straightforward as possible, as in (7) below. I deliberately decided not to embed the NP in a matrix clause (including an imperative) as in (8) in order to avoid any extraneous processing complications that might arise due to the additional lexical items and more complex syntactic structure.

(7) Simple NP with a RC: the sheep that is poking the bird

(8) RCs embedded in a matrix clause: The rabbit is watching the sheep that is poking the bird. / The sheep that is poking the bird is watching the rabbit. / Find the sheep that is poking the bird. 
All test items consisted of two pictures, each containing two characters, and the participants were asked to choose the one character that matched what they heard. ${ }^{32}$ All test items were semantically reversible, with two animate characters, so as to ensure that the participants could not rely on lexical and pragmatic clues, including real-world knowledge. For example, a test item such as (9) is equally plausible pragmatically when the NPs are reversed as in (10). When a phrase such as (9) was presented, one of the accompanying pictures depicted the situation in (9) and the other showed the situation in (10) (see figure 6.1 above).

(9) Test item: the sheep that is poking the bird

(10) Reversed: the bird that is poking the sheep

In the test items, only the complementizer that introduced the RCs except for the relative pronoun whose in genitive RCs. This was to avoid any possible confusion caused by additional inconsistent use of several relative pronouns such as which and who. ${ }^{33}$ For the same reason, that was not omitted in DO, IO, oblique, and OCOMP $\mathrm{RCs}$, where its use is optional.

All verbs in the test items were in the present progressive tense because most of the pictures showed an ongoing action. However, in OCOMP RCs, where the object of comparison becomes a head noun as in (11), present tense was used because such a phrase requires a copular be instead of a regular verb. More specific explanation about the test items will follow.

\footnotetext{
32 A pilot study that I conducted following O'Grady et al. $(2001,2003)$ that contained three pictures ( speakers in Hawai ' $\mathrm{i}$ with Korean heritage. O'Grady et al. contained another picture in which the characters were performing an action irrelevant to the test RC.

33 English RCs introduced by the complementizer that are obligatorily restrictive while RCs introduced by relative pronouns which or who may be either restrictive or non-restrictive.
} 
(11) OCOMP RC: the bird that the turtle is smaller than

\subsubsection{Subject RCs}

Figure 6.1 is an example of a test item containing a subject RC. In order to keep the $\mathrm{NP}$ as short and structurally simple as possible, the RC was derived from a simple sentence containing a subject, a present progressive transitive verb, and a direct object: The sheep is poking the bird. Transitive verbs were necessary in order to have two NPs, one associated with the subject and the other with the direct object. ${ }^{34}$ Such patterns are semantically reversible and both interpretations are depicted: the left picture correctly depicts the situation presented by the stimulus phrase, while the right picture shows the reverse situation. The subject of the sentence became the head noun of the test item leaving a gap in the subject position of the RC. The correct answer in figure 6.1 is $\mathrm{B}$.

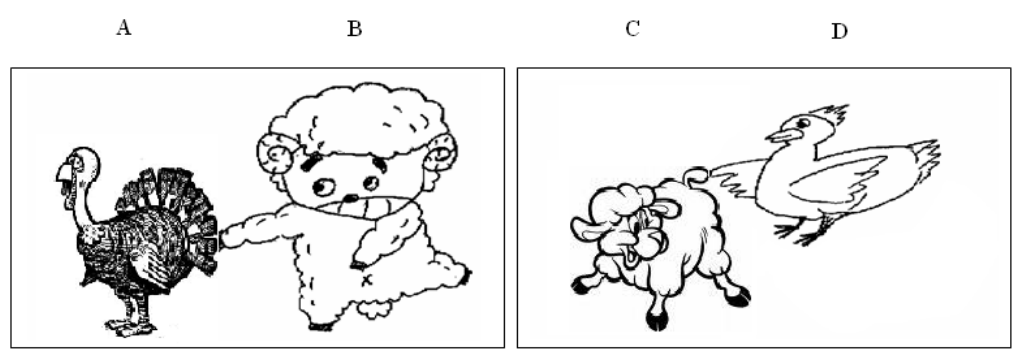

FiguRE 6.1 (REPEATED). A SUBJECT RC: “THE SHEEP [THAT IS POKING THE BIRD]"

\subsubsection{Direct object RCs}

Figure 6.2 is an example of a test item containing a DO RC. As with subject RCs, the DO RC was derived from a simple sentence containing a subject, a present progressive transitive verb, and a direct object: The bee is touching the ant. These

\footnotetext{
${ }^{34}$ Diessel and Tomasello (2005) distinguish subject RCs with intransitive verbs from those with transitive verbs. RCs with an intransitive verb, which do not allow semantic reversibility, proved to be easier than RCs with transitive verbs.
} 
patterns, too, are semantically reversible and both interpretations are depicted: the left picture correctly depicts the situation presented by the stimulus phrase while the right picture shows the reverse situation. The DO of the sentence became the head noun of the test item, leaving a gap in the DO position of the RC. The correct answer in figure 6.2 is $\mathrm{A}$.

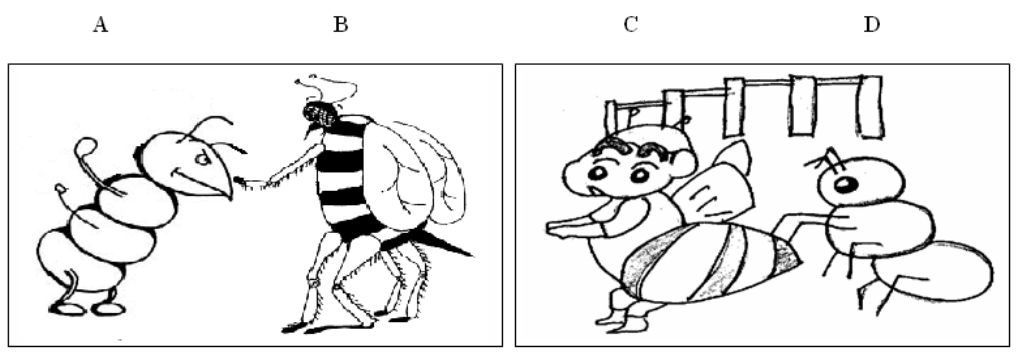

FigURE 6.2. A DO RC: “THE ANT [THAT THE BEE IS TOUCHING ___]”

\subsubsection{Indirect object RCs}

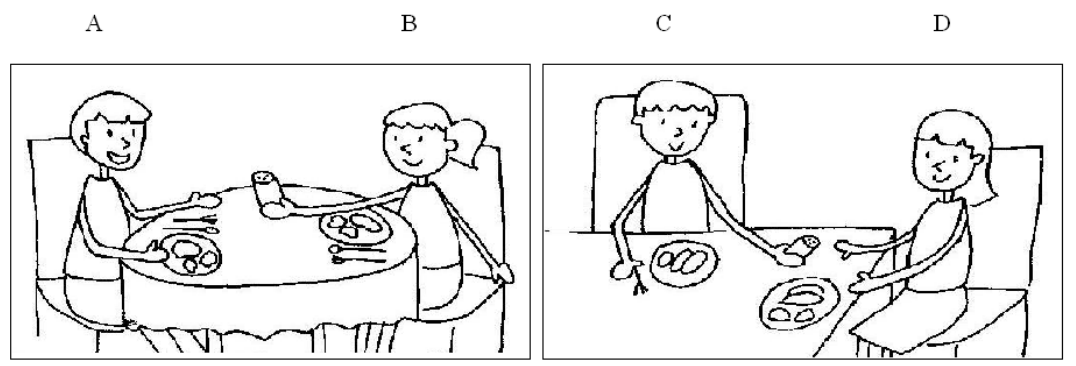

FIGURE 6.3. AN IO RC: “THE MAN [THAT THE WOMAN IS PASSING THE SALT TO __ ] ]

Figure 6.3 is an example of a test item containing an IO RC. The RC was derived from a sentence containing a subject, a present progressive dative ditransitive verb, a direct object, and an indirect object following dative to: The woman is passing the salt to the man. This can, of course, also be expressed as a double object construction: The woman is passing the man the salt. However, since the grammatical acceptability of the IO RC derived from such a sentence, as in (12), is questionable, it was not considered. 
(12) ? the man that the woman is passing the salt

Despite the possibility of pied-piping with IO RCs, such a construction was not among the test items. Although the RC in which the preposition to is fronted (the man to which/whom the woman is passing the salt) is grammatical, the relative pronoun which or whom must be used. As explained above, to reduce confounding factors, only the relative marker that is used in this research, except for genitive RCs, where whose is unavoidable. Therefore, the preposition was stranded in the test items for both IO RCs and oblique RCs.

Test items containing IO RCs were made up of nine or ten words, whereas the rest of the test items usually had only seven or eight words. Since the design of the research was to keep the test items as simple as possible, adverbials or noun modifiers were not added to the other five types of RCs to match the length of IO RCs. The subject, the woman, and the indirect object, the man, are semantically reversible and both interpretations are depicted: the left picture correctly depicts the situation presented by the stimulus phrase, while the right picture shows the reverse situation. The IO has been relativized, leaving a gap in the IO position of the RC. The correct answer in figure 6.3 is $\mathrm{A}$.

\subsubsection{Oblique $\operatorname{RCs}^{35}$}

Figure 6.4 is an example of a test item containing an oblique RC. Again, to keep the test item as simple as possible, the $\mathrm{RC}$ was derived from a sentence containing a subject, a present progressive verb, a preposition, and an object of the preposition:

\footnotetext{
${ }^{35}$ Keenan and Comrie (1977:66) define oblique NPs as "NPs that express arguments of the main predicate rather than ones having a more adverbial function." However, many studies in L2 acquisition do not apply this distinction between arguments and non-arguments, if in fact they deal with oblique RCs at all. Therefore, in the current study, I did not differentiate arguments from non-arguments in the oblique NPs and included non-arguments as obliques.
} 
The bee is flying above the bird. The subject, the bee, and the oblique, the bird, are semantically reversible and both interpretations are depicted: the left picture correctly depicts the situation presented by the stimulus phrase while the right picture shows the reverse situation. Relativization leaves a gap in the oblique position of the RC. The correct answer in figure 6.4 is $\mathrm{A}$.

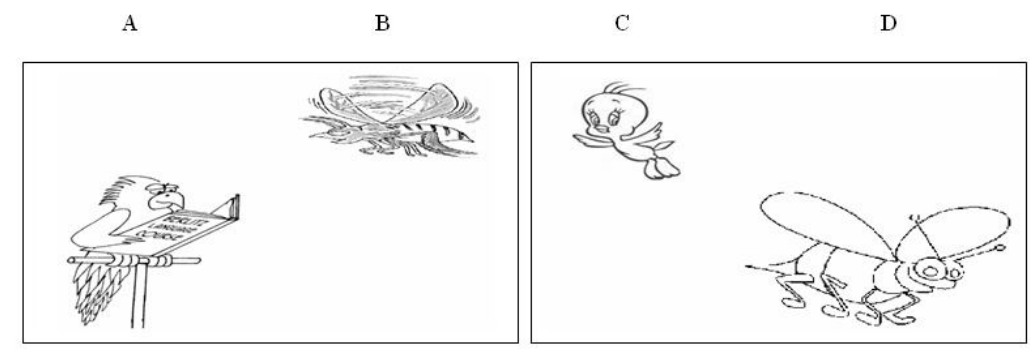

FIGURE 6.4. AN OBLIQUE RC: “THE BIRD [THAT THE BEE IS FLYING ABOVE __] ]

\subsubsection{Object of comparison RCs}

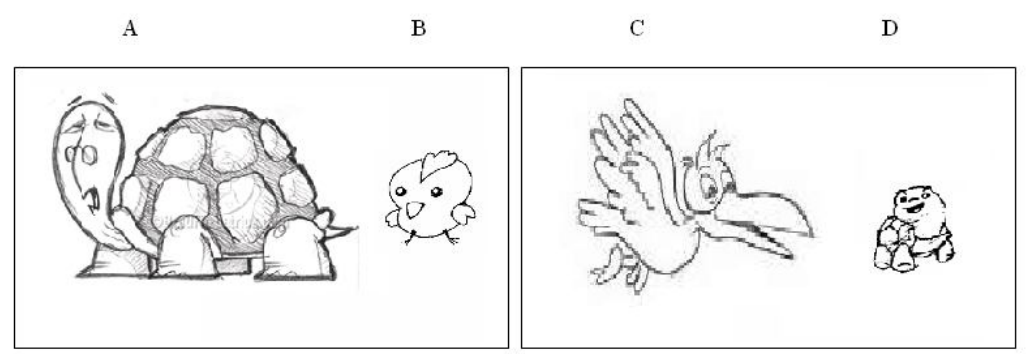

FIGURE 6.5. AN OCOMP RC: “THE BIRD [THAT THE TURTLE IS SMALLER THAN __] ]

Figure 6.5 is an example of a test item containing an OCOMP RC. The RC was derived from a sentence containing a subject, a copular be verb, a comparative form of an adjective, and an object of comparison: The turtle is smaller than the bird. The subject, the turtle, and the OCOMP, the bird, are semantically reversible and both situations are depicted: the right picture correctly depicts what the stimulus phrase presents while the left picture shows the reverse situation. The OCOMP in the 
sentence became the head noun of the test item, leaving a gap in the OCOMP position of the RC. The correct answer in figure 6.5 is $\mathrm{C}$.

\subsection{Production task}

The production task was modeled after Goodluck and Stojanovic (1996), whose task involved pairs of pictures and stickers of different colors. In the revised task that I used, children were given four envelopes. In each envelope was a pair of pictures, each of which contained an animal corresponding to the target of relativization and another animal. Each target animal was performing or receiving a different action (figure 6.6) and was marked with a colored (red or blue) dot. The animal performing an action was expected to elicit a response including a subject RC such as "The blue dot is on the mouse [that is touching the rabbit]." On the other hand, a character corresponding to the theme was targeted to elicit an object RC such as "The blue dot is on the bear [that the rabbit is scratching ]."
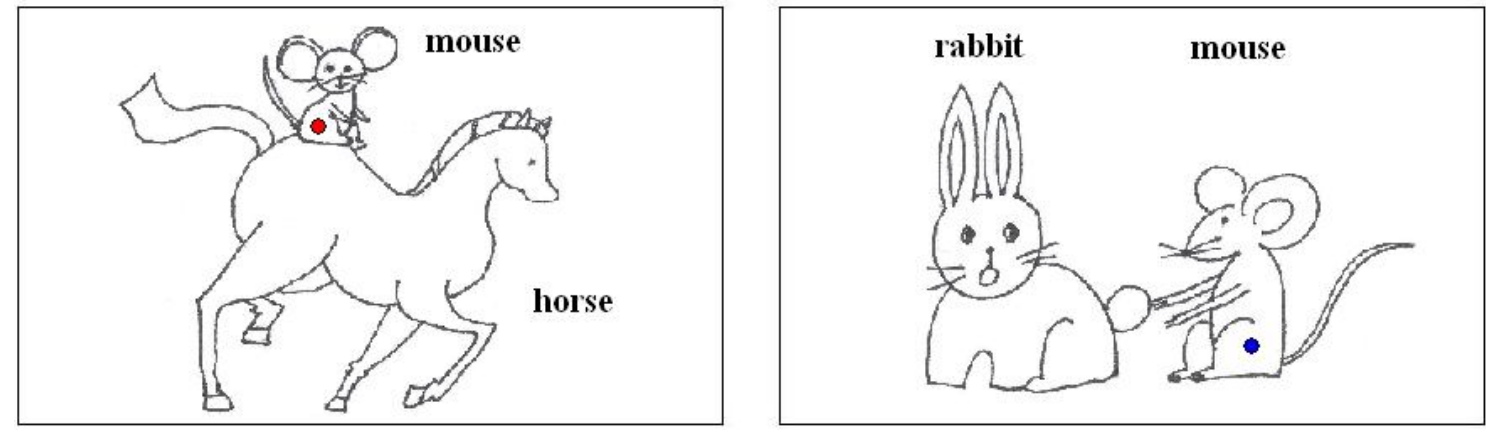

FIGURE 6.6. SAMPLE PICTURES USED FOR RC PRODUCTION TASK

As in the comprehension task, the target animals in the two pictures were not exactly the same, which satisfies the felicity condition. Children were asked to pick an envelope and take out the pair of pictures without showing them to me. I told them that I was holding a sheet of paper with multiple pictures that included all the pictures 
in the envelopes, but without the colored dots. Then I asked, 'Which animal has a red (blue) dot?' Their task was to describe the animals that had colored dots so I could draw the correct color dots on the animals in my pictures. Before opening the next envelope, they showed the pictures to me and I recorded their responses. They eventually opened all four envelopes and described eight animal characters.

\section{Results}

\subsection{Comprehension task}

In the earlier chapter on passives, I reported accuracy and response times (RTs) for each test session because participants achieved relatively high scores in every session. However, since the children did not always perform well with all RCs, results from approximately five sessions (based on the time when the tests were conducted) will be clustered together for reporting purposes. Only the RTs for correct items will be reported.

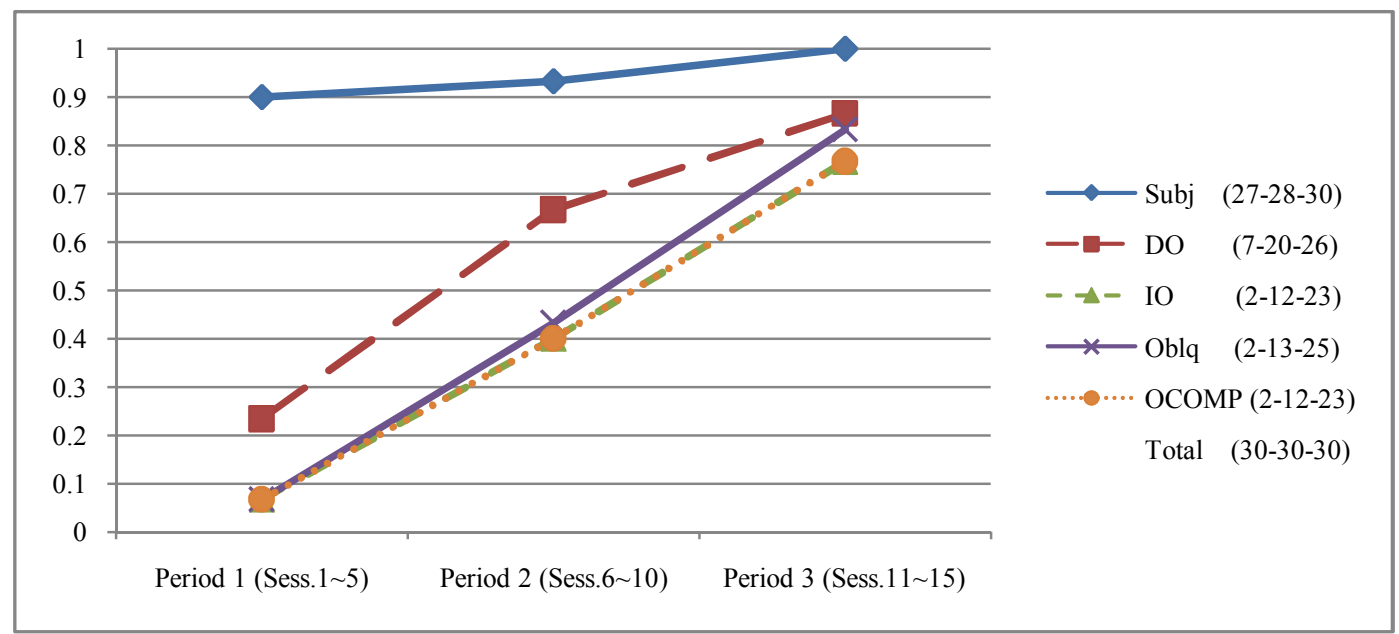

*Numbers in parentheses next to the labels are the number of correct items in each period.

FIGURE 6.7. SAMMY'S ACCURACY ON RC COMPREHENSION TASK 
Figure 6.7 shows Sammy's accuracy in three periods. Test sessions 1 through 5 were conducted within three months of his arrival in Korea. The second period, sessions 6 through 10, covers the next four months, and the last period, sessions 11 through 15 , the final five months. As expected, Sammy scored higher (at least 90\%) on subject RCs than on any other type in all three periods; his second-highest score was on DO RCs. The other three types of RCs were of equal difficulty for Sammy in the first period but, in the next two periods, all his scores except that for subject RC (which was high through the entire research period) rose sharply. A likely explanation for the sudden increase in proficiency is the formal lessons he was receiving in his English grammar classes at school or in private institutions, since RCs constitute a separate chapter of English grammar books and are emphasized in English classes in Korea. His accuracy patterns for IO, oblique, and OCOMP RCs are strikingly similar.

Figure 6.8 shows Sammy's RT changes for all RC types. RTs in period 1 for RCs other than subject and DO RCs should be interpreted with some caution as the average RTs come from only two or three correct items. The RTs show no signs of attrition. This, too, may reflect the attention to RCs in Sammy's grammar lessons.

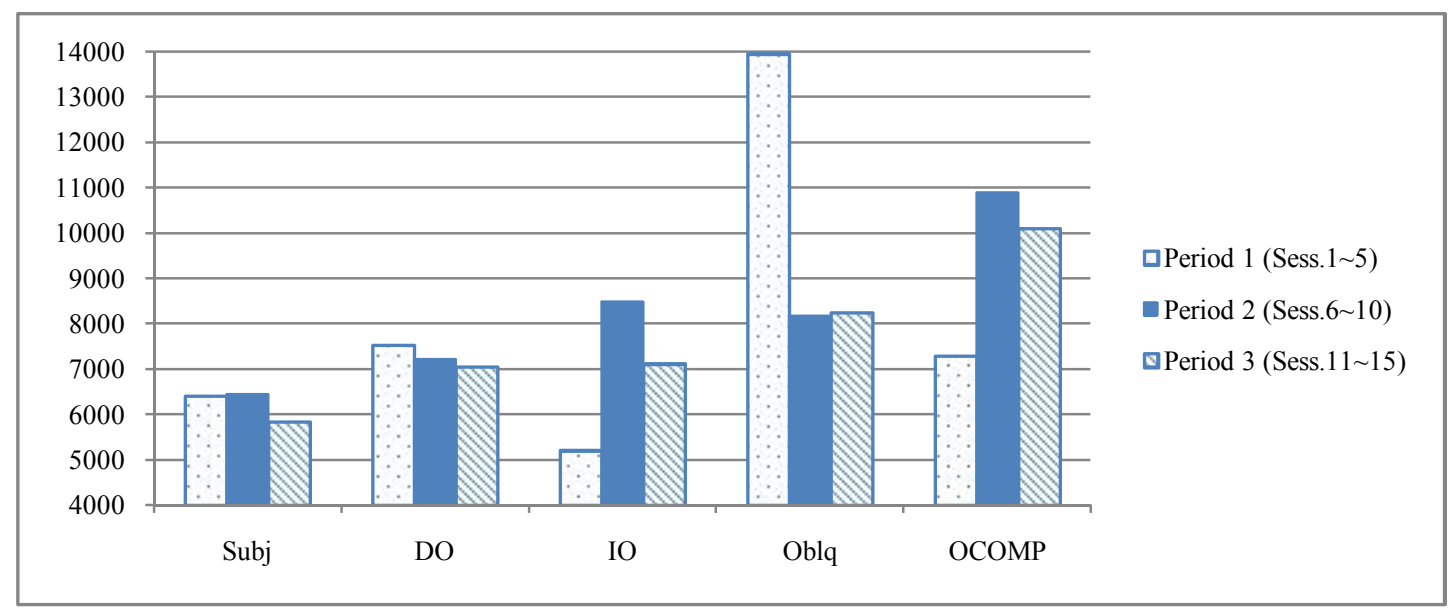

*RTs include the 4 seconds during which the test item recording was provided.

FIGURE 6.8. SAMMY'S RT ON RC COMPREHENSION TASK 
While Sammy's results were divided into three periods of five sessions each, the results for Hera and Rita are divided into six periods. The first three periods each consist of five sessions over a span of approximately three months. Period 4 includes seven sessions (16 22) conducted in the final four months of the first year of investigation. After four months of no testing, sessions 23 and 24 were conducted, which constitute period 5. The last period includes sessions 25 to 27 , which were carried out after another four-month of break from testing.

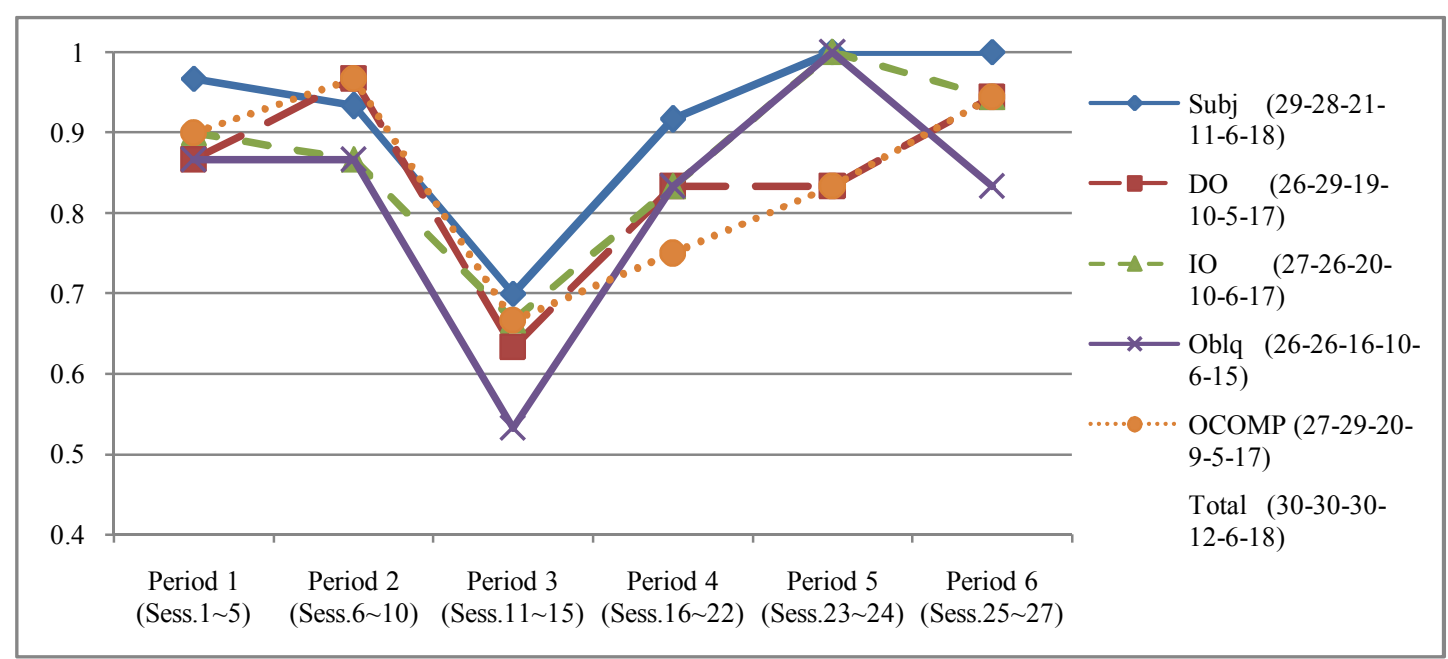

*Numbers in parentheses next to the labels are the number of correct items in each period.

FIGURE 6.9. HERA'S ACCURACY ON RC COMPREHENSION TASK

Figure 6.9 shows Hera's accuracy on the RC comprehension task in the six periods. As mentioned in the chapter on passives, Hera's data from sessions 11 through 20 must be interpreted with caution because she did not take the tasks on the laptop computer seriously when I kept some distance from her during the tasks. Although I do report the results from sessions 11 to 15 in period 3 because she was less distracted in this period, I do not include results from sessions 16 to 20 because Hera pressed keys randomly during these five sessions. Thus, only sessions 21 and 22 are included 
in period $4 .^{36}$ Results of period 3 are also excluded from further analysis. In session 24 , the data sheet was not saved due to malfunctioning of the laptop, so period 5 includes only session 23 .

Hera showed high competence (at least $86 \%$ accuracy) in all six types of RCs in the first two periods. All of her scores also generally remained higher than 80 percent in the last three periods. As for OCOMP RC, her score slight fell below 80 percent in period 4, but overall, Hera did not show any signs of attrition in her RC comprehension.

Figure 6.10 illustrates Hera's RTs. There are some fluctuations for some types of RCs, but all RTs appear to be faster in the final period than in the first two periods. As was the case with her accuracy data, RT data show that Hera's ability to understand RCs were retained.

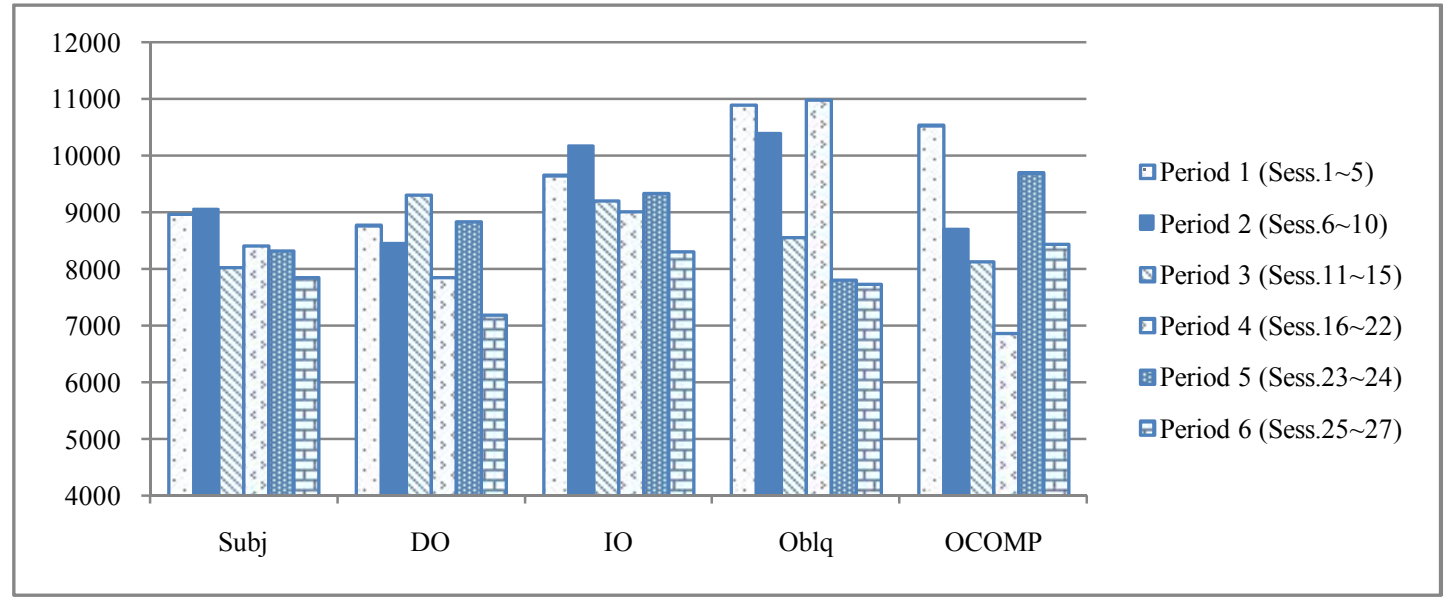

*RTs include the 4 seconds during which the test item recording was provided.

FIGURE 6.10. HERA'S RT ON RC COMPREHENSION TASK

Rita's accuracy scores in figure 6.11 are in sharp contrast with her older sister's. While her sister showed proficiency in all types of RCs in the beginning, Rita's

\footnotetext{
36 Chapter 3 (Articles) divided this period into two separate periods, one consisting of sessions 16 20 and the other sessions 21 22 because Hera kept her focus with article experiments during all sessions.
} 
understanding of RCs was generally low across the six periods. Even with subject RCs, in which she clearly scored higher than the other four types, her accuracy ranges only between 50 and 70 percent. Rita maintained her relatively high understanding of subject RCs throughout the project, but her performance on the other four types of RC shows a different picture. Her scores for DO and IO RCs seem to rise at times, ranging between approximately 10 and 30 percent, but finish slightly lower than the first few sessions. The scores for the other two RC types (oblique and OCOMP) also show some fluctuation ( 0 to approximately 30 percent). In at least one session during each of the final two periods, Rita was unable to respond correctly on any item for these two RC types. Overall, it seems that Rita never had a full understanding of RCs except for the subject RC.

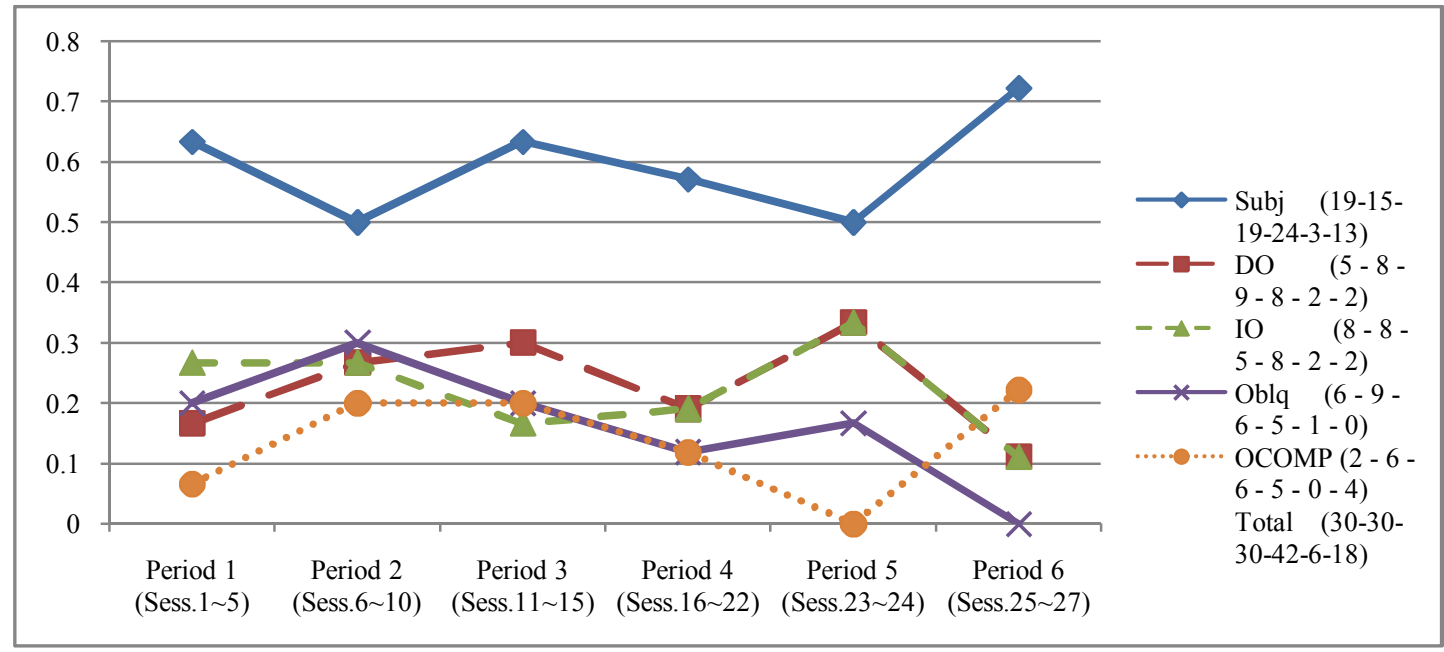

* Numbers in parentheses next to the labels are the number of correct items in each period.

FIGURE 6.11. RITA'S ACCURACY ON RC COMPREHENSION TASK ${ }^{37}$

Figure 6.12 shows Rita's RTs for the comprehension task. The RTs in the final period are faster than in the first period for all RC types. Thus, although there are some

\footnotetext{
37 As in Hera's case, Rita's data from session 24 was discarded. Period 5, therefore, includes results from only session 23 .
} 
fluctuations, Rita's RT data do not provide evidence of attrition because she responded faster in the later test sessions than in her earlier sessions.

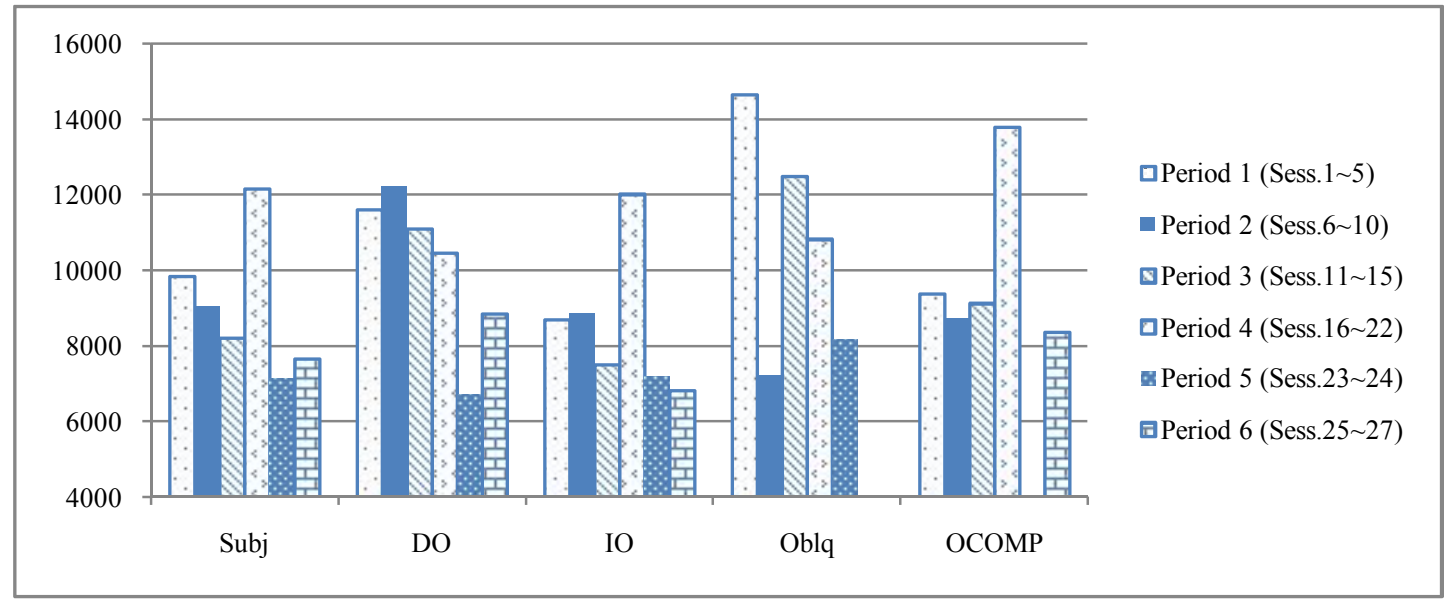

*RTs include the 4 seconds during which the test item recording was provided.

FIGURE 6.12. RITA'S RT OF RC COMPREHENSION TASK

\subsubsection{Error analysis}

Since there are four choices in the picture, the participants could make three kinds of errors. First, the reversal error, referred to by Diessel and Tomasello (2005) as the 'conversion' error, occurs when the grammatical relation of the gap inside the $\mathrm{RC}$ and that of the other animate NP within the RC are reversed. For example, when the reversal error occurs in the subject $\mathrm{RC}$ the sheep [that is poking the bird], it is interpreted as the sheep [that the bird is poking ___. In figure 6.1 below, the participant would choose character $\mathrm{C}$ in the picture on the right when the correct answer is the sheep, B, in the other picture.

The second type of error is the head error, which occurs when the participant reverses the head noun and the other animate inside the RC. In figure 6.1, this would result in the $\mathrm{RC}$ being interpreted as the bird [that is poking the sheep] and $\mathrm{D}$ would be selected. 

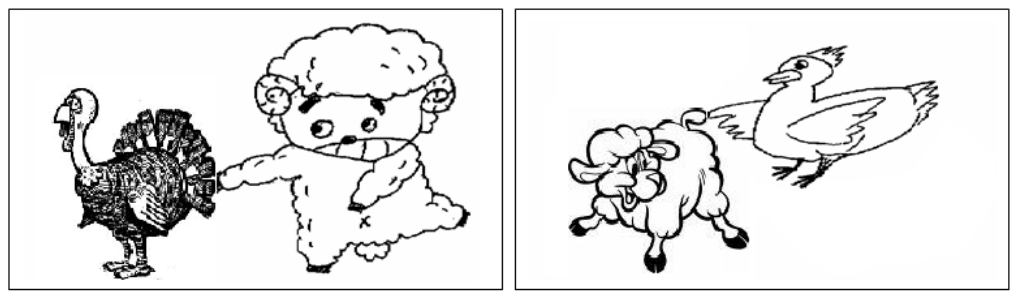

FIGURE 6.1 (REPEATED). TEST ITEM: “THE SHEEP [THAT IS POKING THE BIRD]"

The third type of error is a combination of the reversal error and the head error. The occurrence of both errors results in the interpretation the bird [that the sheep is poking ___ a a the selection of A from figure 6.1. Table 6.1 is summaries of these three error types, along with the correct response.

\section{TABLE 6.1. SUMMARY OF ERROR TYPES RELATED TO FIGURE 6.1}

\begin{tabular}{|c|c|c|c|}
\hline \multicolumn{2}{|r|}{ Test item in figure 6.1} & Error type & Description \\
\hline A & $\begin{array}{l}\text { the bird [that the sheep is } \\
\text { poking __ _ ] }\end{array}$ & Mixed & $\begin{array}{l}\text { Both the reversal error and head error are } \\
\text { applied. }\end{array}$ \\
\hline B & $\begin{array}{l}\text { the sheep [that } \_ \text {is } \\
\text { poking the bird] }\end{array}$ & $\begin{array}{l}\text { Correct } \\
\text { answer }\end{array}$ & This is the correct answer. \\
\hline C & $\begin{array}{l}\text { the sheep [that the bird is } \\
\text { poking __ }\end{array}$ & Reversal & $\begin{array}{l}\text { The grammatical relations of the gap and the } \\
\text { other NP within the RC are reversed. }\end{array}$ \\
\hline $\mathrm{D}$ & $\begin{array}{l}\text { the bird [that } \_ \text {is } \\
\text { poking the sheep] }\end{array}$ & Head & $\begin{array}{l}\text { The head NP and the NP within the RC are } \\
\text { reversed. }\end{array}$ \\
\hline
\end{tabular}

\subsubsection{Error analysis of subject RC}

Sammy and Hera responded incorrectly on five and twelve subject RC items, respectively, throughout the entire project, and their errors appeared to be random rather than systematic. ${ }^{38}$ On the other hand, Rita erred on 35 percent (57 errors) of

\footnotetext{
${ }^{38}$ Errors from Hera's period 4 were excluded as mentioned earlier in section 4.1. Eight of Hera's 12 errors came from period 3 when she started pressing random buttons on the keyboard.
} 
subject RC items; the analysis of her errors in table 6.2 shows that she rarely committed simple reversal errors, and she made more mixed errors than head errors.

TABLE 6.2. NUMBER OF RITA'S SUBJECT RC ERRORS IN EACH PERIOD (\%)

\begin{tabular}{|c|c|c|c|c|c|c|}
\hline Error type & Period 1 & Period 2 & Period 3 & Period 4 & Period 5 & Period 6 \\
\hline Reversal & 0 & $5(35.7)$ & 0 & $1(7.7)$ & 0 & 0 \\
\hline Head & $4(36.4)$ & 0 & $6(60)$ & $6(46.2)$ & $1(33.3)$ & $4(66.7)$ \\
\hline Mixed & $7(63.6)$ & $9(64.3)$ & $4(40)$ & $6(46.2)$ & $2(66.7)$ & $2(33.3)$ \\
\hline Total & 11 & 14 & 10 & 13 & 3 & 6 \\
\hline
\end{tabular}

\subsubsection{Error analysis of DO, IO, oblique, and OCOMP RCs}

Sammy's results suggest that among the four non-subject RCs, the DO RC was the easiest one to process, with virtually no difference between the other three types. Meanwhile, Hera performed similarly well on all four RC types, probably due to her proficiency on all types of RCs. On the other hand, Rita tended to comprehend DO and IO RCs better than the oblique and OCOMP RCs, even though her overall performance on these four RC types was quite low.

I will do the error analysis of these four RC types as a group since they share a linear characteristic: they all start with $<\mathrm{NP}_{1}$ rel $\mathrm{NP}_{2} \mathrm{~V}>$ as shown in (13). When the participants were confused and made the reversal error, they interpreted these as (14), which results in a $<\mathrm{NP}_{1}$ rel $\mathrm{V} \mathrm{NP}_{2}>$ sequence.

$$
\mathrm{NP}_{1} \quad \text { rel } \mathrm{NP}_{2} \quad \mathrm{~V}
$$

DO RC: the ant that the bee is touching

IO RC: the man that the woman is passing the salt to

Oblique RC: the bird that the bee is flying above

OCOMP RC: the bird that the turtle is smaller ${ }^{39}$ than

\footnotetext{
${ }^{39}$ The sequence 'copular + complement (adjective)' will be treated as V for the sake of word order analysis.
} 
DO RC (Reversal): the ant that _ is touching the bee

IO RC (Reversal): the man that _ is passing the salt to the woman

Oblique RC (Reversal): the bird that _ is flying above the bee

OCOMP RC (Reversal): the bird that _ is smaller than the turtle

Diessel and Tomasello (2005:898) suggest that this tendency to convert a $<\mathrm{NP}_{1}$ rel $\mathrm{NP}_{2} \mathrm{~V}>$ sequence to $\mathrm{a}<\mathrm{NP}_{1}$ rel $\mathrm{V} \mathrm{NP} \mathrm{NP}_{2}>$ sequence is "due to the activation of the wrong grammatical pattern." In other words, since the canonical word order of English in non-embedded simple sentences is $\left\langle\mathrm{NP}_{1} \mathrm{~V} \mathrm{NP}_{2}\right\rangle$, it is quite natural for the participants to perceive the test item as a $<\mathrm{NP}_{1}$ rel $\mathrm{V} \mathrm{NP}_{2}>$ sequence even when they are given a $<\mathrm{NP}_{1}$ rel NP $2 \mathrm{~V}>$ sequence. In the repetition task of Diessel and Tomasello, children who tried to repeat an oblique RC such as (15) below that did not follow the canonical English word order, often started with the word order of subject RC, but then realized that they had made a mistake and corrected the word order.

(15) Is that the boy who play/Mary played with in the garden?

$$
\mathrm{NP}_{1} \quad \text { rel } \quad \mathrm{V} / \mathrm{NP}_{2} \quad \mathrm{~V}
$$

This reliance on canonical word order provides an explanation for another puzzling test result. Recall that to arrive at the mixed error the participants have to make two types of errors - a reversal error and a head error. Intuitively, it seems strange that the mixed error rate was generally higher than the head error rate because participants had to go through a more complicated process to make a mixed error (table 6.3 below). However, this makes sense if one supposes that the English canonical word order $<\mathrm{NP}_{1} \mathrm{~V} \mathrm{NP}_{2}>$ is so strong that when a child makes a head error (which has a noncanonical word order), a reversal error also occurs to create a canonical word order. 
The example below demonstrates that the DO RC in (16a) and the head error resulting in (16b) have non-canonical word orders. However, when a reversal error also takes place, the result is the mixed error in (16c), yielding a canonical $<\mathrm{NP}_{1}$ rel $\mathrm{V} \mathrm{NP}_{2}>$ sequence.

$\mathrm{NP}_{1}$ rel $\mathrm{NP}_{2} \quad \mathrm{~V} \quad$ non-canonical word order (16a) DO RC: the ant that the bee is touching

(16b) DO RC (head): the bee that the ant is touching

$$
\mathrm{NP}_{1} \text { rel } \quad \mathrm{V} \quad \mathrm{NP}_{2} \text { canonical word order }
$$

(16c) DO RC (mixed): the bee that _ is touching the ant

(16d) DO RC (reversal): the ant that _ is touching the bee

The error patterns of the three participants on these four types of RCs are shown in table 6.3 and figure 6.13. As reported earlier, the number of Sammy's errors declined in the later periods. In the first period, he mostly produced reversal and mixed (reversal + head) errors, suggesting that the canonical English word order was activated when he was attempting to comprehend the RCs with non-canonical word order. However, in period 2 the proportion of head errors increased and in period 3 errors were equally distributed among the three error types. This reinforces the previous speculation that Sammy was receiving grammar lessons that led him to perform better and eschew reliance on the canonical word order strategy. 
TABLE 6.3. NUMBER OF CHILDREN'S ERRORS ON NON-SUBJECT RCS IN EACH PERIOD (\%)

\begin{tabular}{|c|c|c|c|c|c|c|c|}
\hline & & Period 1 & Period 2 & Period 3 & Period 4 & Period 5 & Period 6 \\
\hline \multirow{3}{*}{ Sammy } & Head & $6(5.6)$ & $13(20.6)$ & $7(30.4)$ & & & \\
\hline & Reversal & $65(60.7)$ & $35(55.6)$ & $8(34.8)$ & & & \\
\hline & Mixed & $36(33.6)$ & $15(23.8)$ & $8(34.8)$ & & & \\
\hline \multirow{3}{*}{ Hera } & Head & $3(23.1)$ & $3(30)$ & $16(37.2)$ & $3(37.5)$ & 0 & 0 \\
\hline & Reversal & $6(46.2)$ & $3(30)$ & $18(41.9)$ & $2(25)$ & 0 & $1(20)$ \\
\hline & Mixed & $4(30.8)$ & $4(40)$ & 9 (20.9) & $3(37.5)$ & $2(100)$ & $4(80)$ \\
\hline \multirow{3}{*}{ Rita } & Head & $16(16.3)$ & $17(19.5)$ & 27 (28.7) & $23(18.4)$ & $5(27.8)$ & $7(11.1)$ \\
\hline & Reversal & 39 (39.8) & $32(36.8)$ & $30(31.9)$ & $53(42.4)$ & $9(50)$ & $21(33.3)$ \\
\hline & Mixed & $43(43.9)$ & $38(43.7)$ & 37 (39.4) & $49(39.2)$ & $4(22.2)$ & 35 (55.6) \\
\hline
\end{tabular}

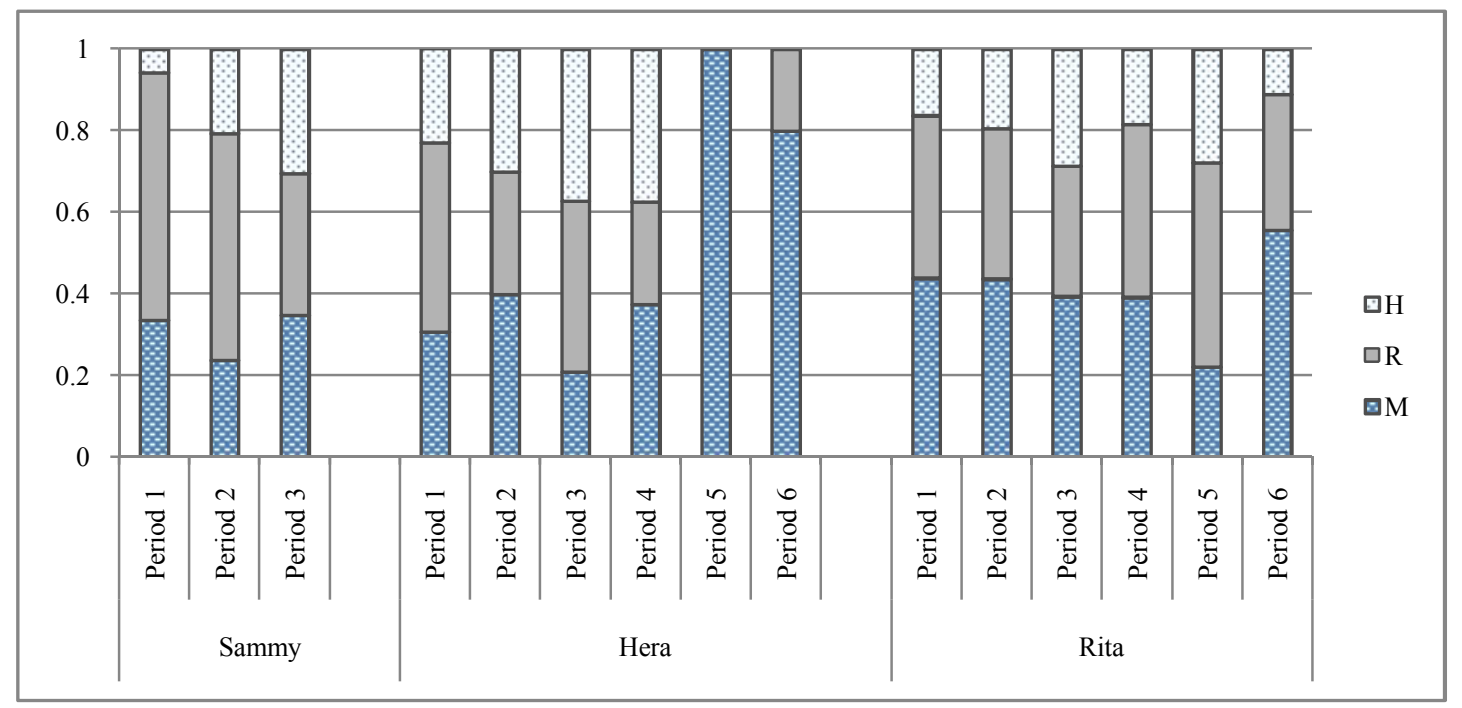

*M: MIXED ERROR, R: REVERSAL ERROR, H: HEAD ERROR

FiguRE 6.13. PROPORTION OF CHILDREN'S ERRORS ON NON-SUBJECT RCS IN EACH PERIOD $(\%)$

Hera's errors are rather difficult to analyze due to their scarcity. More than half of her errors were made in period 3, when she paid less attention to the task. Also, we must remember that in period 4, the results from five sessions were excluded due to Hera's random choice of answers. In general, errors caused by relying on the canonical word order (reversal + mixed errors) occupy a bigger proportion (over $76 \%$ ) than expected 
by chance, which would be 66.6 percent, when random errors from sessions 11 to 20 are excluded.

Among the three children, Rita had the most difficulty dealing with these four types of RCs as evidenced by the high number of errors throughout the project. Error analysis shows that she usually applied the canonical word order strategy to interpret these RCs. The proportion of reversal and mixed errors exceeds 80 percent in all periods except 3 and 5. Even in those two periods, the percentages (71.3\% and $72.2 \%)$ are slightly higher than expected by chance $(66.6 \%)$. It seems that Rita's misinterpretation is consistently based on the canonical English word order.

\subsection{Production task}

The RC production task consistently elicited RCs from Sammy and Hera, but Rita succeeded in producing only a limited number of RCs. However, the RCs that all three children produced were heavily concentrated on subject RCs. In fact, all RCs from Sammy and Rita were subject RCs, while Hera occasionally produced other types like DO, IO, and genitive RCs. In response to items that targeted DO RCs such as figure 6.14 , children found a way to make it a subject $\mathrm{RC}$ by describing the situation in an alternative way, as in (17), or used the passive voice to answer with a subject RC, as in (18). ${ }^{40}$ When they did not use RCs to describe the target, they found a way to point out the target character while describing the situation in the picture, as in (19). Table 6.4 summarizes their RC production performance in each session.

\footnotetext{
${ }^{40}$ Children's such strategies of responding with subject RCs to items that targeted object RCs are also observed in studies like Zukowski (2009).
} 
TABLE 6.4. THREE CHILDREN'S RC PRODUCTION (* UNGRAMMATICAL)

\begin{tabular}{|c|c|c|c|c|c|c|c|}
\hline \multirow{2}{*}{ Sessions } & \multicolumn{2}{|c|}{ Sammy } & \multicolumn{2}{|c|}{ Rita } & \multicolumn{3}{|c|}{ Hera } \\
\hline & Subject RC & Description & Subject RC & Description & Subject RC & Other RCs & Description \\
\hline 1 & 3 & 5 & 1 & 7 & 6 & 0 & 2 \\
\hline 2 & 0 & 8 & 3 & 5 & 6 & 0 & 2 \\
\hline 3 & 5 & 3 & 2 & 6 & 4 & 0 & 4 \\
\hline 4 & 5 & 3 & 2 & 6 & 7 & 0 & 1 \\
\hline 5 & 1 & 7 & 3 & 5 & 6 & $1(\mathrm{IO})$ & 1 \\
\hline 6 & 7 & 1 & 1 & 7 & 8 & 0 & 0 \\
\hline 7 & 7 & 1 & $2(* 2)$ & 6 & 6 & $2(2 \mathrm{IO})$ & 0 \\
\hline 8 & 7 & 1 & 0 & 8 & 3 & $\begin{array}{c}3 \text { (DO, IO, } \\
\text { Gen) }\end{array}$ & 2 \\
\hline 9 & 8 & 0 & 0 & 8 & 6 & 0 & 2 \\
\hline 10 & 6 & 2 & 0 & 8 & 6 & 0 & 2 \\
\hline 11 & 7 & 1 & 0 & 8 & 8 & 0 & 0 \\
\hline 12 & 7 & 1 & 0 & 8 & 8 & 0 & 0 \\
\hline 13 & 8 & 8 & 0 & 8 & 7 & $1(\mathrm{IO})$ & 0 \\
\hline 14 & 6 & 2 & 0 & 8 & 7 & 1 (DO) & 0 \\
\hline 15 & 8 & 0 & 0 & 8 & 8 & 0 & 0 \\
\hline 16 & & & 0 & 8 & 6 & 0 & 2 \\
\hline 17 & & & 0 & 8 & 8 & 0 & 0 \\
\hline 18 & & & 0 & 8 & 8 & 0 & 0 \\
\hline 19 & & & 0 & 8 & 4 & $1(* \mathrm{DO})$ & 3 \\
\hline 20 & & & 0 & 8 & 7 & $1(\mathrm{IO})$ & 0 \\
\hline 21 & & & 0 & 8 & 6 & 0 & 2 \\
\hline 22 & & & 0 & 8 & 7 & $1(* \mathrm{IO})$ & 0 \\
\hline 23 & & & 1 & 7 & 8 & 0 & 0 \\
\hline 24 & & & 0 & 8 & 5 & 1 (DO) & 2 \\
\hline 25 & & & 0 & 8 & 7 & 1 (DO) & 0 \\
\hline 26 & & & 0 & 8 & 8 & 0 & 0 \\
\hline 27 & & & 0 & 8 & 7 & 1 (DO) & 0 \\
\hline
\end{tabular}

*'Description' refers to correctly pointing out the character without using an RC. 


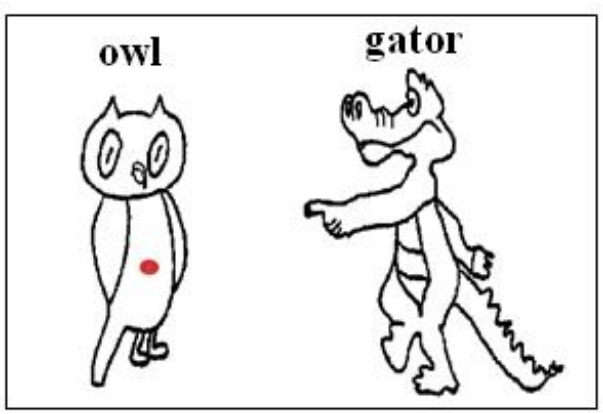

FIGURE 6.14. AN RC PRODUCTION TASK ITEM TARGETED TO ELICIT A DO RC: "THE OWL [THAT THE GATOR IS POINTING AT ]"

(17) the owl [who is just staring at the gator] (Sammy, session 9)

(18) the owl [who is getting pointed by the alligator] (Sammy, session 14)

(19) the owl is standing and the gator talk(s)... and pointing to the, the owl.

(Rita, session 4)

Sammy produced more RCs in later sessions than in early ones. Again, this suggests that his RC proficiency was positively affected by grammar lessons from public and private education. Still, the subject RC was the only type of RC that he used.

Rita also produced only subject RCs and her RC productions are heavily weighted toward the early sessions. Hera consistently produced at least one correct $\mathrm{RC}$ in each of the first six sessions. In session 7, even though she produced two RCs, they were ungrammatical, as in (20). After session 7, she produced only one more RC in session 23. She appeared to begin avoiding the use of RCs four months after her return to Korea.

(20) * cow [that $\varnothing$ eating an apple and giving it to the bear]

Hera was the most consistent child in terms of the number and variety of RCs used. She produced at least six RCs per session, except in sessions 3 and 19, and even then, 
she produced four and five RCs, respectively. Hera also used six DO RCs, seven IO RCs, and a genitive RC scattered across 11 sessions. Examples of non-subject RCs from Hera are presented in (21) to (23). In addition, both errors in sessions 19 and 22 involved using a pronoun instead of leaving a gap, as English RCs do. For example, as the structure of her IO RC in (24) became complicated, Hera inserted the underlined resumptive pronoun that is co-indexed with the head noun, 'a lion,' in a double object construction instead of leaving a gap in the dative position as in (22). ${ }^{41}$

(21) DO RC: a tiger [that the eagle is scratching (session 8)

(22) IO RC: a monkey [that a tiger is throwing a apple to (session 8)

(23) Genitive RC: the tiger [who, whose tail is bit by a mouse] (session 8)

(24) Error: a lion ${ }_{\mathrm{i}}$ [whom a rabbit beside him $_{\mathrm{i}}$ is giving $\underline{\text { him }}_{\mathrm{i}}$ apple] (session 22)

\section{Discussion}

Sammy's overall RC performance gradually increased. In the comprehension task, his scores for all RCs except for subject RC, which was over 90 percent from the beginning, rose significantly. By the end of the study, he scored approximately 80 percent on all RCs except the subject RC, in which he scored 100 percent. In the production task, Sammy also performed better in the later sessions than in the first five sessions, although his production throughout was limited to only subject RCs. This boost in proficiency seems to have been an effect of the grammar lessons he was receiving in English classes at school and private institutions.

In contrast to Sammy, Hera demonstrated a high understanding (at least $86 \%$ ) of all RCs in the early sessions of the comprehension task. Even in the later sessions, the scores for all RC types remained around or exceeded 80 percent. In the production

${ }^{41}$ Use of resumptive pronouns in RCs, especially far from the head noun, is not too difficult to observe. Some studies such as McKee and McDaniel (2001) report resumptive pronoun in English RCs from both native children and adults. 
task, Hera consistently produced subject RCs but she occasionally used DO, IO, and genitive RCs as well. Thus, English attrition was not observed.

Rita's comprehension of RCs was not as high as that of Sammy and Hera. Still, her understanding of subject RCs was clearly better than the other four types: scores for non-subject RCs consistently remained under 35 percent. Indeed, Rita scored 0 percent on oblique RC in the last period and on OCOMP RCs in the secondto-last period. In the production task, she produced at least one subject RC in each of the first seven sessions, but in the other 15 sessions, she produced a total of one subject RC. Thus, while it is difficult to observe $\mathrm{RC}$ attrition in the comprehension task (because it seems that she was never proficient with RCs other than subject RC), Rita began to avoid producing RCs rather quickly, only five months after her return to Korea.

In conclusion, Rita was the only one to show a possible sign of attrition. Although it is difficult to discuss attrition with her comprehension task data, her production data demonstrate an early avoidance of RCs. In the earlier sessions, I was able to elicit RCs from Rita even though they were limited to subject RCs. However, after the first five months of testing, I heard only one more subject RC in the next 20 months even though she retained a fairly high understanding of subject RCs during the same period. Thus, early signs of attrition in Rita's RCs were first observed in the production, not in the comprehension. 


\section{CHAPTER 7 \\ NATURALISTIC DATA: \\ NULL SUBJECT AND CODE SWITCHING}

\section{Introduction}

This chapter describes the children's use of null subjects and code switching. Unlike the previous chapters that reported results from experiments (chapter 4 included both experimental and naturalistic data), there was no experiment specifically designed to measure the participants' use of either null subjects, which are ungrammatical in English, or code switching. However, the irregular past tense production task (chapter 4) and the passive production task (chapter 5) are revisited to investigate the children's use of null subjects. Code switching data come from the entire collection of recordings, which includes all the experiments.

While I expected the occurrence of code switching, especially in the later sessions, I did not foresee the children's use of null subject in English. This does not mean, however, that the syntactic subject has never been a topic of attrition research. Tsimpli et al. (2004) examined Greek and Italian near-native speakers of English who had lived in the UK for at least six years to examine their use of null/overt subjects and preverbal/postverbal subjects in their null-subject L1s, Greek and Italian. They conducted a number of production, comprehension, and grammaticality judgment tasks, but in terms of the null subject parameter, they only report results of the comprehension task from Italian native speakers. They conclude that the Italian native speakers showed attrition effects only in the interpretation of overt pronominal subjects while the availability of null subject remained. 
In this chapter, I will describe the three returnee children's production of null subjects and code switching, both of which seem to be heavily motivated by Korean: Korean allows null subjects, and code switching usually occurred when Korean was embedded inside an English utterance. Since attrition does not begin without contact with another language, the grammatical concepts discussed in the previous chapters (articles, irregular past tense verbs, passives, and relative clauses) were also under the influence of Korean. However, while the previous chapters dealt with English structures that already existed in the children's repertoires, this chapter describes the emergence of new parameters.

\section{English null subjects ${ }^{42}$}

I analyzed children's responses in the irregular past tense production task and passive production task. I chose these two tasks for null subject investigation because both tasks elicited responses in complete sentences. Sample items from the tasks, which were not conducted on the same day, are repeated from chapters 4 and 5 below.

\section{(1) TEST ITEM FOR IRREGULAR PAST TENSE PRODUCTION TASK}

Yesterday, John went to the beach to swim.

But before swimming, he decided to build a sand castle.

After the sand castle was done, he enjoyed swimming.

Q: What did John do at the beach yesterday before swimming?

Target answer: $\underline{\text { John built a sand castle. }}$

${ }_{42}$ Subject drop in adult matrix clauses appears in diaries. Haegeman (1990) noticed use of null subjects in the diary of Virginia Woolf:

A very sensible day yesterday. Saw no one. Took the bus to Southwark Bridge... Saw a flight of steps down to the river. I climbed down.

However, this does not seem to be what Sammy is doing. If Sammy's use of null subjects is similar to subject drop in diaries, a question of why he did not drop subjects in the very early testing sessions arises. 
Each session involved 10 to 15 test items in the irregular past tense production task and eight test items in the passive production task. However, since two questions were asked in the passive production task, children produced 16 responses. Target answers for all these questions were complete sentences that included an overt subject and a tensed verb.

(2) TEST ITEM FOR A PASSIVE PRODUCTION TASK

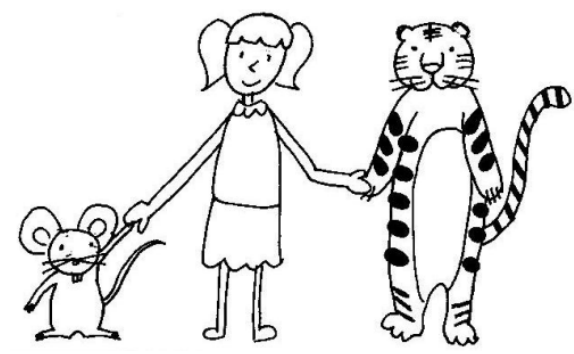

1) Look!

The tall girl brings a tiger and a mouse.

3) Q1: What did the tall girl do?

Target A: She brought a tiger and a mouse. Target A: She got brushed by the tiger.

Interestingly, Hera and Rita never produced a single instance of a null subject throughout the entire 27 sessions. Sammy also did not omit the subject in the early sessions. However, after the first three sessions, his use of null subjects increased. Figure 7.2 shows that null subjects began appearing in session 4. After session 7 , when Sammy responded all but once without a subject (figure 7.3) in the two tasks, he consistently dropped the subject more than half the time except in session 14 . 


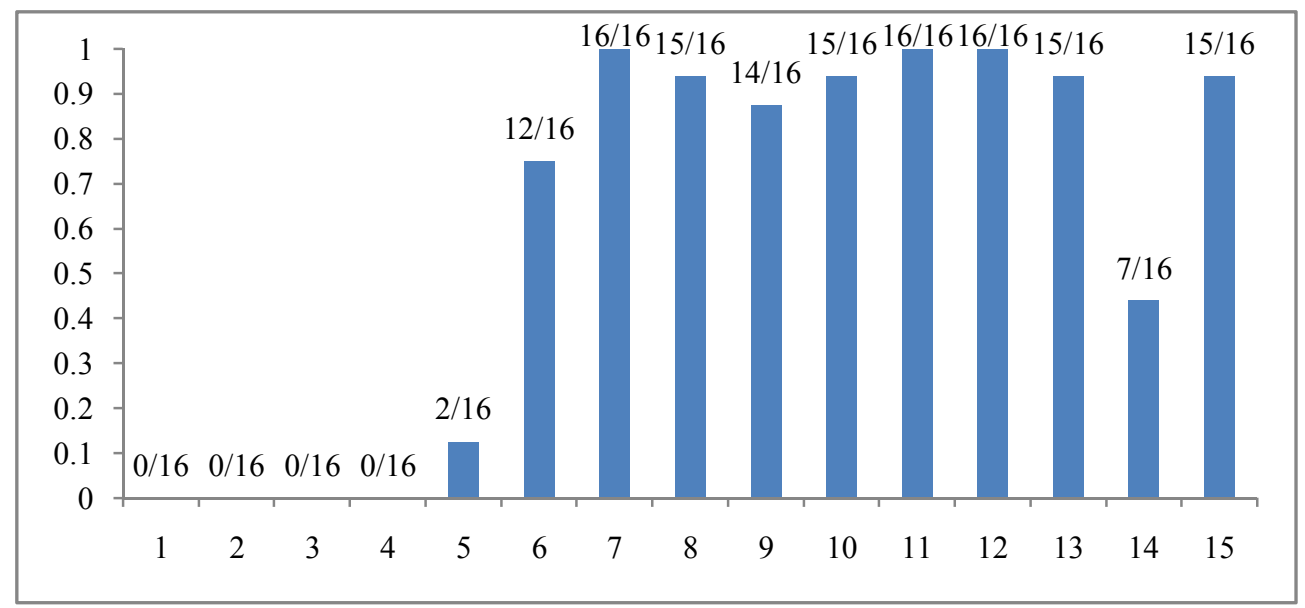

FIGURE 7.1. SAMMY'S USE OF NULL SUBJECTS IN THE PASSIVE ELICITATION TASK (NULL/TOTAL)

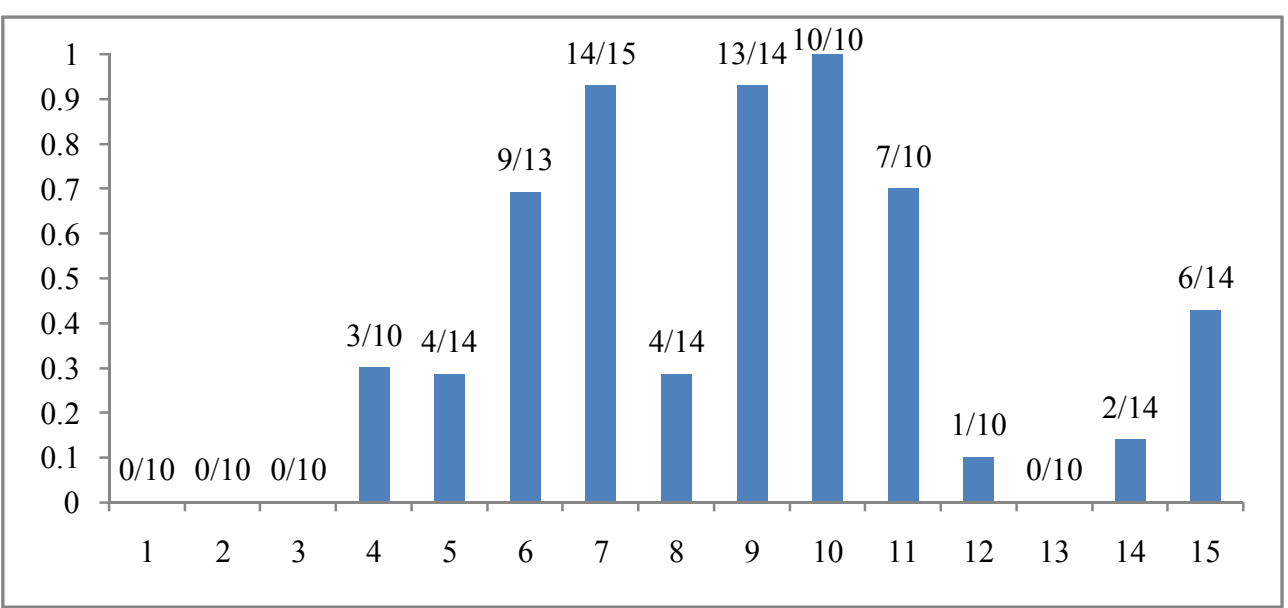

FIGURE 7.2. SAMMY'S USE OF NULL SUBJECT IN IRREGULAR PAST TENSE ELICITATION TASK (NULL/TOTAL)

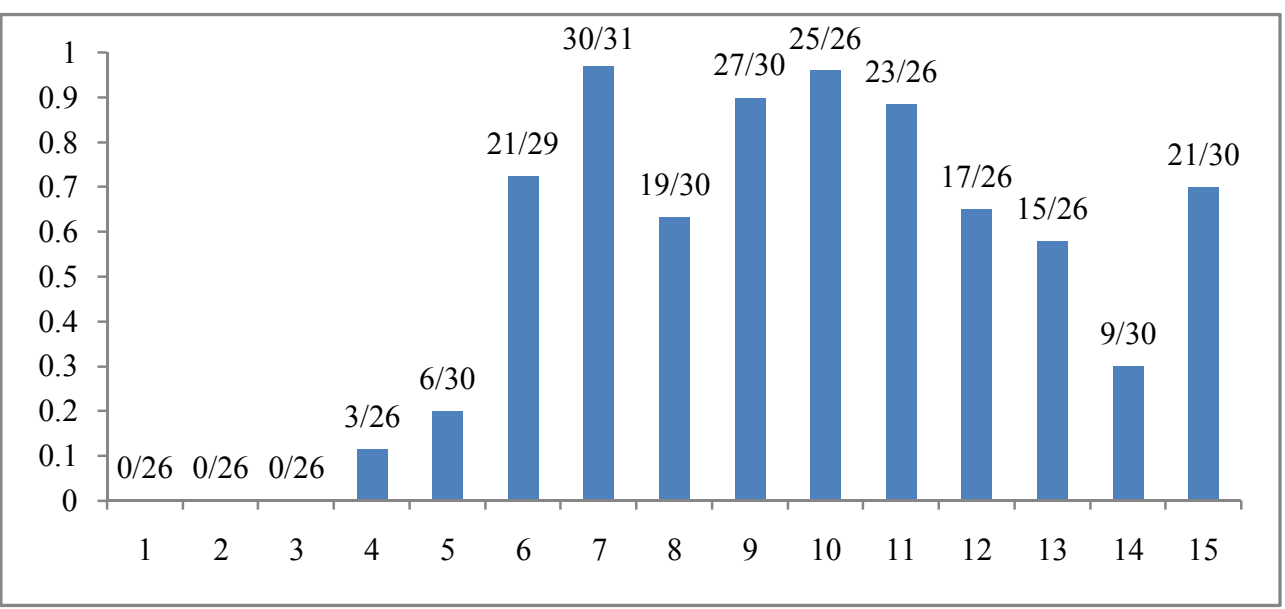

FIGURE 7.3. SAMMY'S AGGREGATE USE OF NULL SUBJECT IN TWO TASKS (NULL/TOTAL) 
We have to note that Sammy dropped subjects more frequently and consistently in the passive elicitation task (figure 7.1) than in the irregular past tense elicitation task (figure 7.2). Once he started dropping subjects, approximately two months after his return to Korea, null subjects appeared 82.4 percent of the time in the passive production task but only 49.3 percent in the irregular past tense production task. This may reflect a 'processing bottleneck' in the sense of Bloom (1990), who suggested that subjects are more likely to be dropped when the VP is relatively long, thereby increasing the processing load. His analysis of speech data from three young children (Adam, Eve, and Sarah) demonstrated a significant correlation between VP length and subject drop. The example test items in (1) and (2) above show that the length of VP in children's response to the irregular past tense elicitation task is expected to be shorter than that to the passive elicitation task. Sammy's average VP length in responses to the irregular verb task was 3.71 words compared to 5.49 words in the passive task. Thus, it seems possible that the passive task was eliciting more null subjects from Sammy because the responses required longer VPs than the irregular past tense task.

Further analysis of Sammy's data is provided in table 7.1, which breaks down his null/overt subject responses in each task according to three verb categories: finite, non-finite, and ambiguous. Null subjects are known to be related to the property of the accompanying verb (e.g., underspecification of INFL such as non-finiteness; see e.g., Hyams 1998). Finite verbs carry tense/agreement features while non-finite verbs do not. Ambiguous verbs are difficult to judge in terms of their finiteness. Examples (3) to (5) are actual responses from Sammy. The verb he used in (3), threw, is unambiguously a past tense form, which is different from the corresponding participle form thrown. The verb in example (4), rescued, is arguably non-finite because it is the 
participle form used in a passive sentence, in which Sammy made an error by omitting the be-verb. The final example, (5), contains a verb that is ambiguous because brought has the same form in both past tense and participle form.

(3) Q: What did the woman wearing a skirt do? Finite verb: Ø threw a cup and a book.

(4) Q: What happened to the tall boy? Non-finite verb: He [was] rescued by the bear.

(5) Q: What did the younger sister do? Ambiguous: $\varnothing$ brought a dog and a cat.

TABLE 7.1. ANALYSIS OF SAMMY'S NULL/OVERT SUBJECTS IN RELATION TO FINITENESS OF VERBS

\begin{tabular}{|c|c|c|c|c|}
\hline \multirow{2}{*}{} & \multicolumn{2}{|c|}{ Passive elicitation } & \multicolumn{2}{c|}{ Irregular past tense elicitation } \\
\cline { 2 - 5 } & overt & null & overt & null \\
\hline Finite verb & $57 \%$ & $54 \%$ & $41 \%$ & $30 \%$ \\
\hline Ambiguous & $42 \%$ & $44 \%$ & $59 \%$ & $36 \%$ \\
\hline Non-finite verb & $1 \%$ & $2 \%$ & $0 \%$ & $34 \%$ \\
\hline
\end{tabular}

Table 7.1 shows that more null subjects than overt subjects are clustered with nonfiniteness in the irregular past tense elicitation task, which supports Hyams (1998). However, the proportions of overt and null subjects occurring with finite verbs in the passive production task are strikingly similar, which suggests that the emergence of null subjects might not be related to the finiteness of verbs in Sammy's case.

As mentioned above, null subjects were never observed in the speech of Hera and Rita, who were proficient English-speakers and were unable to speak any Korean when they returned to Korea. On the contrary, although Sammy was an excellent English speaker by the time of his return, he was also a native speaker of Korean. It seems that Sammy's Korean quickly gained dominance in the first couple of months after his return to Korea, and he transferred the Korean null subject parameter setting 
to English. In the case of Hera and Rita, two years' exposure to Korean was apparently not sufficient for such a transfer to occur. In conclusion, rather than the clustering of null subjects and finiteness of verbs, transferring of the null subject parameter from Korean seems to be a more plausible explanation for Sammy's null subjects in English (White 1985). ${ }^{43}$

\section{Code switching}

I investigated the occurrence of code switching (CS) during the entire data collection period, all of which was audio-recorded. CS can be roughly defined as the bilingual's use of more than one language within a single utterance; it does not include the choice of different languages according to different contexts or situations. Thus, recordings of Hera reading a Korean book were not included in the analysis. Borrowed words from English were considered CS when they were produced with Korean phonology. For instance, Rita would pronounce 'tube' as /tjubi/ instead of the English pronunciation /tju:b/ applying Korean phonology to an English word. ${ }^{44}$ This, I counted as an instance of CS. However, proper names in Korean such as a person's name or a place name were not considered instances of CS even when they were produced with Korean pronunciation.

Four measures were used in the CS analysis. First, the mean length of utterance (MLU) in each session measured children's English proficiency. Although there was occasional CS, the recordings are heavily English dominant and MLU can serve as an estimate of the children's English proficiency. I could then explore

\footnotetext{
43 In her study, White showed that French- and Spanish-speaking learners of English behaved differently with respect to English null subjects. In grammaticality judgment tasks, Spanish speakers were significantly more likely to accept null subjects in English than were French speakers. She explains this differential behavior based on properties of the L1, since Spanish but not French allows null subjects.

44 Rita produced multiple instances of 'tube' using Korean phonology. The additional vowel after the final $/ \mathrm{b} /$ sound seemed to alternate between high central and high back.
} 
whether the proportion of CS is related to a change in English proficiency. Typically, the number of morphemes produced is divided by the number of utterances in order to calculate MLU. For this study, however, the number of words replaced the number of morphemes for practical reasons. ${ }^{45}$

The second measure, CS frequency, represented the number of Korean words used in each session. The number of Korean words was divided by the total number of words uttered by the participants in each session (No. of Korean words / No. of total words). Thus, CS frequency will increase as CS increases.

The third measure involved calculating the CS turn frequency for each session. The number of a child's turns that included CS was divided by the child's total number of turns in each session (No. of turns with CS / No. of total turns). CS turn frequency is also expected to increase as CS increases.

Fourth and finally, CS density is measured. This measure is divided into two categories following Shin (2002). Single words of Korean origin are classified as 'single words' and fragments consisting of more than one Korean word are called 'multi-word fragments.' I divided the number of code switched Korean words (that are not 'single words') by the number of turns that included 'multi-word fragments.' This resulted in the average number of Korean words used in each turn that were part of multi-word CS. A sample calculation of these four measures follows the excerpt below from one of Hera's recordings (session 18). Although a translation is provided of Korean portions, a linear gloss is not, since it is irrelevant to the word count.

\footnotetext{
45 Rather than counting the morphemes that the three children produced in approximately 100 hours of recording, a word counting tool in Microsoft word processing software was used.
} 
1 Hera: I um, I, I love to grill bird, especially chamsay (sparrow).

SG: Grill?

2 Hera: Uhm.. saylul kwuwese meknun key cohayo. (I like eating grilled bird.)

SG: Oh, really?

3 Hera: I like to grill birds. I love meat.

SG: Really?

4 Hera: Uh huh.

SG: So, do you like chicken too?

5 Hera: Uh huh, especially um, especially chamsay (sparrow). Because um, I've heard that um, actually um, the truth is that um, um, I didn't even taste it before but I heard that it was very tasty.

SG: Uh hm, I guess so.

6 Hera: Did you taste it?

SG: I think so. I think so.

7 Hera: Um, ya, and um, and um, um, I read in the book that um, if you want to catch, and um, if you live in sikol (countryside), and you have um, a garden and, and um, and you live in a sikol (countryside) with lots and lots of birds, especially chamsay (sparrow) and then um, and then um... and then, um, for, and then um, to catch the birds um, first you um, put um, um, lots of grains with, few grams of sweet rice inside um, inside um, wine through and then um, and then you scatter it in the field and then um, the um, birds um, come to um, eat and then come to eat it and then say 'wow, mm... this taste good and then um, and then they fly up to a tree and then um, uh, ku taumey swuley chwuihayse ttangey ttelecyeyo (then they get drunk and fall to the ground). And then um, and then um, and then you get a basket and then run to the field, now pick um, all the um, bird.

SG: That's so easy.

8 Hera: ya... but um, I'm afraid that um, we don't have um, any wine.

In the above excerpt of Hera talking about how to catch sparrows to grill, she uttered 247 words in 8 turns. Therefore, her MLU is 30.88 ( 247 words / 8 turns). Then, frequency is 0.065 (16 Korean words / 247 total words). Among Hera’s eight 
utterances, only four (turns 1, 2, 5, and 7) contain CS. Thus, CS turn frequency (the proportion of turns that contain CS) is 0.5 (4 CS turns / 8 total turns). Finally, there are five 'single word' occurrences (one each in turns 1 and 5, and three in turn 7), and the CS density in 'multi-word fragments' is 5.5 as there are 11 Korean words in two 'multi-word fragments' (one each in turns 5 and 7).

TABLE 7.2. SAMMY'S CS ANALYSES OF EACH SESSION

\begin{tabular}{|c|c|c|c|c|c|}
\hline \multirow{2}{*}{ Sessions } & \multirow{2}{*}{ MLU } & CS frequency & Turn frequency & \multicolumn{2}{|c|}{ CS density } \\
\cline { 5 - 6 } & & & single word & multi-word \\
\hline 1 & 5.15 & $1 / 3267(0.03 \%)$ & $1 / 634(0.16 \%)$ & 1 & 0 \\
\hline 2 & 5.53 & $3 / 2074(0.15 \%)$ & $3 / 375(0.80 \%)$ & 3 & 0 \\
\hline 3 & 4.84 & $4 / 2052(0.2 \%)$ & $4 / 424(0.94 \%)$ & 4 & 0 \\
\hline 4 & 4.62 & $2 / 1583(0.13 \%)$ & $2 / 344(0.58 \%)$ & 2 & 0 \\
\hline 5 & 5.32 & $4 / 1766(0.23 \%)$ & $4 / 332(1.20 \%)$ & 4 & 0 \\
\hline 6 & 4.40 & $1 / 1373(0.07 \%)$ & $1 / 312(0.32 \%)$ & 1 & 0 \\
\hline 7 & 4.61 & $0 / 1024(0 \%)$ & $0 / 222(0 \%)$ & 0 & 0 \\
\hline 8 & 4.52 & $4 / 1067(0.38 \%)$ & $2 / 236(1.69 \%)$ & 4 & 0 \\
\hline 9 & 4.19 & $1 / 1340(0.08 \%)$ & $1 / 320(0.31 \%)$ & 1 & 0 \\
\hline 10 & 4.29 & $2 / 1162(0.18 \%)$ & $2 / 271(0.74 \%)$ & 2 & 0 \\
\hline 11 & 4.68 & $0 / 1427(0 \%)$ & $0 / 305(0 \%)$ & 0 & 0 \\
\hline 12 & 4.51 & $1 / 1293(0.08 \%)$ & $1 / 287(0.35 \%)$ & 1 & 0 \\
\hline 13 & 4.09 & $12 / 1144(1 \%)$ & $8 / 280(2.86 \%)$ & 7 & $2.5(5 / 2)$ \\
\hline 14 & 5.35 & $1 / 1235(0.08 \%)$ & $1 / 231(0.43 \%)$ & 1 & 0 \\
\hline 15 & 5.06 & $3 / 875(0.34 \%)$ & $3 / 173(1.73 \%)$ & 3 & 0 \\
\hline
\end{tabular}

Sammy rarely code switched to Korean and his MLU remained stable throughout (table 7.2). When he did code switch, it was because he could not come up with either low-frequency words such as grave (myoci) and weightlifting (yekdo) or culture specific terms such as Korean thatched-roof house (chokacip) and seasoned barbecued meat (bulkoki). As a result, his proportion of turns that contain CS (turn 
frequency) is usually low and with two exceptions in session 13 all of his CS involve single words. ${ }^{46}$

TABLE 7.3. HERA's CS ANALYSES OF EACH SESSION

\begin{tabular}{|c|c|c|c|c|c|}
\hline \multirow{2}{*}{ Sessions } & \multirow{2}{*}{ MLU } & \multirow{2}{*}{$\begin{array}{c}\text { CS } \\
\text { frequency }\end{array}$} & \multirow{2}{*}{$\begin{array}{l}\text { Turn } \\
\text { frequency }\end{array}$} & \multicolumn{2}{|c|}{ CS density } \\
\hline & & & & Single word & Multi-word \\
\hline 1 & 7.05 & $0 / 3552(0 \%)$ & $0 / 504(0 \%)$ & 0 & 0 \\
\hline 2 & 6.90 & $0 / 3546(0 \%)$ & $0 / 514(0 \%)$ & 0 & 0 \\
\hline 3 & 8.62 & $3 / 6307(0.05 \%)$ & $2 / 732(0.27 \%)$ & 1 & $2(2 / 1)$ \\
\hline 4 & 8.03 & 49/6792 (0.72\%) & $29 / 846(3.43 \%)$ & 33 & $2.29(16 / 7)$ \\
\hline 5 & 6.93 & $33 / 4130(0.8 \%)$ & $19 / 596(3.19 \%)$ & 18 & $3.75(15 / 4)$ \\
\hline 6 & 5.96 & $20 / 2943(0.68 \%)$ & $14 / 494(2.83 \%)$ & 9 & $2.75(11 / 4)$ \\
\hline 7 & 5.55 & $9 / 2365(0.38 \%)$ & $5 / 426(1.17 \%)$ & 4 & $2.5(5 / 2)$ \\
\hline 8 & 5.31 & $4 / 2141(0.19 \%)$ & $4 / 403(0.99 \%)$ & 4 & 0 \\
\hline 9 & 7.13 & $12 / 3513(0.34 \%)$ & $9 / 493(1.83 \%)$ & 8 & $4(4 / 1)$ \\
\hline 10 & 6.91 & 2/2944 (0.07\%) & $1 / 426(0.23 \%)$ & 0 & $2(2 / 1)$ \\
\hline 11 & 6.74 & $8 / 2610(0.31 \%)$ & $5 / 387(1.29 \%)$ & 3 & $2.5(5 / 2)$ \\
\hline 12 & 7.39 & $10 / 3201(0.31 \%)$ & $8 / 433(1.85 \%)$ & 6 & $2(4 / 2)$ \\
\hline 13 & 8.80 & $21 / 3669(0.57 \%)$ & $7 / 417(1.68 \%)$ & 1 & $3.33(20 / 6)$ \\
\hline 14 & 11.54 & $22 / 3554(0.62 \%)$ & $6 / 308(1.95 \%)$ & 4 & $9(18 / 2)$ \\
\hline 15 & 10.62 & $16 / 3665(0.44 \%)$ & $7 / 345(2.03 \%)$ & 6 & $2.5(10 / 4)$ \\
\hline 16 & 10.66 & $26 / 4372(0.6 \%)$ & $6 / 410(1.46 \%)$ & 3 & $7.67(23 / 3)$ \\
\hline 17 & 9.66 & $38 / 4009(0.95 \%)$ & $11 / 415(2.65 \%)$ & 8 & $10(30 / 3)$ \\
\hline 18 & 14.7 & $77 / 6701(1.15 \%)$ & $30 / 456(6.58 \%)$ & 15 & $3.25(52 / 16)$ \\
\hline 19 & 12.39 & $52 / 6071(0.86 \%)$ & $19 / 490(3.88 \%)$ & 16 & $4.5(36 / 8)$ \\
\hline 20 & 9.94 & $31 / 5488(0.57 \%)$ & $14 / 552(2.54 \%)$ & 8 & $3.29(23 / 7)$ \\
\hline 21 & 10.28 & $34 / 4646(0.73 \%)$ & $6 / 452(1.33 \%)$ & 0 & $5.67(34 / 6)$ \\
\hline 22 & 7.46 & $11 / 2157(0.51 \%)$ & $6 / 289(2.08 \%)$ & 3 & $4(8 / 2)$ \\
\hline 23 & 5.21 & $3 / 1475(0.2 \%)$ & $2 / 283(0.71 \%)$ & 1 & $2(2 / 1)$ \\
\hline 24 & 7.11 & $42 / 2700(1.93 \%)$ & $14 / 380(3.68 \%)$ & 0 & $3(42 / 14)$ \\
\hline 25 & 5.86 & $92 / 1482(6.21 \%)$ & $11 / 253(4.35 \%)$ & 1 & $9.1(91 / 10)$ \\
\hline 26 & 5.11 & $39 / 1522(2.56 \%)$ & $15 / 298(5.03 \%)$ & 6 & $3.67(33 / 9)$ \\
\hline 27 & 6.12 & $17 / 1486(1.14 \%)$ & $9 / 243(3.70 \%)$ & 4 & $3.25(13 / 4)$ \\
\hline
\end{tabular}

${ }^{46}$ Sammy's CS frequency in session 13 is exceptionally high because Sammy talked about his day at a park that was holding a traditional exhibition, thus leading him to use more Korean words to describe the scene. 
TABLE 7.4. RITA'S CS ANALYSES OF EACH SESSION

\begin{tabular}{|c|c|c|c|c|c|}
\hline \multirow{2}{*}{ Sessions } & \multirow{2}{*}{ MLU } & \multirow{2}{*}{$\begin{array}{c}\text { CS } \\
\text { frequency }\end{array}$} & $\begin{array}{c}\text { Turn } \\
\text { frequency }\end{array}$ & \multicolumn{2}{|c|}{ CS density } \\
\cline { 5 - 7 } & & Single word & Multi-word \\
\hline 1 & 7.50 & $1 / 6277(0.016 \%)$ & $1 / 837(0.12 \%)$ & 1 & 0 \\
\hline 2 & 5.43 & $5 / 4526(0.11 \%)$ & $3 / 833(0.36 \%)$ & 2 & $3(3 / 1)$ \\
\hline 3 & 5.07 & $2 / 2227(0.09 \%)$ & $2 / 439(0.46 \%)$ & 2 & 0 \\
\hline 4 & 4.53 & $35 / 4443(0.79 \%)$ & $23 / 980(2.35 \%)$ & 12 & $2.09(23 / 11)$ \\
\hline 5 & 6.02 & $35 / 3571(0.98 \%)$ & $16 / 593(2.70 \%)$ & 9 & $2.88(26 / 9)$ \\
\hline 6 & 4.91 & $7 / 2808(0.25 \%)$ & $5 / 572(0.87 \%)$ & 3 & $2(4 / 2)$ \\
\hline 7 & 6.17 & $3 / 4006(0.08 \%)$ & $3 / 649(0.46 \%)$ & 3 & 0 \\
\hline 8 & 6.25 & $34 / 3349(1.02 \%)$ & $12 / 536(2.24 \%)$ & 10 & $6(24 / 4)$ \\
\hline 9 & 5.92 & $6 / 3389(0.18 \%)$ & $4 / 572(0.70 \%)$ & 3 & $3(3 / 1)$ \\
\hline 10 & 7.03 & $7 / 5219(0.13 \%)$ & $4 / 742(0.54 \%)$ & 2 & $2.5(5 / 2)$ \\
\hline 11 & 6.00 & $1 / 3927(0.025 \%)$ & $1 / 655(0.15 \%)$ & 1 & 0 \\
\hline 12 & 8.14 & $10 / 4476(0.22 \%)$ & $7 / 550(1.27 \%)$ & 4 & $2(6 / 3)$ \\
\hline 13 & 6.34 & $3 / 3019(0.1 \%)$ & $3 / 476(0.63 \%)$ & 3 & 0 \\
\hline 14 & 7.12 & $1 / 4775(0.21 \%)$ & $1 / 671(0.15 \%)$ & 1 & 0 \\
\hline 15 & 7.10 & $11 / 4653(0.24 \%)$ & $7 / 655(1.07 \%)$ & 7 & $4(4 / 1)$ \\
\hline 16 & 6.59 & $11 / 3956(0.28 \%)$ & $7 / 600(1.17 \%)$ & 3 & $2(8 / 4)$ \\
\hline 17 & 7.44 & $15 / 4124(0.36 \%)$ & $7 / 554(1.26 \%)$ & 3 & $3(12 / 4)$ \\
\hline 18 & 7.14 & $23 / 4420(0.52 \%)$ & $13 / 619(2.10 \%)$ & 9 & $3.5(14 / 4)$ \\
\hline 19 & 6.95 & $5 / 3462(0.14 \%)$ & $4 / 498(0.80 \%)$ & 3 & $2(2 / 1)$ \\
\hline 20 & 7 & $12 / 3311(0.36 \%)$ & $6 / 473(1.27 \%)$ & 3 & $3(9 / 3)$ \\
\hline 21 & 7.72 & $2 / 4024(0.05 \%)$ & $2 / 521(0.38 \%)$ & 2 & 0 \\
\hline 22 & 7.55 & $5 / 3928(0.13 \%)$ & $3 / 520(0.58 \%)$ & 5 & 0 \\
\hline 23 & 6.09 & $26 / 3154(0.82 \%)$ & $18 / 518(3.47 \%)$ & 16 & $3.33(10 / 3)$ \\
\hline 24 & 6.53 & $5 / 2109(0.24 \%)$ & $4 / 323(1.24 \%)$ & 3 & $2(2 / 1)$ \\
\hline 25 & 4.42 & $201 / 1875(10.72 \%)$ & $54 / 424(12.74 \%)$ & 22 & $5.42(179 / 33)$ \\
\hline 26 & 3.87 & $43 / 1282(3.35 \%)$ & $24 / 331(7.25 \%)$ & 10 & $2.36(33 / 14)$ \\
\hline 27 & 4.24 & $5 / 1455(0.34 \%)$ & $1 / 343(0.29 \%)$ & 0 & $5(5 / 1)$ \\
\hline & & & & & \\
\hline & & & 3 & 0 \\
\hline
\end{tabular}

Tables 7.3 and 7.4 contain the CS analyses of Hera and Rita for each session, respectively, and table 7.5 summarizes the results in tables 7.3 and 7.4 grouped into four periods. The first and second periods cover the first 14 months of data collection (22 sessions). There are 11 sessions in each of the two periods. The third period includes sessions 23 and 24, which were conducted four months after session 22 . 
Finally, the last three sessions, which were conducted after another four months, constitute the fourth period.

TABLE 7.5. HERA AND RITA’S CS ANALYSES IN FOUR PERIODS

\begin{tabular}{|c|c|c|c|c|c|c|c|c|}
\hline \multirow{2}{*}{ Sessions } & \multicolumn{4}{|c|}{ Hera } & \multicolumn{4}{|c|}{ Rita } \\
\cline { 2 - 9 } & MLU & $\begin{array}{c}\text { CS } \\
\text { frequency }\end{array}$ & $\begin{array}{c}\text { Turn } \\
\text { frequency }\end{array}$ & $\begin{array}{c}\text { Multi- } \\
\text { word CS } \\
\text { density }\end{array}$ & MLU & $\begin{array}{c}\text { CS } \\
\text { frequency }\end{array}$ & $\begin{array}{c}\text { Turn } \\
\text { frequency }\end{array}$ & $\begin{array}{c}\text { Multi- } \\
\text { word CS } \\
\text { density }\end{array}$ \\
\hline $1 \sim 11$ & 7.02 & 0.34 & 1.51 & 2.73 & 5.90 & 0.31 & 1.00 & 2.93 \\
\hline $12 \sim 22$ & 10.41 & 0.71 & 2.63 & 4.37 & 7.19 & 0.222 & 0.98 & 2.75 \\
\hline $23 \sim 24$ & 6.30 & 1.08 & 2.41 & 2.93 & 6.26 & 0.59 & 2.62 & 3 \\
\hline $25 \sim 27$ & 5.65 & 3.3 & 4.41 & 5.96 & 4.20 & 5.4 & 7.20 & 4.52 \\
\hline
\end{tabular}

Hera and Rita share a similar CS pattern. Their MLUs are highest during sessions 12 22 and lowest in the final three sessions, while their CS frequency, turn frequency, and multi-word CS density are highest in the final three sessions. Both children's CS frequencies (average number of Korean words per 100 words) show a big increase from the first year (sessions 1 to 22) to the second year (sessions 23 to 27) of data collection, which suggests that their English proficiency is decreasing. Although there are occasional fluctuations, measures in table 7.5 demonstrate their increasing use in Korean (CS frequency, turn frequency, and multi-word density) despite the decreasing MLUs.

In the early sessions, their CS pattern was rather simple. They usually inserted simple Korean words/phrases in English utterances like Sammy did, or they started a new clause in Korean (intersentential CS as in (6) below). However, after 10 months, the variety and complexity of CS increased. In the later sessions, they attached Korean particles (e.g., nominative $-i$ and inclusion - to ) to English NPs as in 
(7), (8), and (10). Rita even applied the English regular past tense -ed to a Korean noun banggu (gas) and converted it to a verb as in (9).

(6) Hera (session 5):

I'm going first so.. ok? So Rita can have.. umma, na mence hal-ke-ya.

Mom, I first do-Fut-Vocative (Mom, I'm going first.)

(7) Hera (session 24):

Dad promised me that he will take me to the cheese factory um, and um...

$$
\begin{aligned}
\text { cheese factory-to } & b o-k o, \text { um... } \\
\text {-Inclusion } & \text { see-Connective }
\end{aligned}
$$

(We'll also see the cheese factory and),

(8) Hera (session 27):

$$
\begin{array}{cc}
\text { 'shooted'- } i & \text { anila 'shot.' } \\
\text {-Nominative } & \text { Negation }
\end{array}
$$

(It is 'shot', not 'shooted.')

(9) Rita (session 16):

And did you know that my daddy banggu-ed every time?

$$
\text { gas-ed }
$$

(10) Rita (session 25):

$$
\begin{aligned}
& \text { Ilen kind of mouse-to issney. } \\
& \text { this -Inclusion there is } \\
& \text { (There is also this kind of mouse.) }
\end{aligned}
$$

While most of the CS involved embedding Korean in English clauses, the children occasionally embedded English in Korean clauses as well. Examples (8) and (10) from Hera and Rita, respectively, are the lone examples that demonstrate such cases. Hera produced (8) while she was listening to a story during the irregular past tense judgment task, and Rita uttered (10) when she was looking at the pictures for the 
relative clause comprehension task. Both examples exhibit English NPs inside clauses that conform to Korean word order. These examples appeared very late in the project, which suggests that their Korean proficiency was gaining strength at the time.

Increased use of Korean shown by the upsurge of CS frequency and gradual growth in density and turn frequency toward the end of the project could be simply indicating that Hera and Rita have become proficient in Korean. However, at the same time, their MLU drop in the second year compared to the first year of return to Korea suggests that their English is weakening. This in turn suggests that Hera and Rita's decreasing use of English accompanied with increasing Korean proficiency is a sign of English attrition. 


\section{Chapter 8 \\ PART I SUMMARY}

The first part of this dissertation (chapters 2 to 7) reported on several aspects of English attrition from the three participants (Sammy, Hera, and Rita) who returned to Korea from a two-year stay in the U.S. All three children were fluent English speakers when they began participating in the project at the time of their return to Korea, but the sisters, Hera and Rita, barely understood any Korean while Sammy was a proficient speaker of both Korean and English. This chapter provides a summary of the results.

\section{Participants' English proficiency}

All three children's use of English resembled that of young native English speakers in many ways. First, as noted in the chapter on passives (ch. 5), they produced more tokens of passives in the priming condition of the production task than in the nonpriming condition. The priming condition obviously elicited more passives than the non-priming condition from Hera (98 vs. 87 out of total 108 tokens) and Rita (79 vs. 61 out of total 108 tokens), while Sammy produced one more token in the priming condition (57 vs. 56 out of total 60 tokens). Meanwhile, their errors in the passive comprehension task were largely reversal mistakes, which involve treating the theme subject of a passive as the agent.

Second, the error analysis of the children's performance on the RC comprehension task was also instructive (ch. 6). They had the least problem with subject RCs, as their subject RC accuracy was usually higher than the scores of the other four types, direct object, indirect object, oblique, and object of comparison RCs. 
Most of their errors in those four types of RCs (which follow the word order $<$ NP rel NP V ...>) involved the children misinterpreting these RCs as if they were in the canonical English word order, <NP rel V NP...>.

It was also evident that all participants knew that English required overt subjects (ch. 7). Although this may seem natural, we have to note that Sammy started dropping subjects two months after his return to Korea. Since he was then already a proficient bilingual speaker, his growing Korean dominance seemed to trigger the transfer of the Korean setting of the null subject parameter.

The above behaviors from my three participants demonstrate that their English usage was quite similar to that of young native speakers (at least at the beginning of their participation). However, their use of irregular past tense verbs (ch. 4) is controversial. In many ways, their irregular past tense use reinforces their resemblance to English native speakers. First, like young native speakers, they performed better on the elicitation task than on the judgment task. Secondly, analysis of their naturalistic data showed a rate of overregularization and mis-irregularization errors strikingly similar to that of native English speaking children. Finally, all three children tended to make more errors with less frequently used irregular verbs than with more frequent verbs. While this evidence shows my participants' similarity to native English learners, one aspect of irregular past tense use from Sammy and Hera is different from that of the native speakers. Young native children and Rita tended to make more overregularization errors on non-addition class (verbs that do not require the final $d / t$ sound in the past tense like take-took, come-came) than on the final $d / t$ addition class (verbs that require final $d / t$ sound in the past tense like feel-felt, makemade). However, Sammy and Hera behaved exactly the opposite in both the judgment task and the elicitation task. 
Overall, it seems that the participants' behavior mostly resembled young native speakers' use of English, although Sammy and Hera diverged from the native behavior in one aspect. This is not surprising at all, considering their high English proficiency at the beginning of their participation. Still, each child's performance on various tasks revealed that Hera was the most proficient English speaker followed by Sammy and then Rita.

Hera performed well on every task from the beginning and generally maintained high accuracy throughout her participation. Sammy also showed proficiency in all tasks in the beginning except for the relative clause (RC) comprehension task and the picture-naming task eliciting articles. However, Rita did not perform well on the experiments. Although her accuracy on passives was quite high, she failed to perform well on the other experiments: irregular verbs, articles, and relative clauses. Rita's lack of accuracy on these tasks may not necessarily reflect her English proficiency. Rather, it may be due to her lack of metalinguistic skills, as evidenced by her high accuracy of irregular past tense use in her spontaneous data as opposed to her poor performance in irregular past tense experiments (judgment and elicitation tasks).

Thus although all children had lived in the U.S. for two years, individual English proficiency varied, perhaps due to factors such as age and environment. Hera, who was nearly five years old when she was first exposed to English in Hawai' 1 , was more proficient than Rita, who was only three at the time. Even though the sisters were in a similar environment (as they lived together), it is possible that age played a role in their different English proficiency.

Ostensibly, once English started dominating the sisters' lives, it became the dominant language even at home. The only time they heard Korean was when their 
mother spoke to them in Korean, and even then, the sisters mostly replied in English. However, Sammy reported that even after he started feeling more comfortable with English, he usually spoke Korean with his mother when they were living in Michigan. Thus, Sammy was more frequently exposed to Korean than the sisters, which could have affected the distinctive path of English development.

The environment that the three children were put in after their return to Korea is also different. Although their parents were invested in maintaining their children's English, their approaches differed. Sammy was mostly involved in formal lessons, as he had to study for exams in middle school, while Hera and Rita's parents focused on providing them more English input such as having a native English tutor visit their home and play with them. In addition, the amount of time that the three children used English differed. As for the sisters, about five hours of school was probably the only time they were in a Korean-dominant environment. The after-school institution that they attended for about half a year only recruited returnee children like them, and the use of Korean was prohibited. When they came back home, they spent time together speaking English under the supervision of a monolingual Korean babysitter until their parents came back home late. However, although Sammy's mother tried to speak English with him at home in Korea, Sammy spent most of his time with his friends at school and private institutions. Sammy reported that he usually did not use English with his friends except when they are forced to (e.g., in English class).

Such individual variation in the stage of English acquisition and in the environments they were put in after their return to Korea may have been the cause of the different path and rate of attrition. Now we turn our attention to the individual change of English proficiency observed during the data collection period: one year after Sammy's return to Korea and two years after Hera and Rita's. 


\section{Individual attrition: Sammy, Hera, and Rita}

\subsection{Sammy}

Sammy, the oldest participant, did not show much sign of attrition. Although there were occasional fluctuations, his performance was consistent in many tasks. However, his use of articles (only in the story-telling task) and null subjects declined in later sessions.

In the story-telling task, Sammy's correct use of $a$ steadily declined (86\% $76 \%-54 \%)$ while the incorrect use of the increased $(10 \%-22 \%-41 \%)$ to fill the gap in $a$-eliciting conditions. Additionally, in the-eliciting conditions, correct use of the increased $(44 \%-60 \%-67 \%)$ while the incorrect use of $a$ decreased $(43 \%-33 \%$ $-28 \%$ ). There seems to be a trend of the overuse, which leads Sammy to increasingly use definite articles in both correct and incorrect contexts. It should be noted that the overuse of the is a fairly well documented phenomenon in L2 English literature (e.g., Parrish 1987; Thomas 1989). In this sense, Sammy is gradually behaving like an L2 learner of English by substituting $a$ with the in $a$-eliciting contexts.

Sammy's use of null subjects in later sessions also demonstrates English deterioration. Although he never dropped subjects in his responses to the passive production and irregular past tense elicitation tasks in the first few testing sessions, once he started using null subjects about two months after his return to Korea, he consistently dropped English subjects. Such infelicitous use of English null subjects seems to have been influenced by Korean, which allows null subjects.

\subsection{Hera and Rita}

Among the sisters, the older, Hera, did not show any signs of English attrition in the experiments. However in her spontaneous speech data, her use of Korean gradually 
increased in the second year compared to the first year despite her decreasing MLU. Code switching frequency, turn frequency, and multi-word density all demonstrate her increased use of Korean in the English speech data.

The younger sister, Rita, presents a dramatically different picture, as she showed some signs of attrition in every aspect of English that was tested. First, as seen in chapter 3, although Rita never seemed to have acquired full mastery of English articles, she produced $a$ in the picture-naming task (especially in sessions 16 to 24) and the in the story-telling task fairly well in the appropriate contexts. However, while her correct use of the in the story-telling task was maintained, her correct use of $a$ dropped suddenly from 75 percent to 20 percent in the final three sessions.

Second, the rate of Rita's correct irregular past tense verb use in spontaneous speech declined in the final three sessions (ch. 4). Although it was difficult to gauge her irregular past tense competence with experiments because she was not able to perform well, her correct usage in natural speech mostly exceeded 80 percent. However, each of the scores in the final three sessions $(76 \%, 52 \%$, and $63 \%)$ is lower than that of any other prior 24 sessions.

Third, Rita showed a significant regression in the passive structure production experiment (ch. 5). She was a very prolific passive producer in the passive elicitation task. Out of the 34 errors she made, 16 were concentrated in the final three sessions. Then, 16 of the other 18 errors were the result of replacing by with another preposition like with or from. However, only four errors from the final three sessions are of this type. The other 12 errors in the final three sessions involve omitting the get verb or omitting by or the combination of the two. The first type of error (get omission) was once observed in an earlier session but the other two types (by omission and the combination of get and by omission) were unprecedented. 
Fourth, Rita started avoiding RCs in the RC production task (ch. 6). To begin with, she was not an active RC producer. I was able to elicit only $14 \mathrm{RCs}$ out of 56 attempts in the first seven sessions. However, in the final 20 sessions, she only produced one more RC (out of 160 attempts). Thus, it is difficult to know whether Rita could not produce RCs or simply avoided using them in later experiments. Still, this shows her early avoidance (or possibly attrition) of RCs.

Finally, Rita shows a trend similar to her older sister with regards to code switching (ch. 7). While her MLU dropped in the second year, use of Korean as evidenced by the growth of code switching frequency, turn frequency, and multi-word density increased. This suggests that her strengthening Korean is accompanied by weakening English.

Overall, Rita is the one who showed most English attrition among my participants. Her code switching and RC avoidance began relatively early. However, her poor performance on English articles, passive production, and irregular past tense use appeared in the final three sessions, which is approximately two years after her return to Korea. We have to note that Rita was in a very good environment for English maintenance in Korea. Although she was not surrounded by native English speakers, she usually spoke English with her older sister at home, where they spent most of the day. Also, she was either sent to a private institution that only accepted returnee children like her or had a native English tutor visit her twice a week. Still, signs of attrition were detected in several places.

\section{Course of attrition}

In the introduction chapter, I presented three major hypotheses accounting for the course of attrition: the regression hypothesis, the threshold hypothesis, and the 
interference hypothesis. Various data from my participants partially support the prediction of each hypothesis.

\subsection{Regression hypothesis}

The regression hypothesis, also referred to as first in, last out, suggests that the path of attrition is the mirror image of the path of acquisition. It is difficult to prove this hypothesis without data that can demonstrate the children's order of acquisition. Still, Rita's attrition data provide evidence to support the regression hypothesis. All of Rita's attrition involves production (elicitation tasks or spontaneous speech data) rather than comprehension. This is a mirror image of the path of acquisition since it is widely known that comprehension precedes production, not only in L1 acquisition but also in L2 and heritage language acquisition. Especially with passives and RCs, which tested both comprehension and production, attrition only appeared in her production while her understanding of passives and (subject) RCs remained high. Therefore, we can infer that the production skill is affected by attrition before comprehension. ${ }^{47}$

\subsection{Threshold hypothesis}

This hypothesis suggests that if a certain threshold of use is achieved for certain linguistic constructions/phenomena, they may be less vulnerable to attrition or even immune from loss. Although it is hard to compare the attrition rates of different constructions (e.g., RCs vs. passives) within a single speaker, the two sisters' different rate of attrition is relevant to this hypothesis. As mentioned earlier, of the three children, Hera was the most proficient English speaker and Rita the least. This suggests that Hera had achieved a high threshold of English when she started

\footnotetext{
47 Also note that Sammy showed signs of attrition only with regard to production: null subjects and article use in the picture-naming task.
} 
participating whereas Rita's threshold was lower than her sister's. After two years in Korea, Hera, who had reached a high threshold in the beginning, rarely showed signs of attrition. On the other hand, Rita's English deteriorated in several aspects. This demonstrates that the one with a lower threshold is more vulnerable to attrition.

\subsection{Interference hypothesis}

This hypothesis emphasizes the cross-linguistic influence of the competing language (Korean) in the new environment to account for loss in the attriting language (English). Sammy's overuse of null subjects supports this hypothesis. I have suggested that the emergence of null subjects in his English speech data is due to the increasing dominance of Korean, which allows null subjects (ch. 7). Since Sammy never stopped being a proficient Korean speaker even though he reported in the first testing session that he was more comfortable with English, it seems that Korean quickly became his more dominant language and thus, the Korean null subject parameter value was transferred to his English. 


\section{PART II.}

PICTURE-NAMING LATENCY 


\section{Chapter 9}

\section{THE HALA PROJECT}

\section{Introduction}

This chapter reports on children's performance of the Hawai' $i$ Assessment of Language Access (HALA) test, which assesses the relative strength of two or more languages in terms of picture-naming times. I administered the HALA test to two groups of Korean children: (1) children who had returned to Korea after a few years in an English-dominant country (the U.S., the U.K., and Canada), and (2) children who had moved from Korea to Hawai' $i$.

Naming times have been used to measure language strength in bilinguals in a number of studies over several decades. Ervin (1961) reports the use of picturenaming response time to evaluate English-Navaho and English-Italian bilinguals. Hernandez and Kohnert (1999) found response time to be a useful tool in studying two different age groups of English-Spanish bilingual adults engaged in languageswitching tasks. Another study that made use of language-switching tasks within a picture-naming framework was that of Costa and Santesteban (2004), who attempted to probe the mechanisms of lexical access by testing proficient bilinguals and L2 learners. Gollen et al. (2008) also used picture-naming times to probe the effects of frequency and age with English-Spanish bilinguals.

Reaction time is also frequently used in longitudinal or cross-sectional studies. Mägiste (1979) divided her Swedish-German bilingual participants into eight groups depending on their length of residence in Sweden. Based on different response times of the groups performing several tasks including picture naming, she estimates that it takes from four to six years to become a balanced bilingual under optimal conditions. 
Other studies such as Fozard et al. (1994) use both cross-sectional methods and longitudinal analyses to investigate the correlation between age and reaction time. Response time is also one of the measures used to study Alzheimer's disease in both cross-sectional and longitudinal analyses of patients. Strain et al. (1998) report the results of several tasks, including picture naming, to compare patients with Alzheimer's disease at different stages of the disease.

Most of these studies report that error rates and naming times correlate with factors such as proficiency (Ervin 1961; Mägiste 1979), word frequency (Gollan et al. 2008; Strain et al. 1998), and age (Hernandez and Kohnert 1999; Gollan et al. 2008; Fozard et al. 1994), all of which have the potential to affect the speed of word retrieval from the lexicon. In this study, however, the factors of primary interest are proficiency in the two languages involved (Korean and English) and word frequency level since they appear to be related to English attrition. As acknowledged in many studies, including O'Grady et al. (2009), infrequent language use lowers accessibility to the language in question, which in turn eventually leads to further language loss. This could be extrapolated to word use: we would expect that words used less frequently would be more vulnerable to attrition. The purpose of the HALA portion of my study was to observe the performance of children who were expected to experience changes in their language proficiency on a picture-naming task containing items of high and low frequency.

In general terms, then, the children who returned to Korea from Englishdominant countries (the returnee group) were expected to show increasing proficiency in Korean and decreasing proficiency in English. In contrast, the children who moved from Korea to Hawai' $i$ (the Hawai' $i$ group) were expected to lose proficiency in Korean while improving their English. The discussion in Gollan et al. of the effect of 
frequency on bilinguals who had different backgrounds in terms of such factors as age and language dominance suggests more specific predictions for this attrition study: (1) among the high-frequency items and low-frequency items used by the HALA test, low-frequency items are expected to be affected by attrition before the high-frequency items are, (2) the non-dominant language will probably be more vulnerable to attrition than the dominant language, and (3) children with a shorter stay in English-dominant environments are likely to experience English attrition sooner than children who stayed longer. As mentioned above, these predictions are based on the relationship between frequency of language use and language access. When infrequent use of the non-dominant language inevitably leads to delay in retrieving words from the lexicon, low-frequency words are likely to take even longer to be accessed than words that are used more often. ${ }^{48}$

\section{The HALA project}

The Hawai' $i$ Assessment of Language Access (HALA) project seeks to exploit the diagnostic potential of speech production latencies to develop a suite of simple tests that can be used to assess the relative strength of languages for bilingual speakers and communities. The HALA project focuses on a comparative measure - speed of access to words and structure-building operations in one language relative to the speaker's other language(s) (O'Grady et al. 2009). Thus, the comparison is not made between two different speakers; that is, a speaker responding faster than another speaker is not of central interest. Rather, a single speaker's reaction time to the pictures in two or more languages is the critical measure. For instance, if reaction time in Korean turns

\footnotetext{
${ }^{48}$ Unfortunately, these predictions will not be discussed further as this project was not able to detect any sign of attrition.
} 
out to be faster than in English, it indicates that Korean is the dominant language for that participant.

The HALA instrument consists of two picture-naming tasks, including bodypart naming and nature-term naming, and a phrase-building task. In each task, participants are presented with a series of pictures - simple scenes in the case of the two picture-naming tasks and contrasting sets of objects in the phrase-building task. Following a beep, the pictures are presented at a predetermined rate in a sequence that has been incorporated into a video file, which can be downloaded and played on either a PC or a Macintosh computer. Participants simply name or describe each picture as it appears on the screen before them. Their responses are digitally recorded for subsequent analysis of accuracy, and more importantly, of response times (O’Grady 2009). A detailed description of test items will be provided below in section 3.2 .

The results of recent work that has made use of the project have been encouraging. O'Grady et al. (2009) report a strong correlation between language strength and response times in 11 highly proficient bilingual speakers of English and Korean, who considered English to be their stronger language. The participants exhibited a very high level of accuracy in both languages with no statistical difference. However, body part naming times were significantly faster in English, which corresponded with the participants' self-report of English dominance. In a later study, Tang (2010) diagnosed the bilingual situation in Truku, where Mandarin Chinese is the dominant language over the endangered Truku language. Overall, all four different age groups demonstrated Mandarin dominance in terms of both accuracy and RTs, with Mandarin dominance decreasing as age increased. 
These studies mainly focus on reporting results from the body-part naming test. The idea of devising the body-part naming test was to focus on a semantic field with the following three properties (O'Grady et al. 2009). First, it includes items for which we can expect counterparts in all languages. As pointed out by Kohnert et al. (1998), one of the problems with previous picture-naming tasks used to measure bilinguals' proficiency is that the items depicted were "assumed to have equal frequency ... [when] lexical items do not always share the same lexical-semantic frequency cross-linguistically or cross-culturally" (p. 426). Second, at least some of the vocabulary items in question are basic enough to have been acquired by all users of the language at an early age. And third, because of their basic status, body-part terms can also be expected to be relatively resistant to replacement by loan words. As such, we can reasonably expect elicitation of those terms in the target language rather than items borrowed from a competitor language. For instance, the test item banana in the nature-term task is a borrowed word that does not have an equivalent in native Korean, and chicken, used in some of the phrase-building items, was elicited in the borrowed English form quite frequently over the Korean equivalent talk. No such problem arose in the body-part task. ${ }^{49}$

The above properties lead to each body-part picture eliciting only one correct answer in the target language (although synonyms like abdomen or belly for stomach were also produced) while some items in the nature-term naming and phrase-building tasks were more likely to elicit incorrect responses due to confusion in language choice. Therefore, only the results from the body-part naming task will be reported.

\footnotetext{
${ }^{49}$ As expected, the results of nature-term and phrase-building tasks lacked consistency. In particular, results of the phrase-building task contained too many fluctuations, being almost impossible to make any generalization.
} 


\section{Methods}

\subsection{Participants}

The participants in the HALA phase of experimentation, whose native language was Korean before they moved to an English-dominant environment, can be divided into two groups. The first group (the returnee group) consisted of 15 children (ages 5;6 to 12;5) who had returned to Korea from English-dominant countries four to 18 months before the first test session in December 2009. However, results from only 11 children (six females and five males) will be reported here. Two participants, who are brothers, were excluded because they were tested on the same version twice in one of the experimental sessions, and another two were excluded since they were tested only three times while the others participated in four sessions. The 11 children who are included in the analysis will be further divided into two subgroups based on their length of stay in English-dominant countries.

The second group (the Hawai' 1 group) consisted of five children (ages 5;11 to $12 ; 10)$ who came to Hawai' $i$ from Korea within nine months of their first sessions in October 2009. However, two children will be excluded from the analysis, which leaves only three children (one female and two males) from this group. One child was clearly more proficient in English than the others as she had lived in Englishdominant countries on several occasions for short periods of time, and another child participated in only three sessions while the others were tested five times.

Although the main interest of this project is loss of English by Korean returnee children (like those in the returnee group), this objective is made difficult by the lack of a true baseline group - that is, a group of children who were exposed to English in English-dominant environments and then returned to Korea and were no 
longer exposed to English. ${ }^{50}$ A true baseline group, if there was one, would provide a more accurate chronology and patterns of English attrition after discontinued use of English upon returning to Korea. In this regard, the study of the loss of Korean in the Hawai $i$ group is less problematic, as the parents did not worry about the decline in their children's use of Korean at home since one of the goals of their short stay (less than two years) in the U.S. was to improve their children's English. In fact, at least one couple regretted that they could not provide more English input since their English was not proficient enough for everyday use with their children at home. Thus, children in the Hawai' $i$ group received minimal Korean input while English dominated their lives in Hawai' $\mathrm{i}$.

\subsection{Materials}

The material used in this chapter is a revised version of the body-part naming task that was used in previous HALA studies. Originally, there were 43 body-part items divided into three strata. Based on item analysis and further investigation of the results from several pilot studies across a wide range of participants, 12 items were removed, which left 31 items divided into two strata: 17 items in stratum 1 and 14 items in stratum 2 (table 9.1). Stratum 1 comprises frequently used body parts, which are expected to be elicited more easily than the less frequently used items in stratum 2 .

\footnotetext{
50 When I was a returnee to Korea 25 years ago as a child entering elementary school, I had lost all my Korean and was able to speak only English after more than three years in the U.S. At that time, English was not as highly valued in Korean society as it is today. Thus, my parents' effort to retain my English was not as intense as those of today's parents with a returnee child. Even in school, my Korean incompetence was more a target of derision in the classroom than my English proficiency was an object of envy (as it definitely would be now). However, in today's Korean society, where English is a highly valued foreign language, it would be extremely difficult, if not impossible, to recruit children who could form a true baseline group given that the highly educated middle- to upper-class parents of the returnees typically invest a lot of time and effort to retain their children's English.
} 
TABLE 9.1. TEST ITEM BY STRATUM

\begin{tabular}{|cc|cc|}
\hline \multicolumn{2}{|c|}{ High frequency / stratum 1 } & \multicolumn{2}{c|}{ Low frequency / stratum 2 } \\
\hline back & leg & ankle & forehead \\
ear & lips & arm & heel \\
eye & mouth & cheek & neck \\
face & nose & chin & palm \\
fingers & shoulder & elbow & thumb \\
foot & stomach & eyebrow & toe \\
hand & teeth & fingernail & wrist \\
head & tongue & & \\
knee & & & \\
\hline
\end{tabular}

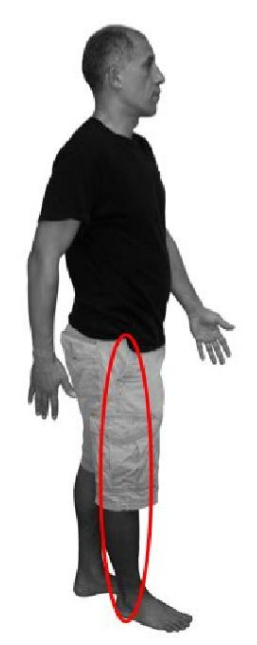

FIGURE 9.1. TEST ITEM FOR BODY-PART, “LEG”

Before the actual testing began, participants went through a practice session that consisted of six non-body-part objects such as book and cup. Next, they saw a blackand-white photo of a body part appear on a Samsung Sens Q-45 laptop screen. An example of a test item is provided in figure 9.1. The photo's appearance was synchronized with a short beep to attract participants' attention. While the photo remained on the screen, the participants' task was to respond by naming the redcircled body part as quickly as possible or by asking to skip. After a picture had remained on the screen for 4 seconds in stratum 1 and 4.5 seconds in stratum 2 , a 
picture of the next item appeared automatically, replacing the previous picture. The whole procedure was audio-recorded in a wav. file for later analysis of accuracy and RT; the recording was done with Audacity 1.2.6 and the embedded microphone on the lap-top. A Zoom H2 handy portable stereo recorder was also used as a backup.

\subsection{Design and procedure}

Participants were tested twice for each session at their homes, once in Korean and once in English, with at least three days between each test. There were two versions of the test: the sequence of pictures was shuffled for the second test in order to prevent participants from being affected by any memory of the first test. For both versions, though, all items in stratum 1 were presented before any item from stratum 2 appeared. Version 1 was always tested in Korean and version 2 in English. Half of the participants were tested on Korean (version 1) first and the others took the English test (version 2) first. When two siblings were tested (there were no more than two siblings participating from any family), each started with a different version of the test even though testing took place separately.

The returnee group was tested during four different sessions over an eightmonth span. They were first tested in December 2009. Session 2 was administered in March 2010, and session 3 in May-June 2010. Their final test was in August 2010. On the other hand, the Hawai' $i$ group was tested during five different sessions over a ten-month period: in October and December 2009, and in February, April, and August 2010.

Before each test session began, members of the returnee group were asked to rate their own language proficiency in both languages. ${ }^{51}$ They were presented with a

\footnotetext{
${ }^{51}$ Only the participants of the returnee group self-assessed their proficiency. The self-assessment section was not yet ready when the Hawai' $i$ group started participating.
} 
sheet of paper on which was written the question "How would you rate your Korean and English?" On two lines, each of which represented a continuum of proficiency in the two languages, with 'very poor' on the left end and 'very good' on the right end, the participants simply marked the place where they thought their proficiency level was best represented (figure 9.2). Placing the two lines horizontally one above the other provided participants with the chance to self-assess one of their languages in comparison to the other. The lines were exactly $100 \mathrm{~mm}$ long and the distance of each child's mark from the left end of the line was measured later. For example, if the marks of a participant were measured to be $87 \mathrm{~mm}$ for Korean and $75 \mathrm{~mm}$ for English, it shows that the child is more confident with Korean. Moreover, if the difference of measurement between two languages, $12 \mathrm{~mm}$ for instance, increased on the next session after three months to, say, $20 \mathrm{~mm}$, then it might suggest that the child's confidence in Korean is growing while English is falling. The results of selfassessment will be relevant in the discussion section.

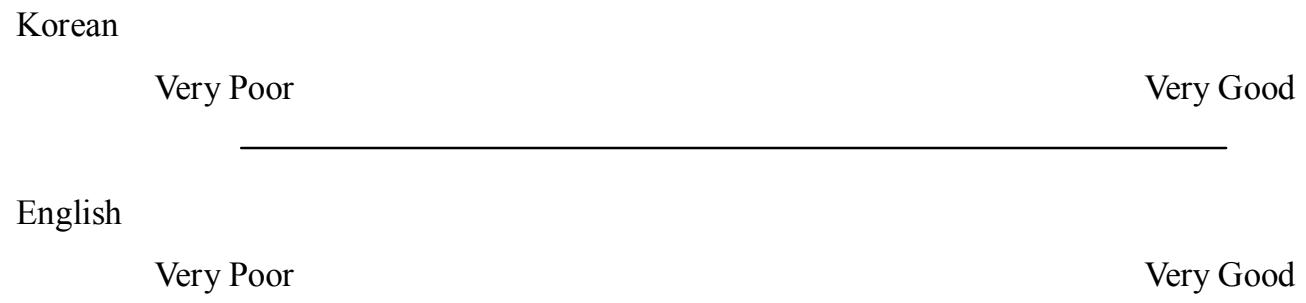

Very Good

FIGURE 9.2. PARTICIPANTS' SELF-ASSESSMENT SHEET

After the task, I gathered information about the participants' English use both from the children themselves and their parents. The information included their English use in school and private institutes, their language choice with friends and family members, the amount of time spent reading or watching English TV, movies, etc. Their background information and self-assessment were collected only once every 
session, not on every test day. In other words, the information was gathered four times with the returnee group and five times with the Hawai $i$ group. The questionnaire is attached in appendix $\mathrm{C}$.

\subsection{Coding data}

The recorded sound files were imported into Praat TextGrids to mark boundaries at the onset of the beep and the onset of children's response. The primary dependent measure for the HALA experiment is RT measured in milliseconds from the coincident onset of the picture/beep to the onset of the first relevant speech sound of the participant. Accuracy of picture naming is another dependent measure. The data was coded following the guidelines of Schafer (2010).

While it is clear where the onset of the beep is, determining the onset of a child's response can be tricky at times. Filler syllables or hesitation sounds such as "um," "uh," "er," as well as any non-linguistic sounds such as intake breaths or lip smacks were considered to be part of the interval before the speech response begins, and thus part of the naming time. However, items that included interruptions or distractions such as a cough, sneeze, or clearing of the throat were excluded from the RT analysis. In addition, if the speaker first provided one response, in whole or part, and then repaired to a correct response, such as "hand, no finger" or "ha-, finger" for "finger," the naming time was counted as invalid. Thus $3.5 \%$ and $1.5 \%$ of the accurate naming data from the returnee group and Hawai' $\mathrm{i}$ group, respectively, were excluded.

As for accuracy, clear and accurate responses that were produced within the given time ( 4 seconds in stratum 1 , and 4.5 seconds in stratum 2 ) were coded as correct. Examples of incorrect responses included failure to recognize the intended object, failure to access the correct term, phrasal descriptions, overly broad terms (e.g., 
face for nose), and no answers. However, correct responses that were excluded from the RT analysis because the response included an interruption, distraction, or repair were deemed correct for the accuracy analysis. Correct responses that were produced after the beep for the next item were coded 'correct' although their RTs were not measured.

\section{Results}

Some researchers require a certain threshold of accuracy from participants in order to include the results in the RT analysis; for example, all participants scoring lower than $60 \%$ might be excluded. However, I analyzed scores and RTs from all participants for the following reasons. First, I had only a small number of children for this longitudinal study. Second, the low accuracy, especially in stratum 2, is not surprising considering the age of some participants. And, of course, accuracy is an important dependent measure of this project. Lastly, the RTs of children with low accuracy did not diverge from those of other children with high scores. When children did not know the answer, they simply did not respond or they gave the incorrect answer while eagerly responding as fast as they could to familiar items.

\subsection{Returnee group results}

Eleven children were divided into two groups based on their length of stay in Englishdominant countries. Group 1 included two children who had lived in the U.S. for seven years and in the U.K. for three years, respectively. Group 2 consisted of the other nine children who had lived in the U.S. or Canada for 12 to 24 months. The two children in group 1 had not only lived longer in English-dominant countries but also returned to Korea more recently. While it had been only five months after their return 
when they started participating, most of the children in group 2 had already been in Korea for at least a year (table 9.2).

TABLE 9.2. RETURNEE GROUP PARTICIPANTS' BASELINE INFORMATION AT SESSION 1

\begin{tabular}{|c|c|c|c|c|c|}
\hline Group & $\begin{array}{l}\text { Participant } \\
\quad(\mathrm{Sex})\end{array}$ & Age & Place visited & $\begin{array}{l}\text { Length } \\
\text { of stay }\end{array}$ & $\begin{array}{l}\text { Months } \\
\text { after return }\end{array}$ \\
\hline \multirow{3}{*}{ G1 } & $A(F)$ & $10 ; 2$ & U.K. & $36 \mathrm{mon}$ & $4 \mathrm{mon}$ \\
\hline & $\mathrm{B}(\mathrm{M})$ & $9 ; 9$ & Virginia / Maryland & $84 \mathrm{mon}$ & $5 \mathrm{mon}$ \\
\hline & Average & 9;11 & & 5yrs & $5 m o n$ \\
\hline \multirow{10}{*}{ G2 } & $\mathrm{C}(\mathrm{F})$ & $7 ; 7$ & Boston, MA & $18 \mathrm{mon}$ & $5 \mathrm{mon}$ \\
\hline & $\mathrm{D}_{1}(\mathrm{~F})$ & $8 ; 3$ & Honolulu, HI & $24 \mathrm{mon}$ & $18 \mathrm{mon}$ \\
\hline & $\mathrm{D}_{2}(\mathrm{~F})$ & $6 ; 5$ & Honolulu, HI & $24 \mathrm{mon}$ & $18 \mathrm{mon}$ \\
\hline & $\mathrm{E}_{1}(\mathrm{M})$ & $10 ; 7$ & Ontario, Canada & $12 \mathrm{mon}$ & $12 \mathrm{mon}$ \\
\hline & $\mathrm{E}_{2}(\mathrm{M})$ & $8 ; 9$ & Ontario, Canada & $12 \mathrm{mon}$ & $12 \mathrm{mon}$ \\
\hline & $\mathrm{F}_{1}(\mathrm{M})$ & $10 ; 7$ & Toronto, Canada & $16 \mathrm{mon}$ & $12 \mathrm{mon}$ \\
\hline & $\mathrm{F}_{2}(\mathrm{~F})$ & $6 ; 6$ & Toronto, Canada & $16 \mathrm{mon}$ & $12 \mathrm{mon}$ \\
\hline & $\mathrm{H}_{1}(\mathrm{~F})$ & $12 ; 5$ & San Diego, CA & $14 \mathrm{mon}$ & $16 \mathrm{mon}$ \\
\hline & $\mathrm{H}_{2}(\mathrm{M})$ & $10 ; 3$ & San Diego, CA & $14 \mathrm{mon}$ & $16 \mathrm{mon}$ \\
\hline & Average & 9;0 & & 17 mon & $13 m o n$ \\
\hline
\end{tabular}

*Participants with the same initials but a different subscripted number are siblings.

Table 9.2 shows that the average age of group 2 is about one year younger than that of group 1. However, group 1 participants had stayed at least a year longer in Englishdominant environments than group 2 participants, which indicates that in general, the children in group 1 were exposed to English earlier than most of the children in the other group. Also, the number of months since their return was shorter for group 1 
participants than group 2 participants. Thus, we would expect participants in group 1 to be more proficient in English.

\subsubsection{Returnee group accuracy}

Not surprisingly, accuracy in stratum 1 (high-frequency items) was always higher than in stratum 2 (low-frequency items) in both Korean and English for both groups. However, the language strength displayed in the two strata varied across the groups.

Group 1 showed higher accuracy for English in both strata in all four sessions, which indicates that the stronger language of this group is English (figure 9.3). Generally, accuracy in both strata and language seems to be on a rise. Although increasing accuracy in Korean was anticipated, a rise in English accuracy is unexpected, considering that these children are in Korea. The increasing score for English is more surprising in stratum 2 than in stratum 1 because it seems that children are simply staying at ceiling in stratum 1.
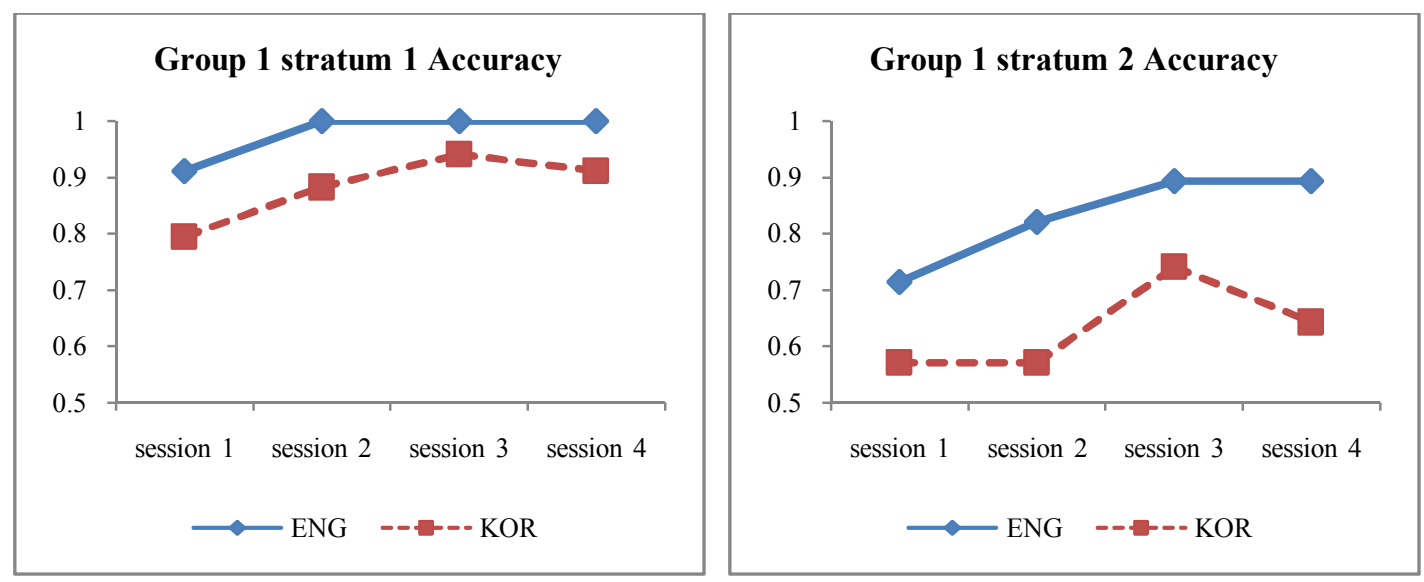

FIGURE 9.3. ACCURACY OF RETURNEE GROUP 1

In contrast to group 1, group 2 scored higher in Korean than in English in both strata across the sessions, which suggests that Korean is the more dominant language (figure 
9.4). In general, the scores across sessions in each language seem to be stable. Again, accuracy failed to show any signs of English deterioration.
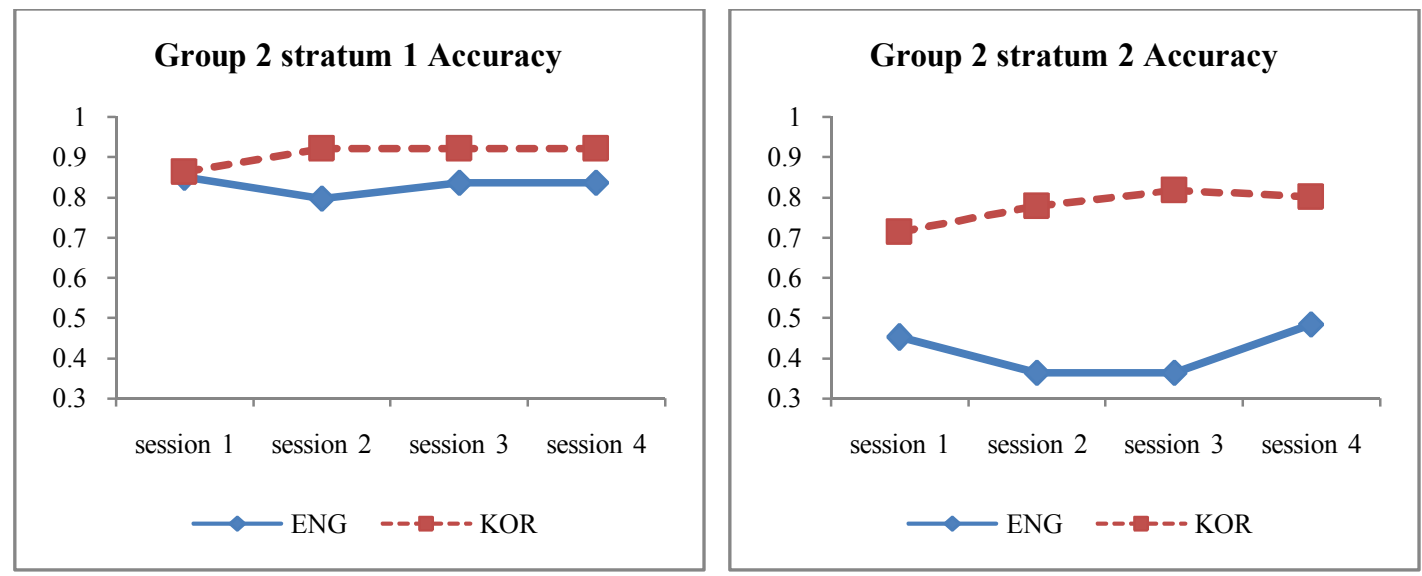

FIGURE 9.4. ACCURACY OF RETURNEE GROUP 2

To sum up, it was predicted that group 1 would be more proficient in English since they had been in Korea for a shorter time and had stayed longer in English-dominant countries (which also suggests that they were exposed to English earlier) than group 2. The accuracy scores of group 1 in both strata suggest that children in this group have a better command of body-part words in English than in Korean. The scores for participants in group 2 show the reverse trend; Korean is their dominant language. These results are exactly in line with the expectation. However, no sign of English attrition was detected in either group.

\subsubsection{Returnee group response time}

Just as participants scored better on stratum 1 items than stratum 2 items, RT was always faster with high-frequency words in stratum 1 than with low-frequency words in stratum 2 in both languages of both groups. However, in general, the analysis of 
RTs did not reveal as much about each group's language dominance as did the analysis of accuracy.

As for group 1, it is difficult to tell in which language the children respond faster as the RTs in the two languages are quite similar in many sessions (figure 9.5). Korean RTs are consistent in both strata although they slightly speeded up in session 3. Interestingly, the English RTs seem to become faster in the later sessions. This is contrary to expectation, as English RTs are expected to slow down as the children spend more time in Korea. In the final session, especially of stratum 2, they responded faster in English, which suggests that they may still be English dominant.
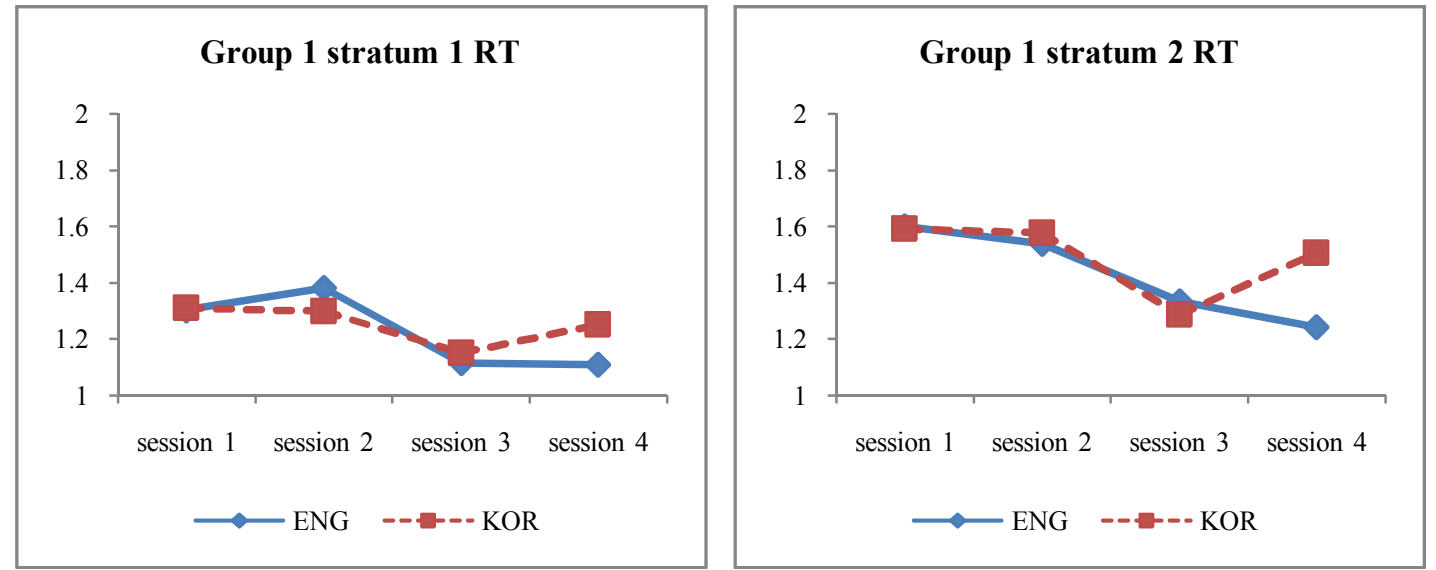

FIGURE 9.5. RT OF RETURNEE GROUP 1
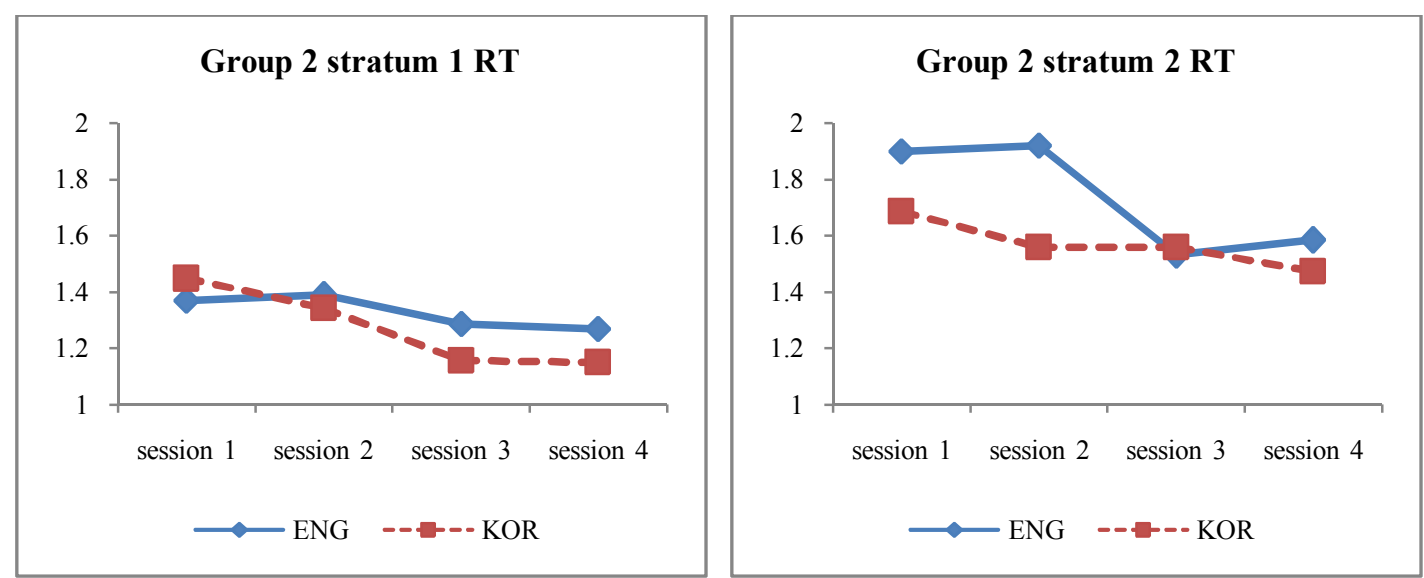

FIGURE 9.6. RT OF RETURNEE GROUP 2 
In group 2, Korean RTs were generally slightly faster than English RTs in both strata (figure 9.6), which is expected as this group is arguably Korean dominant. RTs for both languages are quite consistent across sessions, except that English RTs became faster in sessions 3 and 4 for stratum 2. This runs against what would be expected if there was attrition in vocabulary access.

In summary, while Korean RTs of both groups remained consistent across strata and sessions, both groups' English RTs in later sessions tended to speed up. Although RTs in session 4 suggest that English might be the stronger language for group 1, the RT data do not point toward a dominant language for that group. In contrast, Korean seems to be the dominant language of group 2 as they generally respond faster in Korean. As with the accuracy data, however, RTs do not demonstrate any sign of English attrition.

\subsection{Hawai'i group results}

TABLE 9.3. HAWAI'I GROUP PARTICIPANTS’ BASELINE INFORMATION AT SESSION 1

\begin{tabular}{|c|c|c|}
\hline Participant (Sex) & Age & Length of Stay (in English-dominant environment) \\
\hline $\mathrm{I}_{1}(\mathrm{M})$ & $8 ; 1$ & 3 months \\
\hline $\mathrm{I}_{2}(\mathrm{~F})$ & $5 ; 10$ & 3 months \\
\hline $\mathrm{J}(\mathrm{M})$ & $7 ; 6$ & $\begin{array}{c}\text { 9 months (not including 3 months after birth and } \\
2 \text { months of English camp) }\end{array}$ \\
\hline Average & $\mathbf{7 ; 2}$ & $\mathbf{5}$ months \\
\hline
\end{tabular}

All three children in the Hawai' $i$ group, who had moved to Honolulu from Korea, were first tested in October 2009. By that time, the two children who are siblings had been in Hawai ${ }^{i}$ for three months; it was their first time living outside Korea. The third child was born in Canada but returned to Korea only three months after his birth. Although he attended an English camp in Canada for a couple of months in 2006 when he was four years old, his parents reported that he never became proficient 
enough to communicate in English prior to coming to Hawai' i. He had been in Hawai' $\mathrm{i}$ for nine months when the first testing session took place. Table 9.3 summarizes the participants' basic information. Participants $\mathrm{I}_{1}$ and $\mathrm{I}_{2}$ are siblings.

\subsubsection{Hawai'i group accuracy}

As expected, the children's accuracy in stratum 1 for both languages was always higher than in stratum 2 (figure 9.7). Participants in this group scored higher in Korean in both strata and in every session. In general, the Korean accuracy remained stable while English accuracy consistently rose. This indicates that while the dominant language of this group is still Korean, English proficiency is gradually increasing.
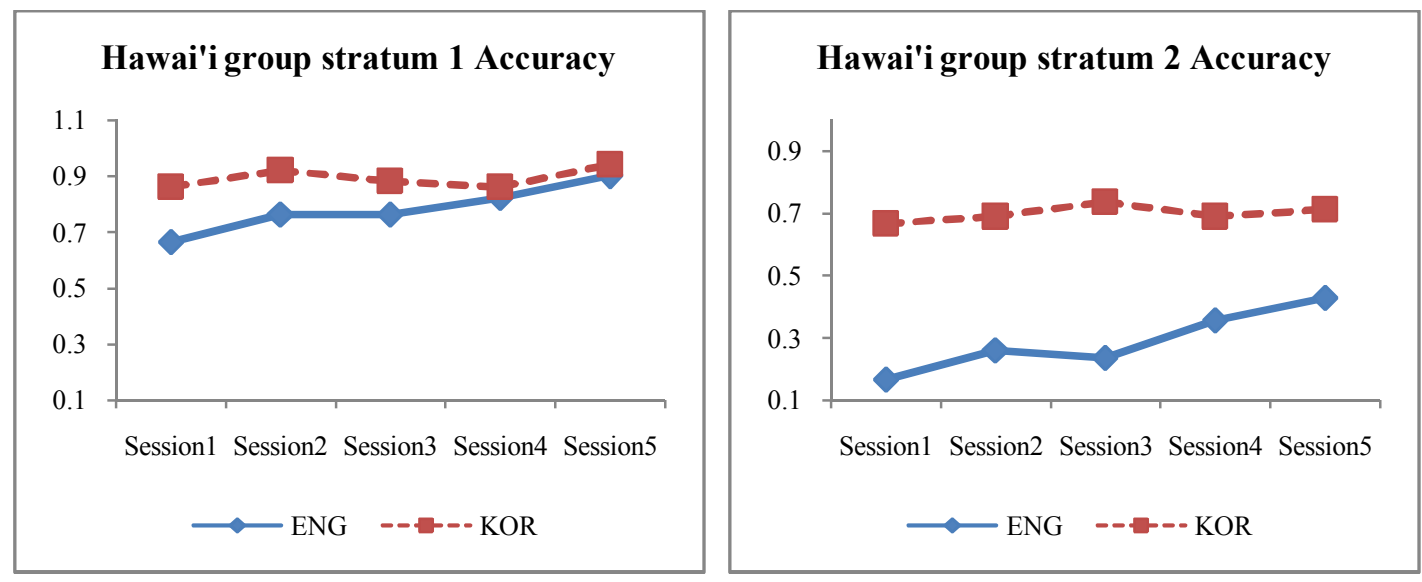

FIGURE 9.7. ACCURACY OF HAWAI'I GROUP

\subsubsection{Hawai'i group response time}

RTs for both languages were always faster in stratum 1 than in stratum 2 (figure 9.8). Korean RTs remained stable in both strata. English RT in stratum 1 was also quite consistent, but speeded up in the last two sessions of stratum 2. In most cases, children responded faster in Korean than English but the trend was reversed in those two sessions of stratum 2. This indicates that the children's English proficiency 
gradually increased and reached a point where they were able to access body-part terms in English as quickly as in Korean.
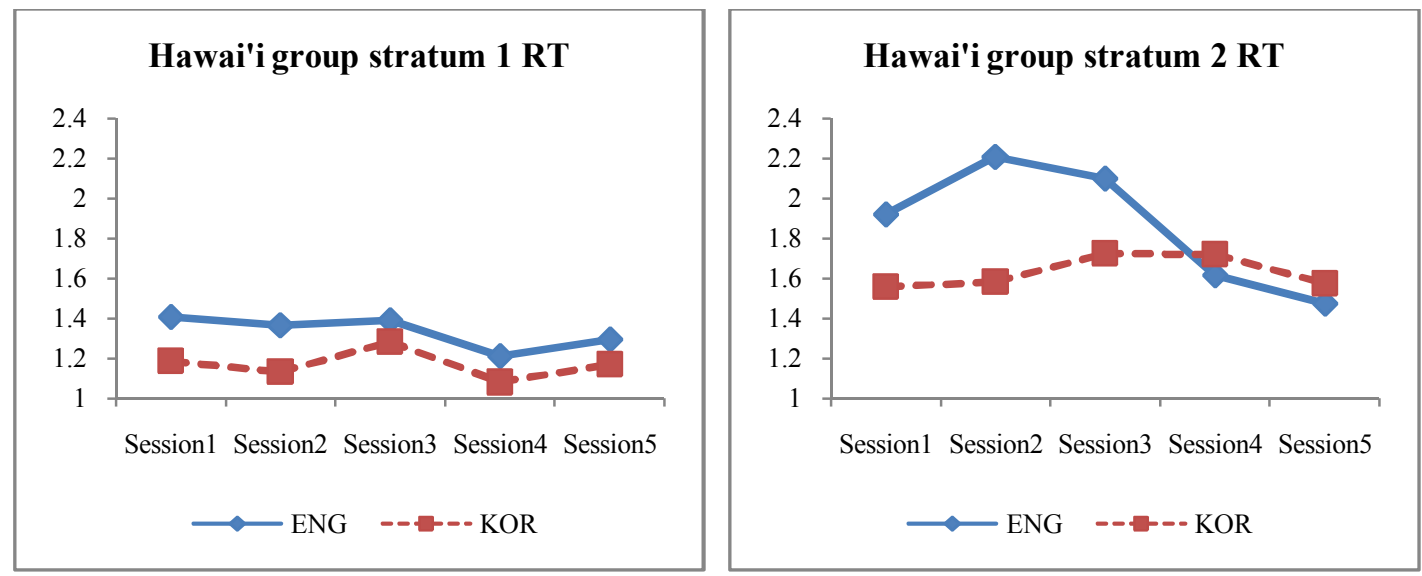

FIGURE 9.8. RT OF HAWAI' I GROUP

\section{Discussion}

Eleven returnee children (the returnee group) and three other children who had moved to Hawai' $i$ from Korea (the Hawai' $i$ group) were tested on the HALA project for approximately a year. The returnee group was further divided into two subgroups based on their length of stay in English-dominant countries. Returnee group 1 had stayed longer in an English-dominant environment than returnee group 2. The returnee group was expected to show English attrition (falling accuracy and slowing RT in English) and increasing Korean proficiency (rising accuracy and faster RT in Korean), while the Hawai' $\mathrm{i}$ group was expected to demonstrate the opposite trend, Korean attrition and increasing English proficiency.

In the case of the Hawai' $i$ group, both the accuracy and RTs for Korean remained stable in both strata: this was not surprising, as a dramatic change in the children's native language use within a year is probably hard to expect. However, their English accuracy steadily increased in both strata (figure 9.7) although it never 
exceeded their Korean accuracy. In addition, their English RTs decreased in the final two sessions (figure 9.8): in both strata, RTs in session 4 were faster than RTs in session 3, which might suggest that there was a "growth spurt" in English proficiency around that period. In fact, in the final two sessions of stratum 2, English RTs were slightly faster than Korean RTs. Thus, at the beginning of the project, all indicators pointed toward Korean dominance: higher accuracy and faster RTs. By sessions 4 and 5, the gap between the two languages had narrowed, as stratum 1 accuracy and stratum 2 RTs show. Had the children stayed longer in Hawai' $i$ rather than returning to Korea at the end of the project, further evaluation might well have shown a shift in language strength. For instance, with gradual English dominance over Korean, we might expect English RTs to keep speeding up and Korean RTs to remain consistent or even slow down, especially in stratum 2 as illustrated in figure 9.9.

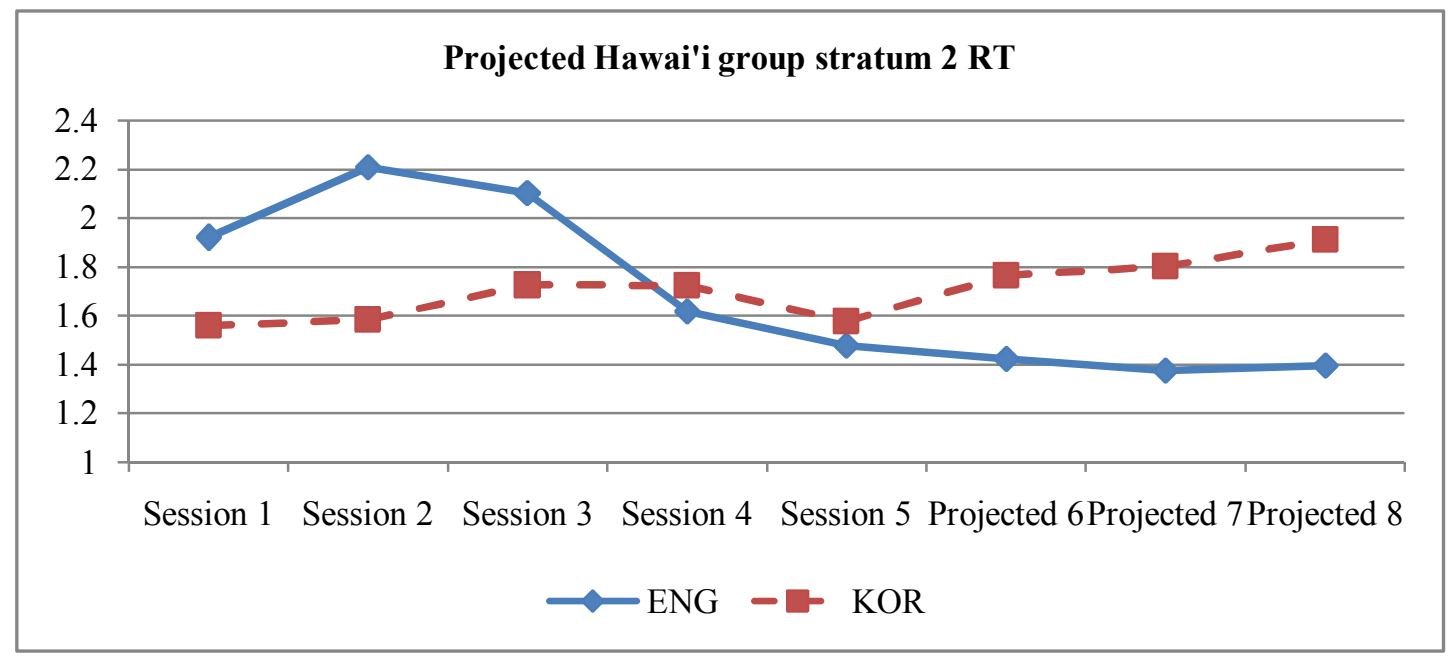

Figure 9.9. PROJECTED RTS OF HAWAI' I GROUP STRATUM 2

This possibly calls for further research as a similar trend demonstrated in figure 9.9 was observed in Mägiste (1979). Mägiste’s cross-sectional study of 163 originally German dominant students living in Sweden suggests that it takes around four to six 
years for the RT of the dominant language of the society (Swedish) to catch up with that of the mother tongue (German). Although it might not take as long as four to six years for the Korean-English bilinguals to shift language dominance because the dominant (attriting) language of Mägiste's participants was also the dominant language in the classroom, the need for longer observation is evident.

The result for the Hawai' $i$ group is important not only because the children manifest changes in the children's linguistic performance but also because it suggests that the repetition of the same test over five sessions within 10 months did not affect the results. Although the children were repeatedly tested with the same materials in a relatively short period of time, they did not perform better due to their presumably increasing familiarity with the test items. If they had, their performance in both languages should have risen. However, their Korean performance was consistent while they showed increasing English proficiency. The absence of a testing effect allows us to infer that language proficiency is the only factor affecting their performance and makes the interpretation of the returnee group data more interesting. Returnee group 1 demonstrated English dominance while returnee group 2 had a stronger proficiency in Korean. This is in line with expectation as group 1 had stayed longer in English-dominant countries and returned to Korea more recently. However, what was unexpected is the fact that both groups' English proficiency seemed to be rising.

This might be accounted for in two ways. First, perhaps more time is needed in order to observe signs of attrition. Children in group 1 had been in Korea for slightly over a year and most of group 2 had been there for around two years by the time this projected ended. Their English performance might show a decline in later 
sessions of data collection. Thus it may well be the case that a longer period of data collection is necessary in order to find out the starting point of attrition.

Second, the children's English could have been maintained due to the ongoing input they receive due to their parents' dedication and effort to maintain or even further develop their English. Children in the returnee group were benefiting from at least three hours of English at school and approximately six hours of afterschool English activities each week. In addition, most children reported that they watch DVDs and read books in English.

Moreover, both children in group 1 reported that they spoke English with their siblings (who were too old or too young to participate in the project) because they felt more comfortable with English. Even in group 2, $\mathrm{D}_{1}$ and $\mathrm{D}_{2}$, who are siblings, chose mostly English as their means of communication, and the mother of participant C reported that she spoke English with her daughter at home in order to provide her with more opportunities to use English.

The children's self-assessment of their proficiency in the two languages (see section 3.3 above) may also partly support the results (table 9.4). Two children (A and B) from returnee group 1 reported consistently increasing confidence with English. This increasing confidence may be reflected in the consistently increasing accuracy (figure 9.3) and decreasing RTs (figure 9.5). However, I must stress again that the participants only assessed the relative strength of their English and Korean at each session, not the relative strength of each language compared to the previous sessions. For example, in session 3, they compared only their proficiency of English and Korean at the moment, not the relative strength of each language compared to their self-assessment in sessions 1 and 2. Therefore, the scores of self-assessment should be treated only as an extra reference to the children's proficiency in the two languages. 
TABLE 9.4. RETURNEE GROUP'S SELF-ASSESSMENT OF LANGUAGE PROFICIENCY

\begin{tabular}{|c|c|c|c|c|c|c|c|}
\hline Group & Participant & Language & Session 1 & Session 2 & Session 3 & Session4 & Average \\
\hline \multirow{4}{*}{ G1 } & \multirow{2}{*}{ A } & Eng & 81 & 87 & 89 & 89 & 86.5 \\
\hline & & Kor & 79 & 78 & 72 & 86 & 78.75 \\
\hline & \multirow{2}{*}{ B } & Eng & 56 & 86 & 77 & 62 & 70.25 \\
\hline & & Kor & 35 & 73 & 75 & 64 & 61.75 \\
\hline \multirow{18}{*}{ G2 } & \multirow{2}{*}{$\mathrm{C}$} & Eng & 69 & 91 & 91 & 95 & 86.5 \\
\hline & & Kor & 46 & 87 & 85 & 100 & 79.5 \\
\hline & \multirow{2}{*}{$\mathrm{D}_{1}$} & Eng & 68 & 60 & 68 & 64 & 65 \\
\hline & & Kor & 68 & 76 & 72 & 65 & 70.25 \\
\hline & \multirow{2}{*}{$\mathrm{D}_{2}$} & Eng & 80 & 51 & 64 & 68 & 65.75 \\
\hline & & Kor & 60 & 51 & 68 & 76 & 63.75 \\
\hline & \multirow{2}{*}{$\mathrm{E}_{1}$} & Eng & 83 & 78 & 70 & 65 & 74 \\
\hline & & Kor & 100 & 90 & 100 & 85 & 93.75 \\
\hline & \multirow{2}{*}{$\mathrm{E}_{2}$} & Eng & 91 & 89 & 87 & 85 & 88 \\
\hline & & Kor & 100 & 99 & 100 & 92 & 97.75 \\
\hline & \multirow{2}{*}{$\mathrm{F}_{1}$} & Eng & 55 & 54 & 45 & 61 & 53.75 \\
\hline & & Kor & 60 & 86 & 84 & 68 & 74.5 \\
\hline & \multirow{2}{*}{$\mathrm{F}_{2}$} & Eng & 32 & 33 & 59 & 39 & 40.75 \\
\hline & & Kor & 51 & 33 & 67 & 61 & 53 \\
\hline & \multirow{2}{*}{$\mathrm{H}_{1}$} & Eng & 63 & 67 & 68 & 61 & 64.75 \\
\hline & & Kor & 77 & 82 & 86 & 91 & 84 \\
\hline & \multirow{2}{*}{$\mathrm{H}_{2}$} & Eng & 49 & 32 & 46 & 57 & 46 \\
\hline & & Kor & 55 & 34 & 50 & 82 & 55.25 \\
\hline
\end{tabular}

*Numerals for the self-assessed stronger language is bold-faced.

In conclusion, this project was not able to identify any signs of English attrition in the returnee group or of Korean attrition in the Hawai' $i$ group. Still, the findings from these two groups are useful. For example, we know from studying the Hawai' $i$ group that even without deliberate effort to maintain Korean, one year in an Englishdominant environment did not corrupt their Korean proficiency: the parents still spoke to them in Korean at home as the parents were not proficient enough in English to converse with the children in English. This suggests the need for a longer study of language attrition, at least with regards to naming latency. In addition, the Hawai' $\mathrm{i}$ group demonstrated the absence of a testing effect due to the repetition of the same 
tests. For its part, the returnee group showed that it is possible to maintain their English proficiency even two years after returning to Korea. This too suggests the need for a long-term study to detect the starting point for attrition when the attriting language (English) is highly valued in the home society (Korea), as input will be provided in an effort to maintain the potentially attriting language. It thus seems that the dedication and hard work from the returnee children's parents are worth the investment. 


\section{CHPATER 10 \\ CONCLUDING REMARKS}

My interest in language attrition is deeply rooted in my childhood. I was a returnee myself and had lost all my Korean (first attrition) and become a monolingual English speaker by the time I returned to Korea and entered elementary school after three years of stay in the U.S. I recall then quickly becoming Korean dominant by second grade (second attrition) and when I revisited the U.S. in fifth grade my English proficiency was so low that I was recommended to attend a language class before joining the normal curriculum.

Throughout this dissertation I have been intent on describing the English attrition process in Korean-English bilingual children who had moved to Korea from English-dominant countries. The first part of the dissertation (chapters 2 to 8 ) reported the results of a longitudinal study of three returnee children. While Hera did not show signs of English attrition within two years of her return to Korea, Rita's English proficiency seemed to deteriorate in several aspects. Sammy was observed only for a year because he returned to Michigan after a year in Korea. In most of the experiments, he did not show English attrition, but his increased use of null subjects in English seemed to have been influenced by his growing Korean usage. The second part of this dissertation (chapter 9) reports on a body-part naming task that was administered four times, at approximately three-month intervals to 11 returnee children. The result did not show signs of English attrition.

If I were able to observe the child that I was more than 25 years ago, I am sure that two years of research would be packed with signs of obvious English attrition. However, Korean society has changed, and English currently occupies an 
even more prestigious status than a quarter century ago. While there was virtually no effort to maintain my English when I was young, all participants in my project were provided with constant English input in various ways. This creates a situation that is far from ideal for attrition research. A perfect example of an attrition research participant would be a child of a missionary who had become a proficient Tagalog speaker after living in the Philippines for several years. It would be extremely difficult to find another speaker or a chance to engage in a Tagalog conversation, or a motivation to invest in Tagalog maintenance after she returns to Korea. Under these circumstances, we could expect a fairly rapid rate of Tagalog loss due to discontinued use.

However, there were a couple of factors that impeded English attrition of my participants. First, the parents' (and/or the society's) attitude toward English led them to invest money and time in maintaining and even in further developing their children's English proficiency. This is perhaps the most important factor that can account for the children's delayed English attrition. Second, these children, especially Hera and Rita, were in consistent contact with English speakers and their everyday means of communication was mostly English. These two factors are illustrated in the following comparison of my childhood and my participants' situation.

I returned to Korea around the same age as Hera as we both entered elementary school shortly after our return. However, the value of English in the two cases clearly cannot be the same. Except with my parents, I had no one to speak English with. My baby sister had just been born and was barely babbling, and I did not have any English-speaking friends in Korea. And even my parents were focused on teaching me Korean for my quick assimilation back into Korean society. However, Hera spent most of her time with her younger sister, Rita, who was also much more 
comfortable with English than Korean. Also, thanks to the friends she met at a private institution for returnees and visitors to her home like me and English tutors, she must have considered English as a quite valuable language. Then, this serves as an additional internal motivation for the children to continue using English.

\section{Methodological issues}

\subsection{Part I case studies: loss of English morphology and syntax}

One of the bright sides of the results from my longitudinal research of three children is that although they occasionally expressed familiarity with the test material (as it was repeatedly recycled), Rita still showed some signs of attrition in later sessions. Therefore, collecting data at different points of time using the same material seems to be an effective measure of attrition research because a direct comparison of children's performance is possible despite their prior experience with the test items.

Still, there are ways to build better testing materials. For example, choosing the more effective test items by getting rid of the ones with potential confounding factors (e.g., a possible priming effect in the irregular past tense verb elicitation task in chapter 4) will result in smaller but more efficient test sets. Articles, passives, and RCs were tested using five sets while irregular past tense verbs had nine. But if the testing materials on all grammatical phenomena can be reduced to, for example, three sets, then adjustments on the testing schedule can also be made with the reduced number of test sets.

For this pioneering longitudinal study, I completed one round of tests every two weeks due to the lack of literature suggesting the starting point of attrition. A potential problem for such frequent data collection is that children may tend to not take the tasks seriously at some point, as exemplified by Hera's toying with the RC 
and passive comprehension tasks in sessions 11 to 20 , probably due to getting bored with the habitually repeated procedure. Now that it seems clear from the results that Korean-English bilinguals' English attrition is not likely to occur within a short period of return to Korea, continuously collecting data every two weeks without a break might not be the most ideal testing procedure. As mentioned above, if the most effective items can be reassembled into three sets, children can have a few months' break after they complete a cycle of three sets in approximately a month. For instance, the participants can be tested two or three times a year (once every four to six months) using the same three sets in the first years of their return. Then, if signs of attrition are detected (as in Rita's case after two years), the experimenter can shorten the term between the tests and collect data more frequently for a more sensitive measure of attrition.

A possible weakness of the methodology I used is that it may not be sensitive enough to detect the earliest sign of attrition. Hera, who was the most proficient English speaker of the three children, did not show any attrition, at least in terms of her performance on the experiments (articles, irregular past tense verbs, passives, and RCs). However, other measures such as speech rate could reveal otherwise. Kagan and Friedman (2003) suggest that speech rate, calculated in words per minute, serves as one of the indicators of spoken proficiency of heritage speakers of Russian. Although I did not apply the oral proficiency interview (OPI) used by Kagan and Friedman, I investigated parts of Hera's story-telling task, one of the article experiments (ch. 3), which took about five minutes in each session. ${ }^{52}$ Her speech from sessions 6 to 7, 21 to 22, and 26 to 27 was analyzed because sessions 6,21 , and

\footnotetext{
52 Since Hera's description of the stories was in a conversation format with me, I excluded my part of the interaction in order to measure her speech rate. On the other hand, speech rate in Kagan and Friedman (2003) was measured from the heritage speakers' solo narration responding to questions that asked for their opinion.
} 
26 , and sessions 7, 22, 27 respectively used the same stories. Also, the three groups of sessions (sessions 6 to 7, 21 to 22, and 26 to 27) roughly represent the beginning, one year, and two year marks from their return to Korea.

TABLE 10.1. HERA'S SPEECH RATE AND USE OF FILLERS IN THE STORY-TELLING TASK

\begin{tabular}{|c|c|c|c|}
\hline Sessions & Months after Return & Speech Rate & Filler Frequency \\
\hline $6 \sim 7$ & 4 months & 131.12 words/min & 1 every 15.67 words \\
\hline $21 \sim 22$ & 13 months & 124.83 words/min & 1 every 6.55 words \\
\hline $26 \sim 27$ & 25 months & 102.34 words/min & 1 every 9.00 words \\
\hline
\end{tabular}

Table 10.1 shows that there is not a big difference in Hera's speech rate between sessions 6 to 7 and 21 to 22 . Thus, it seems that her speech rate was stable in the first year of her return. However, after two years in Korea, her speech rate in sessions 26 to 27 decreased. Although this analysis is based on a small sample, it suggests that her speech rate slowed down in the second year. Moreover, her use of fillers such as 'uh' or 'eh' demonstrates an interesting picture. In the beginning of this project, she paused and used a filler approximately every 16 words. However, by the end of the first year, her use of fillers increased to one per seven words, and remained that way (one per nine words at the end of the second year). Considering that she was describing the exact same pictures at different times, the result shows that she started using more fillers by the end of the first year, possibly demonstrating her processing burden. In future research, it could be fruitful to analyze a step further and distinguish between pauses (or use of fillers) that occur at mid-clause and those that occur at the end of clauses, as prior research (e.g., Skehan 2009) suggests that the pause location may be an important measure of fluency. Although both native speakers and non-native speakers pause during speech production, native speakers clearly pause less midclause, whereas this is the more frequent pause location for non-natives. 
In summary, although attrition in the experimental settings was not observed in Hera within two years, a glimpse at her speech rate and filler frequency signals a change in her English proficiency. This suggests that the earliest signs of attrition do not involve the attriters' linguistic competence (such as knowledge of grammar) or comprehension but rather their general processing skills in production such as speech rate. Thus, the experiments, targeted to examine a few aspects of English grammar, are likely to produce meaningful results only after attrition is detected in their speech. However, not all levels of performance are influenced to the same degree. As shown in the HALA body-part naming task, participants' ability to produce single vocabulary items did not seem to deteriorate in terms of accuracy and response time within two years.

\subsection{Part II picture-naming latency}

Just as with the grammar tests in part I, participants' familiarity with the HALA test in part II due to repeated testing did not affect their performance. Also, since the bodypart items were already reduced to the current version based on item analysis from earlier studies, there was no noticeable problem with the test items.

The most obvious problem with the methodology in part II seemed to be the short testing period. All groups that participated in the HALA project were tested for less than a year, which seems not to be enough time to observe attrition of the nondominant language of the society that is still valuable (English in Korea and Korean in Hawai'i). Thus, with a more extended period of testing and more participants manifesting differences in age and length of stay in English-dominant environment, assessment of participants' change in their language accessibility will be possible. 


\section{Pedagogical implications}

The scope of attrition research is much wider than mere descriptions of the phenomenon, which is what this dissertation originally aimed at. From the researcher's point of view, issues such as theory and methodology of attrition can be interesting and important. However, from the attriters' as well as their parents' viewpoint, application of the findings, that is, pedagogies customized for the returnees that may be different from those used for L2 learners, could well be the most meaningful contribution of attrition research. Without a doubt, the first step for researchers is to describe the attrition phenomenon and establish related theories. Then, based on these foundations, pedagogies that will benefit those trying hard to evade attrition can be developed.

In fact, the same pedagogy used for L2 learning seems to be effective at times. For example, Sammy's ability to understand various types of RCs improved as a result of an explicit lesson that he received with his L2-English learning friends in the classroom. Constantly exposing children to English in Korea also seems to be a good way to maintain their English or delay attrition as evidenced by Hera and the HALA participants' results.

However, bilingual children's proficiency in the non-dominant language of the society will eventually decline, as shown by Rita's case. If we know what to expect when attrition strikes, we could respond accordingly, depending on the symptoms. For example, Rita's ability to build the passive structure collapsed two years after her return to Korea. She omitted the auxiliary get (be) as well as agentive by (e.g., She __ bited uh, _ the blue fish when she meant "She got bitten by the blue fish"), which was never observed in the earlier errors. Since she still seems to know that the agent is demoted to an oblique while the theme is promoted to the 
subject in passives, we can focus on reviving the auxiliary and by for the agent of long passives.

Currently in Korea, there seems to be an increasing demand and interest in English maintenance, as the returnee education institute that Hera and Rita attended for a few months is attracting many returnees. However, there is a lack of pedagogy specifically targeting potential English attriters. Even the institute only offers a curriculum based on the U.S. education system. Such education could in fact be effective for quite a while, but cannot stop Korean from eventually becoming the returnees' dominant language and leading to English attrition. At this point, the only option is the kind of pedagogy used for Korean L2 learners of English. However, since the needs of English attriters are clearly different from those of L2 learners of English, attrition research should ultimately contribute to the development of appropriate teaching methods for the attriters. ${ }^{53}$

\section{Closing remarks}

As mentioned earlier, the original goal of this dissertation was to provide a thorough description of English attrition in Korean-English bilingual returnee children in diverse aspects. This goal was only partially achieved as Rita was the lone child who showed attrition in several experiments. However, there are several other findings from this research that can contribute to future attrition research.

First, although language attrition can happen very quickly, the value that English possesses in Korean society delays English attrition in Korean-English bilingual children. The fact that most of the children participating in either part I or

\footnotetext{
53 At this stage, we can only speculate that the needs of attriters and L2 learners are different. Still, inferring from the comments of my participants about their school life, I can say that the attriters are not always fully focused in English classes provided by the public schools or private institutions (except for the institution for returnees) because they feel like they already know everything that is taught.
} 
part II of this study did not show signs of English attrition even after two years in Korea needs to be considered in the light of anecdotal reports such as the one below from Bickerton (2009). Even a language like Spanish that is spoken worldwide can soon be forgotten if the bilingual children think it is valueless in the society they are in.

Take my own children. Up until they were four and six respectively, Ash and Jim lived a good part of their lives in Spain, spoke kiddie Spanish indistinguishable from that of Spanish kids, and learned to read in Spanish. In a matter of months after they stopped speaking it, they lost it entirely. Or almost entirely. A few years later we gave them a Spanish newspaper. They read from it fluently, with perfect accents - but they couldn't understand a word of it. ${ }^{54}$ (Bickerton 2009: 97-98)

Second, this dissertation suggests the appropriate methodology for attrition research. In the early phase of attrition, the attriters' production is more likely to present valid results than their knowledge on grammar or comprehension. Thus, developing testing materials that are sensitive to their production skills is essential.

Just as language acquisition is known to have developmental stages, attrition seems to follow its own path. Drawing on the results of attrition described throughout the chapters, I hope this dissertation helps reveal the perils and prospects of attrition research and opens the door to future progress in this area.

\footnotetext{
54 Just as in my case when I was a child, accent seems to be the last and least affected by attrition, which is the reason this dissertation did not deal with the attrition of pronunciation. Although there is no account for why accent would be relatively immune to attrition, my speculation is that it is because pronunciation is heavily dependent on muscle movements in the speech organs. Just like a person who learned to swim or ride a bike in childhood is unlikely to forget them even after years of no practice, attrition of accent may hardly occur because the movement is engraved in the muscle. I thank Dr. Shigeo Tonoike of Aoyama Gakuin University, Japan for this discussion.
} 


\section{Appendix A. List of irregular past tense verbs}

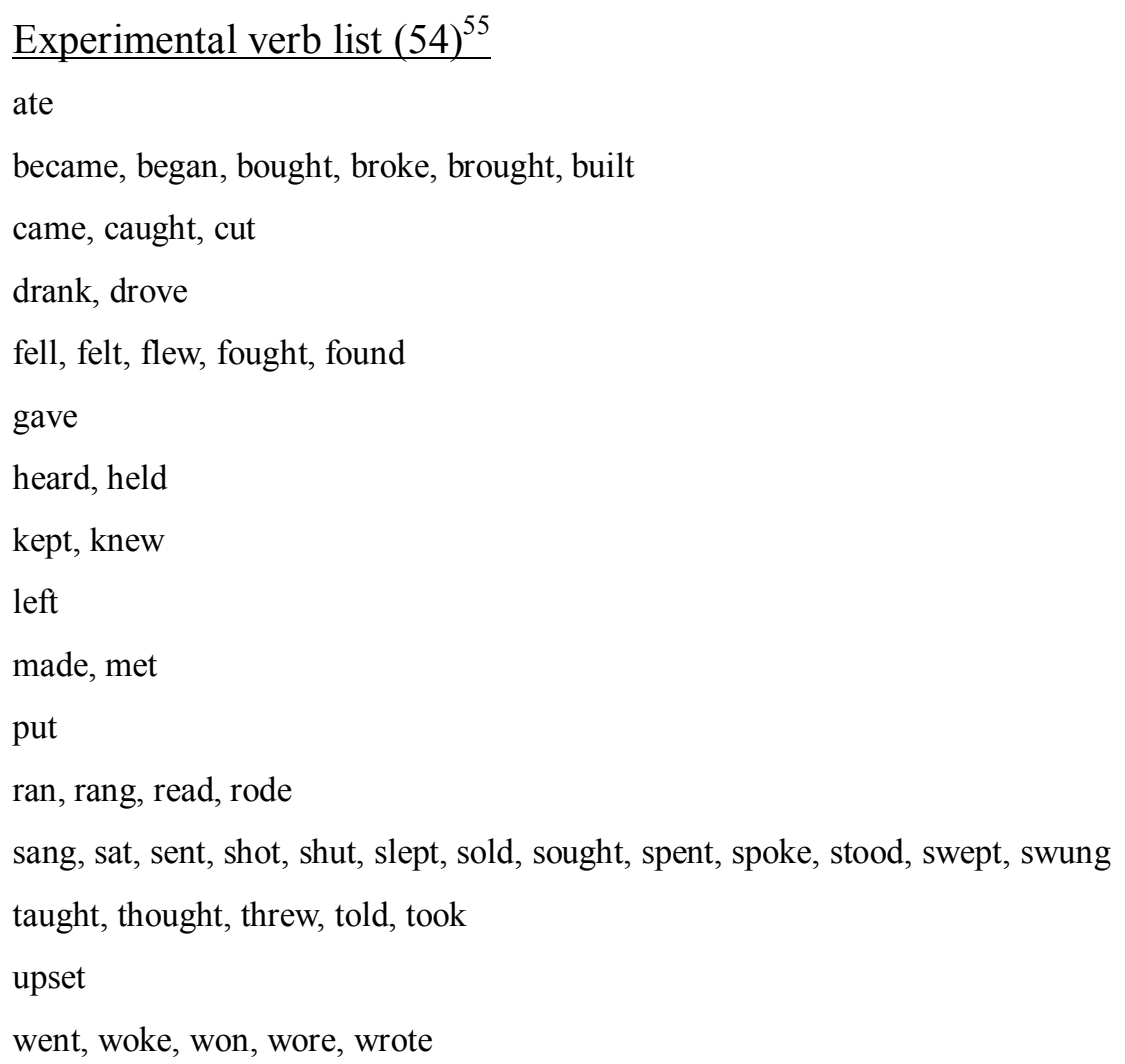

Intentionally excluded from the experimental verb list (7)

did, get, had, said, saw, was, were

Other irregular verbs produced in naturalistic data not included above

Sammy (7): bit, forgot, hit, lost, rode, stole, *understanded

Hera(20): *bend, *bleded, blew, chose, dove, dreamt, drew, forgot, grew, hid, hit, hurt, laid, led, lost, meant, paid, stole, stuck, swam

Rita (16): *bended, *bited, *bleeded, *blowed, drew, fed, forgot, *growed, *hided, hit, hurt, lost, stole, stuck, *swimmed, *taked

55 (x) marks the number of verbs. 


\section{Appendix B. Part I experiment materials}

\section{Article I: picture-naming task}

(1) Experiment 1

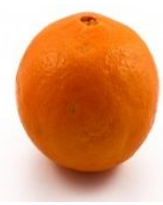

orange
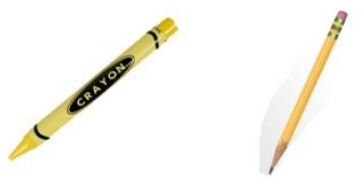

crayon

pencil

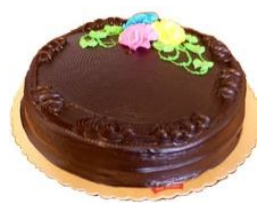

cake

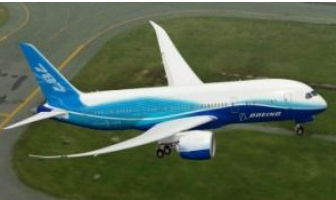

airplane

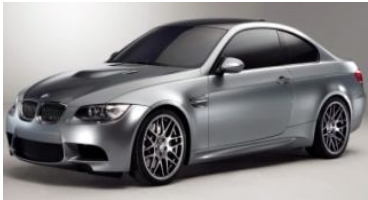

car
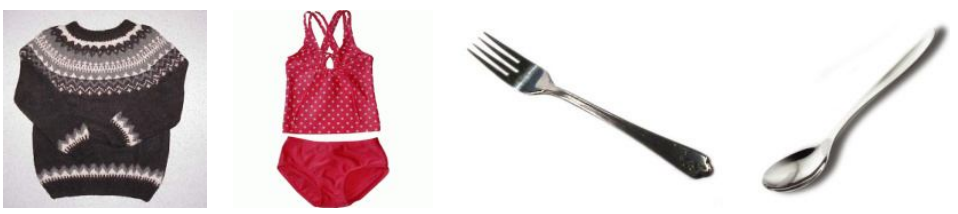

sweater

swimming suit /

fork

spoon

(2) Experiment 2

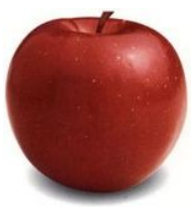

apple

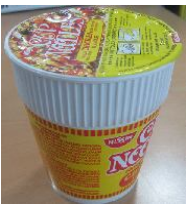

cup noodle

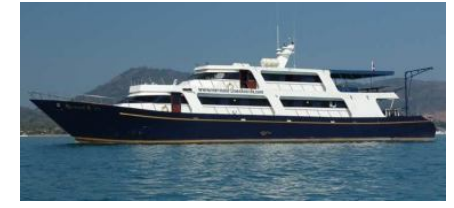

boat

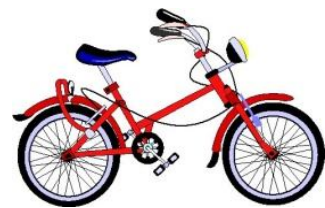

bicycle

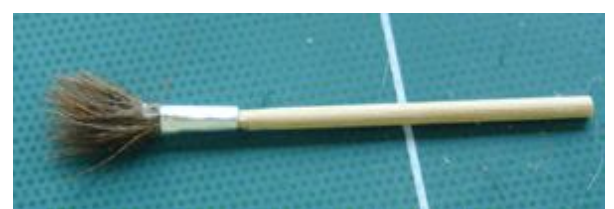

brush

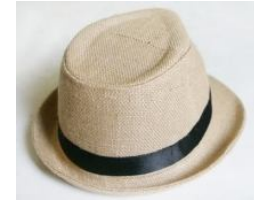

hat

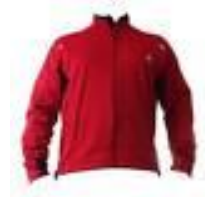

jacket

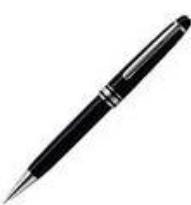

pen

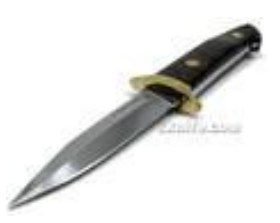

knife

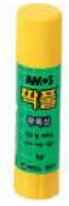

glue 


\section{(3) Experiment 3}
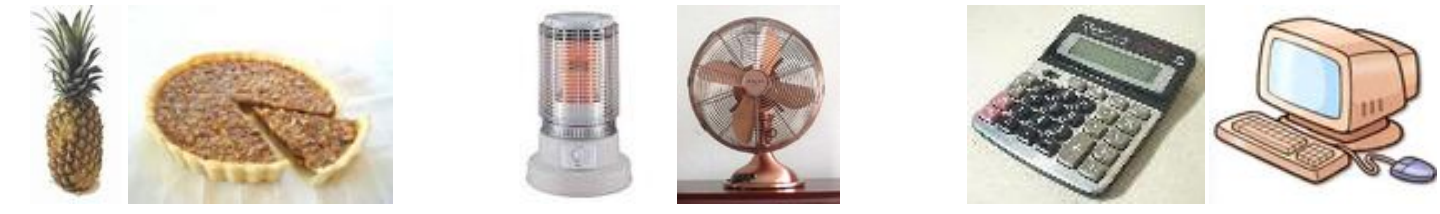

pineapple pie

lamp

calculator

computer /

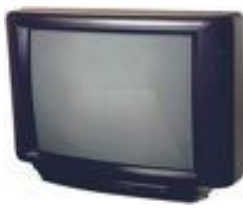

television

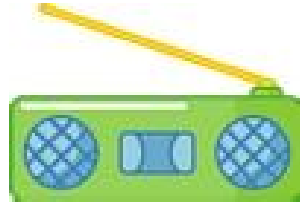

radio

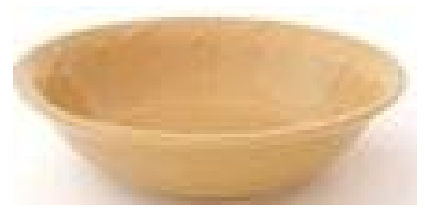

bowl

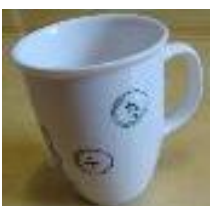

cup

(4) Experiment 4
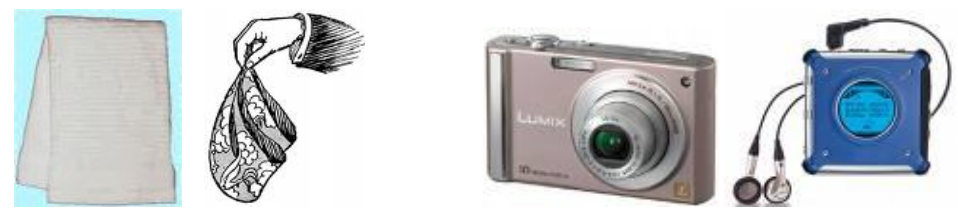

towel handkerchief / camera

mp3 player

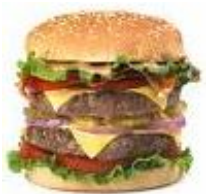

hamburger

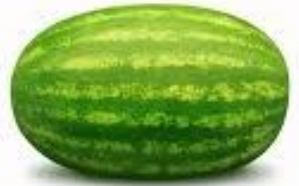

watermelon

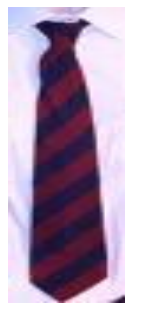

necktie
/ shampoo detergent /
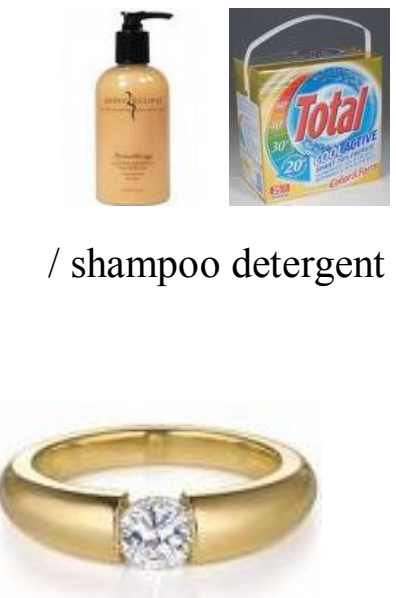

ring

\section{(5) Experiment 5}

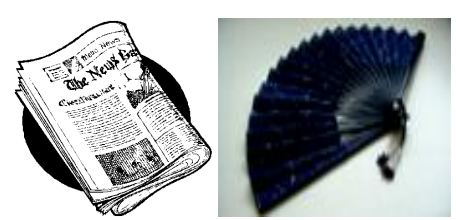

newspaper

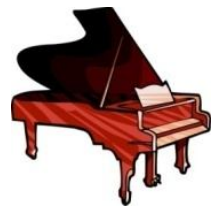

piano

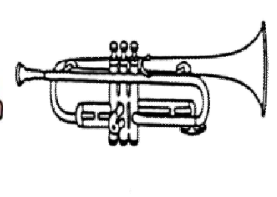

trumpet

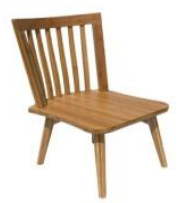

chair

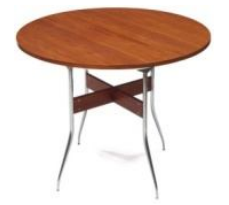

table /

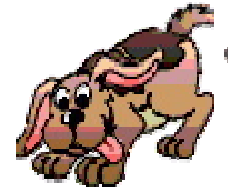

$\operatorname{dog}$

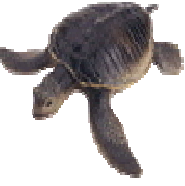

turtle

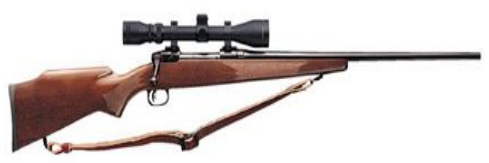

gun

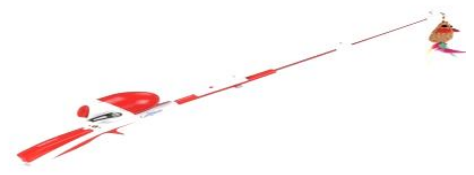

fishing rod 


\section{Article II: story-telling task}

(1) Experiment 1
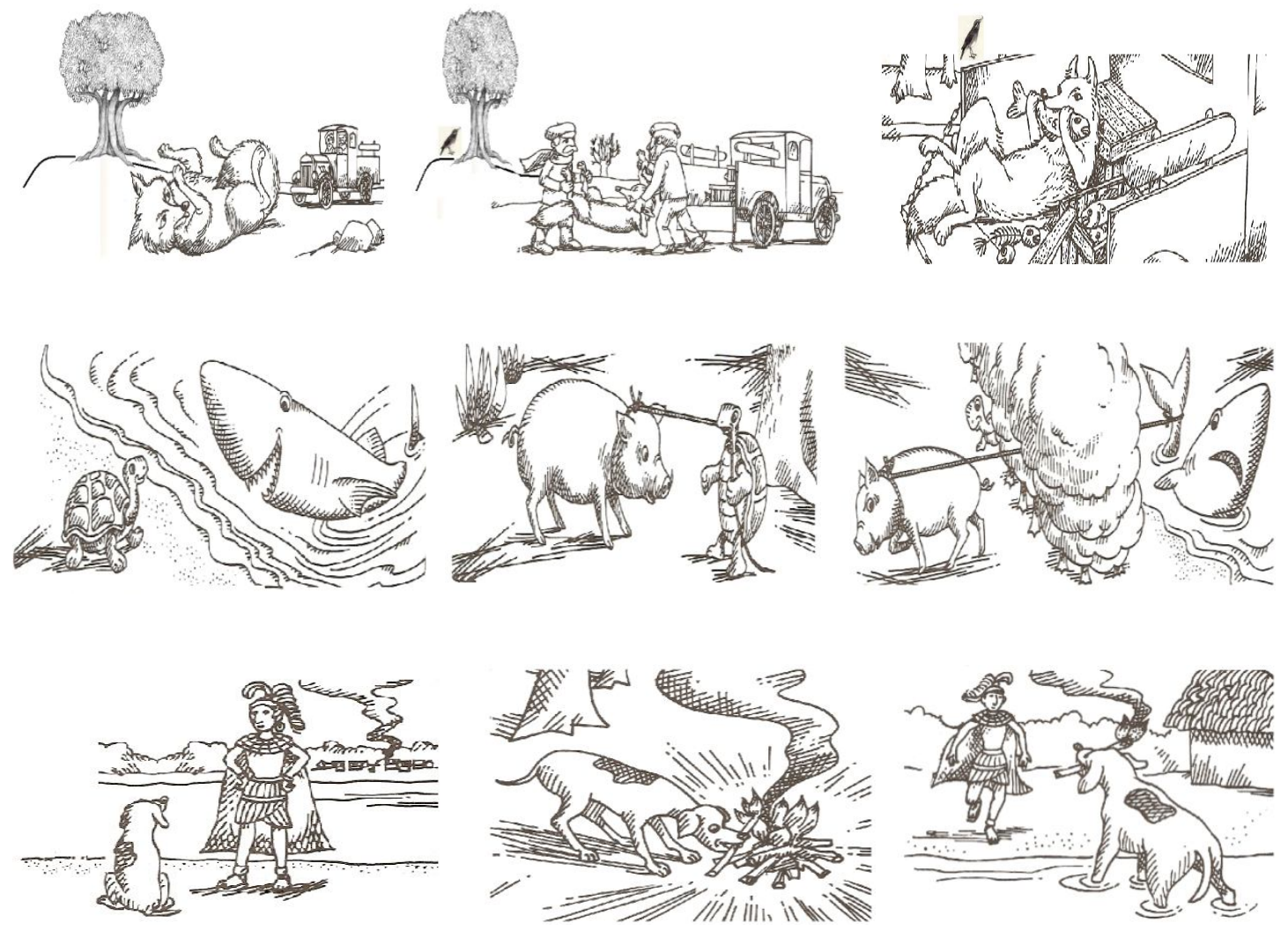

(2) Experiment 2
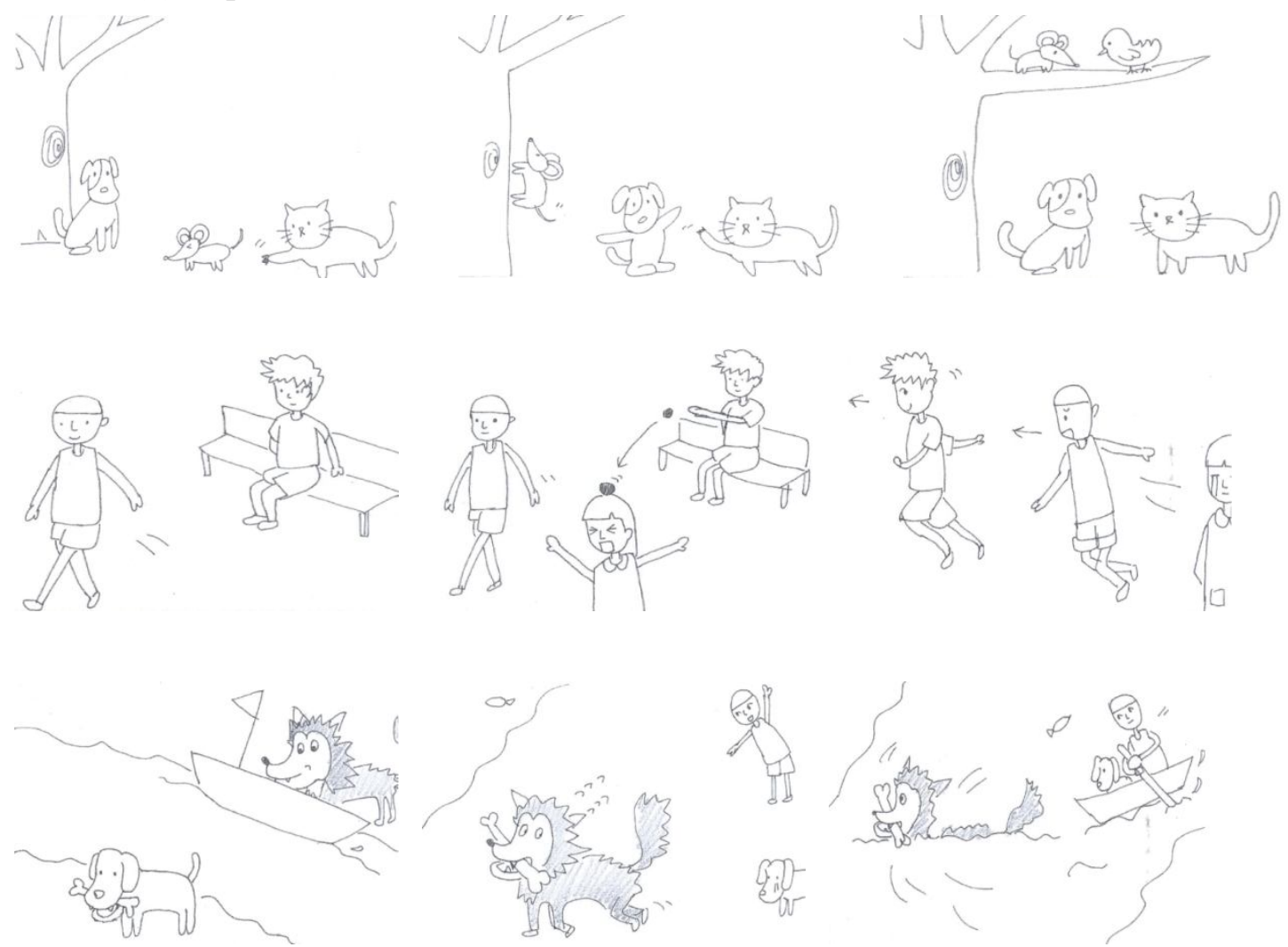


\section{(3) Experiment 3}
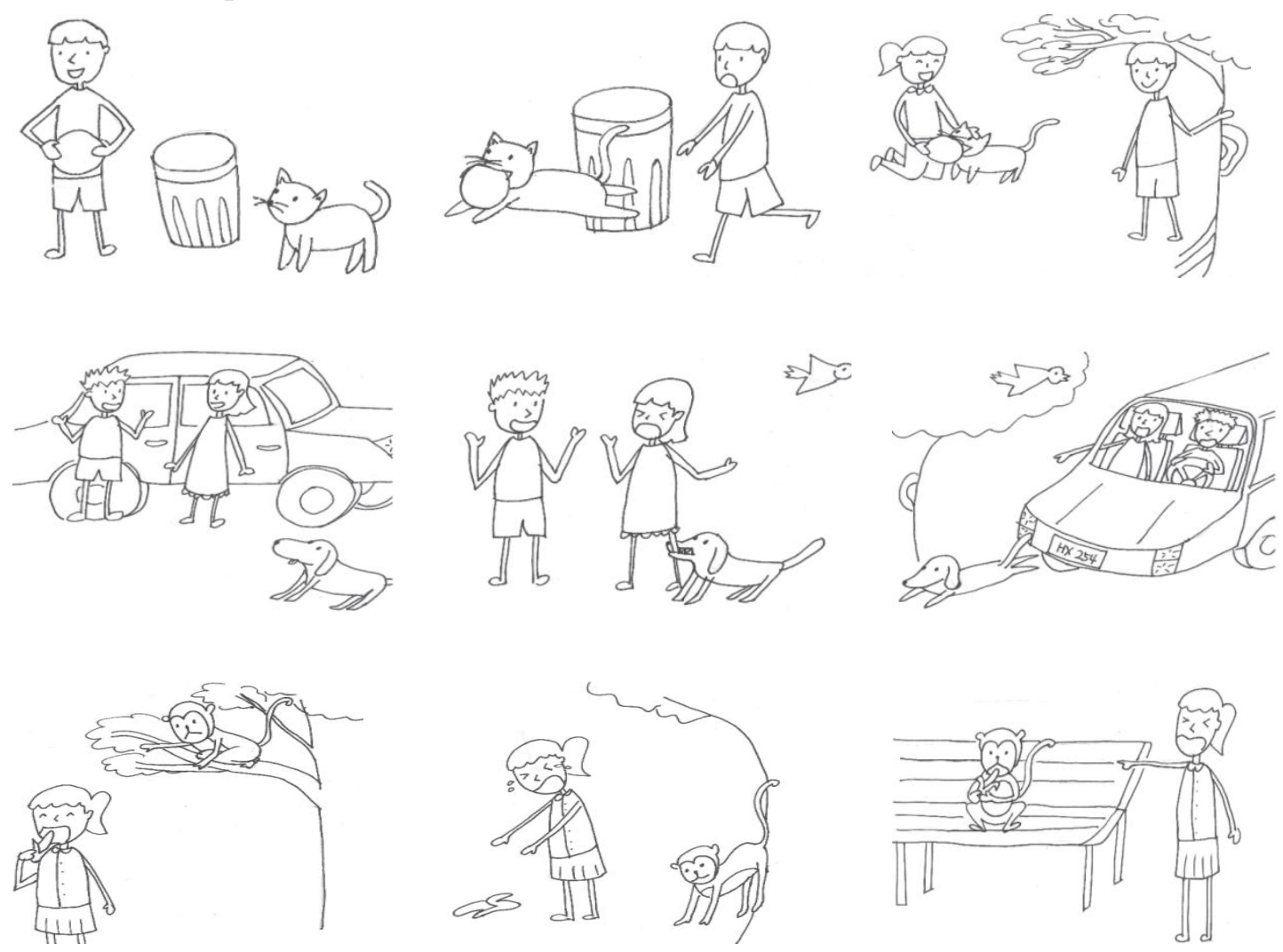

(4) Experiment 4
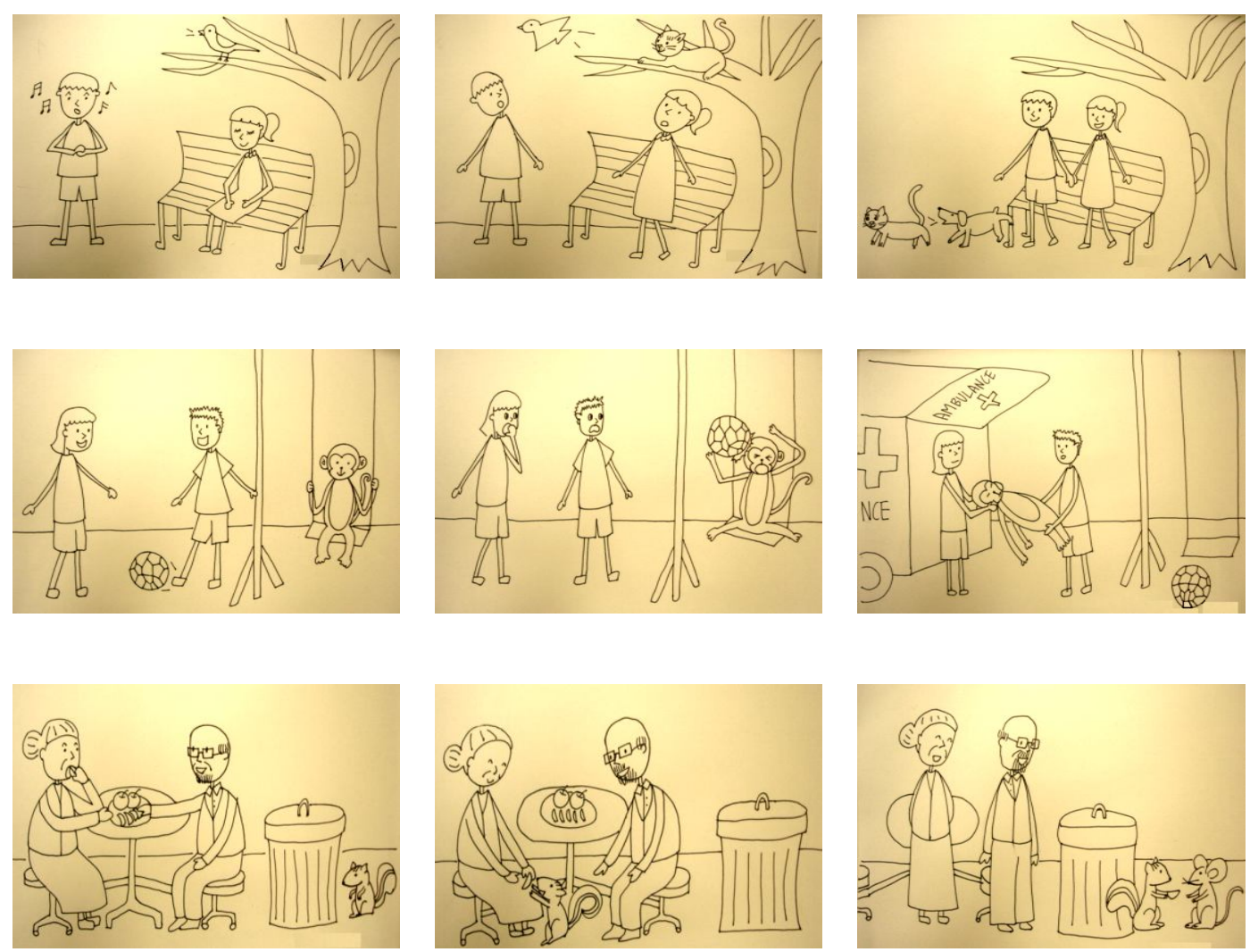


\section{(5) Experiment 5}
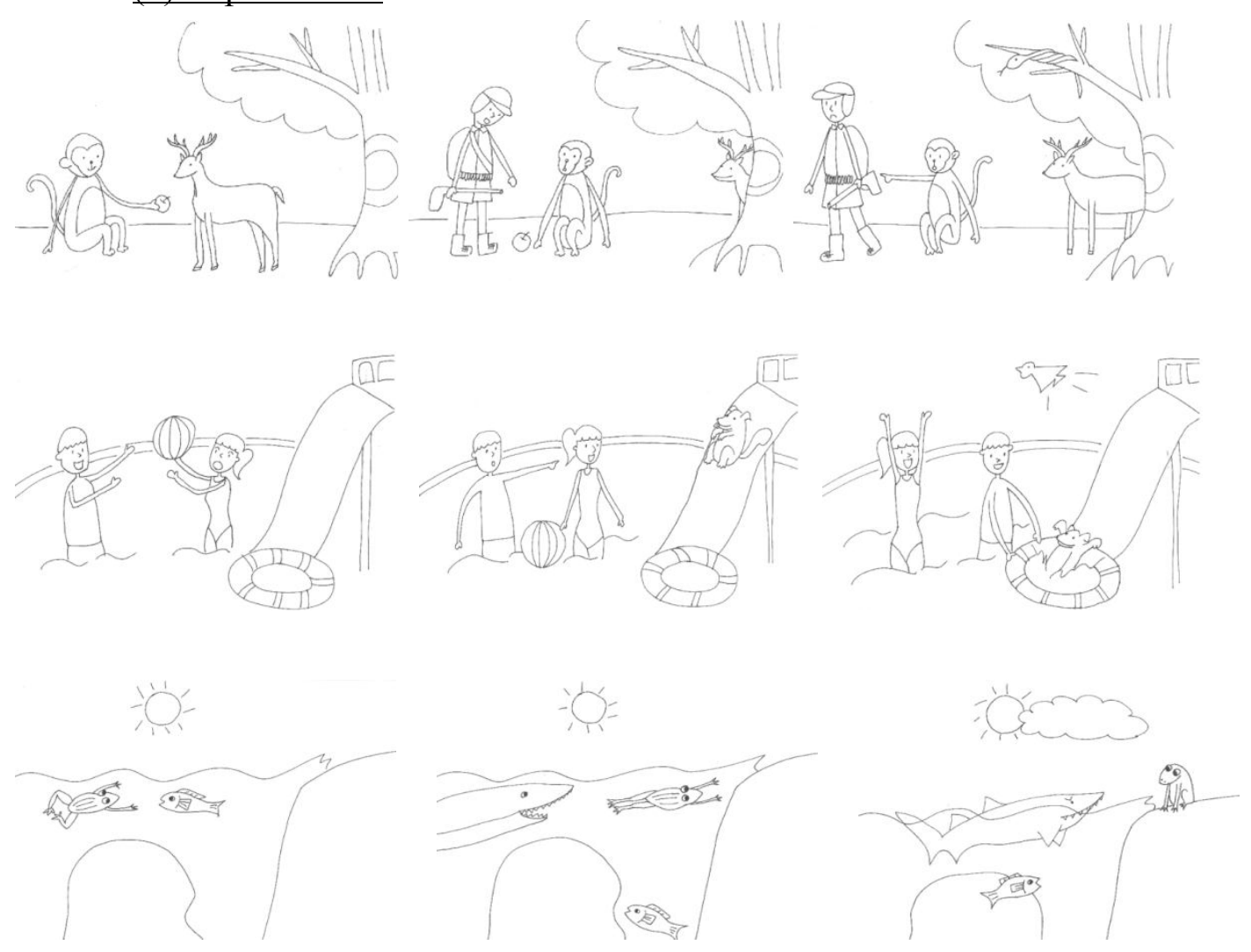

\section{Irregular past tense verb judgment task}

\section{(1) Experiment 1}

Yesterday, Pooh waked up at 6 o'clock. There was a reasons why Pooh woke up early. That's because he was going on a picnic with his friends.

First, he taked a shower. Normally, he don't like to take a shower. But he decided to take a shower since it was a special day. After the shower, he feeled really nice. But after he dried the water, he was feeling hungrily. That's because he woke up early. So, he goed to the kitchen to eat breakfast. His mother prepared pancakes for him. The pancakes looked few delicious. He putted some butter on his first pancake. His mom poured him a glass of milk. The milk was warmen. While he was eating he thinked his mom's pancakes are the best in the world. It was not too sweet and just right. It was also not too firm and just soft. He was sure that there is no one who maked better pancakes than his mom. On his second pancake, he poured some honey. He loved the salty taste of honey. Whenever he was thirsty, he drinked his milk. The orange juice and pancakes was a perfect match. He was full after eating 2 pancakes. After he eated breakfast, he went to the bathroom. He brushed his toothes. Then he checked if he was ready. He weared his new shirt. The new white shirt had a cute puppies on the front. He really liked his new shirt. His mom buyed him the new shirt for the picnic. Now Pooh was ready to go. On his way to school, he feeling very good.

He even singed a song. The weather was sunny but it 
was not too hot. Everything was perfectly. feeling good, too. So they started talk on the way to school.
On his way, he meeted his friend, Piglet. Piglet was

Piglet telled Pooh that he bought a new pair of shoes. The shoes looked really nice. So Pooh bragged about his new shirts.

Then Piglet becomed jealous. Piglet thought that the shirt was really pretty. So Piglet asked Pooh where he buy the shirt. Pooh wished he knowed the answer. But he didn't know because his mother bought it for him. As they were talking, they arrived at school. The school bus were waiting for them. They runned to the bus. Most of their friends was already on the bus. They sitted together on the empty seats at the back. Soon, the bus started to go to the beach. They were going picnic to the Waikiki beach. On the bus, Piglet talked about a book that he readed last night. It was a story about a three brothers. The brothers were on a journey to find treasures. After the brothers finded the treasures, everyone became greedy. All three of them wanted to have the treasures all by themselves. So them started fighting. They fighted until everyone became tired. Soon, they realized it was foolishly to fight. They had a lot of treasures, so they could just split them up evenly. So, they beginned to count the treasures. There were thousands of treasures. Their divided them evenly. The first brother sended some of the treasures to his parents. His parents was very happy. And they became rich, too. The second brother leaved the country with all the money. In another country he bought a huge amount of land. And he started to farming. Then, he bringed his wife and kids to his land. His family was very happy. The youngest brother went home with his share of treasures. But on his way, he was catched by pirates. The pirates found out that he had a lot of money. So, they tried to took the treasure from him. But the youngest brother refused to give them his treasure. So, the pirates swinged their knives at him. The youngest brother was scared. Then suddenly, he heared a very loud voice. Someone had come to rescue him. The man started to fighting with the pirates. Although he was alone, he winned the battle. He was a very strong man. And also, he was a very braved man. The pirates fleed to the mountains. The youngest brother was thankful that he met he. He wanted to give some treasures, but the man refused. So the youngest brother keeped on going his way. He walked two days without even sleeping. His was very hungry and tired. So he sat down by a big tree. And he falled asleep. In his sleep he had a dream. A fairy speaked to him. The fairy told he that his wife was sick. He woke up and hurried to his home. He was upsetted because his wife was sick. He loved her very much. So he didn't wanted to lose her. When he arrived home, him found out that his wife was very sick. He seeked for a doctor who could save his wife's life. He finally found a famous doctor. The doctor comed and saved his wife's life. He was so happy that he cried. Their childs were happy, too. He gived the doctor a lot of money. The doctor was also happy because he earned a fortune. Then, the youngest brother started building a new house. He spended a lot of money on the new house. The house had everything. It even had a huge room only for him wife.

After he builded the house, his family lived happily ever after. As Piglet finished the story, they arriving at Waikiki beach. Pooh and his friends started playing at the beach.

At lunch time, Piglet holded a delicious sandwich in his hand. It was a sandwich that his mom made for him. It had 
turkey ham, tomato, and cheese in it.

Suddenly, a bird flyed down and took the sandwich.

Everyone was surprised. And Piglet are about to crying.

Then, Pooh cutted his sandwich in half and gave one to Piglet. So, they ate a good lunch and had a good time at the beach. After a while, it was times to go home. On the bus back home, Piglet writed a thank you note for Pooh. Piglet appreciated the fact that Pooh shared his lunch with him. When they reached school it are getting dark. They said thank you to the driver who drived them back to school from the beach. When Pooh came back home, he am really tired. But he thought he had a great time today.

Pooh went to bed early and sleeped until 10 o'clock the next day.

\section{(2) Experiment 2}

Last night, Mickey sleeped late at night. It was because he watched a very interesting movies. The movie he watched was 'Kung Fu Panda'. In the movie, there were a panda that loved Kung Fu. The panda's father runned a noodle shop. And he is worked at the noodle shop. His father selled the best noodles in town. Everyone loving his father's noodles. That's because his father had a secret recipe. Everyday, the noodle shop was full of people who comed to eat the noodles. But the panda didn't wants to make noodle. He wanted to be a Kung Fu fighter. One day, he heared a great news. The temple was holding a competition to picking the best Kung Fu fighter. So the panda went to competed. And at the competition, he was selected as the dragon warrior. Everybody feeled it was unfair. That's because the panda were fat and didn't know how to do Kung Fu.

But him was chosen. At first, it seemed impossible to teaching Kung Fu to the panda. But the master finded a way to train the panda. The master knowed that the panda loved to eat. When there was food in front him, the panda did everything to eat it. He could move fast and even jump highly. So the master telled him that he could eat only after the training. And the panda learned a lot. Him learned many new skills and could move faster. He becomed very good at Kung Fu. Then, one day, Poe is attacked the town. No one could stopped him. Even the master couldn't stop Poe. So, the panda fighted Poe. When Poe first seeing the panda, he laughed. Poe thinked the panda couldn't fight. That's because the panda was fat. And also, he didn't looked like a fighter. But when the fight beginned, Poe couldn't laugh. The panda was better than Poe thought. So them fought for a long time. Whenever the panda falled on Poe, Poe screamed. That's because the panda was so heavy. It were a very long fight. They keeped fighting until sunset. Both of them was very tired. But when the panda punched Poe one more time, the fight were over. The Kung Fu panda winned the battle. Everyone was happy. And the panda's father was very proud of him son. $\quad$ Poe fleed away and the town was peaceful again.

One day, Minnie drived her car to the market. It was a very hot day. And hers was feeling hungry. So, first, she eated lunch in the market. She had a tuna sandwich. It was very delicious.

After lunch, Minnie started to shopping. Minnie had a list that she maked yesterday. She had to buying

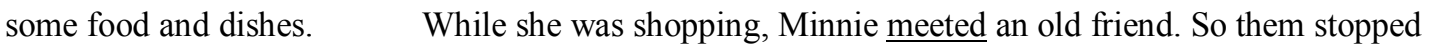


by a coffee shop. And they started to talking for 30 minutes.

After they drinked coffee, Minnie finished her shopping. She found the dishes she was look for. And also, she found some fresh vegetables. So she buyed everything on her list. After the shopping, she start back home. While she was drive, Minnie saw a man riding a bicycle. The man rided the bicycle very dangerously. He seemed not be afraid of the cars. He was also speed very much. Minnie was waiting for the traffic light to turn green. And suddenly, the man flyed to Minnie's car. He bumped into the back of Minnie's car. Minnie goed outside the car. The man was hurt. And the car and bicycle was also damage.

Soon, ambulance arrived. She sended the man to the hospital. And she checked hers car. When she checked her trunk, she got mad. The accident breaked all her dishes. She didn't know what to doing. She taked the dishes back to the market. She told what had happened to the manager. And she asked the manager if her could get new dishes. But the manager refused to give she a refund. So she throwed away the dishes. And then, she had to buying new dishes.

It was a bad day for Minnie because she spended extra money because of the accident.

When Micky woke up, it was snowing. He weared his jacket and hat. Then he went out to sweeping the snow. It snowed so much during the night. After he sweeped the snow in front of his house, he was feeling tired. He is wanted to go back inside and rest. So he came back to his house and sitted on the sofa. He was sitting there for a while and to taking a rest. Then he picked up the newspaper and started to reading it. After he readed the newspaper, he wanted to eat breakfast. He was eating bread and egg for breakfast. While he was eating, he was watched TV. Suddenly, his telephone ringed. It was his teacher from school. Him wanted Mickey to come to school. But Mickey didn't wanted to go because it was Sunday. So he seeked for an excuse. But he couldn't finds a good excuse. $\quad$ So he gived up and decided to go to school. His teacher wanted Mickey to help to clean the school. The snow last night covered the whole schools. So Mickey and some of him friends started to sweep the snow. Some of his friend even singed while sweeping. It was a song that Mickey never hear of. He wanted to learn the song. So one of his friends teached him the song. After a while, they became tired. So them decided to take a rest. Then someone bringed a hat and suggested making a snowman. So Mickey and his friends started to made a snowman. When they finished the snowman, Mickey putted a branch as the snowman's arm. And then suddenly, the sun started to shines. And it got warmer and warmer. The children thought that the snowman would melted. That upsetted the children. But the snowman did not melting for a while. It just standed there for a moment. When Mickey and his friends were done sweeping the snow, the snowman was gone. Although Mickey had to go school on Sunday, he had fun at school. He writed a diary before going to bed. 


\section{(3) Experiment 3}

Yesterday, Mary sleeped late. It was because she watched a DVDs. The movie who she watched was 'Beauty and the Beast'. In the movie, there was a girl named Belle. She singed very well. And she living with her dad. She also readed a lot of books. She always was stopped by the library. In the library, she would checking out interesting books.

Then one day, Belle's father goed deep into the woods. He couldn't find his way out. Then, he was arrived at the Beast's castle. And the Beast catched Belle's dad. The Beast locked him in the prison. Belle started to worrying because her dad wasn't coming back. Only the dad's horse comed back to Belle.

So Belle went to the castle to rescuing her dad. She suggested that she would e locked up instead of her dad. So Belle becomed the prisoner. The Beast needed to find a true love to breaking a spell. A fairy cast a spell on the castle. It was because the Beast don't have a warm heart. So Belle beginned to live in the Beast's castle. And her father returned to his home. But Belle's father telled Gaston that Belle was locked up. Gaston was an arrogant man. He wanted to marry Belle. So Gaston and the people went to the castle. They fighted against the Beast to rescue Belle. But there was something the peoples didn't know. They didn't know that Belle and the Beast falled in love for each other. While Belle was living with the Beast, the Beast tried to e nice to Belle. And Belle liked the castle because there were many book. Especially, the servants makedher feel at home. They served nice food of her. And they were very kind to her. The servants also keeped telling the Beast to be nice to Belle. They hoped that they would falls in love. They wished that their love would breaking the spell. While the Beast and Gaston were fighting, the Beast was injured. When Gaston swinged his sword, the Beast got hurt. But still, the Beast was able to fights. And finally, the Beast winned the battle.

But the Beast was hurt really bad. He was bleeding very much. Belle thinked that the Beast was dead. She crying and said 'I love you' to the Beast. Then, a miracle happened. When the Beast heared Belle say 'I love you', the beast started to float in the air. Then, everything started e turn back to normal. The Beast became a handsome princess. Everyone became human again. And everyone feeled happy. They lived happily ever after. She liked the movies very much. But Gaston upsetted her. That's because he were mean and arrogant. He speaked to Belle as if he was the best man in the world. Mary didn't like his attitude. But Mary liked the Beast. Although the Beast didn't have a warm heart in the beginning, Belle bringed him love. And the Beast learned how e love and have a warm heart.

Also Mary thought that the servants was very entertaining. Especially, their performance when Belle sitted on the dinner table was excellent. Mary had a really nice time watching the DVD.

She decided to watching the movie again someday. After watching the movie, she putted the DVD back into the case and went to sleep.

It was a Christmas day. John eated breakfast early in the morning. Then he went to the church. 
He weared his new jacket. The new jacket had a picture of a big star on the back. It also had a tiny stars on the pockets. It was a Christmas gift that his mom buyed for him. He also got a new pair of shoe. It was a gift from his dad. Last year, John's parents gived him a pair of roller blades. It was a gift that John really wanting. The roller blade is John's favorite thing. On his way to the church, he meeted his friend Frank. Frank was limping. So John asked him why he limping. Frank said that he breaked his left foot. Yesterday, Frank was come home from the market. He bought some snacks and drinks. His mom sended him to the market. But on his way back, he slipping on ice and fell down. He didn't see the ice because there were snow on top of it. He cutted his hand on a piece of glass on the road. He was bleeds a little bit. So at first, Frank thought he only hurt him hand. But he couldn't walked very well. Soon, he finded out that his leg was broken. So he went to the hospital.

Frank knowed that there was something wrong. After taking an x-ray, the doctor told Frank that him left foot was broken. So he had to put a cast on his leg. So John helped Frank to the church. At the church, John sweeped the front yard. But Frank couldn't helped him because he was hurt.

So Frank seeked for something that he could do. Since it was Christmas day, there were lots of works to be done. Soon, Frank found something that he could did.

He decided make direction signs. So hewrited directions on a big white paper. He also had to draw some arrows on the paper. Then, Frank taked the signs to hall. And he started to putting the signs up. Soon, people started coming to church. There were many people who drived to the church. So John and Frank had to help to people park. Soon, the parking lot was full. And people were keep coming. So Frank holded a sign to send cars to the nearby parking lot. It was one of the signs that Frank made earlier. While Frank was holding the sign, John runned to the nearby parking lot. The parking lot was smaller than the other one. But there were enough space for park all the cars. John standed at the entrance. When a new cars came, he pointed to the empty spaces. Soon, it was times for the morning service. So John and Frank shutted the door of the parking lots. And they joined the service. There were a lot of people because it was Christmas days. John and Frank spended two hours to help the church prepare for the service. They were feeling really good after volunteering to helping the church . But they were also tired . They waked up at 5 o'clock. It took them about an hour to getting ready. They also had to eat an early breakfast.

And they leaved their homes at 6 o'clock. And when everything was over, it was already noon.

\section{(4) Experiment 4}

Mary comed late for dinner. It was because she was had a good time. She was playing at the beach with her friends. At the beach, Mary and her friends builded a sand castle. It was a huge castle. It was not easy because the wave was continuously coming. It taked them more than an hour to build it. But when they were finished, they were happy. The castle was beautiful. 
After they maked the castle, Mary and her friends played in the sea. They swam together. Then, someone suggested playing with a beach ball.

So Mary bringed a beach volley ball. They started playing with the ball. It was not easy to play with the ball in the water.

They pretending to play basketball. When someone shooted the ball, someone else had to block it. It was very fun. But whenever Mary throwed the ball, it didn't go the way she wanted. The ball would always go to somewhere else. After playing in the sea for a while they were tiring. And Mary and her friends beginned feeling hungry. So them came out to eat something. They wanted to buy some food and started looking for food. At last, Mary finded an ice cream truck. The ice cream truck wasn't far from where they were. And the ice cream looked real deliciously. So they buyed ice cream and started eating it. There were strawberry, chocolate, and mango ice cream. Mary and her friends really enjoying the ice cream. Them wanted to eat more but the ice cream truck was already gone. The ice cream man had moved his truck to another place after he selled ice cream to Mary. So they couldn't eat anymore ice cream. After they eated the ice cream, they were feeling tired. So they decided to take a nap. But the sun was too hot to sleep. So they sleeped under the big umbrella that they brought. After taking a nap for half an hour, they dived back into the sea. The water was warmer because the sun was shining so hotter. Mary feeled the warmth of the water and relaxed on her tube. But her friends were still playing with the ball. Mary was watching her friends to play. Suddenly, one of her friends sended the ball over Mary's head. It was a mistake that her friend making. The ball had slipped out of the hand of Mary's friend. But fortunately, Mary catched the ball. After a while they decided to go back home. The sun was already starting to setting. Mary and her friends spended 30 minutes packing and getting ready to return. Since they had a very good time, they decided to coming back again.

And they also decided bring food next time. And everyone goed back home. It was already getting dark. But Mary was happy because she had a great times. She rided her bicycle back home. When Mary arrived at home, her mother were waiting for her. But her dad was already asleeping. Mary

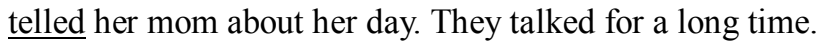
While they were to talking, Mary had dinner. Mary also drinked milk with her dinner. After dinner she was feeling very tiredly. So she got ready to sleeping. But before going to sleep she readed newspaper. There was nothing special. But she always enjoyed to reading the newspaper. It's because the newspaper teached Mary a lot about the world. After reading the newspaper, Mary brushed her toothes.

Then she went to bed. But right before falling asleep, she writed a diary about what she did. She wrote about what she did and what she ate.

She also wrote that she was wanted to go there again. Then she falled asleep. While she was sleeping, she had a dream.

She dreamed of playing at the beach again. She was so deep in her sleep that she didn't even know that the alarm ringed the next morning.

John sitted in front of the TV after dinner. He was ready to watch a movie. The movie John watched was 'The Lion King.' In the beginning, everything in the safari were peaceful. Birds flyed in 
the sky. And other animals enjoyed their lives in the safari.

The king of the safari, Mufasa, gived birth to his son, Simba. Simba was a curious lion. Simba learned a lot of thing by playing in the safari. Simba's father said that whoever breaked the rule of the nature should be punished. They liked to sing together. Them liked doing things together. Simba heared his father tell him stories. And Simba wanted to become the king of the safari to following his dad.

But there was someone who also wanted to be the king. Simba's uncle, Scar, standed on the top of the hill and watched Mufasa and Simba play. Scar was Mufasa's younger brother and wanted to becoming the king. There were also some hyenas to helping Scar. One day, Simba meeted Scar when he was playing in the safari. Simba was in danger. But Simba's father, Mufasa appeared.

Mufasa fighted for his son but Mufasa got killed. Simba couldn't believe what had happening in front of him. Simba were suddenly all alone. After Mufasa died, Scar becomed the king. Simba couldn't do anythings about it. He was too youngest to do anything. So he runned away. He was all by himself. He was lonely and scared.

The thought that he leaved his home made him sad. He didn't know what to doing. But fortunately, he met some nice friends.

They singed songs together and had a great time. As time went by, Simba grew up. Now he was strong enough to becoming the king. One day, he thinked that he saw another lion. The lion were a very beautiful young lady lion. Simba was sure that the lion was familiar to him.

Simba knowed that it was Nalla. Nalla was a friend who used to play with Simba when they was young. Simba couldn't believe that he meet Nalla again. Then, Nalla speaked to Simba. She told Simba that everything was ruined. Scar had destroying everything back at home.

That upsetted Simba. But still, he didn't want to go back home. Him was afraid and ashamed of what he had done. So Nalla seeked for help. Then, the wise old monkey came to helping Simba. The wise old monkey gave him some advice. The advice drived Simba to think about his father. And Simba decided to go back home and being the king. With some help from his friends, Simba was able to be the king again. And Scar fleed away after Simba became the king.

\section{(5) Experiment 5}

Yesterday, Mike waked up early. It was because his dad promising him to go to the zoo. But when he looked out the window, it will was raining.

Mike weared his raincoat. Then he stepped outside. He couldn't believed it was raining.

Mike comed back to the house. He was very sad. He was about to crying. Mike shutted the window so he wouldn't have to see the rain. He waited for the picnic in the zoo for so long. He even was bragged about it to his friends. But the rain breaked his plan. How could he go on a picnic in the rain? Why does it have to rains today? He feeled as if someone shooted him in the heart. But there was nothing he could do. Maybe he could prayed. So Mike goed back to sleep. And when he got up, the rain had stopping. Mike was so exciting and happy. So he rided his dad's car to the zoo. Fortunately, there were not many people at the zoo. It was probably because it was rained before. At the gate, a man selled ice creams. Ice cream was Mike's favorite snacks. Especially, he loved strawberry ice cream. 
So he buyed strawberry ice cream and entered the zoo. At the zoo there were much animals. First, she saw a parrot. The parrot speaked to Mike. It said 'welcome' to Mike. Next, he saw some monkeys. The monkeys was reaching their hand out and screaming. It seemed as though they wanted something from Mike. So Mike throwed some of the grapes he had. The monkey were smart and fast. They catched all the grapes. None of the monkeys missed a single grape. One of the monkeys were really enjoying the grapes. The monkey holded the grapes with one hand. And with the other hand, he grabbed a branch of the nearby tree. He swinged himself with only one hand while eating the grapes. Then Mike saw a bear cage. But the bears was not out. The bears were still sleeping in the house that people builded for them. So Mike couldn't watching them closely. Then Mike saw some giraffes. They were so tall that they cutted the entire top branches on the trees. He was amazed at how tall the giraffes is. But there was something that the giraffe couldn't do very well. When they drinked water, the giraffes had a hard time. It was not easy to bending down and drink. Next at the giraffe, there was a huge cage for birds.

There were many kinds e birds. The birds flied all over the cage. The color of the birds was beautifully. Then he saw a camel. It standed in front of its house. He were looking at Mike and chewing something. Then, suddenly Mike's cell phone ringed. The camel was surprised. So the camel stepped back. Mike thinked it was funny. After he finished to watching the animals, he had lunch with his dad. After lunch, Mike and his dad stayed at the zoo for a couple of more hour.

Mike leaved the zoo after he saw all the animals in the zoo.

Yesterday morning, Mary and her mom beginned cleaning their house. They decided e clean the house because Mary's grandparents were visiting. First, they started with the kitchen. sweeped the floor. And her mom started to cleaning the dishes. It wasn't easy to cleaning the kitchen. After the kitchen was done, they spended 15 minutes resting. Mary was already sweating. But she felt better after washed her face. Then, they starting to clean the living room. Mary putted the things into its original places. And Mary's mom wiped dust off the TV. But suddenly, Mary finded something strange behind the sofa. It was a long round things. But dust was all over. Mary telled her mom that she found something strange. Mary's mom looked at it. It looked familiar. She knowed that it was the candle she was looking for. She lost the candle a few week ago. She dropped it accidentally but she couldn't find it. The candle probably falled down and rolled under the sofa. But Mary's mom didn't saw it. So she thought she lost it. She seeked for the candle for a few days. It was a candle that she really loving. It's because her mother gave it e her. But she gived up because she couldn't find it. She was feeling sad for a few days. And then forgots about it. She was so glad that it felt like she winned a prize. Then they started cleaning the living room again. After finishing the living room, they started to cleaning the garden. But Mary didn't knows anything about gardening. So her mother teached her how to take care of the trees and flowers. But it wasn't easy. First, Mary's mom bringed scissors. And she started to cutting some branches off the trees. And Mary cut the grasses. They keeped doing it 
for 30 minutes. Soon, they was done. And they were also tired.

Mary's mom maked some ice tea for Mary. It was so refreshing. The house looked much cleanest after the cleaning was over. And Mary taked a shower and rested.

\section{(6) Experiment 6}

Last week, Pooh was on a camping trip. His father drived Pooh to the camping site. It was quite far away. $\quad$ On the way, Pooh sleeped in the car. After two hours, Pooh arriving at the camping site. All of his friends from school was already there. So he said good-bye to his father and joined his friends. Soon, Pooh meeted his friends, Tiger and Piglet. They were all exciting about the camping. $\quad$ First of all, they set up the tent. Pooh and Piglet holded the tent up and Tiger hammered the poles. About 30 minutes passing setting up the tent. After the tent ready, they cleaned the area. Pooh picked up trashes and Tiger sweeped the dust. And Piglet cleaning the inside of the tent. After the cleaning was done, they eated lunch. They had sandwich who Tiger brought. It was delicious because Tiger's mom makes the best sandwiches in the world. After lunch, they went pick up woods. The woods were for the camp fire. While picking up the woods, Pooh accidentally breaked a branch of a nearby tree. Piglet and Tiger yelled at Pooh. All Pooh could says was that it was an accident. After gathering all the woods, they putted the woods near the tent. Then, they went inside the tent and sitted down. For a couple of hours, they was played a board game. It was very fun. After dinner, they builded a camp fire. They has used most of the woods they collected earlier. It was a very big camp fire. Everyone got exciting. They singed songs and played games. One of the games that they played was catch. So people runned away, and it had to catch the people. But the people couldn't go too far. They had to staying near the camp fire.

When Pooh was it, he catched 3 of his friends. Pooh wasn't fast but he knew where his friends going. So they had a very good time. They played catch for about 30 minutes. Then they becomed tired. So they decided to taking a rest.

They drinked water and soda, and also had some snacks. They also chatted a lot. Then, after a while, them formed groups of 3 . So, Pooh, Tiger and Piglet became 1 group. Each of the members had to run to a tree and came back and ring the bell. At the beginning Pooh's team was in second place but Tiger ringed to bell first. So Pooh's team winned the game. And their received a prize. The prize was a nice T-shirt. After the game, they leaved the camp fire. The fire were almost off. So it was ok to just leave.

They returned to their tents. It got a little coldest but it was not too cold. Pooh writed a diary before going to bed. And then him brushed his teeth and got ready to sleep. And they readed a comic book together in their blankets. Soon, they were asleep.

The next morning, they waked up early. They had to going mountain climbing. They were scheduled to watching the sunrise. Since it was cold in the morning, they weared sweaters and jackets. And everyone started to climbing up the mountain. It was not a high mountain, but its was not easy to climb. On the way up, they saw a lot of things. They even heared birds singing. Pooh wanted to finding the birds singing.

But it was too dark. So stepped inside the woods to find the birds. Then 
suddenly, the birds flied away from the tree branch.

Pooh was surprised a lot. So he just standed there like an ice. All his friends which saw him laughed. They continued climb up the mountain. And after a while, they finally reached the top. It taked them about 30 minutes.

They waited for a while at the top. And soon, the sun beginned to rise. It was a very impressive scene.

After they watched the sunrise, they comed down. Then they had breakfast. After the breakfast they got ready to coming back home.

And they rided the school bus back home.

Yesterday, Mike and Bill goed hunting together. Them planned this hunting trip three days ago. They started early in the morning.

Mike bringed his hunting dog. It was a very well training dog. He could walk quietly and run very fast. For a while they could find anything to hunt. But suddenly, a big bear appeared in front of they. Bill was surprised and shooted his gun.

But Bill missed the bear. The bear got angry and swinged his big paw at them. The bear missed Bill but it hit Mike. And the sharp claw of the bear cutted Mike's jacket. Fortunately, Mike was not hurt. But they had to running away. $\quad$ As they were running away, Bill's dog keeped barking to Bill. Soon, Bill knew the reason his dog was barked. There was a small house in front of their.

So they ran into the house. And they shutted the door in a hurry. The master of the house was surprising. The master thought they were the people that selled the house to him a few days ago. But soon, he understanding the situation. The angry bear was still in front of the house. They decided to find a way to making the bear go away. First, they sended Bill's dog and the master's dog out. They barked fiercely at the bear. And then, they throwed rocks at the bear. Soon, the bear went away. So Bill and Mike thanked the master and went home.

The hunting trip teached them a good lesson. You should always be careful.

\section{(7) Experiment 7}

Dora went on a picnics yesterday. So she waked up early in the morning. And then, she got ready to leave. First, she brushed her teeth and washing her face. Then, she took a shower while she heared the birds sing. She was feeling so good after the shower.

That's because Dora was expecting to having a good time with her friends. When she was ready, her mom gived her the lunch box. It was Dora's favorite lunch box. Her mom maked sandwiches and cookies. Everyone loved her mom cookies. Especially Dora's friends couldn't resist the cookies.

Now Dora was ready to going. But when she stepped outside and shutted the door, it was raining. It wasn't raining hard, but still, it was raining.

When she woke up in the morning, it wasn't raining. All of a sudden, she feeled sad. But her mom told to her that the rain would soon stop.

Dora's mom suggested take an umbrella with her. So Dora holded her umbrella on her way to the picnic place. And soon, the rain stopping as her mom told her. Although it rained, the ground wasn't too wet. That was because it didn't rains for a long time. So Dora becomed happy again. When she arriving at school, it was sunny. She meeted with her friends and teacher. Her friends were also happy because the weather was beautiful. After a while, everyone will ready for the 
picnic. So they leaved for the park. The park was not so far away.

It only took about 20 minutes to got there. At the park, some people selled ice creams and pop corn. And also there were lots of people at the park.

The park was clean and quiet. It looked neat because the manager cutted the grass yesterday. At the park, they playing a game before lunch time. In the first game, they had to find hidden treasures before the bell ringed. Everyone was trying hard to finding treasures. They had to find it within 15 minutes. But it wasn't easy find because the park was big. After a while, Dora finally finded a treasure. And then, she discovered two more treasures.

She was so happy because she could exchanging the treasures for prizes. But some of Dora's friend couldn't find any treasure. And that upsetted them.

Finally, the bell rang and Dora went to her teacher to getting prizes for the treasures. Dora's teacher knowed that Dora found three treasures. And she also saw that some of the students found nothing. And the students who found nothings were feeling bad. She decided to do something about this. So Dora's teacher teached the students a lesson. First, the teacher gathered all the students. And then the teacher speaked to them. She wanted to talking about the importance of sharing. So, she telled them a story. After hearing the story, Dora decided to give two treasures to her friends. She gave the treasures to the friends that couldn't found any treasures. They said 'thank you' to Dora and Dora felt good. And finally, it were lunch time. Everyone putted their lunch on the picnic table. And they started to eating lunch together. Then, someone throwed trash on the ground. And the teacher saw it.

So, she told the students not to throwing trash on the ground. So the students seeked a trash can. Fortunately, there was big trash can nearby. So they could threw their trash in the trash can. Some students even pretended playing basketball. They shooted the trash to the trash can as if it was a basketball rim. And then Dora pulled out her cookies. All of her friends wanted to eating the cookie because they knew it was really good. So they keeped asking Dora for cookies.

So Dora shared the cookies with his friends. But soon there were only one cookie left. They fighted for the last cookie. But while they were fighting, something tragic happened. The cookie falled to the ground. Everyone was sad but them had to throw it away. After the lunch, they spended a couple of more hours in the park. Some students played with the ball. And some students took a nap. $\quad$ And other students singed songs. Then, they started to get ready go back home. They cleaning the area and packed their things. And the teacher sweeped the ground. When everyone was ready, they went to the parking lot to wait for the school bus. In the parking lot, there were still some people sell ice creams. So Dora and her friends buyed ice cream. It was really delicious. And after a while, the school bus arrived. So they rided the bus back to school. On the way back to school, everyone was said that they had a good time. And Dora agreed. She thinked that it was probably the best picnic she ever had. Then she thought of her family picnic last years. Last year, his family went to the beach.

And at the beach, them really had a great time. Dora weared the swim suit that her mom bought the day before. When they were tiring of swimming, they came out to the beaches. And they builded a huge sand castle. Dora and her mom and dad all worked hard to building the castle. It almost took an hour. After the castle was 
done, they was feeling really tired. So they sleeped inside the tent that they brought. After some sleep, they were feeling hungry.

So they eated and drinked before playing baseball on the sand. It was really hard to playing baseball on the sand. Everyone was running funny. But her dad was good. Whenever he swinged the bat, the ball went far away. Dora thought that yesterday's picnic was the second best picnic in her life.

So before going to bed, Dora writed a long diary.

\section{(8) Experiment 8}

Yesterday was a busy day for John. In the morning, his parents flied to America for vacation. John also want to go but he couldn't. That was because John have to take care of his dog, Lassie. So he was leaved alone in the house with Lassie. John decided play fetch with Lassie.

So John throwed the stick. He was expecting Lassie to run and get it. But Lassie didn't moved. He just standed still. Lassie just looked at it. So he couldn't played fetch with Lassie. That upsetted John. But John wasn't lonely. That was because his friends was coming. When John's friends comed, they decided to go the beach. Since it was hot, everyone agree. The beach was not very far. It only took about 30 minutes to get the beach. There were a lot of people at the beaches. First, John and his friends builded a sand castle. It wasn't easy to building a sand castle. Especially, the waves gived them a hard time. So some of John's friends tried to block the wave. But the wave keeped coming. So they decided move to another place. So they had to starting all over again. But because everyone participated, soon, they maked the castle. It wasn't big but it was beautifully. After it was over, they went into the water. After swimming in the water for a while, they decided to playing basketball. At the basketball court, there was a boy playing alone with a basketball. And the friends sended John to the boy to ask if he wanted to join.

So John speaked to the boy playing alone. The boy agreed to playing basketball together with John and his friends. So they started to play basketball all together.

Every time there was a loose ball everyone fighted for the ball. That's because everyone wanted win. When the game was almost over, John's team was lose. So John runned hard for the ball. He finally getting the ball and passed it to his friend. And John's friend passed it back to John. John catched the ball. And he made a 3 point shot. John was so happy. It was the first time that John made a 3 pointer. And John cutted the lead to only 2 points. But there wasn't enough time. And soon, John's team get the ball back. John shooted the ball but he missed. It was almost in but it bounced out. And the other team rebounded the ball. One of John's friends from the other team holded the ball and spended all the time. There was nothing John could doing about it. Finally, the game was over. The other team winned the game. But it was a very close game. Although John lost, he had a good time to play with his friends. After the game, they were exhausted. So they taked a rest. They drinked water and talked while they were resting. Then, they dived back into the sea. And after sunset, they decided to going back home. So John and his friends drived back home. 
Yesterday morning, Mary eated breakfast early in the morning. After breakfast, she cleaned the dishes. And then she rested for a few minutes. Then, she readed the newspaper. There were lots of interesting news in the newspaper. She read the newspaper for about 30 minutes.

Then suddenly, the telephone ringed. So Mary answered the phone. It was her mom.

Her mother's voice didn't sounded good. So Mary asked her if there was anything wrong. And her mother telled Mary a sad news.

The news was about Mary's brother. He breaked his leg while playing basketball. Mom told Mary that he were at the hospital. So Mary decided go to the hospital. She got ready and stepped out of the house. She shutted the door and hurried to the bus station. When she arrived at the bus station, the bus was about to leaving. So she ran but the bus was already leaving. She swinged her handbag in the air to stop the bus. Luckily, the bus driver saw her. So Mary was able to getting on the bus. And then she sitted on an empty seat.

She was tired because she had to run to catching the bus. She rided the bus for about twenty minutes. Soon, she arrived at the hospital. There were lots of patients in the hospital. So it was very crowed. She even meeted some of the people she knows. On the way to her brother's room, Mary saw 2 neighbors. One was Mary's teacher who teached her Math last year. The math teacher was at the hospital because she had a colds. They talked for a short time because Mary had to visiting her brother. Then, Mary met the guy who selled ice cream to her last week. He was at the hospital because his son was sick. After a while Mary arrived at her brother's room. Her brother was asleep. So Mary quietly sweeped the floor with a broom.

And when she were done sweeping, her mother came. Her mother was worried so much. Soon, Mary's brother waked up. He said he was all right. But he said that he feeled some pain on his broken leg. And he also said he was hungrily. So he ate some food that mom bringed. After he was done eating, he said he wanted to sleep again. So Mary and her mom decided to going back home. They putted the left over food next to the bed and left.

\section{(9) Experiment 9}

Last week, Jane decided to go on a trip. So she goed to New York. It was her first time to New York. First, she beginned to making plans. In order to make plans, she watching some TV programs on New York. There were so many tall building on the program. Then she deciding to get some books on New York. So she runned to the bookstore. There were so many books about New York at the bookstore. She standed at the bookstore for few hours to pick out the best book. Some books had a lot of pictures. And some books had so 'many informations'. It was so hard to 'deciding' which book to buy. At last, Jane buyed the book with lots of pictures. On her way back home, she stopped to 'buying' some snacks. At home, Jane readed the book very carefully. The pictures fascinated her. Especially, she was liked the part that introduced delicious foods. While she was reading, she finded a lot of great places to eat. So Jane checking the pages that introduced good restaurants. After that, Jane was about to book her flight and hotel. 
Then she thinked of her friend April. Because Jane didn't wanted to go alone, she called April. When April answering the phone, Jane asked April if she wanted to go on a trip.

And Jane explained her plan about the trips. When April heared the plan, she agreed to go with Jane. Jane was so glad that April was coming with her. After Jane speaked with April, she started making reservations. First, she used the internet to booking airline tickets. But it wasn't easy to get cheap tickets. But soon she found two cheap tickets and booking it. She sended the money and reserved the airplane tickets. Next, she was looking for a hotel. Then, suddenly, the telephone bell ringed. It was April. April said that she made a phone calling to New York. There was someone that April knowed in New York. And that friend's name was George. And he owned a hotel. April and George becomed friends when they were at a party last year. So April had talking to him. And George offered them to staying in his hotel for free. Jane was so glad. Jane seeked a way to save some money. And finally she saving some money thanks to April.

So, Jane and April were ready to leaving tomorrow. The next day, Jane waked up early in the morning. The airplane was leaving early so she had to get ready. First, she took a shower. After the shower, she ate a quick breakfast. Then, she weared heavy clothes. It was because the weather in New York could being very cold. After she was ready, there was still some time left. So she sweeped the floor of her house. Jane didn't want come back to a dirty house. After cleaning, she was ready to leaving. Jane shutted every window and made sure the windows were locked. Then she went to the taxi that was waiting for her. Jane rided the taxi for 15 minutes. When she arrived at the airport, April was already there wait for her. So they checked in and got on the plane. Soon the plane started and they flied to New York. The sky was clear and the weather was beautiful. After eat lunch on the airplane, Jane and April got sleepy. So they sleeped for about a couple of hours. After a couple of hours, Jane opening her eyes. But the plane was still flying. They still needed to going three more hours. So Jane falled asleep again. After three hours, the plane got ready to land. Everyone sitted down and fastened their seat belts. And finally, Jane and April arriving at New York. At the New York airport, Jane and April were waiting for their luggage to come out. But their luggage didn’t coming out for a long time. That upsetted Jane and April.

After a few minutes, their bags finally came out. Jane and April holded their bags and went out. There were many people in New York. They decided to taking a taxi to their hotel. So April catched a taxi. It was took about 30 minutes to the hotel. On the way to the hotel, Jane and April enjoyed the scene of New York. And the driver talked about many things while he drived. The driver was knew lots of things about New York.

He said he had been living in New York all his life. So April writed down what the driver explained. It was a very enjoyable ride to hotel. The hotel was very big. In the lobby, there were even singers that singed welcome songs. And April's friend was also there to welcoming them. Jane and April went up the room and left their luggage. When they came down, it were snowing. So they fighted each other with snowballs. They having much fun snowball fighting. But one of the snowballs that April throwed went over Jane's head. And the snowball heading to the nearby house. 
The snowball hit a window of the house. And the snowball breaked the window. So they had to pay for the window that they breaking. And at the end, nobody winned the snowball fight. And then, they went to sleeping. The next day, Jane and April decided start a tour of New York.

After visiting several places, they went to a park. It was a place where people shooted many movies. So Jane and April decided take a walk. In the park, there were many things that people builded for the movies. It was very interesting just to look around the park. And it were many people at the park. Some people read books and some were jogging. Some people even played baseball and swinged bats. Since Jane and April was tired, they decided to sit on a bench and rest. And they were feeling thirstily. They saw a man who selled ice cream and soda. So they bought ice cream. They ate the ice cream with the sandwich them brought. They cutted the sandwich in half and enjoyed their dinner. At night, they were on the airplane back home.

The trip was very entertaining and teached them a lot.

\section{Irregular past tense verb elicitation task}

\section{(1) Experiment 1}

1) Last night, John had to go to a party. But before going to the party, he decided to ride his bicycle for 2 hours. After the ride, he had a great time at the party.

What did John do before going to the party?

2) Yesterday, Bill was walking down the street. Then, he kicked a small rock on the sidewalk. It traveled across the road breaking a window of a nearby house.

What happened to the window yesterday?

3) Last night, Mary was expecting a few guests at her house. But since her place was not clean, she decided to sweep the floor before the guests came. After sweeping the floor, the guests arrived.

What did Mary do before the guests came?

4) Yesterday night, Jane was feeling cold in the room. She found out it was because the door was open. So she told Ashley to shut the door. Then, it became warmer.

What did Ashley do to keep the room warm?

5) Yesterday, John was at a job interview. The room was full of people. People sat down on a chair until they were called. When his name was called, John had to stand up for the interviewers to see him.

What did John do for the interviewers to see him?

6) Today, Jane learned how to do multiplication. But before she could multiply, her teacher had to teach her how to add numbers.

What did the teacher do before Jane learned how to do multiplication? 
7) Yesterday, Mary saw a big mango tree. There were a lot of mangos on the tree but they were too high up the branches. She managed to get some mangos by throwing rocks.

What did Mary do to get the mangos from the big tree?

8) Yesterday at school, Jane was studying in her classroom. After a while, she heard her teacher ringing a bell. Then, she knew it was lunch time.

What did the teacher do to let Jane know it was lunch time?

9) John has been trying to sell his car for the past 2 weeks. Yesterday, a man came to see his car and bought it. John was so happy to finally sell the car.

What did John do yesterday?

10) Yesterday, John went hunting to the mountains. Suddenly, he was attacked by a big bear. He was able to shoot the bear and kill it. He brought back the dead bear.

How did John kill the bear?

\section{(2) Experiment 2}

1) Yesterday, John went to the beach to swim. But before swimming, he decided to build a sand castle.

After the sand castle was done, he enjoyed swimming.

Before swimming, what did John do at the beach yesterday?

2) Yesterday, Jim went hunting to the mountains. Before lunch, he saw a rabbit running by. So he decided to catch the rabbit. After the rabbit hunting, he had a delicious lunch.

What did Jim do before yesterday lunch?

3) Last night, Mary was decorating her room for a party. Just before finishing, she wanted a ribbon on her wall. So she decided to cut a yellow paper to make a ribbon.

What did Mary do to make a ribbon last night?

4) Yesterday, Jack's father was working outside. Then, suddenly rain started to pour. So Jack had to hold an umbrella for his dad for two hours.

Yesterday, what did Jack do when his father was working outside in the rain?

5) Yesterday, Steve went to his friend's house. When he was going to his friend's house, it was raining. So he brought an umbrella with him. But when he was about to go back home, the rain stopped. So he wanted to leave the umbrella at his friend's house. He came home without the umbrella.

What did Steve do with his umbrella yesterday? 
6) Yesterday, Mark went hunting. Suddenly, a wild cat attacked him from the bushes. So he had to shoot the wild cat with his gun.

What did Mark do when the wild cat attacked him?

7) Last night, the wind was blowing hard. So Grace decided to shut the window to prevent the wind from making a mess in her room.

What did Grace do to stop the wind in her room?

8) Yesterday, Martha found out there was something wrong with the TV she bought. She went to the store to speak to the manager. Then, she got a refund.

Yesterday, what did Martha do at the store to get a refund?

9) Yesterday, Andy got hurt. When his friend Jeff was swinging a bat, Andy got hit.

What did Jeff do to hurt Andy?

10) Yesterday morning, Jose had to go to work early in the morning. First, he had to wake up at 6 o'clock to get ready. Second, he took a shower. Third, he took a taxi to work.

What was the first thing Jose did in the morning?

\section{(3) Experiment 3}

1) John had to attend a meeting last night. But before he went to the meeting, he had to build a dog house for his new dog. After building the dog house, John went to the meeting.

What did John do before going to the meeting yesterday?

2) Yesterday, Ted played tennis for three hours. After playing tennis he was feeling thirsty and wanted to drink water. So after drinking water, he played tennis again.

Yesterday, what did Ted do when he was thirsty?

3) Yesterday, there was a thief in Mary's house. When Mary found out that there was a thief in her house, the thief was already fleeing. So Mary could not catch the thief.

Why couldn't Mary catch the thief yesterday?

4) Yesterday, a policeman saw a thief running away. The policeman tried to catch the thief but the thief was so fast. So the policeman had to shoot a gun in the air to scare the thief.

What did the policeman do to scare the thief?

5) Usually, Phil walks to school. But yesterday morning, he was late to school. So he had to ride bicycle to school. 
How did Phil go to school yesterday?

6) Now, Jane knows how to bake a cake. It's because her mom had to teach Jane how to bake cakes yesterday.

What did Jane's mom do yesterday?

7) Mike has a lot of money today. It's because he was able to sell his car yesterday.

What did Mike do yesterday?

8) Yesterday, Jack saw a cat attacking a bird. But fortunately, the bird was able to fly to the sky before it was caught.

How did the bird get away from the cat yesterday?

9) Yesterday, Jennifer was taking a nap. She woke up because her telephone was suddenly ringing.

What happened before Jennifer woke up?

10) Yesterday, Julia was walking down the street. Then suddenly, she was hit by a ball. The ball came from the boys who were throwing a baseball at a nearby park.

What were the boys doing at the park yesterday?

\section{(4) Experiment 4}

1) Yesterday, Mary made a doll house. She had to cut papers and woods to make it.

What did Mary do to make a doll house, yesterday?

2) Last night, Tom went to a restaurant. In the restaurant, he saw a waiter holding a tray.

What did the waiter do in the restaurant last night?

3) Last night, John found a coin while he was walking. John picked the coin up and decided to keep it.

Last night, what did John do with the coin he found?

4) Yesterday, Barbra found a credit card on the bus. She wanted to find the owner but she couldn't. So she decided to put the card on the 'lost and found' box.

Yesterday, what did Barbra do with the credit card she found?

5) Last night, Jack's bird flew out of the cage and made a mess in Jack's room. So Jack put the bird back into the cage and had to shut the door.

Last night, what did Jack do after he put the bird back into the cage? 
6) Yesterday was Jerry's first day of work at a hair salon. Mostly, he had to sweep the floor after the customer's hair cut.

What did Jerry mostly do at the hair shop yesterday?

7) Yesterday, Betty was playing baseball. Then suddenly, a bug flew into Betty. So she had to swing her bat to kill the bug.

How did Betty kill the bug yesterday?

8) When Jim was sleeping last night, mosquitoes were bugging him. So he had to wake up and kill it. What happened to Jim last night while he was sleeping?

9) Yesterday, Jacky was on a game show. Jacky competed against other players and was able to win a lot of money.

What did Jacky do yesterday?

10) Last night, Rob was feeling cold in his room because the heater was out of order. So he had to wear a sweater and a jacket.

Last night, what did Rob do when he was cold?

\section{(5) Experiment 5}

1) Last night, Andrew was going home from school. But he was hungry so he had to eat a hamburger.

What did Andrew do on his way home, last night?

2) Yesterday morning, Amy thought it was hot. So she wore shorts when she went to school. But it was cold at night. So the cold weather last night made Amy become sick.

What happened to Amy last night?

3) Yesterday, Bob had a party at his house. So after work, Bob had to quickly drive his car back home. How did Bob come back home yesterday?

4) Yesterday, Cory was on his way home. On the street he saw two dogs fighting. What did the dogs on the street do yesterday?

5) Yesterday, Cindy was going to school. On the way, Cindy could hear the school bell ring. What happened to Cindy when she was going to school yesterday?

6) Yesterday, Derek was going to the supermarket. On his way, Derek was glad to meet his friend, John. Yesterday, what happened to Derek on his way to the supermarket? 
7) Yesterday, Jane was late for school but she missed the bus. So she had to run to school.

How did Jane get to school yesterday?

8) Mary usually sleeps at 10, but she wasn't sleepy last night. So she decided to read a book before she went to bed.

What did Mary do before going to bed last night?

9) Mark had nothing to do yesterday. But after watching the TV, he wanted to sing the song that he heard. So he did.

What did Mark do yesterday after watching TV?

10) Nancy went jogging to the park yesterday. After a while, she got tired. So she decided to sit on the bench.

Yesterday, what did Nancy do after jogging?

11) Yesterday, Pat went to the post office. It was because he had to send a letter to his mom.

What did Pat do at the post office yesterday?

12) Yesterday, Rob was tired after work. So he decided to sleep for 30 minutes before dinner. Yesterday, what did Rob do before dinner?

13) Yesterday, Sam dropped a cup and broke it. That had to upset Sam's mom.

Sam broke a cup yesterday. What did that do to Sam's mom?

14) In the writing class yesterday, the teacher made Tom write a letter to his father. So he did it.

What did Tom do in the writing class yesterday?

\section{(6) Experiment 6}

1) Yesterday, John went to the market to buy some fruits. At the market, he decided to buy some strawberries and bananas.

What did John do at the market yesterday?

2) Last night, Aaron was walking in the park. While he was walking in the park, he saw an apple falling from the tree.

What happened to the apple last night?

3) Last night, Bob went out to buy something to eat. When he stepped out of the door, he could feel the cold weather. 
What happened to Bob last night as he stepped outside?

4) Yesterday, Cindy went to a nearby park. At the park, she saw two cats fighting.

What did the cats do yesterday?

5) Yesterday, David went to the mountain to find wild berries. And luckily, he did.

What did David do yesterday?

6) Yesterday, Grace picked up the 10 dollar bill that she found on the ground. But soon, the woman who dropped the money appeared. So Grace had to give it back to the woman.

What did Grace do with the 10 dollars yesterday?

7) Last night, Harry went to see a movie. But before going to the movies, she had to make dinner.

What did Harry do before going to the movies?

8) Last night, Jake went to his friend's party. But before going to the party, he had to seek his tuxedo.

What did Jake do before going to the party?

9) Yesterday, Jane went to buy a dress. She found a nice dress and had to spend 100 dollars.

What did Jane do yesterday?

10) Yesterday, Lucy met her old friend. Since they had a lot of time, Lucy could speak to her for 2 hours.

What did Lucy do when she met her friend yesterday?

11) Mary was doing her math homework last night. Since the problem was very difficult, Mary had to think for 30 minutes.

What did Mary do while doing her math homework last night?

12) Yesterday, a friend visited Pat. Since the friend didn't know where the restroom is, Pat had to tell him.

What did Pat do to this friend yesterday?

13) Yesterday, a car hit Roy while he was crossing the road. Roy was not hurt but the accident did upset Roy.

What did the accident do to Roy? 
14) Yesterday at school, the teacher asked a question. But no one answered. Knowing the correct answer, Sam answered the question.

Why did Sam answer the question yesterday?

\section{(7) Experiment 7}

1) Yesterday, John was busy all day long until 10 o'clock. And, finally he could begin to eat dinner.

What did John do at 10 o'clock yesterday?

2) Last night, Jim was playing baseball. When he hit the ball, it went flying breaking a window.

What did the ball that Jim hit do last night?

3) Last night, Susan went to a party. So she had to bring some food with her.

What did Susan do when she went to a party last night?

4) Yesterday morning, Sally started off to the beaches for vacation. But soon, she had to come back because there was a family emergency.

What did Sally do after starting off for vacation yesterday morning?

5) Yesterday, Bob went to the beaches. After playing in the ocean for a while, he decided to catch some fish.

Yesterday, what did Bob do after playing in the ocean?

6) Yesterday was a busy day for Barbra. In the morning, she had to visit her friend's house, and in the afternoon she had to go shopping. Finally, late at night, she could drive back home.

What did Barbra do yesterday late at night?

7) Yesterday, a bird was singing on a tree branch in the park. Suddenly, a cat tried to catch the bird. So the bird had to fly away.

What did the bird do when the cat tried to catch it?

8) Yesterday, a policeman was chasing a thief. But the thief was able to run away.

What did the thief do when the policeman chased him yesterday?

9) Yesterday, Andy woke up early. So he ate breakfast and started to read the newspaper.

What did Andy do after breakfast yesterday?

10) Yesterday, David went to the park. After walking for a while, he was tired. So he decided to sit on the bench. 
What did David do after walking for a while in the park yesterday?

11) Yesterday, Fred received a mail. But the mail was not for Fred. So he had to send it back.

What did Fred do after receiving the mail yesterday?

12) Yesterday, Issac went to visit his friend. But his friend was not at home. So Issac had to stand outside the house..

What did Issac do when he visited his friend yesterday?

13) Yesterday, Kile found a 100 dollar bill on the street. Kile decided to take it to the police.

What did Kile do with the money he found yesterday?

14) Yesterday was a holiday. So Laura decided to go to her grandmother's house.

What did Laura do yesterday?

15) Yesterday, Mike went to a party. And he was lucky enough to win a prize.

What did Mike do in the party yesterday?

\section{(8) Experiment 8}

1) Yesterday, John brought some apples from the farm. And after a few hours, the apples were cooked becoming an apple pie.

What happened to the apples yesterday?

2) Yesterday, Bill had to finish his homework by midnight. So he had to begin his homework at 5 o'clock.

What did Bill do at 5 o'clock last night?

3) Yesterday, Brad's friend visited Brad at the hospital. On his way, Brad's friend was kind enough to buy some fruits.

What did Brad's friend do yesterday before coming hospital?

4) Yesterday, a monkey was playing on a big tree. And suddenly, the monkey made a mistake falling down from the tree.

What happened to the monkey yesterday?

5) Yesterday, Cindy was walking along the street. And she was lucky enough to find a 10 dollar bill on the street.

What happened to Cindy yesterday on the street? 
6) Yesterday, Doug was at the park. At the park, he was lucky enough to hear beautiful birds singing. What happened to Doug yesterday at the park?

7) Yesterday at school, teacher asked a question to the students. Knowing the answer, Erin answered it correctly.

Why did Erin answer the question?

8) Yesterday, Jim went to the river. At the river, he saw some birds singing.

What happened to Jim at the river yesterday?

9) Today, Harry has an important meeting early in the morning. So Harry had to sleep early last night. What did Harry do last night?

10) Last night, Jack needed a CD player. So he had to seek for it.

What did Jack do last night?

11) Yesterday, Jane went on a fieldtrip for 3 days. At night, Jane was thinking of her mom because it was her first time not sleeping at home.

What did Jane do last night?

12) Yesterday, Lora had a party at her friend's home. So she had to go to her friend's house at 6 o'clock. What did Lora do at 6 o'clock yesterday?

13) Yesterday, Mike was at the beach. Because the sun was so hot, he had to wear a hat. What did Mike do at the beach yesterday?

14) Yesterday, at his English class, Jason had to do something for his parents at school. So he spent the English class writing a letter to his parents.

What did Jason do yesterday at his English class?

\section{(9) Experiment 9}

1) Yesterday, Aaron was at home. After eating lunch, Aaron watched TV.

What did Aaron do before watching TV yesterday?

2) Bob was invited to his friend's house yesterday. So he decided to bring some fruits with him.

What did Bob do when he went to his friend's house yesterday?

3) Yesterday, Cindy had a busy day. So at night, after coming home, Cindy went straight to bed. 
What did Cindy do before sleeping yesterday?

4) Last night, Doug was at a party. After drinking some wine, he went home.

What did Doug do before going home last night?

5) Yesterday, Erin was feeling hot in her room. So she opened the window.

What did Erin do before opening the window yesterday?

6) Yesterday, Fred was working at a restaurant. After giving water to the customers, Fred delivered food.

What did Fred do before delivering food yesterday?

7) Yesterday, George found some money on the street. After keeping the money he ran away.

Yesterday, what did George do with the money before running away?

8) Yesterday, Harry went to the supermarket. After leaving the supermarket, he realized that he didn't buy milk.

Yesterday, what did Harry do before realizing that he didn't buy milk?

9) Yesterday, John bought some apples. After making juice with the apples, John drank the juice.

What did John do before drinking the apple juice yesterday?

10) Yesterday, Jessie was very busy. After meeting her friend, Jessie went to the dentist.

What did Jessie do before going to the dentist yesterday?

11) Last night, Mike was cooking dinner. After putting some garlic in the soup, he boiled it.

What did Mike do before boiling the soup last night?

12) Last night, Nancy was a thome. After spending some time with her mom, she watched TV.

What did Nancy do before watching TV last night?

13) Yesterday, Pete was at the hospital. After telling Pete to lie down, the doctor gave a shot to Pete. Yesterday, what did the doctor do to Pete before giving him a shot?

14) Yesterday, Roy went to buy a TV. After taking the cheapest TV, he paid the money at the counter. What did Roy do before paying money at the counter yesterday? 


\section{Passive comprehension task}

(1) Experiment 1

The dog is blocked by the cat.

The man is pushed by the woman.

The rabbit is pinched by the mouse.

The bear is dragged by the dog.

The duck is brushed by the cat.

The bear is scratched by the lion.

\section{(2) Experiment 2}

The chef is hugged by the waiter.

The pilot is kissed by the woman.

The doctor is called by the nurse.

The old lady is helped by the old man.

The policeman is stopped by the fireman.

The passenger is approached by the flight attendant.

\section{(3) Experiment 3}

The monkey is bitten by the rabbit.

The boy is hit by the girl.

The horse is licked by the cow.

The fox is tripped by the dog.

Mickey is pointed at by Minnie.

The lion is kicked by the cheetah.

\section{(4) Experiment 4}

The policeman is cleaned by the fireman.

The child is followed by the woman.

The swimmer is poked by the boxer.

The teacher is found by the student.

The girl is covered by the boy.

The boy is soaked by the girl.

\section{(5) Experiment 5}

The turtle is washed by the bird.

The bear is knocked by the fox.

The lion is hurt by the tiger.

The tiger is slapped by the bear.
The man is scared by the woman.

The bear is loved by the wolf.

The woman is observed by the man.

The girl is heard by boy.

The man is seen by the woman.

The cat is surprised by the dog.

The fox is frightened by the snake.

The scientist is feared by the cook.

The tiger is thought of by the bear.

The teacher is liked by the student.

The dancer is welcomed by the police.

Santa is looked at by Rudolph.

The man is considered by the woman.

The girl is doubted by the boy.

The woman is hated by the man.

The man is respected by the woman.

The bear is noticed by the elephant.

The hamster is watched by the bird.

The bear is scared by the man.

The boy is loved by the girl.

The penguin is observed by the bear.

The man is heard by the woman.

The lion is thought of by the bear.

The dog is frightened by the cat.

The snake is surprised by the fox.

The woman is respected by the man.

The woman is liked by the man.

The policeman is welcomed by the dancer. 
The grandpa is moved by the grandma.

The tiger is pulled by the bear.
The boy is hated by the girl.

The boy is looked by Santa.

\section{Passive production task}

\section{(1) Experiment 1}

1) Look! The boy wearing a hat hit the ball with the bat.

Look over here! The ball flies and hits the boy wearing glasses. So the ball, but not the bat, hit one of the boys.

What did the boy wearing a hat do?

What happened to the boy wearing glasses?

2) Look! The man with no hair moved a box and a chair to the ground.

Look over here! The chair blocked the man with a long beard. So the chair, but not the box, blocked one of the men.

What did the man with no hair do?

What happened to the man with a long beard?

3) Look! The woman in skirts threw a book and a cup.

Look over here! The book slapped the woman in pants. So the book, but not the cup, slapped one of the women.

What did the woman in skirts do?

What happened to the woman in pants?

4) Look! The younger sister brought a dog and a cat.

Look over here! The dog kicked the older sister. So the dog, but not the cat, kicked one of the sisters.

What did the younger sister do?

What happened to the older sister?

5) Look! The little girl dropped a glass and a plate.

Look over here! The tall girl is hurt by the glass. So the glass, but not the plate, hurt one of the girls.

What did the little girl do?

What happened to the tall girl?

6) Look! The female mechanic left a radio and a telephone.

Look over here! The male mechanic was tripped by the radio. So the radio, but not the telephone, tripped one of the mechanics.

What did the female mechanic do?

What happened to the male mechanic? 
7) Look! The old maid slipped a fork and a knife.

Look over here! The young maid was poked by the fork. So the fork, but not the knife, poked one of the maids.

What did the old maid do?

What happened to the young maid?

8) Look! The fat girl brought a red fish and a yellow fish.

Look over here! The skinny girl was bitten by the yellow fish. So the yellow fish, but not red fish, bit one of the girls.

What did the fat girl do?

What happened to the skinny girl?

\section{(2) Experiment 2}

1) Look! The small boy brings a cat and a dog.

Look over here! The cat scratches the big boy. So the cat, but not the dog, scratches one of the boys.

What did the small boy do?

What happened to the big boy?

2) Look! The older brother throws a blanket and a hat.

Look over here! The blanket covers the younger brother. So the blanket, but not the hat covers one of the brothers.

What did the older brother do?

What happened to the younger brother?

3) Look! The tall girl drops a book and a bag.

Look over here! The book knocks the little girl. So the book, but not the bag knocks one of the girls.

What did the tall girl do?

What happened to the little girl?

4) Look! The male farmer brings a cow and a pig.

Look over here! The cow licks the female farmer. So the cow, but not the pig, licks one of the farmers.

What did the male farmer do?

What happened to the female farmer?

5) Look! The woman with short hair spills water and juice.

Look over here! The woman with long hair is soaked by the juice. So the juice, but not the water, soaks one of the women. 
What did the woman with short hair do?

What happened to the woman with long hair?

6) Look! The man with glasses throws a ball and a glove.

Look over here! The man with a hat is pushed by the ball. So the ball, but not the glove, pushes one of the men.

What did the man with glasses do?

What happened to the man with a hat?

7) Look! The skinny boy dropped a knife and a fork.

Look over here! The fat boy is cut by the knife. So the knife, but not the fork, cuts one of the boys.

What did the skinny boy do?

What happened to the fat boy?

8) Look! The tall girl brought a turtle and a dog.

Look over here! The small girl is dragged by the dog. So the dog, but not the turtle, drags one of the girls.

What did the tall girl do?

What happened to the small girl?

\section{(3) Experiment 3}

1) Look! The tall girl brings a dog and a cat.

Look over here! The dog finds the small girl. So the dog, but not the cat, finds one of the girls.

What did the tall girl do?

What happened to the small girl?

2) Look! The older brother comes with a monkey and a rabbit.

Look over here! The rabbit points at the younger brother. So the rabbit, but not the monkey points at one of the brothers.

What did the older brother do?

What happened to the younger brother?

3) Look! The slim boy brings Mickey and Minnie.

Look over here! Mickey washes the fat boy. So Mickey, but not Minnie washes one of the boys.

What did the slim boy do?

What happened to the fat boy? 
4) Look! The female farmer brings a horse and a pig.

Look over here! The horse pulls the male farmer. So the horse, but not the pig, pulls one of the farmers.

What did the female farmer do?

What happened to the male farmer?

5) Look! The woman with a yellow shirt comes with Goofy and Tiger.

Look over here! The woman in black is called by Tiger. So Tiger, but not Goofy, calls one of the women.

What did the woman with a yellow shirt do?

What happened to the woman in black?

6) Look! The man with glasses brings a lion and a tiger.

Look over here! The man with a hat is supported by the lion. So the lion, but not the tiger, supports one of the men.

What did the man with glasses do?

What happened to the man with a hat?

7) Look! The fat boy comes with Donald and Bugs Bunny.

Look over here! The skinny boy is hugged by Donald. So Donald, but not Bugs Bunny, hugs one of the boys.

What did the fat boy do?

What happened to the skinny boy?

8) Look! The tall girl leaves a turtle and a hamster.

Look over here! The small girl is followed by the turtle. So the turtle, but not the hamster, follows one of the girls.

What did the tall girl do?

What happened to the small girl?

\section{(4) Experiment 4}

1) Look! The small boy comes with Goofy and Pooh.

Look over here! Pooh cleans the tall boy. So Pooh, but not Goofy, cleans one of the boys.

What did the small boy do?

What happened to the tall boy?

2) Look! The big girl brings Tiger and Mickey.

Look over here! Tiger takes the young girl to the door. So Tiger, but not Mickey, takes one of the girls. 
What did the big girl do?

What happened to the young girl?

3) Look! The older sister brings Pooh and Tiger.

Look over here! Tiger moves the younger sister. So Tiger, but not Pooh, moves one of the sisters.

What did the older sister do?

What happened to the younger sister?

4) Look! The woman with a sunglass comes with an eagle and a goat.

Look over here! The eagle rescues the woman with a hat. So the eagle, but not the goat, rescues one of the women.

What did the woman with sunglasses do?

What happened to the woman with a hat?

5) Look! The older brother comes with Donald and Minnie.

Look over here! The younger brother is fed by Donald. So Donald, but not Minnie, feeds one of the brothers.

What did the older brother do?

What happened to the younger brother?

6) Look! The fat boy comes with a rabbit and a mouse.

Look over here! The slim boy is colored by the rabbit. So the rabbit, but not the mouse, colors one of the boys.

What did the fat boy do?

What happened to the slim boy?

7) Look! The black girl brings a monkey and a gator.

Look over here! The white girl is waked by the monkey. So the monkey, but not the gator, wakes one of the girls.

What did the black girl do?

What happened to the white girl?

8) Look! The man with a sunglass comes with a tiger and a lion.

Look over here! The man with a hat is punched by the lion. So the lion, but not the tiger, punches one of the men.

What did the man with sunglasses do?

What happened to the man with a hat? 


\section{(5) Experiment 5}

1) Look! The small boy comes with a dog and a bear.

Look over here! The bear saves the tall boy. So the bear, but not the dog, saves one of the boys.

What did the small boy do?

What happened to the tall boy?

2) Look! The big girl brings a tiger and a mouse.

Look over here! The tiger brushes the young girl. So the tiger, but not the mouse, brushes one of the girls.

What did the big girl do?

What happened to the young girl?

3) Look! The older sister brings a bear and a tiger.

Look over here! The bear finds the younger sister. So the bear, but not the tiger, finds one of the sisters.

What did the older sister do?

What happened to the younger sister?

4) Look! The woman with a hat comes with a boy and a girl.

Look over here! The boy kisses the woman with sunglasses. So the boy, but not the girl, kisses one of the women.

What did the woman with a hat do?

What happened to the woman with sunglasses?

5) Look! The older brother comes with a duck and a mouse.

Look over here! The younger brother is approached by the duck. So the duck, but not the mouse, approaches one of the brothers.

What did the older brother do?

What happened to the younger brother?

6) Look! The fat boy comes with a rabbit and a mouse.

Look over here! The slim boy is helped by the rabbit. So the rabbit, but not the mouse, helps one of the boys.

What did the fat boy do?

What happened to the slim boy?

7) Look! The white girl brings a monkey and a gator.

Look over here! The black girl is pinched by the monkey. So the monkey, but not the gator, pinches one of the girls. 
What did the white girl do?

What happened to the black girl?

8) Look! The man with a necktie comes with a tiger and a lion.

Look over here! The man with a ribbon is stopped by the lion. So the lion, but not the tiger, stops one of the men.

What did the man with a necktie do?

What happened to the man with a ribbon?

\section{Relative clause comprehension task}

\section{(1) Experiment 1}

1) The girl [that __ is helping the boy with the math problem.]

2) The frog [that the fish is feeding ___ ]

3) The girl [that the boy is giving the book to

4) The bird [that the bee is flying above .]

5) The patient [whose doctor is sitting on the chair.]

6) The bird [that the turtle is smaller than .]

7) The ant [that the bee is touching .]

8) The dog [that the cat is sleeping on

9) The sheep [that is poking the bird on its tail.]

10) The man [that the woman is taller than

11) The lawyer [whose client is talking on the phone.]

12) The duck [that the cat is throwing the towel to

13) The bear [that the tiger is pulling ]

14) The woman that the man is drinking with

15) The pig [that the dog is fatter than

16) The actor [that is shouting at the director]

17) The student [whose teacher is singing a song.]

18) The dolphin [that the wolf is handing a shirt to

19) The deer [that is visiting the tiger]

20) The elephant that the bear is hopping by

21) The man [that the woman is congratulating

22) The deer [that the tiger is larger than .]

23) The fox [that the penguin is showing the racket to

24) The player [whose coach is swinging the bat.]

25) The deer [that the rabbit is smiling behind

26) The turtle [that the bird is washing

27) The princess [that is speaking to the knight] 
28) The snake [that the lion is happier than .]

29) The professor [whose student is carrying a camera.]

30) The prince [that the king is waving his hand to

31) The cat [that the duck is bigger than

32) The bear [that is scratching the lion]

33) The squirrel [that the monkey is sitting over

34) The trainer [whose boxer is turning on the light]

35) The cat [that the pig is dressing

36) The man [that the girl is kicking the ball to

\section{(2) Experiment 2}

1) The farmer [that is pushing the lady]

2) The drummer [that Santa is hugging

3) The boy [that the girl is reading a book to

4) The squirrel [that the mouse is falling on

5) The mother [whose child is swimming in the pool]

6) The dancer [that the singer is darker than

7) The woman [that the man is kissing

8) The grasshopper [that the butterfly is resting above

9) The cowboy [that is pointing at the baby]

10) The woman [that the man is faster than

11) The nurse [whose patient is eating an apple]

12) The woman [that the man is serving coffee to

13) The dog [that the cat is hitting ]

14) The woman that [the man is passing by

15) The soldier [that the boxer is shorter than

16) The sailor [that is punching the pirate]

17) The dolphin [whose trainer is catching the ball]

18) The cat [that the dog is teaching math to

19) The mailman [that is laughing at the painter]

20) The lion [that the tiger is jumping over ]

21) The rabbit [that the mouse is brushing 1

22) The maid [that the milkman is thinner than

23) The girl [that the boy is passing the ball to

24) The driver [whose passenger is wearing a hat]

25) The bear [that the penguin is sliding by

26) The pianist [that the golfer is watching

27) The lion [that is biting the bear] 
28) The boy [that the girl is angrier than ]

29) The coach [whose player is holding the trophy]

30) The monkey [that the panda is offering food to ]

31) The pig [that he cow is heavier than ]

32) The horse [that is looking at the woman]

33) The boy [that the girl is sweeping under

34) The teacher [whose student is writing on the board]

35) The bee [that the ant is tickling

36) The bird [that the mouse is selling ice cream to

\section{(3) Experiment 3}

1) The boy [that is finding the girl]

2) The bird [that Mickey is leaving

3) The woman [that the man is making a pie for

4) The girl [that the boy is screaming over

5) The doctor [whose patient is closing the door]

6) The driver [that the swimmer is stronger than

7) The cat [that the dog is leading

8) The man [that the woman is working behind

9) The lion [that is thinking of the bear]

10) The woman [that the man is older than

11) The teacher [whose student is saying something]

12) The turtle [that the wolf is getting a hat for

13) The man [that the woman is calling

14) The pelican [that the eagle is landing by

15) The elephant [that the bear is lighter than

16) The monkey[that is reaching to the rabbit]

17) The trainer [whose bear is using a ball]

18) The boy [that the girl is asking a question to

19) The customer[that is answering the clerk]

20) The dog [that the cat is running by

21) The girl [that the boy is supporting

22) The boy [that the girl is healthier than

23) The bear [that the tiger is providing jam for

24) The dentist [whose client is going to the window]

25) The frog [that the turtle is standing on

26) The man [that the fox is following

27) The tiger [that is coming to the pig] 
28) The fox [that the dog is slower than

29) The player [whose coach owns a violin]

30) The hen [that the squirrel is paying money to

31) The snake [that the mongoose is longer than

32) The man [that is stopping the woman]

33) The squirrel [that the monkey is lying above

34) The student [whose professor knows the answer]

35) The rabbit [that the mouse is pinching

36) The monkey [that the deer is bringing a bag to

\section{(4) Experiment 4}

1) The monkey [that is cheering the eagle]

2) The cat [that the pig is cleaning _ _ ]

3) The man [that the woman is telling something to

4) The monkey [that the mouse is cutting above

5) The student [whose teacher is acting on stage]

6) The woman [that the man is dirtier than

7) The boy [that the girl is rescuing __ ]

8) The cat [that the dog is spinning by

9) The goat [that is hurting the cow]

10) The mouse [that the rabbit is sadder than

11) The coach [whose player is calling someone]

12) The dog [that the cat is giving a cup to __ ]

13) The girl [that the boy is wiping

14) The girl [that the boy is spilling beside

15) The girl [that the boy is slimmer than _ ]

16) The rabbit [that is lifting the monkey]

17) The patient [whose nurse is opening the door]

18) The cow [that the dog is kicking a ball to __ ]

19) The man [that is scaring the woman]

20) The woman [that the man is peeling orange under

21) The turtle [that the monkey is blocking

22) The man [that the woman is weaker than

23) The grandpa [that the grandma is reading a newspaper to

24) The mother [whose child is placing flowers on the table]

$25)$ The tiger [that the bear is rolling behind

26) The bird [that the fox is chasing _ ]

27) The sailor [that is shaving the swimmer] 
28) The fisherman [that the farmer is whiter than __ ]

29) The passenger [whose driver is putting on a hat]

30) The wolf [that the rabbit is serving cake to _ _ ]

31) The woman [that the man is younger than _ ]

32) The girl [that is warning the boy]

33) The boy [that the girl is shooting over

34) The boxer [whose trainer saw a bird]

35) The woman [that the man is hating _

36) The girl [that the boy is teaching English to _ _ ]

\section{(5) Experiment 5}

1) The girl [that is aiming the boy]

2) The man [that the woman is arresting

3) The man [that the woman is passing salt to

4) The frog [that the duck is floating beside ]

5) The student [whose professor is drawing a picture]

6) The girl [that the boy is funnier than

7) The boy [that the girl is nursing

8) The girl [that the boy is building a castle by

9) The bear [that is beating the tiger]

10) The man [that the woman is richer than

11) The doctor [whose patient is hanging the coat]

12) The girl [that the boy is throwing the hat to ]

13) The mouse [that the rabbit is checking ]

14) The fireman [that the policeman is climbing over

15) The woman [that the man is cleaner than

16) The farmer [that is bumping into the hunter]

17) The mother [whose child likes the hat]

18) The dolphin [that the monkey is asking a question to

19) The boy [that is disturbing the girl]

20) The girl [that the boy is crawling under

21) The boy [that the girl is grabbing ]

22) The girl [that the boy is skinner than

23) The woman [that the man is selling fruits to

24) The teacher [whose student moves the chair]

$25)$ The sailor [that the swimmer is studying above

26) The woman [that the man is massaging

27) The cow [that is licking the pig] 
28) The duck [that the cat is tinier than ]

29) The patient [whose nurse is ringing the bell]

30) The boy [that the girl is offering a carrot to ]

31) The girl [that the boy is speedier than ]

32) The man [that is moving the woman]

33) The woman [that the man is sinking behind

34) The player [whose coach is breaking the wood]

35) The girl [that the boy is capturing ]

36) The man [that the woman is making pizza for

\section{Relative clause production task}

(1) Experiment 1
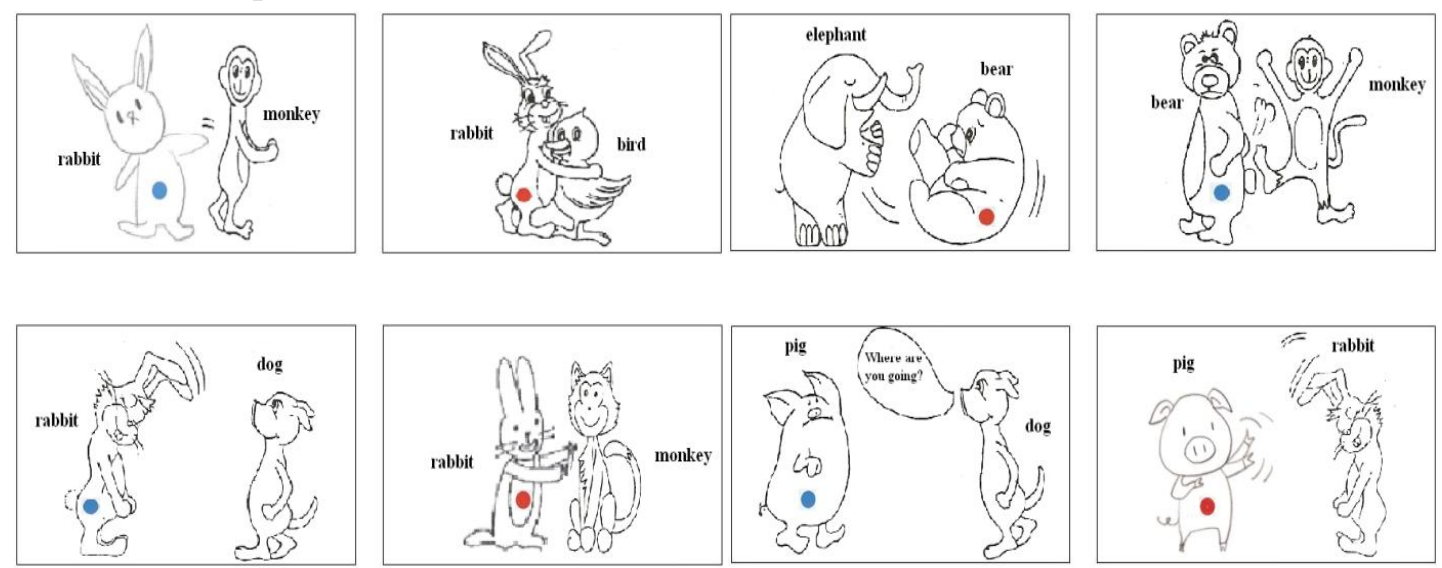

(2) Experiment 2
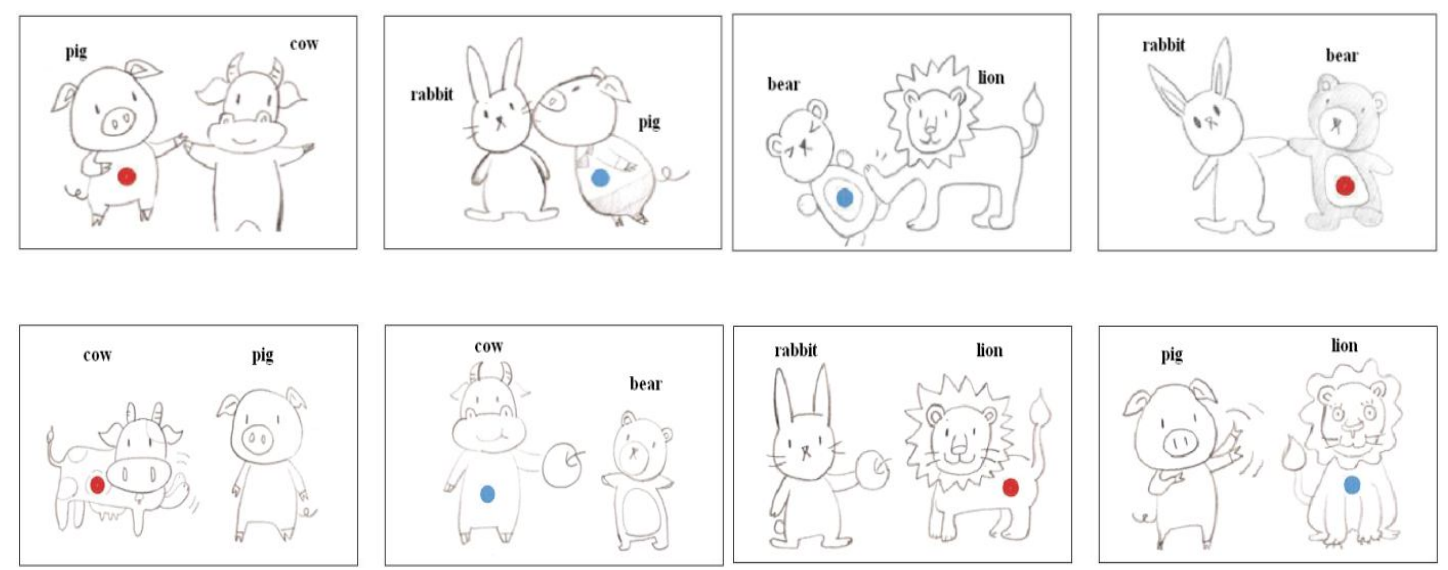
(4) Experiment 4
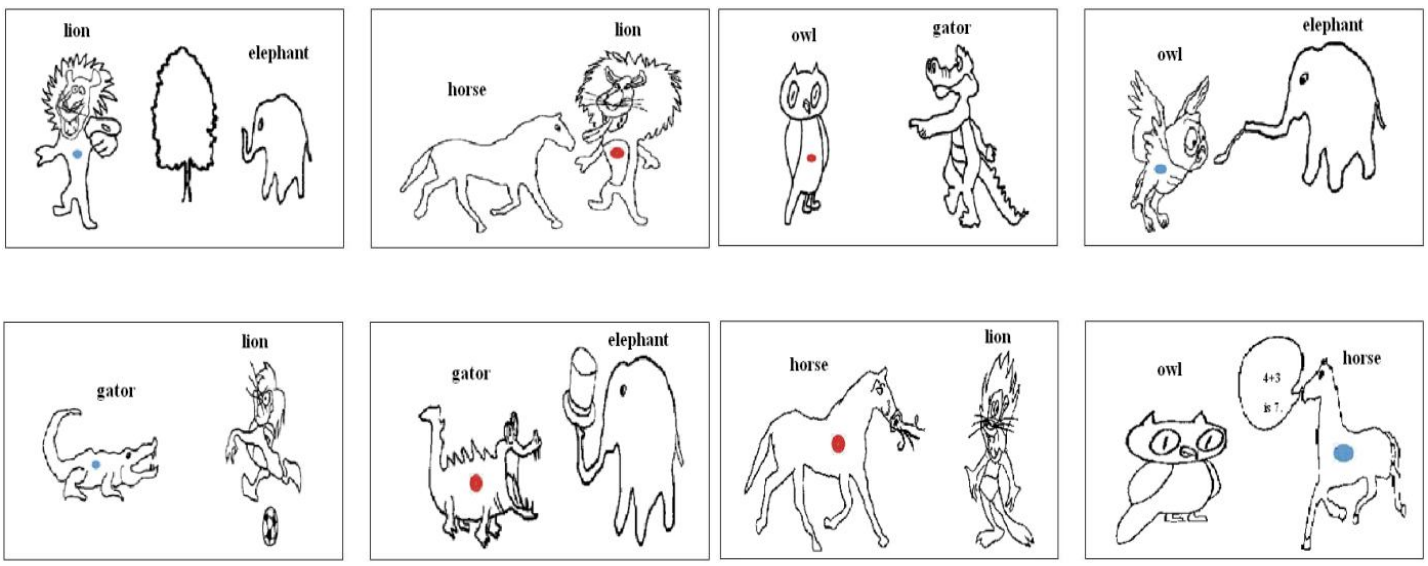

(5) Experiment 5
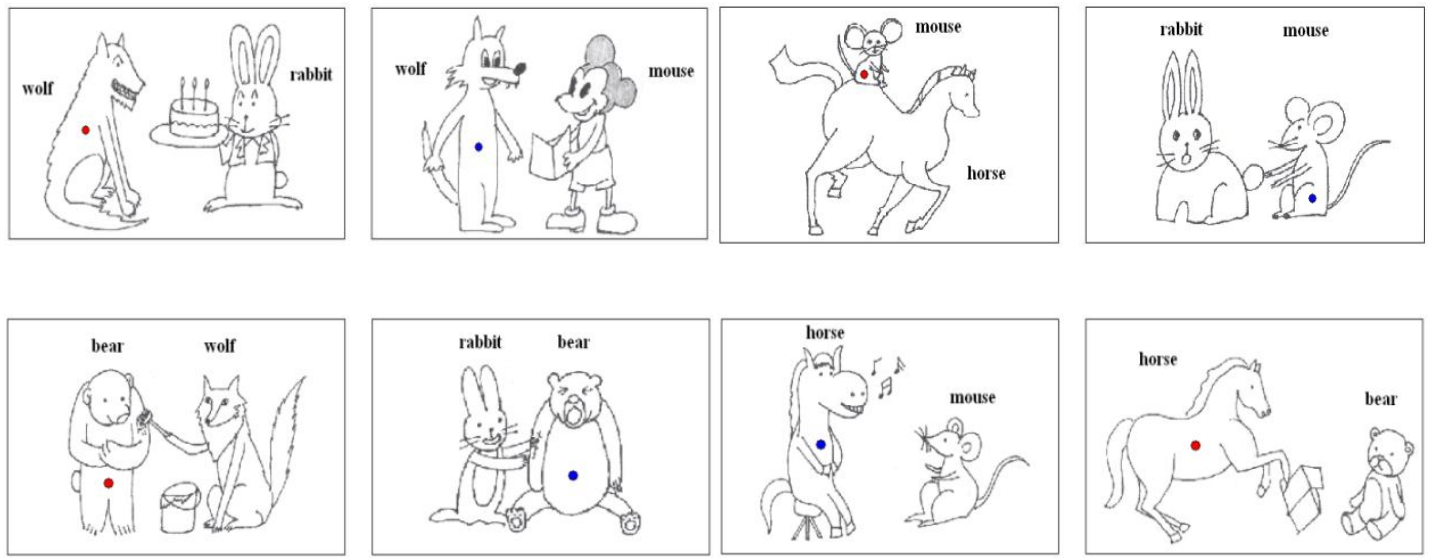


\section{APPENDiX C. HALA QUESTIONNAIRE}

Name:

Male or Female

Age:

Date of Birth:

1. How long have you been in the U.S?

2. Name all the countries you lived in besides Korea and the U.S., the length of stay, and how old you were at the time.

3. Which language do you feel more comfortable in, English or Korean?

4. When did you start learning Korean?

5. When did you start learning English?

6. Which language do you use in school? How many hours do you spend in school?

7. Which language do you use when you are talking with your parents?

8. Which language do you use when you are talking with your brother(s) or sister(s)?

9. Do you attend a Korean Community school or go to a Korean church? How many hours do you spend there?

10. Which language do you use when you are talking with friends? If you use both Korean and English, how many English-speaking friends do you have? How many Korean-speaking friends do you have?

11. These days, to what extent are you exposed to English compared to Korean? This includes your daily activity such as school life, talking to friends, watching TV, reading books, listening to music, etc. (e.g., 60\% English, 40\% Korean) 


\section{References}

Altenberg, Evelyn. 1991. Assessing first language vulnerability to attrition. In Herbert Seliger and Robert Michael Vago (eds.), First language attrition, 189-206. New York: Cambridge University Press.

$\mathrm{Au}$, Terry, Leah Knightly, Sun-Ah Jun, and Janet Oh. 2002. Overhearing a language during childhood. Psychological Science 13(3). 238-43.

Bahrick, Harry. 1984. Fifty years of second language attrition: Implications for programmatic research. The Modern Language Journal 68(2). 105-18.

Bar-Shalom, Eva, Stephen Crain, and Donald Shankweiler. 1993. A comparison of comprehension and production abilities of good and poor readers. Applied Psycholinguistics 14. 197-227.

Baldie, Brian. 1976. The acquisition of the passive voice. Journal of Child Language 3. $331-48$.

Bardovi-Harlig, Kathleen, and David Stringer. 2010. Variables in second language attrition. Studies in Second Language Acquisition 32. 1-45.

Berman, Ruth, and Elite Olshtain. 1983. Features of first language transfer in second language attrition. Applied Linguistics 4(3). 222-34.

Bickerton, Derek. 2009. Bastard tongues: a trailblazing linguist finds clues to our common humanity in the world's lowliest languages. New York: Hill and Wang.

Bloom, Paul. 1990. Subjectless sentences in child language. Linguistic Inquiry 21. 491-504.

Bock, Kathryn. 1986. Syntactic persistence in language production. Cognitive Psychology 18. 355-87.

Borer, Hagit, and Kenneth Wexler. 1987. The maturation of syntax. In Thomas Roeper and Edwin Williams (eds.), Parameter Setting, 123-72. Dordrecht: D. Reidel. 
Bowers, Jeffrey, Sven Mattys, and Suzanne Gage. 2009. Preserved implicit knowledge of a forgotten childhood language. Psychological Science 20(9). 106469.

Brown, H. Douglas. 1971. Children's comprehension of relativized English sentences. Child Development 42. 1923-36.

Brown, Roger. 1973. A first language: The early stages. Cambridge, MA: Harvard University Press.

Bybee, Joan, and Dan Slobin. 1982. Rules and schemas in the development and use of the English past tense. Language 58(2). 265-89.

Clark, Eve, and Kathie Carpenter. 1989. The notion of source in language acquisition. Language 65. 1-30.

Clyne, Michael. 1981. Deutsch als Muttersprache in Australien. Wiesbaden: Steiner.

Cohen, Andrew. 1974. The Culver city Spanish immersion program: How does summer recess affect Spanish speaking ability? Language Learning 24(1). $55-68$.

Cohen, Andrew. 1975. Forgetting a second language. Language Learning 25(1). 12738.

Cook, Vivian. 1975. Strategies in the comprehension of relative clauses. Language and Speech 18(3). 204-12.

Costa, Albert, and Mikel Santesteban, 2004. Lexical access in bilingual speech production: Evidence from language switching in highly proficient bilinguals and L2 learners. Journal of Memory and Language 50. 491-511.

Crain, Stephen, and Janet Fodor. 1993. Competence and performance in child language. In Esther Dromi (ed.), Language and Cognition: A Developmental Perspective, 141-71. Norwood, NJ: Ablex. 
De Bot, Kees, and Michael Clyne. 1989. Language reversion revisited. Studies in Second Language Acquisition 11(2). 167-78.

Diessel, Holger. 2004. The acquisition of complex sentences. Cambridge, MA: Cambridge University Press.

Diessel, Holger, and Michael Tomasello. 2005. A new look at the acquisition of relative clauses. Language 81(4). 882-906.

Doughty, Catherine. 1991. Second language instruction does make a difference. Studies in Second Language Acquisition 13. 431-69.

Ervin, Susan. 1961. Learning and recall in bilinguals. American Journal of Psychology 74. 446-51.

Finer, Daniel, and Ellen Broselow. 1986. Second language acquisition of reflexivebinding. In S. Berman, J.-W. Choe and J. McDonough (eds.), North East Linguistics Society (NELS) 16, 154-68. University of Massachusetts at Amherst: Graduate Linguistics Students Association.

Fox, Danny, and Yosef Grodzinsky. 1998. Children's passive: A view from the byphrase. Linguistic Inquiry 29. 311-32.

Fozard, James, Max Vercruyssen, Sara Reynolds, P. A. Hancock, and Reginald Quilter. 1994. Age differences and changes in reaction time: The Baltimore longitudinal study of aging. Journal of Gerontology 49(4). 179-89.

Gass, Susan. 1979. Language transfer and universal grammatical relations. Language Learning 29. 327-44.

Gollan, Tamar, Rosa Montoya, Cynthia Cera, and Tiffany Sandoval. 2008. More use almost always means a smaller frequency effect: Aging, bilingualism, and the weaker links hypothesis. Journal of Memory and Language 58. 787-814. 
Goodluck, Helen, and Danijela Stojanovic. 1996. The structure and acquisition of relative clauses in Serbo-Croatian. Language Acquisition 5(4). 285-315. Haegeman, Liliane.1990. Non-overt subjects in diary contexts. In Joan Mascaro and Marina Nespor (eds.), Grammar in Progress, 167-79. Dordrecht: Foris. Hamburger, Henry, and Stephen Crain. 1982. Relative acquisition. In Stan A. Kuczaj II (ed.), Language development, Vol.1: Syntax and semantics, 244-73. Hillsdale, NJ: Erlbaum.

Hawkins, John. 1999. Processing complexity and filler-gap dependencies across grammars. Language 75(2). 244-85

Hernandez, Arturo, and Kathryn Kohnert. 1999. Aging and language switching in bilinguals. Aging, Neuropsychology, and Cognition 6. 69-83.

Horgan, Dianne. 1978. The development of the full passive. Journal of Child Language 5. 65-80.

Hyams, Nina. 1998. The underspecification of functional categories in early grammar. In Herald Clahsen (ed.), Generative perspectives on language acquisition, 92-127. Philadelphia: John Benjamins.

Hyltenstam, Kenneth, Emanuel Bylund, Niclas Abrahamsson, and Hyeon-Sook Park. 2009. Dominant-language replacement: The case of international adoptees. Bilingualism: Language and Cognition 12(2). 121-40.

Ionin, Tania, Heejeong Ko, and Kenneth Wexler. 2003. Article semantics in L2 acquisition: the role of specificity. Language Acquisition 12(1). 3-69.

Ionin, Tania, Maria Luisa Zubizarreta, and Salvador Bautista Maldonado. 2008. Sources of linguistic knowledge in the second language acquisition of English articles. Lingua 118. 554-76. 
Jordens, Peter, Kees De Bot, and Henk Trapman. 1989. Linguistic aspects of regression in German case marking. Studies in Second Language Acquisition 11(2). 179-204.

Kagan, Olga, and Debra Friedman. 2003. Using the OPI to place heritage speakers of Russian. Foreign Language Annals 36. 536-45.

Keenan, Edward, and Bernard Comrie. 1977. Noun phrase accessibility and universal grammar. Linguistic Inquiry 8. 63-99.

Kohnert, Kathryn, Arturo Hernandez, and Elizabeth Bates. 1998. Bilingual performance on the Boston Naming Test: Preliminary norms in Spanish and English. Brain and Language 65. 422-40.

Kuczaj II, Stan. 1978. Children's judgments of grammatical and ungrammatical irregular past-tense verbs. Child Development 49. 319-26.

Kučera, Henry, and Winthrop Nelson Francis. 1967. Computational analysis of present-day American English. Providence, RI: Brown University Press.

Kuhberg, Heinz. 1992. Longitudinal L2-attrition versus L2-acquisition, in three Turkish children-empirical findings. Second Language Research 8(2). 138-54.

Lachter, Joel, and Thomas G. Bever. 1988. The relation between linguistic structure and associative theories of language learning - A constructive critique of some connectionist learning models. Cognition 28. 195-247.

McDaniel, Dana, Cecile McKee, and Judy Bernstein. 1998. How children's relatives solve a problem for minimalism. Language 74. 308-34.

McKee, Cecile, and Dava McDaniel. 2001. Resumptive pronouns in English relative clauses. Language Acquisition 9(2). 113-56. 
Maratsos, Michael. 2000. More overregularizations after all: New data and discussion on Marcus, Pinker, Ullman, Hollander, Rosen \& Xu. Journal of Child Language 27. 183-212.

Maratsos, Michael, Dana Fox, Judith Becker, and Mary Anne Chalkley. 1985. Semantic restrictions on children's passives. Cognition 19. 167-91.

Marchman, Virginia. 1997. Children's productivity in the English past tense: The role of frequency, phonology, and neighborhood structure. Cognitive Science 21(3). 283-304.

Marcus, Gary, Steven Pinker, Michael Ullman, Michelle Hollander, T. John Rosen, an d Fei Xu. 1992. Overregularization in language acquisition. Chicago, IL: The University of Chicago Press.

Mägiste, Edith. 1979. The competing language systems of the multilingual: A developmental study of decoding and encoding processes. Journal of Verbal Learning and Verbal Behavior 18. 79-89.

McCormack, Bede. 2004. Methodological aspects of a generative-based attrition study. In Monika Schmid, Barbara Köpke, and Merel Keijzer (eds.), First language attrition: Interdisciplinary perspectives on methodological issues, 243-58. Philadelphia: John Benjamins.

O’Brien, Karen, Elaine Grolla, and Diane Lillo-Martin. 2006. Long passives are understood by young children. Boston University Conference on Language Development (BUCLD) 30, 441-51.

O’Grady, William. 2009. Assessing heritage language competence. Manuscript of a speech at 2009 summer heritage institute at UIUC, Urbana-Champaign, IL. 
O'Grady, William, Miseon Lee, and Miho Choo. 2001. The acquisition of relative clauses by heritage and non-heritage learners of Korean as a second language: A comparative study. Journal of Korean Language Education 12. 284-94.

O’Grady, William, Miseon Lee, and Miho Choo. 2003. A subject-object asymmetry in the acquisition of relative clauses in Korean as a second language. Studies in Second Language Acquisition 25. 433-48.

O’Grady, William, Amy Schafer, Jawee Perla, On-Soon Lee, and Julia Wieting. 2009. A psycholinguistic tool for the assessment of language loss: The HALA project. Language Documentation and Conservation 3(1). 100-12.

Oh, Janet, Sun-Ah Jun, Leah Knightly, and Terry Au. 2003. Holding on to childhood language memory. Cognition 86. B53-64.

Olshtain, Elite. 1989. Is second language attrition the reversal of second language acquisition? Studies in Second Language Acquisition 11(2). 151-66.

Olshtain, Elite, and Margaret Barzilay. 1991. Lexical retrieval difficulties in adult language attrition. In Herbert Seliger and Robert Michael Vago (eds.), First language attrition, 139-50. New York: Cambridge University Press.

Pallier, Christophe, Stanislas Dehaene, Jean-Baptiste Poline, Denis Lebihan, A.-M. Argenti, Emmanuel Dupoux, and Jacques Mehler. 2003. Brain imaging of language plasticity in adopted adults: Can a second language replace the first? Cerebral Cortex 13. 155-62.

Parrish, Betsy. 1987. A new look at methodologies in the study of article acquisition for learners of ESL. Language Learning 37. 361-83.

Pica, Teresa. 1983. Methods of morpheme quantification. Studies in Second Language Acquisition 6. 69-78.

Pinker, Steven. 1999. Words and rules. New York: Perennial. 
Reetz-Kurashige, Anita. 1999. Japanese returnees' retention of English-speaking skills:

Changes in verb usage over time. In Lynne Hansen (ed.), Second language attrition in Japanese contexts, 21-58. New York: Oxford University Press.

Robertson, Daniel. 2000. Variability in the use of the English article system by Chinese learners of English. Second Language Research 16. 135-72.

Rumelhart, David E., and James L. McClelland. 1986. On learning the past tenses of English verbs. In James L. McClelland, David E. Rumelhart, and the PDP Research Group (eds.), Parallel distributed processing: Explorations in the microstructure of cognition, Vol. 2: Psychological and biological models, 216-71. Cambridge, MA: Bradford Books/MIT Press.

Schaeffer, Jeannette, and Lisa Matthewson. 2005. Grammar and pragmatics in the acquisition of article system. Natural Language and Linguistic Theory 23(1). 53-101.

Schafer, Amy. 2010. HALA, How to code responses. Unpublished manuscript, University of Hawai' $i$ at Mānoa.

Schafer, Robin, and Jill de Villiers. 2000. Imagining articles: What $a$ and the can tell us about the emergence of DP. In Catherine Howell, Sarah Fish, and Theo Keith-Lucas (eds.), Boston University Conference on Language Development (BUCLD) 24, 609-20.

Shin, Sarah. 2002. Differentiating language contact phenomena: Evidence from Korean-English bilingual children. Applied Psycholinguistics 23. 337-60.

Skehan, Peter. 2009. Modelling second language performance: Integrating complexity, accuracy, fluency, and lexis. Applied Linguistics 30(4). 510-32. 
Slobin, Dan. 1971. On the learning of morphological rules: A reply to Palermo and Eberhart. In Dan Slobin (ed.), The ontogenesis of grammar, 215-23. New York: Academic Press.

Strain, Eamon, Karalyn Patterson, Naida Graham, and John Hodges. 1998. Word reading in Alzheimer's disease: Cross-sectional and longitudinal analyses of response time and accuracy data. Neuropsychologia 36(2). 155-71.

Stromswold, Karin. 1994. What a mute child tells us about language acquisition. Unpublished manuscript, Center for Cognitive Science, Rutgers University. Tang, Apay.2010. Baseline results from a psycholinguistic tool for the assessment of language shift in Truku Seediq. Working Papers in Linguistics 41(5). University of Hawai' $i$ at Mānoa.

Tees, Richard, and Janet Werker. 1984. Perceptual flexibility: Maintenance or recovery of the ability to discriminate non-native speech sounds. Canadian Journal of Psychology 38. 579-90.

Thatcher, Katherine, Holly Branigan, Janet McLean, and Antonella Sorace. 2008. Children's early acquisition of the passive: Evidence from syntactic priming. 2007 Child Language Seminar, City University, London. 187-96.

Thomas, Margaret. 1989. The acquisition of English articles by first- and secondlanguage learners. Applied Psycholinguistics 10. 335-55.

Tomiyama, Machiko. 1999. The first stage of second language attrition: A case study of a Japanese returnee. In Lynne Hansen (ed.), Second language attrition in Japanese contexts, 59-79. New York: Oxford University Press.

Tsimpli, Ianthi, Antonella Sorace, Caroline Heycock, and Francesca Filiaci. 2004. First language attrition and syntactic subjects: A study of Greek and Italian nearnative speakers of English. International Journal of Bilingualism 8(3). 279-302. 
Turner, Elizabeth Ann, and Ragnar Rommetveit. 1967. The acquisition of sentence voice and reversibility. Child Development 38. 649-60.

Ullman, Michael, Roumyana Pancheva, Tracy Love, Eiling Yee, David Swinney, and Gregory Hickok. 2005. Neural correlates of lexicon and grammar: Evidence from the production, reading, and judgment of inflection in aphasia. Brain and Language 93(2). 185-238.

Van Hout, Angeliek, Kaitlyn Harrigan, and Jill de Villiers. 2010. Asymmetries in the acquisition of definite and indefinite NPs. Lingua 120(8). 1973-90.

Ventureyra, Valérie, Christophe Pallier, and Hi-Yon Yoo. 2004. The loss of first language phonetic perception in adopted Koreans. Journal of Neurolinguistics 17. 79-91.

Warden, David. 1976. The influence of context on children's use of identifying expressions and references. British Journal of Psychology 67(1). 101-12.

Weiner, E. Judith, and William Labov. 1983. Constraints on the agentless passive. Journal of Linguistics 19. 29-58.

Weltens, Bert, Theo Van Els, and Erik Schils. 1989. The long-term retention of French by Dutch students. Studies in Second Language Acquisition 11(2). 205-16.

White, Lydia. 1985. The pro-drop parameter in adult second language acquisition. Language Learning 35. 47-62.

Xu, Fei, and Steven Pinker. 1995. Weird past tense forms. Journal of Child Language 22. 531-56.

Yang, Charles. 2002. Knowledge and learning in natural language. New York: Oxford University Press. 
Yoshitomi, Asako. 1999. On the loss of English as a second language by Japanese returnee children. In Lynne Hansen (ed.), Second language attrition in Japanese contexts, 80-111. New York: Oxford University Press.

Yukawa, Emiko. 1997. Language attrition from the psycholinguistic perspective: A literature review. Stockholm: Centre for Research on Bilingualism, Stockholm University.

Zukowski, Andrea. 2009. Elicited production of relative clauses in children with Williams syndrome. Language and Cognitive Processes 24(1). 1-43. 